\section{Check for updates}

Cite this: Org. Chem. Front., 2021, 8 1026

Received 11th September 2020,

Accepted 5th January 2021

DOI: 10.1039/d0qo01085e

rsc.li/frontiers-organic

\title{
Stereoselective synthesis and applications of spirocyclic oxindoles
}

\author{
Alexander J. Boddy (ID) and James A. Bull (D)*
}

The development of novel synthetic strategies to form new chemical entities in a stereoselective manner is an ongoing significant objective in organic and medicinal chemistry. This review analyses the development of new stereoselective approaches to spirocyclic oxindoles with spiro-3- to 8-membered rings. It highlights the importance of these structures for applications in medicinal chemistry, as intermediates or final products in total synthesis and as model compounds for the development of enantioselective catalytic methodologies.

\section{Introduction}

The application of spirocyclic structures in drug discovery has seen a dramatic increase in attention in recent years, alongside major developments in their synthetic chemistry. ${ }^{1}$ Defined as a bicycle connected by a single fully-substituted carbon atom, which is not connected by an adjacent atom, spirocycles are inherently highly 3-dimensional structures. The shared tetrahedral $\mathrm{sp}^{3}$-carbon atom positions the planes of the 2 rings orthogonally, despite the torsional strain this may impose on

Department of Chemistry, Imperial College London, Molecular Sciences Research Hub, White City Campus, Wood Lane, London W12 OBZ, UK.

E-mail:j.bull@imperial.ac.uk

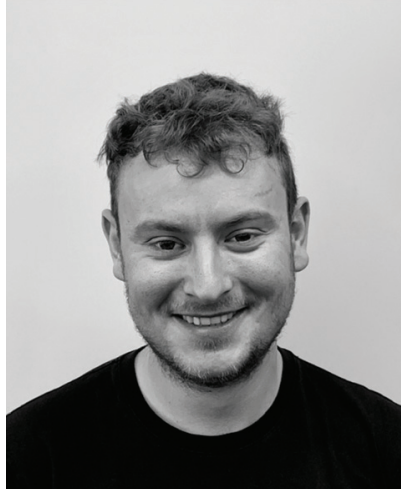

Alexander J. Boddy
Alexander Boddy graduated from Durham University with an MChem with Industrial Training in 2016, including a final year placement at Infineum UK. He completed his PhD in the laboratory of Dr James A. Bull at Imperial College London in 2020. His PhD research, in collaboration with AstraZeneca, developed new synthetic methodologies to access saturated heterocycles for potential use in drug discovery. Alexander is now a Senior Scientist in Chemical Development at GlaxoSmithKline.

the substituents of the rings. ${ }^{2}$ Spirocyclic compounds can improve certain physicochemical properties such as lipophilicity, aqueous solubility and metabolic stability, in comparison to the respective monocyclic structure. ${ }^{3}$ Furthermore, they access relatively underexplored chemical space and novel intellectual property (IP) space. Saturated spirocycles provide a dense, rigid scaffold, with the potential to append more substituents, and so occupy an increased number of defined vectors compared to flat aromatic compounds. ${ }^{4}$ All of these factors have contributed to a greater uptake in medicinal chemistry and have demanded significant advances in organic synthesis to provide spirocycles in a controlled and stereoselective manner. ${ }^{5}$

This review focuses specifically on spirocyclic oxindoles (spirooxindoles or spiroindolones). These are a widespread

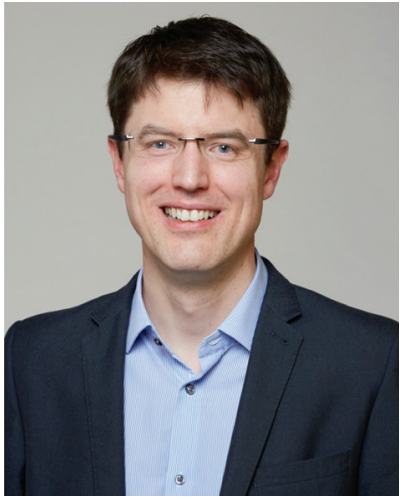

James A. Bull
Dr James Bull is a University Research Fellow at Imperial College London. His research focuses on the development of synthetic and catalytic methods to access medicinally relevant structural motifs and heterocycles. He obtained his MSci degree from the University of Cambridge, then spent a year at GlaxoSmithKline. He returned to University of Cambridge for his PhD with Professor Steven Ley. In 2007 he joined Université de Montréal as a postdoc with Professor André Charette. He started a Ramsay Memorial Fellowship at Imperial College in 2009, an EPSRC Career Acceleration Fellowship in 2011, and in 2016 was awarded a Royal Society University Research Fellowship. 
motif within modern organic synthesis, drug discovery and natural product chemistry. Stereoselective synthetic methods towards this privileged class of spirocycles have seen enormous development in recent years. This review aims to combine the analysis of recent synthetic strategies with an overview of the importance of these scaffolds for medicinal chemistry and in natural product synthesis. Since 1950 there have been 6896 publications containing spirooxindoles, 3283 of these publications have appeared since 2012. ${ }^{15}$ Oxindoles are often used as rigid scaffolds for testing new asymmetric synthetic methodology and due to the demand of discovery chemistry for controlled and modular syntheses, and with the plethora of publications in this area, we will focus on stereoselective processes. This review examines spirocyclic oxindoles containing a spiro-(3 to 8)-membered ring, in turn, analysing carbocyclic then monoheteroatom nitrogen-containing and oxygen-containing spirocycles. The review will cover recent developments from 2013, following major work by Singh and Desta, ${ }^{6}$ until April 2020. Specific bioactivity and applications of each ring system will be discussed at the start of the relevant section and provide a reference work for the preparation of different spirocyclic patterns. Within each section, the discussion is split by the reaction type employed to construct the spirocycle.

Fig. 1 shows a representative set of each ring system, which will be covered in this review, as they feature in medicinal or natural products. ${ }^{7}$ Notable biological activity is indicated, including use as anti-cancer agents, ${ }^{8}$ and anti-viral agents. ${ }^{9}$ Some ring types are not represented in these bioactive compounds, i.e. aziridines, likely due to their instability relative to larger ring sizes, but will nonetheless be featured in the review.

Given the importance of this structural class, spirocyclic oxindoles have been featured in other reviews discussing their synthesis, ${ }^{10}$ including asymmetric synthesis, ${ }^{11}$ use of isatin starting materials ${ }^{12}$ or the synthesis of target product scaffolds. ${ }^{13}$ General reviews on spirocyclic compounds (i.e. spiroindolenes) also often contain spirocyclic oxindoles without specifically focusing on these. ${ }^{14}$ We expect the analysis presented in this review of the structural types, synthesis and applications to lead to further studies, and aid in the identification of future opportunities to expand the applications of this fascinating class of compounds.

\section{Frequency analysis of spirooxindoles}

To quantify the importance of spiroindolones in the medicinal chemistry and organic synthesis literature, we analysed publications which feature spiroindolones containing up to one heteroatom in the spirocycle between $1970-2020$ (Fig. 2). ${ }^{15}$ The number of publications in which these structures feature has grown significantly over the last 50 years and has consistently reached numbers above 400 per year since 2013. Even accounting for the generalised increase in publications, this represents an extensive level of attention. The number of publications on
5- and 6-membered rings (silver and gold in Fig. 2) dominates the contribution to this total. However, in the last decade the relative contribution of 3-, 4- and 7-membered spirocycles (dark/light blues and orange) has increased.

We also analysed the frequency of the different types of rings which feature in this review (Fig. 3). Considering 3-membered spirocycles, we can see that cyclopropane rings are much more common than their aziridine or epoxide analogues. Similarly, cyclobutanes far outnumber azetidines or oxetanes. Notably the number of oxetanes is surprisingly low, especially, when compared to azetidines. The position of the heteroatom has a significant influence on the frequency of a certain ring. This may generally correlate with ease of synthesis or lower complexity, i.e. 3,4'-spirotetrahydropyran oxindoles far outnumber the 3,2'- or 3,3'-analogues. 7-Membered rings are generally underrepresented when bridged examples are discounted (these will generally have been counted in the numbers for other ring sizes as these are a less significant contribution). There is only one example of a non-bridged monoheteroatom containing 8-membered spirooxindole in the literature (synthesised as an analogue of cipargamin). ${ }^{16}$

Although there will be a clear correlation between the number of publications for each ring size, we have tried to discuss each ring type on an equal basis, though inevitably the 5-membered nitrogen section is largest.

\section{Three-membered rings}

\section{Spirocyclopropyl oxindoles}

Three-membered ring containing spiroindolones feature in pharmaceutical compounds as well as being used as reactive intermediates, i.e. in ring opening reactions. ${ }^{17}$ These ring opening reactions can often be coupled with ring closing reactions to form spirocycles of larger ring size. There has recently been an excellent review on the catalytic enantioselective synthesis of polysubstituted spirocyclopropyl oxindoles by Cao and Zhou, ${ }^{18}$ as well as a review of transition metal-free strategies by Ashfeld. ${ }^{19}$

Applications. Spirocyclopropyl oxindoles are featured in a wide variety of reports showing their bioactivity (see Fig. 1 for examples). These bioactivities include examples of antitumour agents, ${ }^{20}$ pain treatment, ${ }^{21}$ treatment of CNS disorders, ${ }^{22}$ antivirals, ${ }^{23}$ among others. ${ }^{24}$

Direct methylene cyclopropanation. Direct cyclopropanation methodology with unprotected oxindoles has been a synthetic challenge which has seen many recent advances (Scheme 1). In 1987, a team at Lilly synthesised spirocycle 2 as a route to a phosphorodiesterase inhibitor (Scheme 1A). ${ }^{25}$ Since this low yielding and step-inefficient synthesis using strong base, Marini reported cyclopropanation using a vinyl selenone reagent in a domino Michael addition and cyclisation sequence (Scheme 1B). ${ }^{26}$ When aryl-substituted vinyl selenone reagents were used, high dr of the cyclopropane was observed with the aromatic rings in a cis-relationship. In 2017, Qian reported the use of a vinyl sulfonium salt in a zinc-mediated 


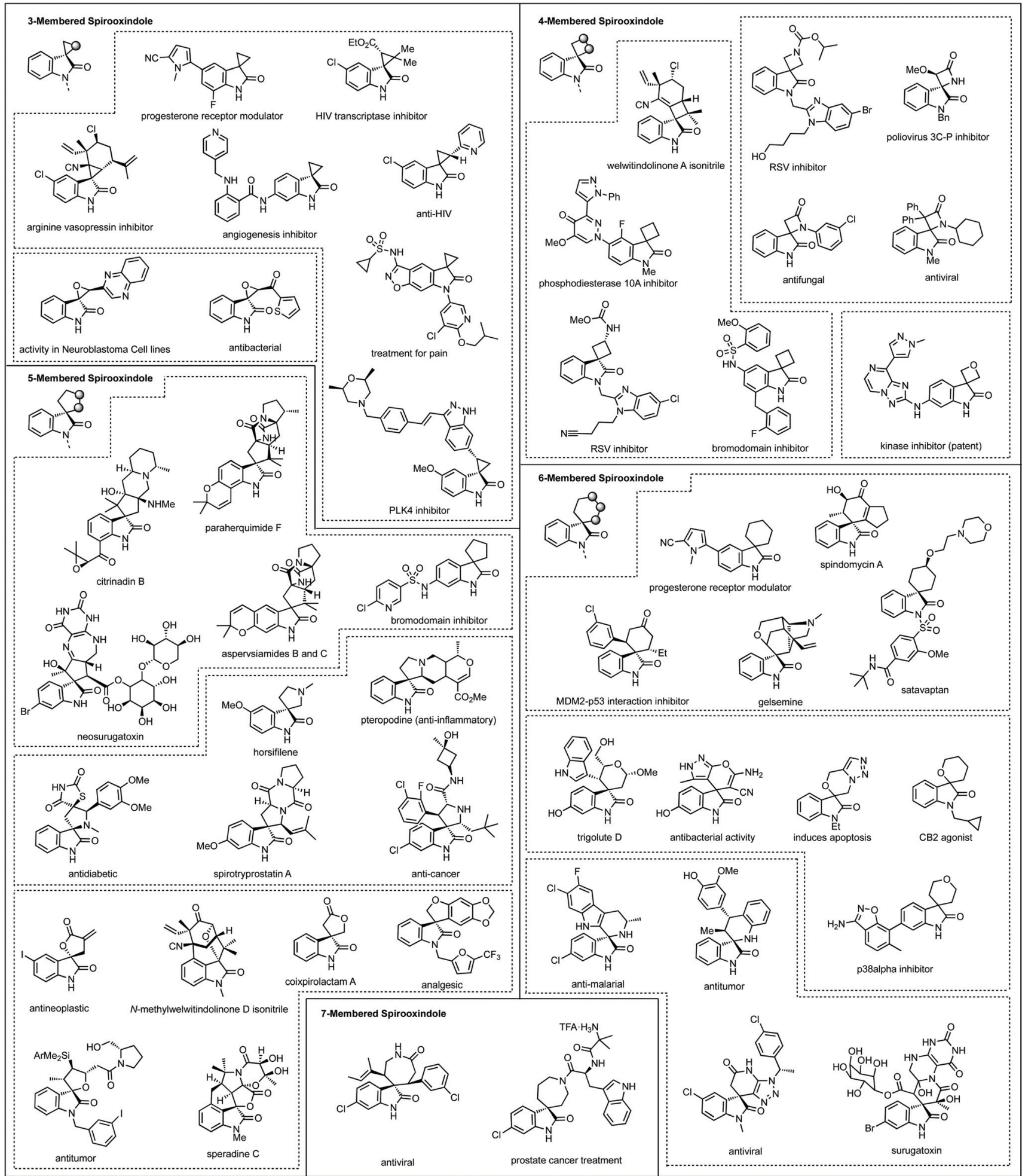

Fig. 1 Bioactive and naturally occurring spirooxindoles.

cyclopropanation (Scheme 1C). ${ }^{27}$ This reaction was notable for its broad functional group tolerance and application to latestage functionalisation of complex scaffolds. Following Qian's report, Feng and Qu showed that a bromoethylsulfonium salt could be used in a similar process without the need for the
$\mathrm{Zn}(\mathrm{OTf})_{2}$ additive (Scheme 1D).$^{28}$ Recently, Hajra reported a domino Corey-Chaykovsky reaction for obtaining the spirocyclic oxindole from the corresponding isatin, spiroepoxide or spiroaziridine (Scheme 1E). ${ }^{29}$ Initially using standard CoreyChaykovsky reaction conditions and generating the sulfur ylide 


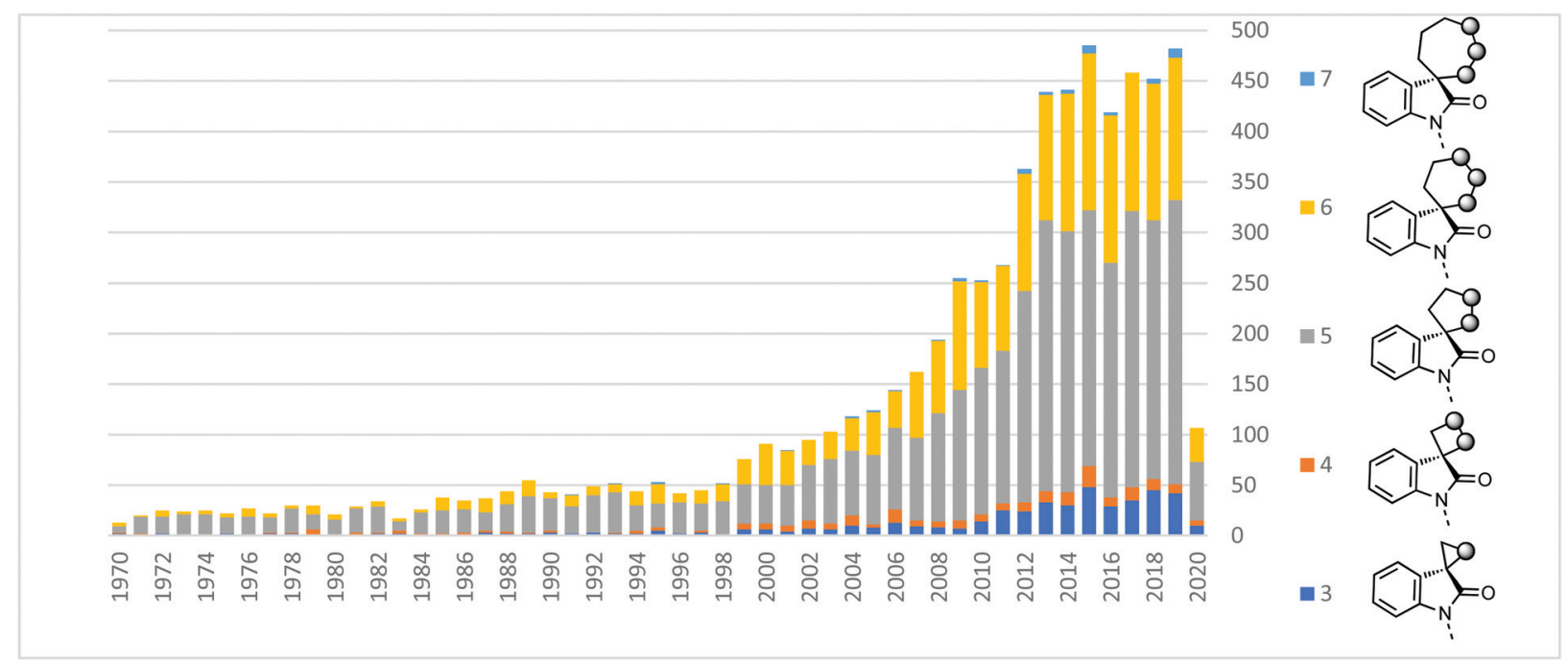

Fig. 2 Incidence of 3-to 7-membered spirooxindoles in the literature up to April 2020. No. of heteroatoms in ring $\leq 1{ }^{15}$

\begin{tabular}{|c|c|c|c|c|c|c|c|}
\hline $\mathbf{X}, \mathbf{X}^{\prime}$-spiro & 3- & 3,2'- & 3,3'- & 3,4'- & 3,2'- & 3,3'- & 3,4'- \\
\hline & ${ }_{17521}$ & $K_{147}^{N H}$ & & & 721 & & \\
\hline & & & 332 & & 155 & 2 & \\
\hline & 7449 & & 8029 & & 2116 & 2945 & \\
\hline & 7209 & 933 & 1937 & 3234 & 548 & 369 & $T_{5816}$ \\
\hline & $46(618)$ & $22(1)^{b}$ & $4(4)^{\prime \prime}$ & 217 (6) & $2(20)$ & $0(341)$ & $68(2)^{b}$ \\
\hline
\end{tabular}

Fig. 3 The spirocyclic rings covered in this review and the number of hits for each heteroatom position. ${ }^{15}$ a Beta-lactams or derivatives thereof. ${ }^{b}$ Numbers in brackets indicates bridged examples.

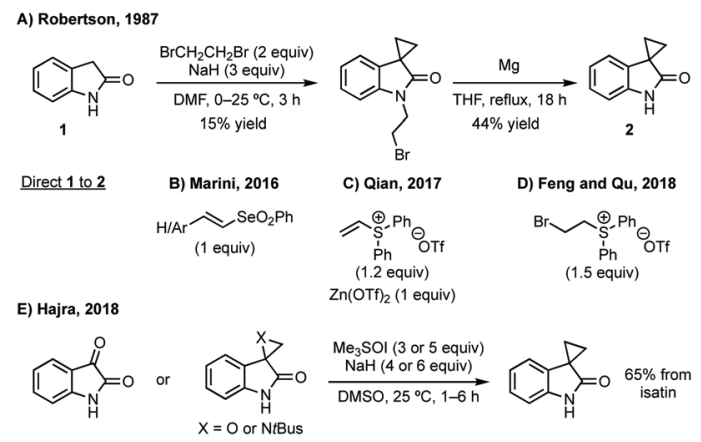

Scheme 1 Summary of recent advances in direct cyclopropanation of unprotected oxindoles. from trimethyl sulfoxonium iodide, Hajra showed the ring opening of the epoxide followed by elimination to form the alkene and subsequent Corey-Chaykovsky reaction to the cyclopropane. In a similar manner, aziridines could be used as starting materials. Significantly the corresponding isatin could be used as starting material by increasing the equivalents of sulfoxonium iodide and sodium hydride. This works by generating the epoxide in situ followed by the optimised (ring opening/elimination) cyclopropanation reaction. All of these methods to access unprotected spirocyclic oxindoles also work with standard protecting groups in place.

Cyclopropanation with diazo compounds. A similarly active field is the direct cyclopropanation of 3-diazooxindoles. Diastereoselective cyclopropanations have been independently developed by Muthusamy, Subba Reddy and Padwa. ${ }^{30}$ The first enantioselective versions were developed at similar times by Arai (up to $74 \%$ ee using chiral Rh cat. 3), ${ }^{31}$ Zhou (up to 99\% ee using $\mathrm{Hg}(\mathrm{OTf})_{2}$ and a chiral phosphine ligand 4$)^{32}$ and Zhou with Ding (up to 95\% ee using a Au catalyst with chiral phosphine ligand 5) (Scheme 2). ${ }^{33}$ Since 2013, Qiu and Xu used chiral Rh cat. 6 to achieve up to $99 \%$ ee in the enantioselective cyclopropanation reaction with high ee for allyl alkene examples which performed poorly in previous reports. ${ }^{34}$ Zhou and Ma have used the Au/5 system developed previously by Zhou for the cyclopropanation with alkenes bearing a difluoromethyl group. ${ }^{35}$ Iwasa used chiral $\mathrm{Ru}(\mathrm{II})$ complex 7 to generate spirocyclopropyl oxindoles with high ee. ${ }^{36}$ Ashfeld reported a cyclopropanation/ring expansion cascade reaction between 3-diazooxindoles and vinyl isocyanate, in the case when the temperature was reduced from $50{ }^{\circ} \mathrm{C}$ to $\mathrm{rt}$, the cyclopropane intermediate could be isolated as one diastereomer. ${ }^{37}$

In 2014, Lu and Xiao showed a $[3+2]$-cycloaddition between 3-ylideneoxindoles and in situ generated 2,2,2-trifluorodiazoethane could afford a pyrazoline which upon heating under reflux in toluene would ring contract to afford $3,3^{\prime}$-cyclo- 


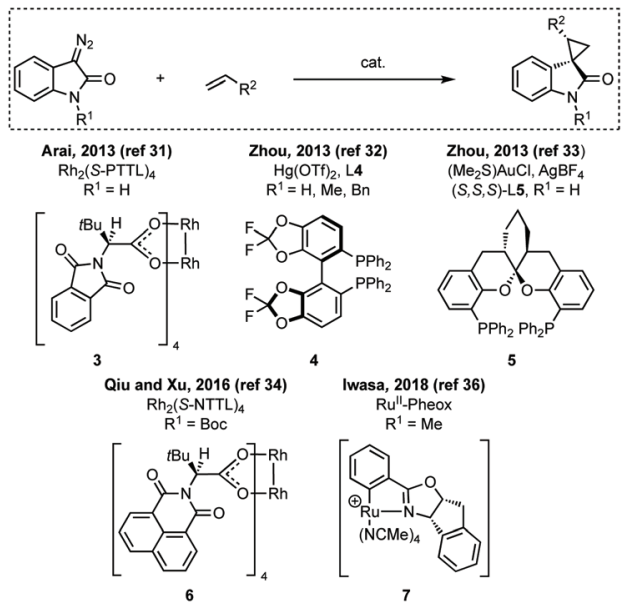

Scheme 2 Advances in enantioselective cyclopropanation of 3-diazooxindoles.

propyl spirooxindoles. ${ }^{38}$ Using chemistry first developed by Carreira, ${ }^{39}$ sodium nitrite was used to oxidise 2,2,2trifluoroethylamine. $\mathrm{HCl}$ to generate 2,2,2-trifluorodiazoethane which can undergo a $[3+2]$-cycloaddition with the electron deficient alkene followed by heating to liberate $\mathrm{N}_{2}$ and form the cyclopropane with high yield and dr (Scheme 3). Using a similar cycloaddition and ring contraction strategy, Babu demonstrated the synthesis of aryl substituted 3,3'-cyclopropyl spirooxindoles while Han and Chen have reported the synthesis of difluoromethyl substituted spirocyclic cyclopropanes. ${ }^{40,41}$ A significant advance in this methodology accesses enantioenriched spirocyclic cyclopropanes through a 1,3-dipolar cycloaddition between dimethyl (diazomethyl) phosphonate and 3-ylideneoxindoles followed by ring contraction mediated by NCS or NBS (this also caused chlorination/ bromination by $\left.\mathrm{S}_{\mathrm{E}} \mathrm{Ar}\right) .{ }^{42}$ Peng used thiourea catalyst 8 derived from a cinchona alkaloid to induce enantioselectivity in the pyrazoline formation and this ee was retained in the 5- to 3-membered ring contraction (Scheme 3).

Cyclopropanation of 3-ylidene oxindoles. He developed a phosphorus mediated reductive cyclopropanation of 3-ylideneoxindoles (Scheme 4). ${ }^{43} \mathrm{P}\left(\mathrm{NMe}_{2}\right)_{3}$ in combination with

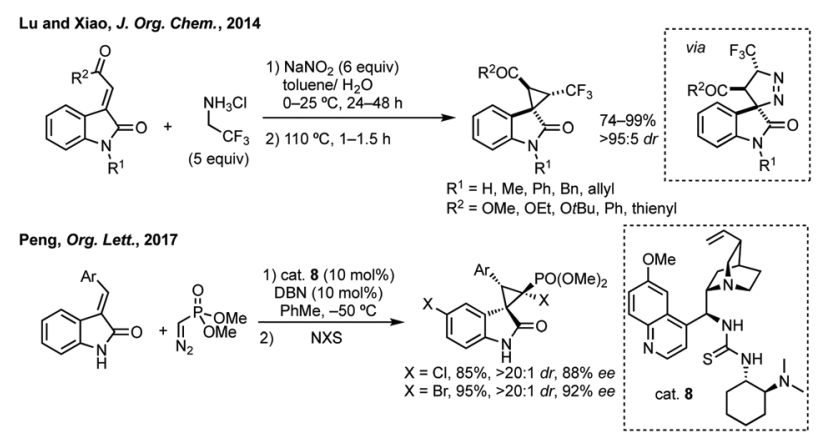

Scheme 3 1,3-Dipolar cycloaddition followed by ring contraction to 3,3'-cyclopropyl spirooxindoles.

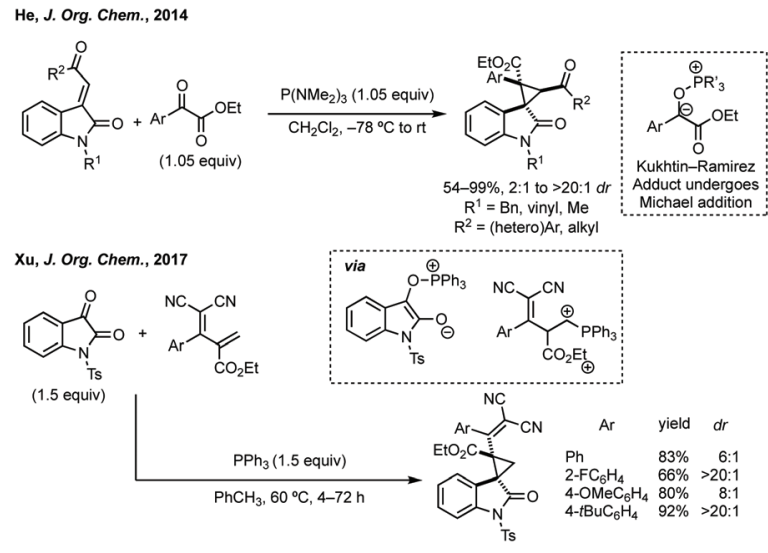

Scheme 4 P(NMe $)_{3}$-mediated reductive cyclopropanation via Kukhtin-Ramirez $(\mathrm{K}-\mathrm{R})$ adduct and $\mathrm{K}-\mathrm{R}$ adduct reaction with diene activated by $\mathrm{PPh}_{3}$.

$\alpha$-ketoesters formed a Kukhtin-Ramirez adduct which behaves as a carbene surrogate and can undergo cyclopropanation via a reported Michael addition and intramolecular $\mathrm{S}_{\mathrm{N}} 2$ reaction liberating triphenylphosphine oxide and the cyclopropyl spirooxindoles in high dr. Lu and Xu developed a related reaction mediated by dialkyl phosphite to couple isatins and $\alpha, \beta$-unsaturated ketones. ${ }^{44}$ In 2017, Xu reported the formation of Kukhtin-Ramirez adducts from isatins and their reactions with dienes to form spirocyclopropanes (Scheme 4). ${ }^{45}$

Du developed a Michael addition/alkylation cascade reaction between 3-chlorooxindoles and arylidenepyrazolones, alkenyl thiazolones (also developed by Sheng and Feng) or, more recently, 2,3-dioxopyrrolidines. ${ }^{46}$ In a quite distinct method, a Ni-catalysed enantioselective cyclopropanation developed by Feng utilised phenyliodonium ylides to generate a free carbene which can react with 3-ylideneoxindoles to generate 3,3'-cyclopropyl spirooxindoles in high yield, $\mathrm{dr}$ and ee (Scheme 5). ${ }^{47}$ More recently, Feng used a related system for the $\mathrm{Mg}$ catalysed reaction of 3-ylidene oxindoles and sulfonium ylides. $^{48}$

Other approaches. In 2013 Charette described an intramolecular C-H arylation of cyclopropanes to access 3,3'-spirocyclopropyl spirooxindoles (Scheme 6). ${ }^{49}$ Using $\mathrm{Pd}(\mathrm{OAc})_{2}$ with $\mathrm{PCy}_{3}$ as a ligand in combination with $\mathrm{K}_{2} \mathrm{CO}_{3}$ and $\mathrm{Ag}_{3} \mathrm{PO}_{4}$ in

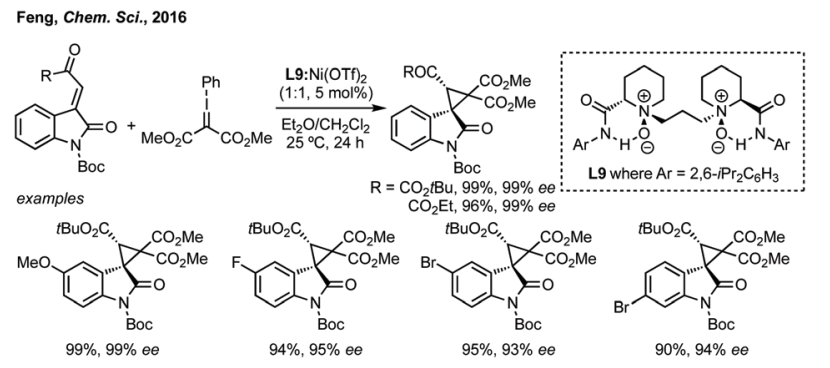

Scheme $5 \mathrm{Ni}$-Catalysed enantioselective cyclopropanation with phenyliodonium derived ylides. 


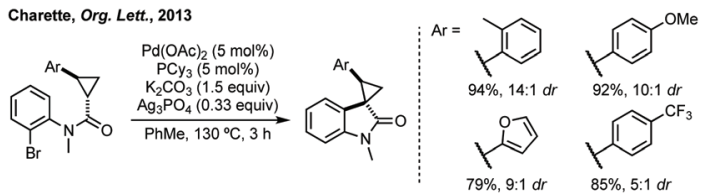

Scheme 6 Pd-Catalysed $\mathrm{C}-\mathrm{H}$ arylation to form 3,3'-spirooxindoles. $\mathrm{Cy}=$ cyclohexane.

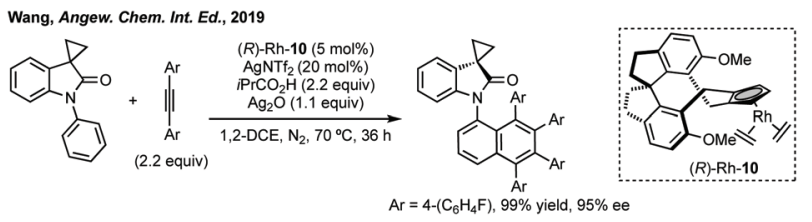

Scheme 7 Enantioselective synthesis of axially chiral oxindoles by $\mathrm{Rh}$ catalysed dual $\mathrm{C}-\mathrm{H}$ activation.

toluene at $130{ }^{\circ} \mathrm{C}$ afforded high yields of the spirooxindole. When aryl substituted cyclopropanes were employed high dr was observed.

Wang reported an enantioselective Satoh-Miura type reaction using a $\mathrm{Rh}^{\mathrm{III}}$ catalyst $\mathbf{1 0}$ to perform a dual $\mathrm{C}-\mathrm{H}$ activation forming an axially chiral spirocycle in high enantioselectivity (Scheme 7). ${ }^{50}$

\section{Spiroaziridinyl oxindoles}

Spiroaziridines don't commonly feature in natural products or medicines, but are utilised in synthesis, and protected versions could be envisaged to be of use in biology.

From 3-bromooxindoles. Zhang and Peng employed 3-bromooxindoles as nucleophiles in an enantioselective Mannich reaction catalysed by cinchona alkaloid derived cat. 11 (Scheme 8). ${ }^{51}$ Cyclisation mediated by silver nitrate afforded the aziridine in high yield and with retention of the ee induced in the prior step.

From 3-ylidene oxindoles. Traditional, non-stereoselective approaches to aziridination employ ethyl nosyloxycarbamate and calcium oxide with 3-ylideneoxindoles. ${ }^{52} \mathrm{Xu}$ and Wang, and Chen independently reported an aziridination of 3-ylideneoxindoles using hydroxycarbamate derivatives to afford a single diastereomer (Scheme 9). ${ }^{53}$

Aziridination of isatin ketimines. A team led by Marsini at Boehringer Ingelheim reported a diastereoselective aziridination of $\mathrm{N}$-tert-butanesulfinyl ketimino esters at the end of 2015

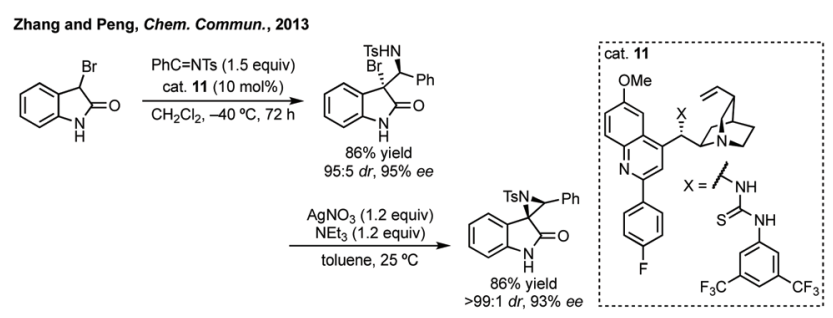

Scheme 8 Enantioselective Mannich reaction followed by cyclisation.

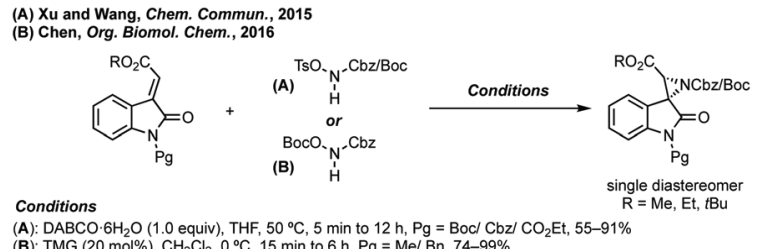

(A): DABCO $6 \mathrm{H}_{2} \mathrm{O}\left(1.0\right.$ equiv), THF, $50{ }^{\circ} \mathrm{C}, 5 \mathrm{~min}$ to $12 \mathrm{~h}, \mathrm{Pg}=\mathrm{Boc} / \mathrm{Cbz} / \mathrm{CO}$
(B): TMG $(20 \mathrm{~mol} \%), \mathrm{CH}_{2} \mathrm{Cl}_{2}, 0^{\circ} \mathrm{C}, 15 \mathrm{~min}$ to $6 \mathrm{~h}, \mathrm{Pg}=\mathrm{Me} / \mathrm{Bn}, 74-99 \%$

Scheme 9 Aziridination of 3-ylideneoxindoles with carbamate protected amines. TMG $=1,1,3,3$-tetramethylguanidine.

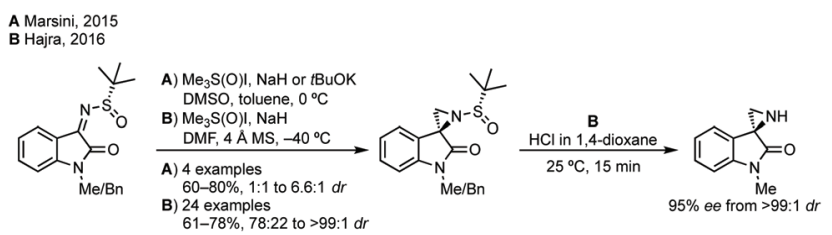

Scheme 10 Diastereoselective aziridination independently developed by Marsini and Hajra.

(Scheme 10). ${ }^{54}$ At a similar time Hajra reported the same reaction with higher diastereoselectivity (up to $>99: 1$ dr vs. 6.6:1 dr). ${ }^{55}$ Both reports use trimethylsulfoxonium iodide with either $\mathrm{NaH}$ or $t \mathrm{BuOK}$ and Hajra found that using DMF as solvent at lower temperature gave much higher diastereoselectivity. Hajra demonstrated one example of deprotection of the sulfinimide converting a protected aziridine with $>99: 1 \mathrm{dr}$ to the free aziridine with $95 \%$ ee, which was subsequently shown to be unstable. ${ }^{55}$

Peng developed an asymmetric Mannich reaction of $\alpha$-diazophosphonates as nucleophiles with isatin $N$-Boc ketimines catalysed by an asymmetric phosphoric acid (Scheme 11). ${ }^{56}$ The product diazo functionality could be reduced using tributylphosphine to afford the chiral hydrazone which could be cyclised to afford the enantiopure aziridine, with undefined stereochemistry at the hydrazine/phosphonate chiral centre.

From azirines. In 2016, Xu and Yuan reported an asymmetric Neber reaction catalysed by (DHQD) $)_{2} \mathrm{PHAL}$ (Scheme 12). ${ }^{57}$ Good enantioselectivity was achieved in the Neber reaction to form the azirine. Sodium borohydride was used to reduce the azirine, although the er and dr of the resulting aziridine was not reported.

\section{Spiroepoxy oxindoles}

Applications. There are two recent examples of spiroepoxides in medicinal chemistry for antibacterial activity as well as

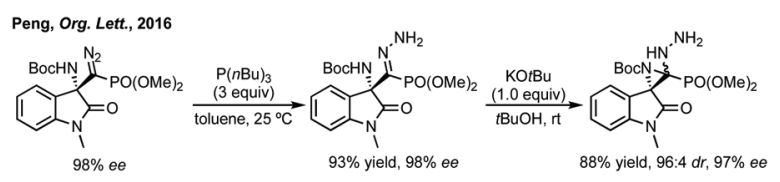

Scheme 11 Synthesis of enantioenriched spiroaziridine. 


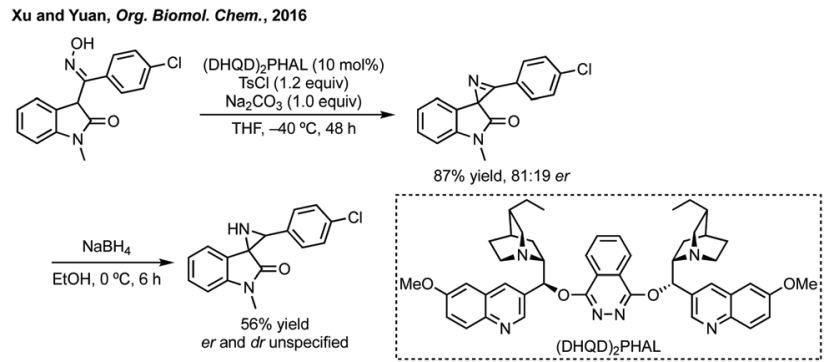

Scheme 12 Asymmetric Neber reaction followed by reduction to spiroaziridine.

activity in Neuroblastoma cell lines (Fig. 1). ${ }^{58}$ Spiro-epoxyoxindoles are also attractive synthetic building blocks. ${ }^{59}$

Epoxidation of isatins and isatin derivatives. Though nonstereoselective, notable advances in the synthesis of spiroepoxyoxindoles have been made recently by Wang and Zhang, ${ }^{60}$ and Pace. ${ }^{61}$ Diastereoselective epoxidations have been developed, ${ }^{62}$ notably the use of a trifluoroethylsulfonium salt in a Corey-Chaykovsky reaction by Cheng and Zhai. ${ }^{63}$ Lin and Jin recently developed a diastereoselective epoxidation mediated by visible light. ${ }^{64}$ Bencivenni was able to form axially enantioenriched 3-methylene oxindoles through a Knoevenagel condensation and, upon epoxidation, the high axially chiral enantioenrichment was maintained with a $5: 1$ $\mathrm{dr}^{65}$

The first report of an enantioselective epoxidation to form a spiro-epoxyoxindole was by Metzner and Briere in 2007, though only one example with $30 \%$ ee was given. ${ }^{66}$ In 2011 , Gasperi developed a moderately stereoselective epoxidation of 3-ylideneoxindoles using tert-butyl hydroperoxide with a prolinol catalyst. ${ }^{67}$ More recently, Gasperi reported a full study of this work and disclosed a highly enantioselective epoxidation reaction of this type, when the oxindole protecting group was Boc, though the diastereoselectivity was poor. ${ }^{68}$ In 2014, Xiao reported the use of camphor-derived sulfonium salts in an asymmetric epoxidation of isatins (Scheme 13). ${ }^{69}$ Substitution on the oxindole did not significantly affect the high enantioselectivity, though changing the R group on the sulfonium salt did reduce the enantioselectivity slightly. Feng described an enantioselective Darzens reaction to synthesise spiro-epoxyoxindoles using $\mathrm{L}-\mathbf{1 2}$ as a hydrogen bonding ligand to induce enantioselectivity in an aldol reaction which is followed by

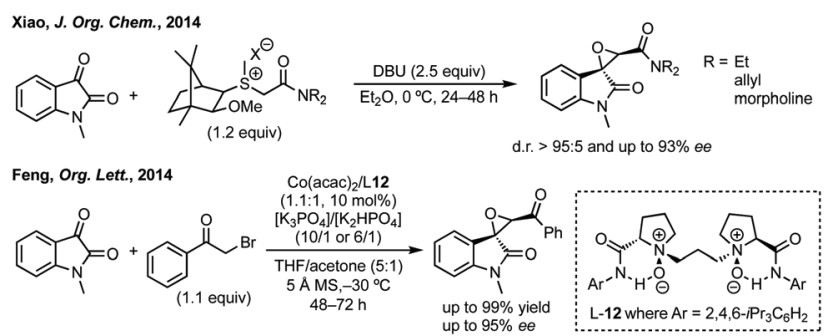

Scheme 13 Enantioselective epoxidations using Darzens reactions.

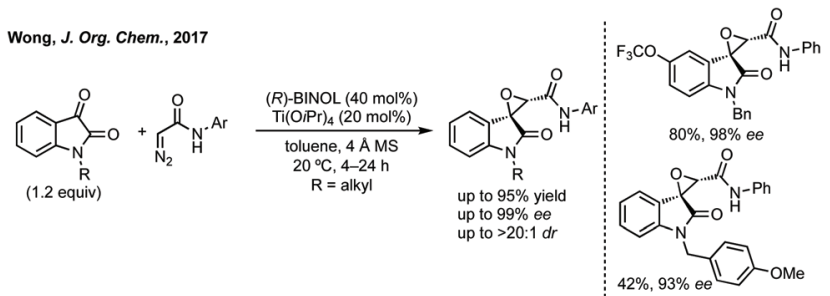

Scheme 14 Asymmetric Darzens reaction developed by Wong.

cyclisation to afford the three-membered ring (Scheme 13). ${ }^{70}$ Lower enantioselectivities were observed when the aryl group of the acyl bromides or the fused oxindole ring were substituted (ee $<85 \%)$.

Improved enantioselectivity was achieved by Wong in 2017 in an asymmetric Darzens reaction using diazoacetamides (Scheme 14). ${ }^{71}$ High yields and enantioselectivities (up to $99 \%$ ee) were observed using a titanium/BINOL complex and this reaction had a broad scope without reduction in enantioselectivity.

Other approaches. Recently, catalytic ring opening of spiroepoxides have been used to form enantioenriched products in a kinetic resolution. Sun, Hong and Wang used Bn-protected indole and napthols in an asymmetric phosphoric acid catalysed epoxide ring opening which resolved the racemic substrate to give one enantiomer in up to $99 \%$ ee. ${ }^{72}$ Zhou and Gao have developed a $\mathrm{P}\left(\mathrm{NMe}_{2}\right)_{3}$-mediated reductive epoxidation via a Kukhtin-Ramirez adduct similar to Scheme $4 .^{73}$ High diastereoselectivity could be achieved in this coupling of isatins with aldehydes.

\section{Four-membered rings}

\section{Spirocyclobutyl oxindoles}

Applications. Spirocyclobutane oxindoles have shown biological activity against a wide variety of targets and disease areas, including phosphodiesterase inhibition ${ }^{74}$ (for treatment of Schizophrenia, Parkinson's or Huntington's), bromodomain inhibition, ${ }^{75}$ progesterone receptor antagonists ${ }^{76}$ and antivirals (see Fig. 1 for example structures). ${ }^{77}$

Natural product synthesis. Welwitindolinone A (Fig. 1) has inspired many approaches in total synthesis from the $\operatorname{Baran}^{78}$ and Wood laboratories. ${ }^{79}$

Advances in stereoselective spirocyclobutane oxindoles have been mainly limited to achievements in $\mathrm{C}-\mathrm{H}$ activation chemistry and $[2+2]$-cycloadditions.

Metal-catalysed $\mathbf{C}-\mathbf{H}$ activation/coupling. Inspired by Overman's study of asymmetric Heck cyclisations to spirocyclic oxindoles, ${ }^{80}$ Sunoj and Kundig developed a Pd-catalysed enantioselective $\mathrm{C}-\mathrm{H}$ arylation reaction to afford oxindole spirocycles of varying ring size (Scheme 15). ${ }^{81}$ The spirocyclic cyclobutane was formed in high yield, albeit with lower enantioselectivity than other ring sizes.

Baudoin formed 3-cyclobutyl $N$-methyl-oxindole through $\mathrm{C}-\mathrm{H}$ activation when trying to develop an arylation/electrocyc- 


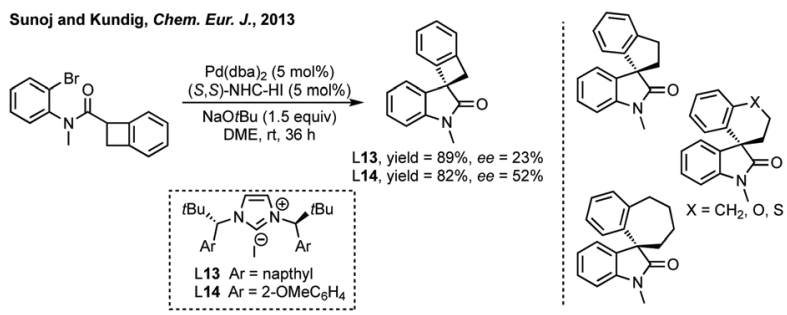

Scheme $15 \mathrm{Pd}$-Catalysed enantioselective $\mathrm{C}-\mathrm{H}$ arylation.

lic cascade reaction. ${ }^{82,83} \mathrm{Xu}$ could form the same unsubstituted cyclobutane, as well as 5- and 6-membered analogues, in an intramolecular 1,5-HAT using aryl iodides by visible light photoredox catalysis. ${ }^{84}$ Gouverneur recently developed a silyl radical-mediated hydrosulfamoylation using sulfonyl chlorides and could effect a cascade spirocyclisation (Giese-type addition followed by aryl C-H transfer) from cyclobutene 15, albeit with only poor diastereoselectivity (Scheme 16). ${ }^{85}$

$[2+2]$-Cycloaddition. A significant advance in spirocyclobutyl oxindole synthesis was made by Wang and successively by Jørgensen in 2014/2015 in the field of organocatalytic [2 + 2]cycloadditions of 3 -ylideneoxindoles (Scheme 17). Wang reported a $[2+2]$-cycloaddition of 3-ylideneoxindoles and enals catalysed by $\alpha, \alpha$-diphenyl prolinol cat. $16 .{ }^{86}$ Jørgensen further developed this type of reaction using a similar prolinol cat. 17 to mediate a cyclopropane ring opening to form a proposed dienamine which can undergo the $[2+2]-$ cycloaddition. ${ }^{87}$

Yan in 2016 and then Guan and He in 2017 have independently published a photocatalysed [2 +2$]$-cycloaddition of 3-ylideneoxindoles to form a bispirooxindole cyclobutane as a single

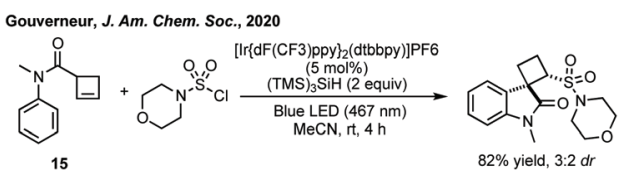

Scheme 16 Visible light mediated cascade spirocyclisation.

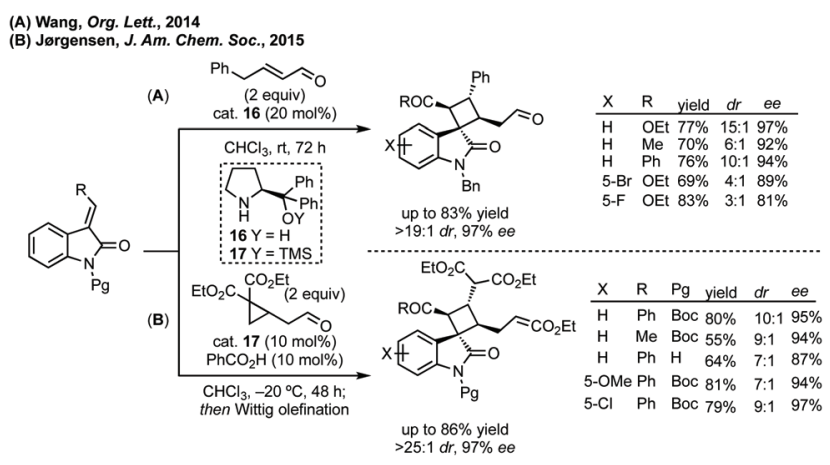

Scheme 17 Advances in organocatalytic [2 + 2]-cycloaddition of 3-ylideneoxindoles with $\alpha, \beta$-unsaturated aldehydes, either directly or in situ generated.

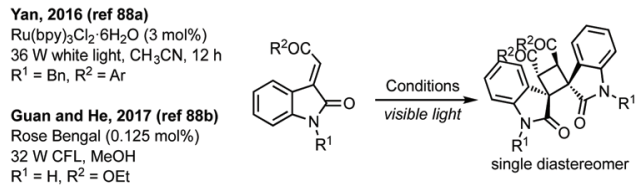

Scheme $18[2+2]$-Photocycloaddition of 3-ylideneoxindoles.

diastereomer (Scheme 18).$^{88}$ Out of a possible 8 diastereomers, one diastereomer was formed in the cycloaddition reaction.

\section{Spiroazetidinyl oxindoles}

There are very few examples of spirocyclic azetidinyl oxindoles. Indeed, an analysis of all N-containing 4-membered 3,2'-spiro oxindole structures shows that all of them are beta-lactams or derivatives. Whereas for the corresponding 3,3'-spirocycles only one out of 332 is a $\beta$-lactam or derivative thereof (yet these are typically symmetrical and easily installed via traditional methods and do not feature heavily in this section). $\beta$-Lactams dominate the nitrogen containing bioactive compounds. This may reflect the lack of synthetic methods towards the unsubstituted spiroazetidinyl oxindoles.

Applications. Spiroazetidine/spiro- $\beta$-lactam oxindoles have shown activity as antivirals, ${ }^{89}$ antibacterials, ${ }^{90}$ antifungals ${ }^{91}$ and insecticides (Fig. 1). ${ }^{92}$

Natural product synthesis. In terms of total synthesis, Weinreb explored the synthesis of chartelline A via the spiro$\beta$-lactam oxindole as a key intermediate (Fig. 4). ${ }^{93}$

'Traditional' non-stereoselective methods. Notable examples of non-stereoselective $\beta$-lactam formation are $[2+2]$ cycloadditions between diazo compounds and isatin derived ketimines or reaction of bromoacetyl bromide or chloracetyl chloride with isatin derived ketimines. ${ }^{94}$

Annulations using NHC catalysis. There have been significant advances in the stereoselective synthesis of $\beta$-lactam containing spirooxindoles by organocatalysed annulation of ketimine derived isatins. In 2014, Ye reported an asymmetric Staudinger reaction of ketenes with isatin derived ketimines catalysed by NHC 18 (Scheme 19A). ${ }^{95}$ In 2017, Xu and Ren developed an NHC catalysed asymmetric Mannich reaction between aldehydes and isatin derived ketimines using cat. 19 in combination with oxidant 20 (Scheme 19B). ${ }^{96}$ Both of these reports demonstrated Boc deprotection of the $\beta$-lactam using either silica gel in toluene under reflux or trifluoroacetic acid in 1,2-dichloroethane, affording the unprotected $\beta$-lactam in $95 \%$ and $98 \%$ ee respectively. In 2019, Deng reported an isothiourea (HBTM, 21) catalysed asymmetric Mannich reaction between ketimines and carboxylic acids (Scheme 19C). ${ }^{97}$

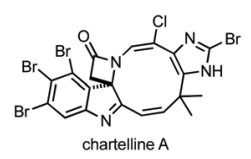

Fig. 4 Structure of chartelline A. 


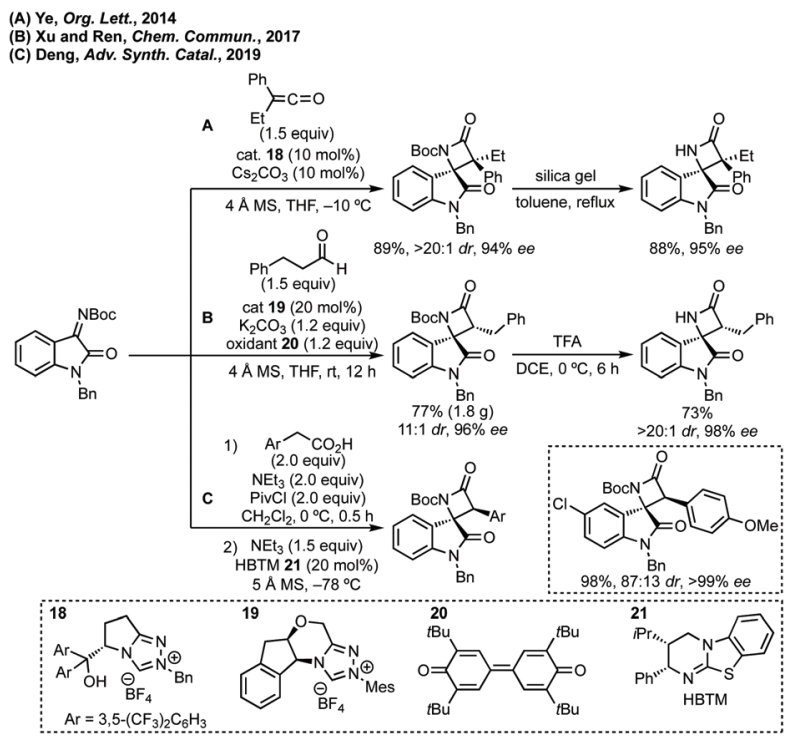

Scheme 19 Organocatalysed beta-lactam formation from isatin derived ketimines.

Deng's work does not use an NHC catalyst and uses a relatively more stable starting material while yielding the products in very high enantioselectivity.

Annulations using Cu/guanidinium catalysis. In 2014, Shanmugam reported a copper-catalysed one-pot, three-component diastereoselective synthesis of 3-spiroazetidinimine-2oxindoles as masked $\beta$-lactams (Scheme 20A). ${ }^{98}$ The spirocycle was built with high anti-diastereoselectivity. ${ }^{99}$ In 2018 , Liu advanced this type of reaction in a highly diastereoselective and enantioselective variant using a chiral guanidinium ligand L22 (Scheme 20B). ${ }^{100}$

Azetidines from allene activation. The two main advances in the synthesis of spiroazetidine oxindoles (non-2-azetidinone structures) are from the Silvani lab in 2016 and 2017 involving allene activation. In 2016, Silvani reported a DABCO catalysed annulation of tert-butyl sulfinyl ketimines with allenes to form spiroazetidinyl oxindoles in high dr (Scheme 21). ${ }^{101}$ This could be followed by $\mathrm{HCl}$ mediated deprotection of the Ellman auxiliary affording the spiroazetidine in $64 \%$ yield. In 2017, Silvani published a follow up study using cinchona derived

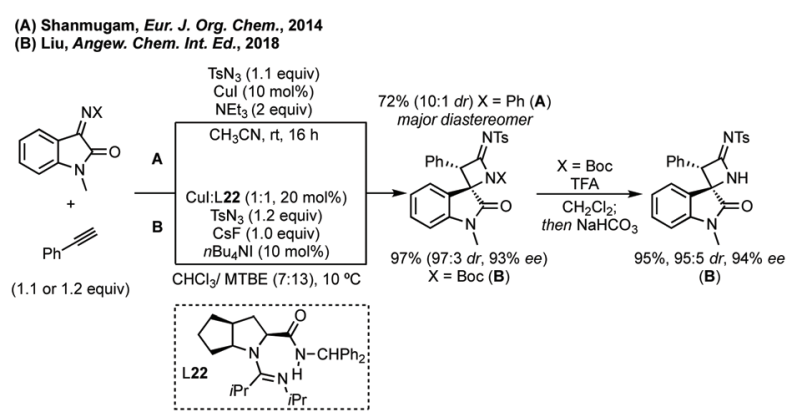

Scheme 20 Cu-Catalysed one-pot, three component synthesis of spiroazetidinimine oxindoles from isatin derived ketimines.

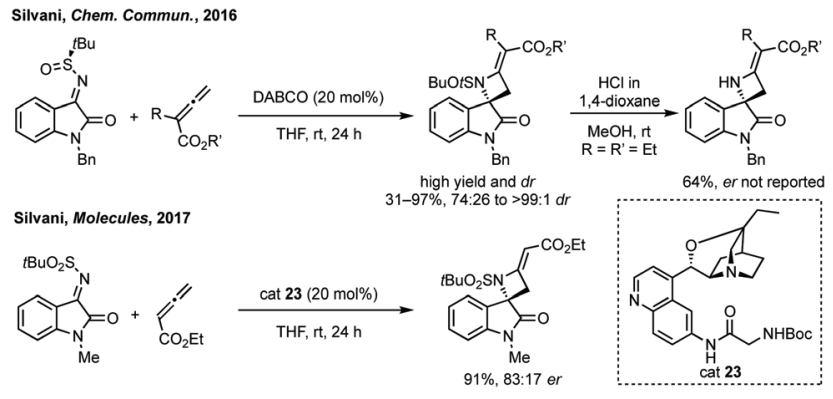

Scheme 21 Diastereoselective formal $2+2$ annulation of $\mathrm{N}$-sulfinylketimines and allenes by Silvani. Development of an enantioselective reaction employing a quinine derived nucleophilic catalyst with $\mathrm{N}$-sulfonylketimines by the same authors.

organocatalyst $\mathbf{2 3}$ for the same reaction with a $t$ Bus protecting group instead of the Ellman auxiliary and generating the spiroazetidine in up to $83: 17$ er (Scheme 21).$^{102}$

By nucleophilic addition. Other recent advances involve nucleophilic addition to isatin or isatin derived ketimines. In 2016, Xu developed an asymmetric Reformatsky reaction of tert-butyl sulfinyl isatin ketimines and ethyl bromoacetate to afford a disubstituted isatin in high yield with high diastereoselectivity (Scheme 22). ${ }^{103}$ Zhang developed an asymmetric allylboration of isatin mediated by a chiral amino alcohol (Scheme 22). ${ }^{104}$ Both Xu and Zhang showed how this diastereoselectivity could be converted to highly enantioenriched products in $4 / 5$ steps. Noda and Shibasaki developed an asymmetric Mannich reaction mediated by a cinchona alkaloid dimer (Scheme 22) ${ }^{105}$ The enantioenriched product could be converted to a spirocyclic $\beta$-lactam in 2 steps involving $\mathrm{Zn}$ mediated $\mathrm{N}-\mathrm{O}$ bond cleavage followed by lactamisation mediated by HCTU.
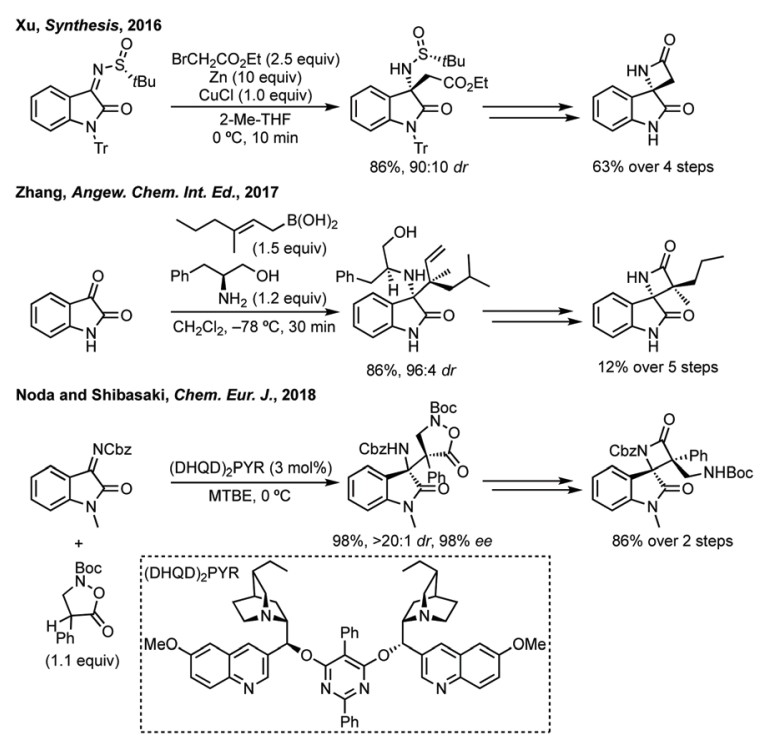

Scheme 22 Examples of enantioselective addition to ketimines or isatins followed by elaboration to $\beta$-lactam spirocycles. 


\section{Spirooxetanyl oxindoles}

Applications. Spirooxetanes have featured in only two recent reports for bioactivity in a Merck patent for kinase inhibitors, ${ }^{106}$ as well as in an SAR study (see below, ref. 109).

Non-stereoselective methods. As developments in stereoselective formation of spirooxetanes have been limited since 2012 (with the lowest number of hits out of any of the structures considered in this review), it is worthwhile mentioning papers that form spirooxetanes without stereoselectivity. Zhang formed spirocyclobutanes from a cascade spirooxetane/ cyclopropane ring opening reaction using $\mathrm{BF}_{3} \cdot \mathrm{Et}_{2} \mathrm{O} .{ }^{83}$ The oxetane starting materials were synthesised in a $[2+2]$-cycloaddition from the isatin and a tetrasubstituted alkene such as 1,1'-bi(cyclopropylidene). ${ }^{107}$ In 2019, Marini reported a domino reaction of 3-hydroxyindoles and phenyl vinyl selenone. ${ }^{108}$ Using $\mathrm{KOH}$ in aqueous conditions Marini showed that protected or unprotected isatins could be used to produce a variety of $3,2^{\prime}$-spirooxetanes in $34-73 \%$ yield. Lindsley synthesised 3,3'-spirooxetane $\mathbf{2 4}$ from the corresponding isatin in 3 steps in an SAR study to find a sub micromolar and selective $\mathbf{M}_{5}$ (muscarinic acetylcholine receptor 5) positive allosteric modulator for the treatment of a variety of neurological diseases. ${ }^{109}$ Final treatment of the diol with triflic anhydride afforded the oxetane in only 6\% yield (Scheme 23 ).

Lewis acid catalysed cycloaddition. In 2014, Feng reported the reaction of isatins with ketenes catalysed by an $N, N^{\prime}$ dioxide ligand and Sc Lewis acid to form spirooxetanones. ${ }^{110}$ In terms of optimisation, Feng reported that a $N$-Bn protecting group gave a significant improvement in ee compared to $\mathrm{Me}$ and molecular sieves increased the yield. The reaction was tolerant of a range of electronics on both aromatic rings giving high yield, dr and ee (Scheme 24).

\section{Five-membered rings}

\section{Spirocylopentyl oxindoles}

Applications. Spirocyclopentyl oxindoles feature in many natural products and active pharmaceuticals (see Fig. 1 and 5). For example, neosurugatoxin is a specific antagonist of nicotinic acetylcholine receptors. ${ }^{111}$ This core scaffold has also been developed for treatment of migraine, which is discussed in the relevant section (ref. 139), as well as bromodomain inhibitors. $^{75}$

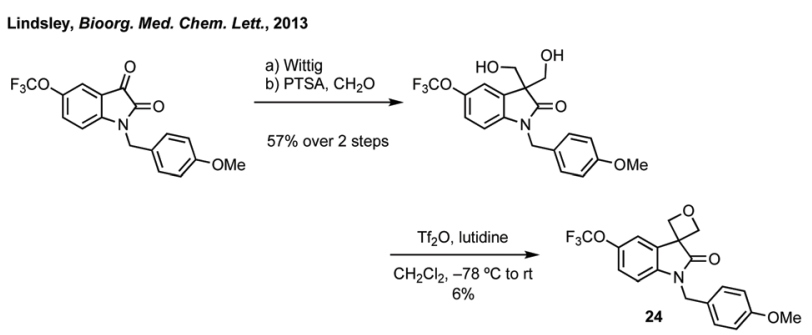

Scheme 23 3-Step sequence to oxetane 24 in a SAR study towards a selective $M_{5}$ positive allosteric modulator.

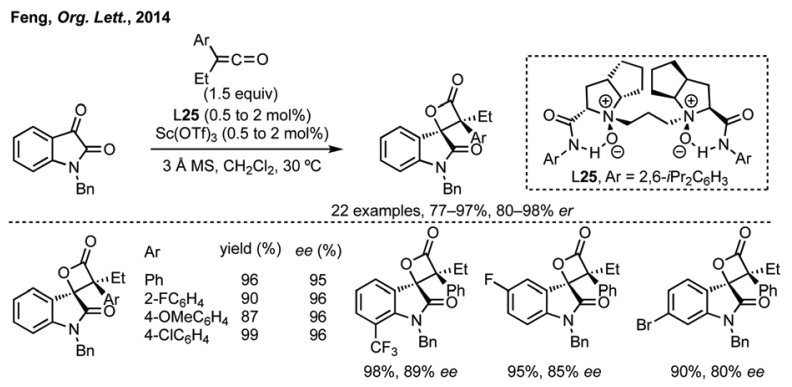

Scheme 24 Enantioselective [2+2]-cycloaddition to form spirooxetanones.
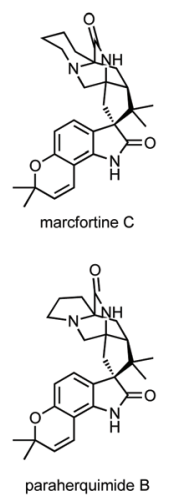
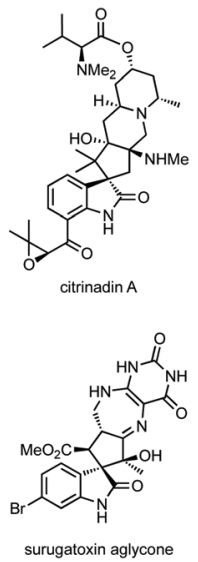
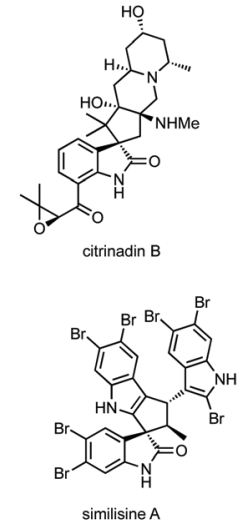

Fig. 5 Selected cyclopentane spiroindolones in nature.

Natural product synthesis. Spirocyclopentane oxindoles have been the focus of many total synthesis studies, with several of these appearing since 2013. Martin reported the total synthesis of (-)-citrinadin A, forming the spirocyclopentane oxindole in an epoxidation/semi-pinacol rearrangement cascade using Davis' oxaziridine reagent (Scheme 25). ${ }^{112}$ Selective epoxidation of the indole $\mathrm{C} 2=\mathrm{C} 3$ followed by stereoselective collapse of the epoxide results in spirocyclopentane formation. Sarpong, Simpkins, Sun and Li have reported total syntheses of numerous natural products using a similar spirocyclisation strategy employing various epoxidising reagents. ${ }^{113}$ A recent study of the biosynthetic spirocyclisation of the paraherquimides (related natural products) by Sherman and coworkers showed that this semi-pinacol rearrangement was the biosynthetic pathway to these spirooxindoles. ${ }^{114}$ Wood synthesised (+)-Citrinadin B forming the spirocyclopentane in a Pd-catalysed enyne cyclisation, initially developed by Trost. ${ }^{115}$ Trost has developed an asymmetric [3 + 2] Pd-trimethylenemethane (TMM) cycloaddition to form the spirocyclopentane core of Marcfortine $\mathrm{B}$ and $\mathrm{C}$ (Scheme 25). ${ }^{116}$ Lewis developed an efficient complexity generating spirocyclisation heating phenylenediamine and $\mathbf{2 6}$ to form the spirocyclopentane, by ring opening of the ester and ortho-alkylation by a FriedelCrafts reaction, in 64\% yield and $3.7: 1 \mathrm{dr}$ as a precursor to surugatoxin aglycone (Scheme 25, for structure of natural 

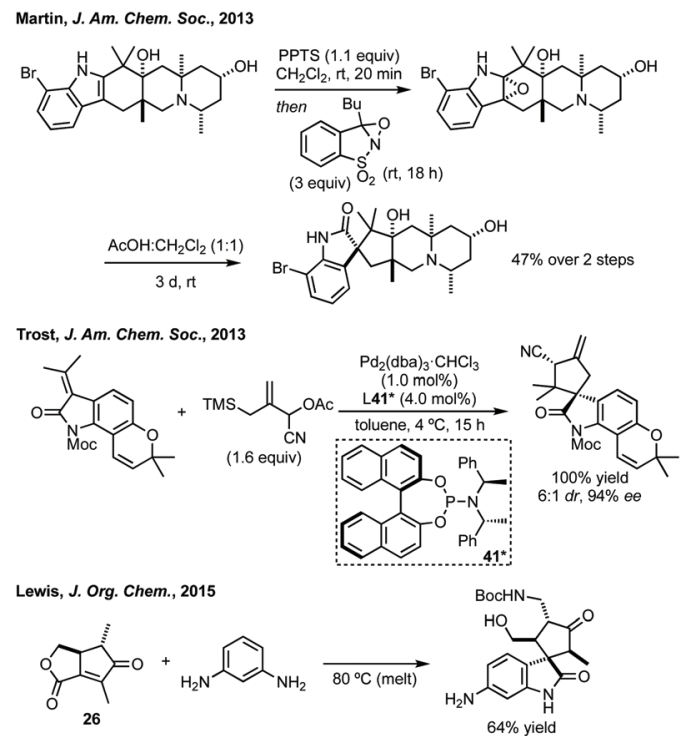

Scheme 25 Selected examples of spirocyclisation to cyclopentanes in total synthesis.

product see Fig. 5). ${ }^{117}$ Zhang and Jia recently described the total synthesis of similisines A and B (Fig. 5), enantiomeric trisindole structures containing a spirocyclopentane oxindole core, through a key acid-mediated Friedel-Crafts cyclisation, though this was low yielding and non-stereoselective. ${ }^{118}$

$[3+2]$-Cycloaddition. A significant route for construction of cyclopentane spirooxindoles has been through $[3+2]$ cycloaddition utilising Morita-Baylis-Hillman ( $\mathrm{MBH})$ carbonates, either to react with or situated on the isatin core. ${ }^{119,120}$ Recent highlights include Chen's demonstration of a $[3+2]$-cycloaddition between isatin derived $\mathrm{MBH}$ carbonates and 3-ylidene oxindoles to form bispirooxindole products in high diastereoand enantiocontrol (Scheme 26A). ${ }^{121}$ In 2019, Chen described the $[3+2]$ cycloaddition of isatin-derived $\mathrm{MBH}$ carbonates with $\beta, \gamma$-unsaturated $\alpha$-keto esters using asymmetric nucleophilic catalyst 27 derived from quinidine (Scheme 26B). ${ }^{122,123}$

Further advances in this field have been made using asymmetric phosphorus catalysis to activate allenes, $\mathrm{MBH}$ carbonates or alkynones to form spirooxindoles. ${ }^{124,125}$ In $\mathrm{Lu}$ and Mei's 2019 report threonine derived cat. 28 was found to give

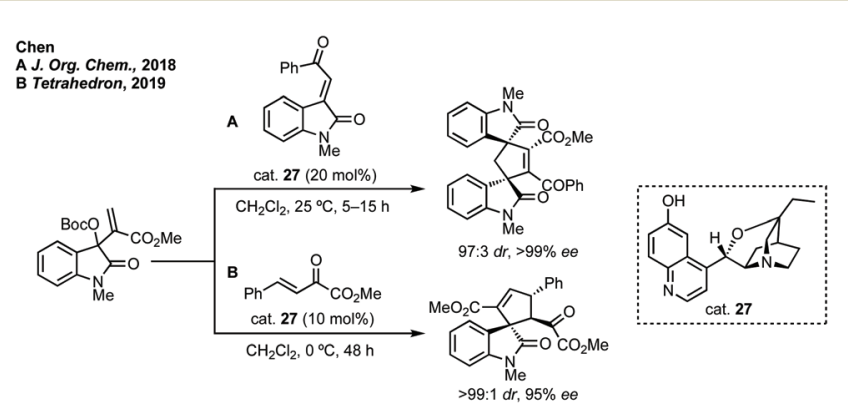

Scheme 26 Selected isatin derived MBH carbonates in a cycloaddition with 3-methyleneoxindoles and $\beta, \gamma$-unsaturated $\alpha$-keto esters.

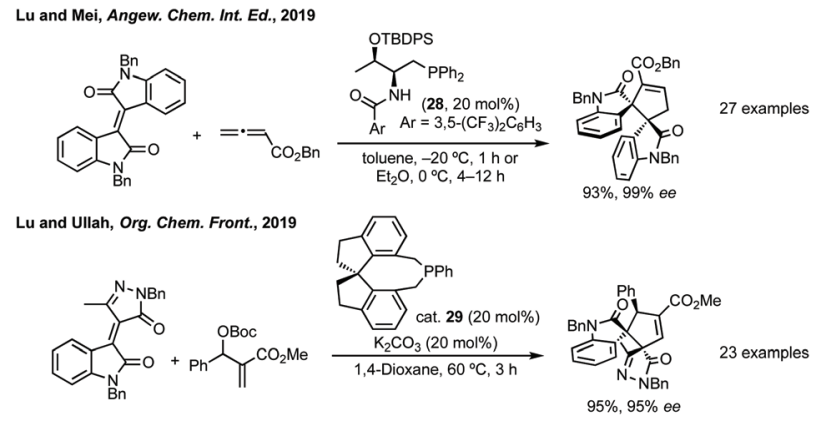

Scheme 27 Lu and coworkers' achievements in asymmetric phosphine catalysed activation of electrophiles to form spirocyclopentene scaffolds.

the highest yield and enantioselectivity in $\mathrm{Et}_{2} \mathrm{O}$ for the $[3+2]$ annulation of isoindigos and allenes (Scheme 27). ${ }^{126} \mathrm{Lu}$ and Mei additionally showed unsymmetrical isoindigos in this process with high regiocontrol, as well as the formal syntheses of a number of complex natural products. Lu, with Ullah, then reported the annulation of pyrazoloneyldiene oxindoles with $\mathrm{MBH}$ carbonates using asymmetric phosphorus catalyst, SITCP 29 (Scheme 27). ${ }^{127}$ Both routes exploit the regioselective addition of the activated electrophile $(\mathrm{MBH}$ carbonate or allene) to the more electrophilic alkene carbon. Related reactions have been developed using isocyanides to activate similar electrophiles including allenes. ${ }^{128}$

\section{Domino Michael addition/aldol (or alternative cyclisation)}

In 2011, Barbas III designed a bifunctional thiourea catalyst 30 for the domino Michael addition/aldol reaction to form bispirooxindoles from 3-substituted oxindoles and 3-methylene oxindoles (Scheme 28). ${ }^{129}$ Since, this Michael addition/cyclisation strategy based upon hydrogen bonding catalysis has been employed to access spirocyclopentane oxindoles on a large number of occasions. ${ }^{130}$ Notable examples include Kanger's use of 3-ylidene oxindoles undergoing asymmetric thiourea catalysed Michael addition alpha to the nitro group of a $\gamma$-nitroketone and spontaneous stereoselective aldol formation (determined by stereochemistry of the first step) to give the five-membered ring (for a related reaction see Scheme 75). ${ }^{131}$ Johnston and Cordova used a prolinol aminocatalyst to promote a Michael addition between an alkyne substituted oxindole and an $\alpha, \beta$-unsaturated aldehyde followed by cyclisation

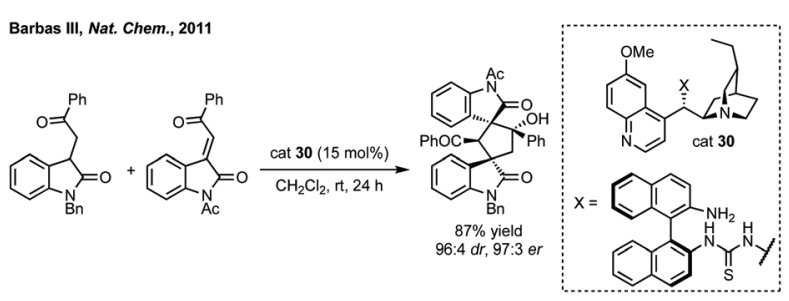

Scheme 28 Barbas III's seminal work on an enantioselective domino Michael/aldol cyclisation. 
to form an enantioenriched spirocyclopentane with moderate dr. ${ }^{132}$ Shi has utilised asymmetric phosphoric acid catalysts to employ various vinyl indoles to react with 3-ylidene oxindoles, formed in situ from 3-indolylmethanol, in a Michael/alkylation cascade. $^{133}$

NHC catalysis. In 2017, Wang reported a Michael addition/ intramolecular aldol/lactonization cascade of enals with 3-methylene oxindoles using an azolium NHC catalyst. ${ }^{134,135}$ Up to $99 \%$ ee and $>99: 1 \mathrm{dr}$ was achieved using cat. 31 and DIPEA for the spirooxindole products (Scheme 29A). Subsequently, Enders published a related study where fused $\beta$-lactam spirooxindoles could be formed (Scheme 29B). ${ }^{136}$ Enders also showed that using a different NHC catalyst (cat. 33), base and solvent, a different spirocyclopentane scaffold could be formed in good yield and high $\mathrm{dr}$ and er (Scheme 29C). This switchable reactivity occurs from the same intermediate formed by Michael addition. This intermediate can then undergo either (B) intramolecular Mannich reaction then lactamisation or (C) aza-Dieckmann type cyclisation and tautomerisation.

Phase transfer catalysis. Zhao and Shang reported a tandem Michael/Michael addition sequence catalysed by an asymmetric phase transfer catalyst. ${ }^{137}$ Employing phosphonium phase transfer catalyst 34, deprotonation of the malonate initiates Michael addition to the 3-ylidene oxindole followed by subsequent Michael addition to the $\alpha, \beta$-unsaturated ester (Scheme 30). Significant reduction in enantioselectivity was observed when attempting to form the six-membered analogue. Zhao and Zou also reported an ammonium phase transfer catalysed asymmetric vinylation of 3-phenyloxindoles which were shown to undergo Pd-catalysed Heck cyclisation and oxidative cleavage to give a spirocyclopentane oxindole with retention of ee. ${ }^{138}$

Spirocyclopentanyl oxindoles feature in a number of lead Calcitonin Gene-Related Peptide (CGRP) medicines developed

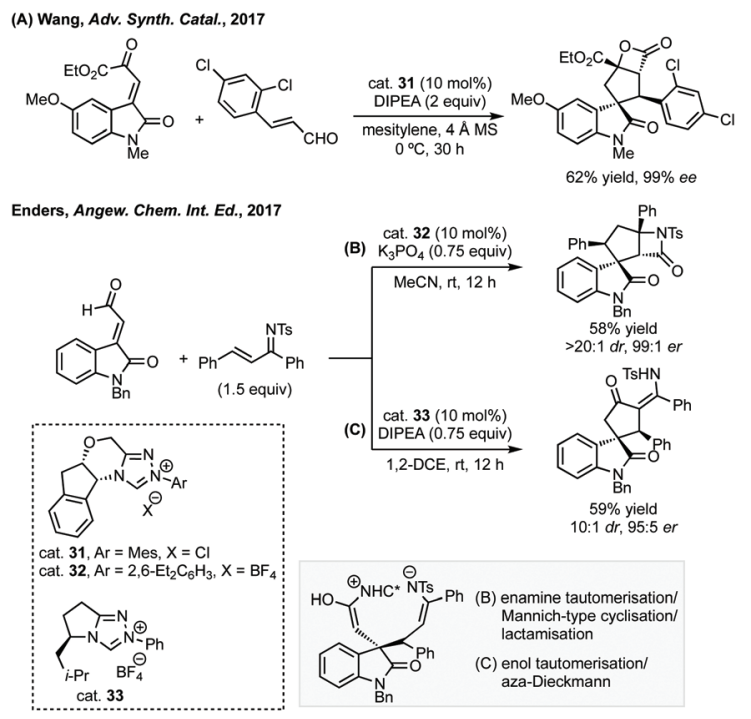

Scheme 29 Work by Zhang and Enders using NHC catalysis to synthesise diverse spirocylopentanyl oxindoles.

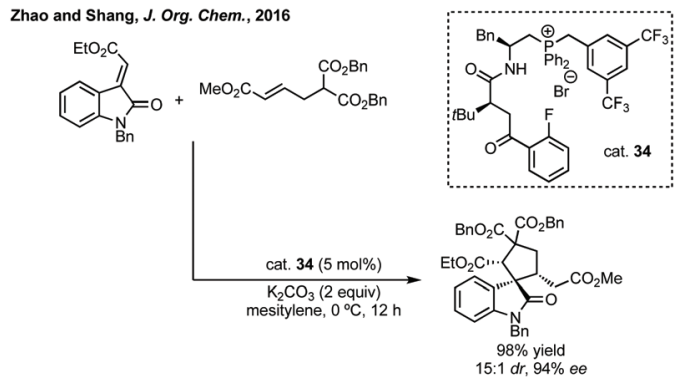

Scheme 30 Phase transfer catalysed enantioselective double Michael addition chemistry to spirocyclopentanes.

by Merck, and more recently Sosei Heptares, for treatment of migraine (Fig. 6). ${ }^{139}$

Towards an efficient asymmetric synthesis of the spirocyclopentane core of these compounds Merck developed an enantioselective phase transfer catalysed spirocyclisation. ${ }^{140}$ Using a doubly quaternised cinchona alkaloid derived phase transfer catalyst 35 up to $96 \%$ ee was achieved for the transformation of substrates such as $\mathbf{3 6}$ to $\mathbf{3 7}$ in quantitative yield which could conceivably be elaborated via the halogenated pyridine (Scheme 31). Merck subsequently collaborated with Houk to model how the novel phase transfer catalysts promote the reaction and induce enantioselectivity (Scheme 31). ${ }^{141}$

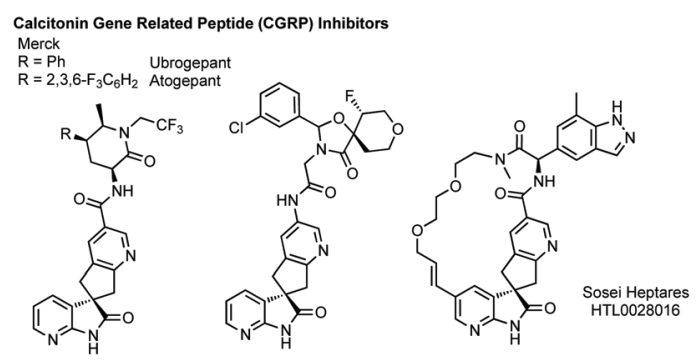

Fig. 6 Selected developments in structures of CGRP inhibitors.

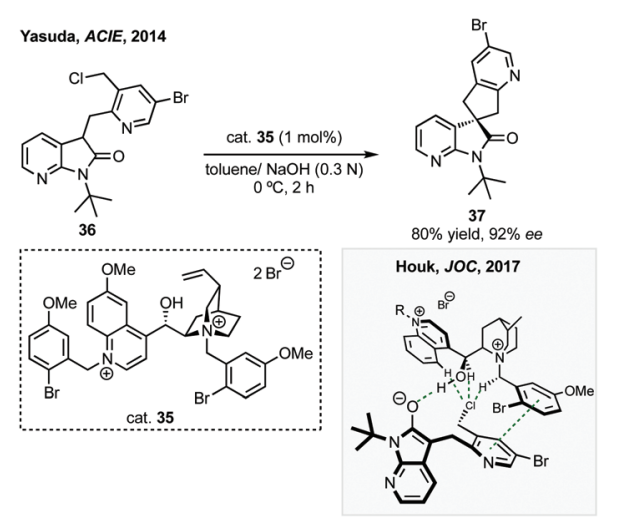

Scheme 31 Merck's development of a phase transfer catalysed spirocyclisation and model for the enantioselectivity developed in collaboration with Houk. 
They proposed three key electrostatic interactions: (1) hydrogen bonding between the hydroxyl of the catalyst and the oxindole enolate; (2) a chloride- $\mathrm{CH}$ interaction activating the leaving group; (3) a $\pi-\pi$ interaction between the pyridine of the formed cyclopentane and the quinicludine benzyl group. Merck also recently published on the monitoring of the reaction kinetics of these inherently complex, dual-phased reaction mixtures in an automated fashion. ${ }^{142}$ These studies remain a significant advance in asymmetric phase transfer catalysis, as well as in the synthesis of enantioenriched spirooxindoles.

Metal/Lewis acid mediated approaches. Feng used a $\mathrm{Mg} / \mathrm{N}$, $N^{\prime}$-dioxide catalyst system in a Michael/Friedel-Crafts/Mannich cascade of isocyanides to generate enantioenriched polycyclic spirocyclopentanes resembling strychnos alkaloids. ${ }^{143}$ Franz recently used an Sc/pybox system for the $[3+2]$-cycloaddition of allenes with 3-ylidene oxindoles. ${ }^{144}$ In a distinct strategy, Su and Yang developed a Pd-catalysed $[3+2]$ annulation of spirovinylcyclopropyl oxindoles with $\alpha, \beta$-unsaturated nitroalkenes (Scheme 32). ${ }^{145}$ Using $\mathrm{Pd}(\mathrm{OAc})_{2}$ and Xantphos in toluene the spirovinylcyclopropyl is ring opened to form a amphoteric $\pi$-allyl species which undergoes the $[3+2]$ annulation in a diastereoselective manner, invoking a $\pi$-stacking between the aromatic ring of the oxindole and the aromatic substituent of the nitroalkene. Rios had previously developed a similar strategy showing one example with $76 \%$ ee using a prolinol catalyst with $\alpha, \beta$-unsaturated aldehydes. ${ }^{146}$

C-H activation/cross-coupling. Cross-coupling methodologies have been extensively utilised to access spirocyclopentane oxindoles. ${ }^{147}$ Related to Trost's development of Pd-catalysed cyclisations towards the Marcfortines (see Scheme 25), Córdova has developed an iminium catalysed asymmetric Michael addition/Pd-catalysed intramolecular allylic alkylation. ${ }^{148}$ Trost has continued to innovate in this field, developing new Pd-catalysed $[3+2]$-cycloadditions from allene and $\mathrm{CF}_{3}$-containing trimethylenemethane precursors with application to enantioenriched spirocyclopentane oxindoles. ${ }^{149}$

Taylor et al. reported a $\mathrm{Cu}(\mathrm{II})$-mediated double $\mathrm{C}-\mathrm{H} / \mathrm{Ar}-\mathrm{H}$ coupling of bis-anilides to form bispirooxindoles (Scheme 33). ${ }^{150}$ This strategy was notable for the transdiastereoselectivity observed and the flexibility in increasing the size of the central ring. Larhed and co-workers, in collaboration with AstraZeneca, have built on their previous work on the Heck-Mizoroki reaction to generate functionalised cyclopentenes, ${ }^{151}$ to develop an intramolecular variant. Exploiting the selectivity of the Heck-Mizoroki reaction to afford spirocyclopentenes with high diastereocontrol (Scheme 33). ${ }^{152}$

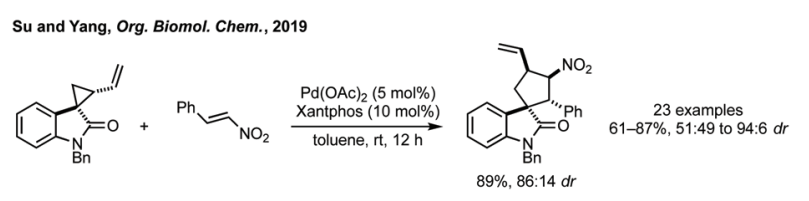

Scheme 32 Pd-Catalysed [3 + 2] annulation of spirovinylcyclopropyl oxindoles.

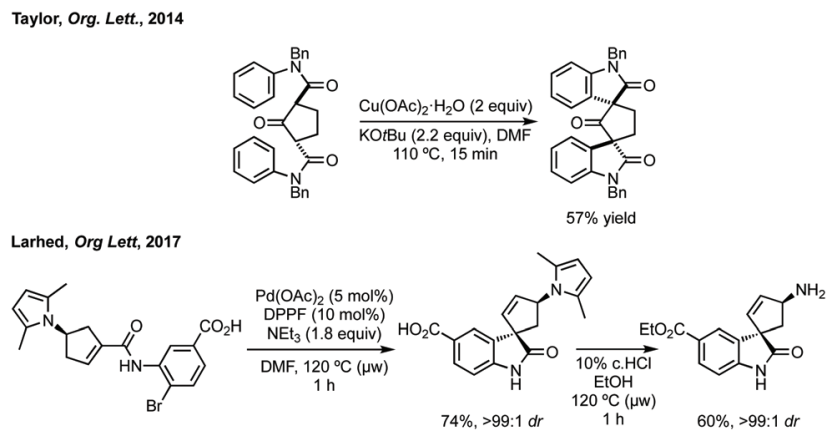

Scheme 33 Selected $\mathrm{C}-\mathrm{H}$ activation and cross-coupling procedures to access spirocyclopentane.

García-López and others have reported $\mathrm{C}-\mathrm{H}$ activation and carbene insertion procedures to afford spirocyclopentanes. ${ }^{153}$

Related to these $\mathrm{C}-\mathrm{H}$ activation approaches is the stereoselective oxidation of spirocyclopentane oxindole $\mathrm{C}-\mathrm{H}$ bonds using $\mathrm{Ru}$ or $\mathrm{Mn}$ catalysis. ${ }^{154}$ Initially developed by Bach in 2014, selective oxidation of one of the enantiotopic carbons of the cyclopentane gave cyclopentanones in high er.

Other approaches. Taylor and Unsworth have a program of work on the synthesis of diverse spirocycles. In 2016, they described the controlled synthesis of two diastereomers of a spirocyclopentanyl oxindole from the same intermediate. ${ }^{155}$ Treatment of a ketodiazo with $\mathrm{Rh}_{2}(\mathrm{oct})_{4}$ in the presence of air afforded the diketone which under either acidic or basic conditions provided the opposite diastereomers of the spirocyclopentanol (Scheme 34).

\section{Spiropyrrolidinyl oxindoles}

Applications. Spiropyrrolidine oxindoles are applied widely in medicinal chemistry. Indeed, many of the natural products featuring a 3,3'- or 3,2'-spiropyrrolidinyl motif display a wide variety of bioactivities. ${ }^{156}$ One of the most significant pharmaceuticals is MI-888 (Fig. 7), a 3,3'-spiropyrrolidine containing MDM2 inhibitor against tumour growth. ${ }^{157}$ The success of this ligand has inspired many other derivatives, ${ }^{158}$ including proteolysis targeting chimeras (PROTACs) ${ }^{159}$ and a molecular glue. ${ }^{160}$ Other applications of spiropyrrolidines include anti-

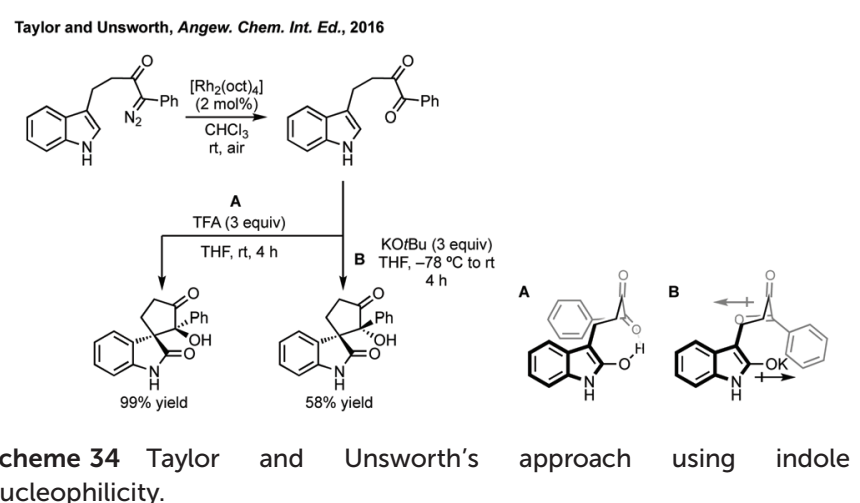



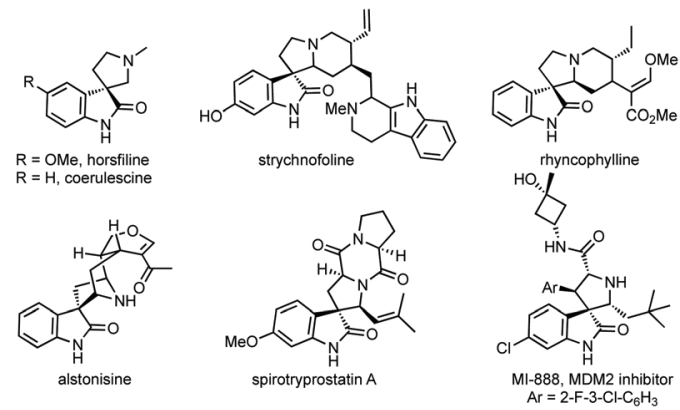

Fig. 7 Selected examples of bioactive 3,3'-spiropyrrolidinyl oxindoles.

cancer, ${ }^{161}$ treatment for Alzheimer's, ${ }^{162}$ diabetes, ${ }^{163}$ HIV $^{164}$ and tuberculosis. ${ }^{165}$

Natural product synthesis. Spiropyrrolidinyl oxindoles, particularly spiro-3,3'-pyrrolidinyl oxindoles, have been the target and inspiration for many total syntheses. ${ }^{166}$ Horsifilene and coerulescine (Fig. 7) are undoubtedly the simplest spiropyrrolidinyl oxindoles in nature and have been the focus of short, elegant total syntheses. ${ }^{167}$ For more complex products, a general approach is to synthesise the corresponding annulated indole (termed a $\beta$-carboline, typically synthesised via a PictetSpengler reaction) and perform an oxidative rearrangement with $t \mathrm{BuOCl}$. This reduces the problem down to the construction of the $\beta$-carboline (typically from tryptophan) and these products have received significant synthetic attention. ${ }^{168}$ This was the strategy used by Cook in his total syntheses of (iso) affinisine oxindole and (iso)alstonisine, ${ }^{169} \mathrm{Xu}$ in the nine-step total synthesis of (-)-strychnofoline, ${ }^{170}$ Zhang in the synthesis of multiple spirotryprostatins ${ }^{171}$ and more recently in She's total synthesis of (-)-gardmultimine A (for structures see Fig. 7 and Scheme 35). ${ }^{172}$ Rhynchophylline and isorhynchophylline have been synthesised formally by Amat and more recently totally by Ip and Tong (Scheme 40$).{ }^{173}$

\section{$[3+2]$-Cycloaddition}

Dipolar cycloaddition. For the synthesis of spiropyrrolidinyl oxindoles, particularly towards 3,3'-spiropyrrolidinyl oxindoles, there is a plethora of reports of the use of $[3+2]$-cycloaddition chemistry. To orientate the advances made in the recent decade it is important to include here Gong's seminal study from 2009. Gong reported the first one-pot catalytic enantioselective $[3+2]$-cycloaddition of 3 -ylidene oxindoles with in situ generated azomethine ylides (Scheme 36). ${ }^{174,175}$ Gong used asymmetric phosphoric acid cat. 38 to afford spiropyrrolidines in high yield, dr and ee.
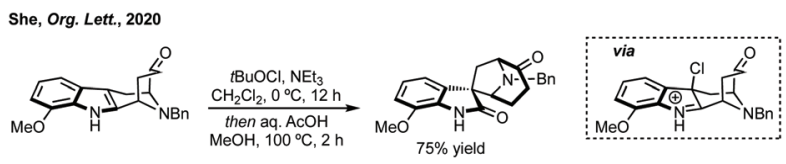

Scheme 35 Selected example from total synthesis of the application of an oxidative rearrangement of a $\beta$-carboline to a spirocyclopentane.
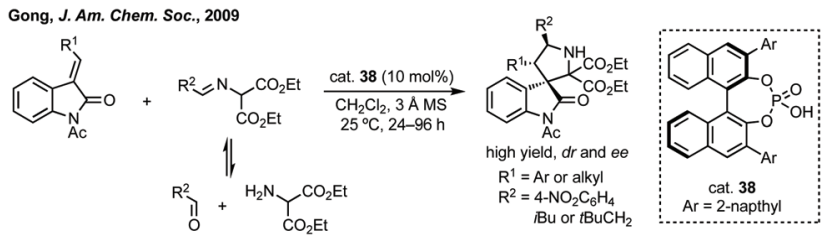

Scheme 36 Seminal report of catalytic enantioselective $[3+2]$-cycloaddition via azomethine ylides.

The utility of this approach by Gong has been demonstrated by the multitude of reports in this area since. These advances include the combination of an isatin derived dipole reacting with an external alkene dipolarophile, ${ }^{176}$ or other dipolaraphiles ${ }^{177}$ such as alkynes ${ }^{178}$ or allenes. ${ }^{179}$ Often these dipoles are derived from aminooxindoles ${ }^{180}$ or they could be malonitrile dipolarophiles, ${ }^{181}$ azomethine imines ${ }^{182}$ or pyridinium ylides. ${ }^{183}$ There are also many applications of this methodology for the synthesis of bispirooxindoles. ${ }^{184}$ Advances have also been made with related systems using copper catalysis. ${ }^{185}$ This azomethine ylide cycloaddition has been used by Hoffman-La Roche to synthesise MDM2 antagonist MI-888 (Fig. 7, ref. 157), including $>100 \mathrm{~g}$ scale synthesis of the final enantiopure product by chiral resolution. ${ }^{186}$

For the construction of 3,2'-spiropyrrolidinyl oxindoles, isatin derived ketimines can be used. ${ }^{187} \mathrm{~N}-2,2,2-$ Trifluoroethylisatin ketimines are very popular as a starting material because of the resultant inclusion of a $\mathrm{CF}_{3}$ group in the final product. In 2015, Yan, K. Wang and R. Wang demonstrated the first enantioselective $[3+2]$-cycloaddition of $\mathrm{N}$-2,2,2-trifluorethylisatin ketimines using prolinol cat. 17 (Scheme 37A). ${ }^{188}$ The same authors subsequently reported a similar cycloaddition catalysed by a cinchona alkaloid derived squaramide catalyst (Scheme 37B). ${ }^{189}$ These reports were followed by many diastereoselective ${ }^{190}$ and enantioselective ${ }^{191}$ cycloadditions using $N$-2,2,2-trifluoroethylisatin ketimines as 1,3-dipole starting materials.

Zhao and Shang developed an asymmetric phase transfer catalysed [3 + 2]-cycloaddition using a thiourea containing ammonium salt 40 with $\mathrm{K}_{2} \mathrm{CO}_{3}$ as base to form polysubstituted $3,3^{\prime}$-spiropyrrolidinyl oxindoles in up to $99 \%$ ee (Scheme 38). ${ }^{192}$

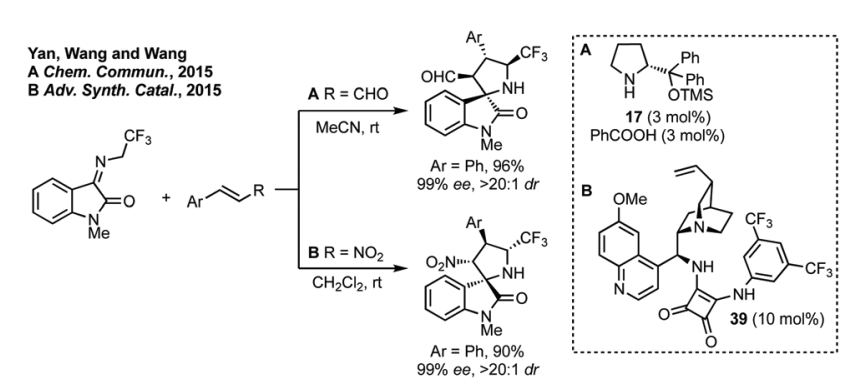

Scheme 37 Selected reports on the use of N-2,2,2-trifluoroethylisatin ketimines in [3+2]-cycloadditions. 


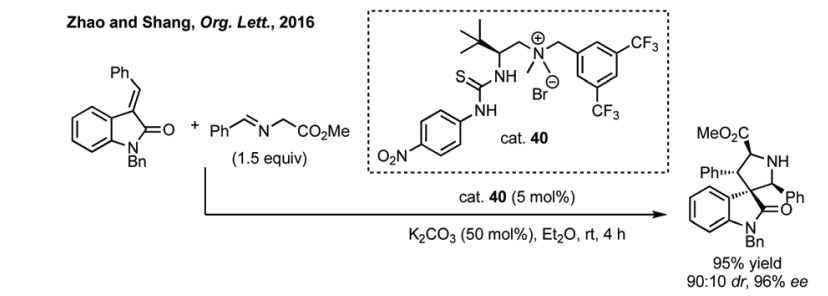

Scheme 38 Asymmetric phase-transfer catalysed $[3+2]-$ cycloaddition.

Finally, Kürti demonstrated the utility of $[3+2]$-cycloaddition chemistry. Kürti demonstrated the total synthesis of natural isatindigoindoline $\mathrm{C}$ in short sequence from isatin through a diastereoselective $[3+2]$-cycloaddition followed by base mediated epimerisation (Scheme 39). ${ }^{193}$ The natural stereochemistry of isatindigoindoline $\mathrm{C}$ was thus confirmed as anti by comparison of the ${ }^{1} \mathrm{H}$ NMR spectra.

Ring expansion. A particularly important development in the synthesis of 3,3'-spiropyrrolidinyl oxindoles was reported by Carreira in 1999. Spirocyclopropyl oxindoles could be reacted with imines in a $[3+2]$-cycloaddition affording spiropyrrolidinyl oxindoles in good dr (up to $98: 2$ ) (Scheme 40). ${ }^{194}$ Carreira and others have used this ring expansion/cyclo-

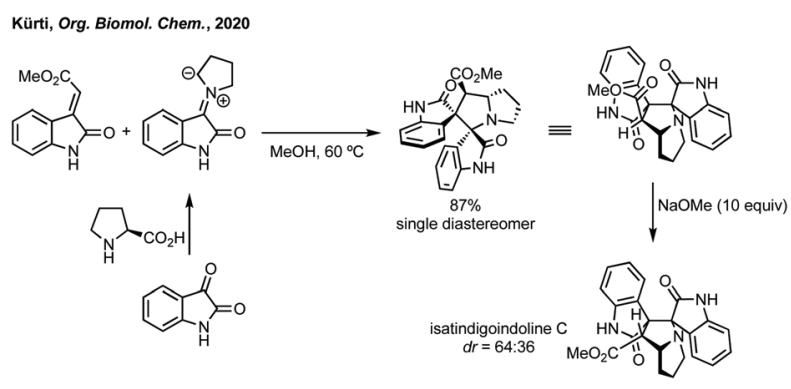

Scheme 39 Short synthesis of isatindigoindoline $C$ using a key [3+2]cycloaddition of an isatin-derived azomethine ylide and a 3 -ylidene oxindole.

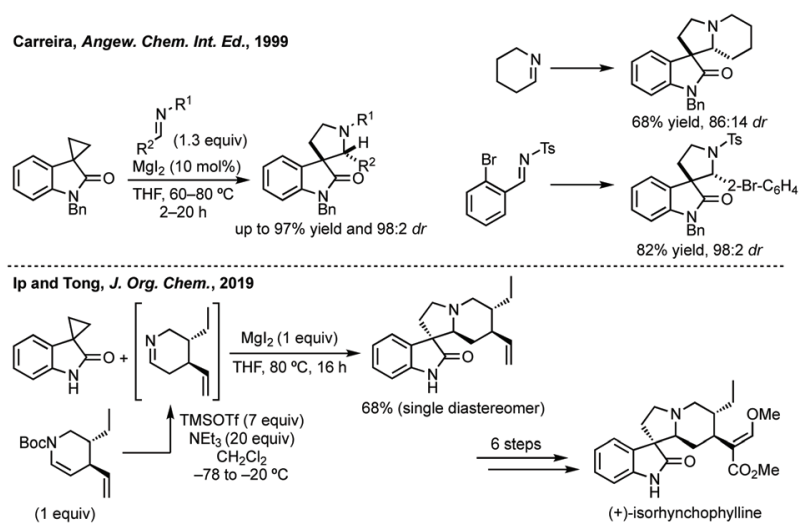

Scheme 40 Carreira's seminal ring expansion strategy and $\mathrm{Ip}$ and Tong's application of this methodology in total synthesis. addition strategy on multiple occasions to affect racemic and stereoselective syntheses of natural products, ${ }^{195}$ as well as being adapted. ${ }^{196}$ Recently, Ip and Tong employed Carreira's method as the key step in the first enantioselective total synthesis of Rhynchophylline and Isoryhnchophylline using a cyclic imine (Scheme 40). ${ }^{197}$

Budynina has performed a similar ring expansion in a sequential azide anion ring opening followed by a Staudinger/ Wittig/Mannich reaction. ${ }^{198}$ Whereas Hajra has ring expanded 3-spiroaziridinyl oxindoles using malonitrile (Scheme 41). ${ }^{199}$ This type of ring expansion chemistry has also been carried out in an inverse fashion, i.e. Lu reacted a 3-ylidene oxindole with a vinyl aziridine (Scheme 41). ${ }^{200}$ In a related aziridine ring expansion, Hajra used $\mathrm{Cu}(\mathrm{OTf})_{2}$ as catalyst to ring expand an aziridine reacting with a 3 -substituted isatin to form a $3,2^{\prime}$ spiropyrrolidine. ${ }^{201}$

Budynina ring expanded a cyclopropane with an isatin derived ketimine (Scheme 42). ${ }^{202} \mathrm{Chu}, \mathrm{He}$ and Liu have recently reported an enantioselective cycloaddition of vinyl cyclopropanes with isatin derived imines using ligand $\mathbf{4 2}$, to form 3,2'-spiro-derivatives (Scheme 42). ${ }^{203}$

MBH carbonates. As seen throughout this review, the use of isatin derived $\mathrm{MBH}$ carbonates is significant to form a 1,3dipole as a three carbon synthon. ${ }^{204}$ In 2017 , Chen demonstrated the use of isatin derived $\mathrm{MBH}$ carbonates in a [3+2]cycloaddition with isatin derived ketimines catalysed by bifunctional DMAP/prolinol catalyst 43 in high yield and enantioselectivity (Scheme 43). ${ }^{205}$ In 2018, Han and Cui

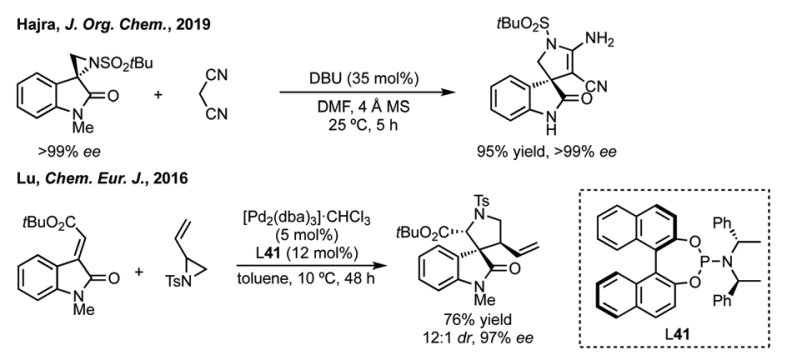

Scheme 41 3,3'-Spiropyrrolidine oxindoles synthesised by aziridine ring expansion.

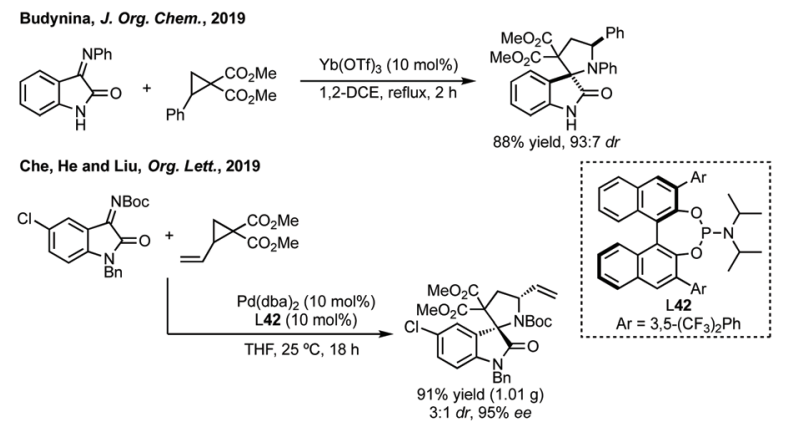

Scheme 42 Selected examples of 3,2'-spiropyrrolidine synthesis by cyclopropane ring expansion. 
Chen, Adv. Synth. Catal., 2017
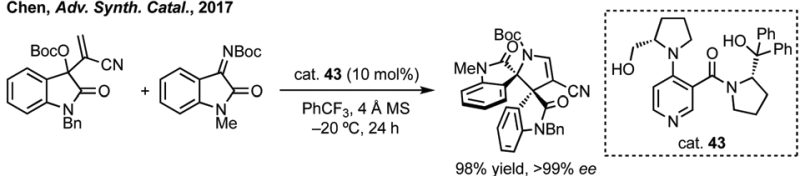

Han and Cui, Org. Biomol. Chem., 2018

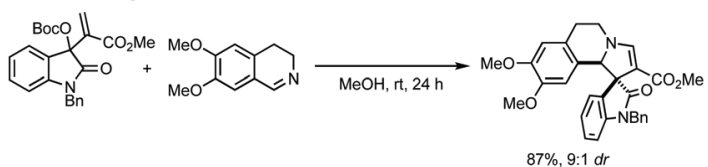

Scheme 43 Synthesis of 5-membered saturated nitrogen containing spirocycles from $\mathrm{MBH}$ carbonates.

reported the diastereoselective $[3+2]$-cycloaddition of isatin derived $\mathrm{MBH}$ carbonates and electron-rich aldimines (Scheme 43). ${ }^{206}$

NHC catalysis. In 2015, Lu and Du reported an NHC catalysed [3 + 2] annulation of 2-bromoenals with 3-aminooxindoles (Scheme 44A). ${ }^{207}$ Using NHC cat. $44 \mathrm{Lu}$ and Du achieved high enantioselectivity of the spiropyrrolidinone product. This report was followed by a similar reaction using NHC cat. 19 by Sun and Ye (Scheme 44B). ${ }^{208}$ Also, Hui and co-workers reported the $[3+2]$ annulation of 3-bromoenals and isatin $N$-Boc ketimines (Scheme 44). ${ }^{209}$ Using azolium cat. 45 with DABCO in toluene afforded the spirocycles in good yield, high enantioselectivity and good scope. More recently, Enders reported an NHC catalysed Mannich reaction between isatin derived ketimines and $\alpha, \beta$-unsaturated aldehydes. ${ }^{210}$ When the ketimine was protected with an ortho-phenol, which can bind the acyl-azolium intermediate allowing cyclisation, overall an enantioselective $[3+2]$ cycloaddition was achieved.

\section{Domino conjugate addition/cyclisation}

Conjugate addition/cyclisation is a common tactic employed to access spiropyrrolidinyl oxindole scaffolds stereoselectively, and highlights the continuum between concerted $[3+2]$-annulation chemistry and stepwise sequences. Stepwise but simultaneous addition/cyclisation sequences will be dealt with first followed by discrete additions and sequential asynchronous cyclisations. Domino Michael addition/cyclisation reactions have been separated according to the isatin reactants: (A) 3-iso-

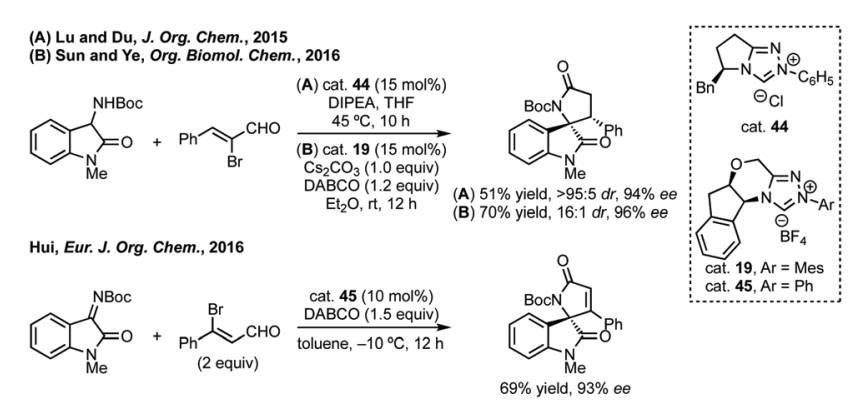

Scheme 44 Selected examples of NHC catalysed $[3+2]-$ cycloadditions. thiocyanato oxindoles or (B) oxindoles with a nucleophilic C3 substituent reacting with olefins and (C) 3-ylidene oxindoles.

(A) 3-Isothiocyanato oxindoles. The use of 3-isothiocyanato oxindoles to synthesise 3,2'-spiropyrrolidine structures in cascade Michael/cyclisation reactions has been extensively studied by the groups of Wang and Yuan, among others (Fig. 8). ${ }^{211}$ In 2013, Wang demonstrated the reaction of 3-isothiocyanato oxindoles with electron deficient olefins catalysed by cat. $44 .^{212}$ Wang also showed cat. 45 could promote the reaction between the same oxindoles and with unsaturated pyrazolones. ${ }^{213}$ At a similar time, Yuan showed that quinine derived thiocarbamate cat. 46 could promote the reaction of 3-isothiocyanato oxindole with alkylidine azlactones, and quinine could promote the same reaction with 3-methyl-4-nitro-5-alkenyl isoxazoles. $^{214}$ This spate of reports in 2013 was followed by the application of a similar strategy with other electron deficient olefins including notable further work by Yuan (Fig. 8). ${ }^{215}$ There has also been significant advances in using this chemistry for the synthesis of bispirooxindoles. ${ }^{216}$ Lindel has recently used this approach to construct the 3,2'-spiropyrrolidone core of cyanogramide. ${ }^{217}$

(B) Nucleophilic C3 substituent. The second significant strategy to access 3,2'-spiropyrrolidines is through domino Michael addition/cyclisation by a nucleophilic C3 substituent on the oxindole reacting with an olefin. In 2014, Yuan reported the reaction of acyl-protected 3-aminooxindoles with olefinic azlactones in good yield and diastereoselectivity using DBU as catalyst (Scheme 45). ${ }^{218}$ Yuan also showed a preliminary asymmetric variant of this reaction using cat. 56 to obtain the product in $61 \%$ ee. $\mathrm{Xu}$ and Yuan then further developed this chemistry with $\alpha, \beta$-unsaturated acyl phosphonates as coupling partners, achieving high yield and enantioselectivity with cat. 57 (Scheme 45). ${ }^{219,220}$ With $\alpha, \beta$-unsaturated aldehydes Wang used prolinol catalyst 17 to promote high enantioselectivity in the spirolactam product, albeit with moderate yields and diastereoselectivity (Scheme 45). ${ }^{221}$ Recently, Hua and Wang employed 3-aminooxindoles in a Michael/keto-imine/FriedelCrafts cascade to form bispirooxindoles in high $\mathrm{dr}$ and ee. ${ }^{222}$ Related to these methods is the use of an electrophilic substituent instead of nucleophilic substituent at C3 of the oxindole i.e. $\mathrm{Cl}$ or Br. An example of this was Liu and Chen's use of 3-bromooxindoles in an enantioselective $[4+1]$ annulation with azadienes using a cinchona alkaloid derived catalyst. ${ }^{223}$ As this strategy relies on the nucleophilic displacement by or with a component on the oxindole starting material it ultimately results in 3,2'-spiropyrrolidine products.

(C) 3-Ylidene oxindoles. A third significant method of accessing spiropyrrolidines in a cascade Michael addition/ cyclisation process is using 3-methylene oxindoles as starting materials. $^{224}$ In 2016, Zhang described an enantioselective Michael addition catalysed by a thiourea-cinchona alkaloid derived catalyst followed by one-pot Mannich/lactamisation to

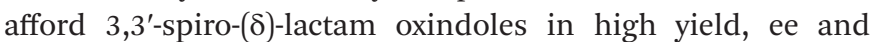
dr. $^{225}$ Wang developed an iodine promoted Michael addition of 3-methylene oxindoles with enamino esters and concomitant DABCO mediated cyclisation to form 3,2'-spiropyrrolinyl 


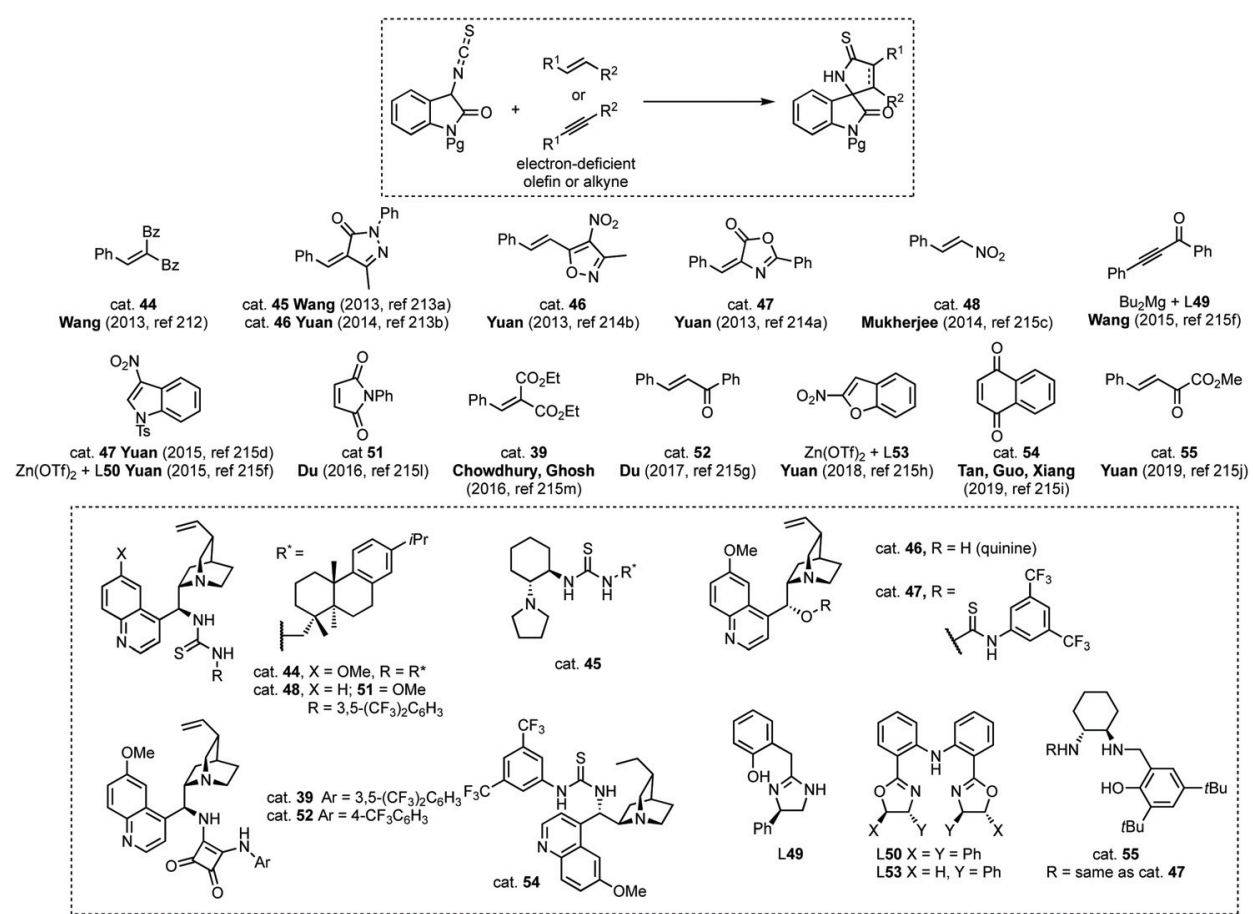

Fig. 8 Electrophiles and catalysts that have been developed for annulation of 3-isothiocyanato oxindoles.

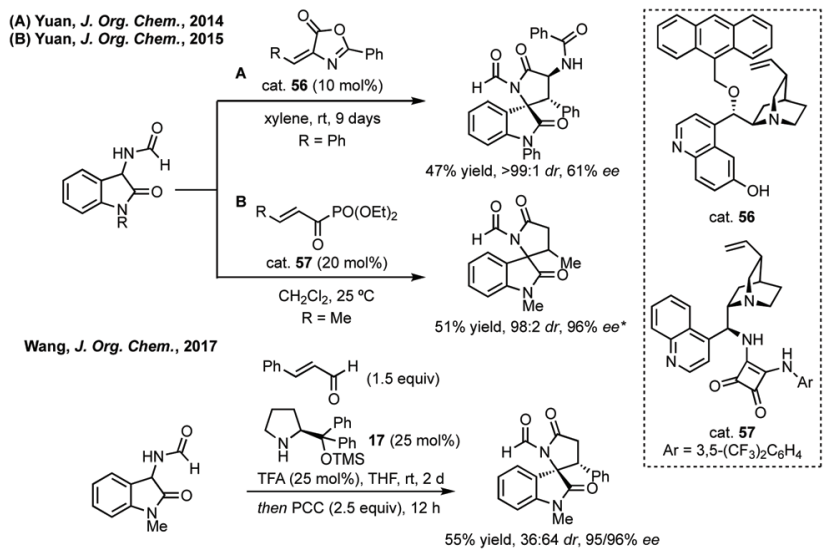

Scheme 45 Selected examples of conjugate Michael addition/cyclisation of oxindoles with a nucleophilic C3 substituent. * Unspecified stereochemistry/unknown absolute stereochemistry.

oxindoles with good diastereoselectivity under ball-milling conditions. $^{226}$ Combining strategies B and C, Xiang and Yang showed that the reaction of 3-aminooxindoles with 3-methylene oxindoles under basic conditions yielded a spirolactam which upon treatment with $\mathrm{TsOH}$ in one-pot cyclised to spirolactam 58 in high dr (Scheme 46). ${ }^{227}$ The C3 position of the aminooxindole was sufficiently nucleophilic under these conditions to undergo conjugate addition alpha to the ester, whereupon the free amine ring opens the oxindole. Du combined the use of acyl protected 3-aminooxindoles and 3-methylene oxindoles to form bispirooxindoles and Enders showed a Mannich/deprotection/aza-Michael cascade between

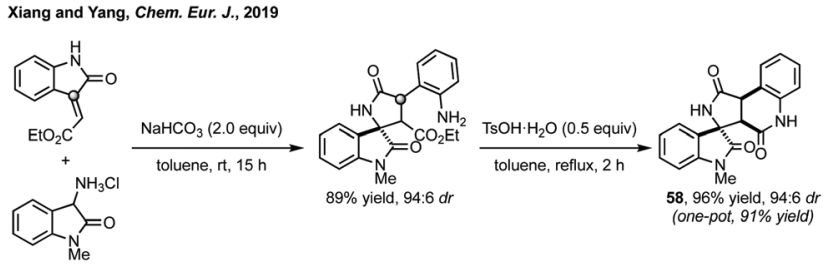

Scheme 46 Selected example of the combination of strategy B and C, using a nucleophilic C3 oxindole substituent and 3-ylidene oxindole.

isatin derived ketimines and 3-substituted oxindoles to bispirooxindoles. $^{228}$

A remarkable extension of strategies $\mathbf{A}$ and $\mathbf{C}$ with dipolar cycloaddition has been developed by Du where compounds containing a spiropyrrolidine oxindole and bispirooxindole were formed by a dual Michael/Mannich and Michael/cyclisation sequence (Scheme 47). ${ }^{229}$ Using dimeric squaramide cat. 59 the reaction between $N$-2,2,2-trifluoroethylisatin ketimine 60 and 3-methyleneoxindole $\mathbf{6 1}$ could be promoted, followed by the reaction between 3-isothiocyanato oxindole 62 and the pendant $\alpha, \beta$-unsaturated amide on 61 . The bispirooxindolespirooxindole compounds with seven stereocentres were afforded in high yield, dr and ee, including on gram scale.

Domino Michael/Michael additions. An excellent advance in 3,3'-spiropyrrolidine oxindole synthesis was made by Liu and at a similar time by Xie. Both teams independently developed a double Michael addition between oxindoles and alkynones with either a chiral guanidinium catalyst or a chiral $N, N^{\prime}$ dioxide $\mathrm{Sc}(\mathrm{OTf})_{3}$ complex (Scheme 48$){ }^{230}$ 
Du, Adv. Synth. Catal., 2019

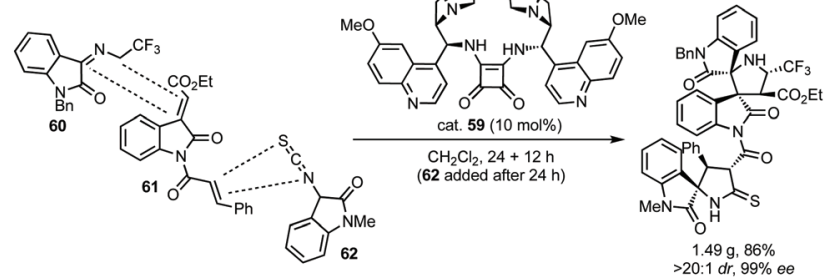

Scheme 47 Example of the use of strategies $A$ and $C$ for the stereoselective construction of seven stereocentres.

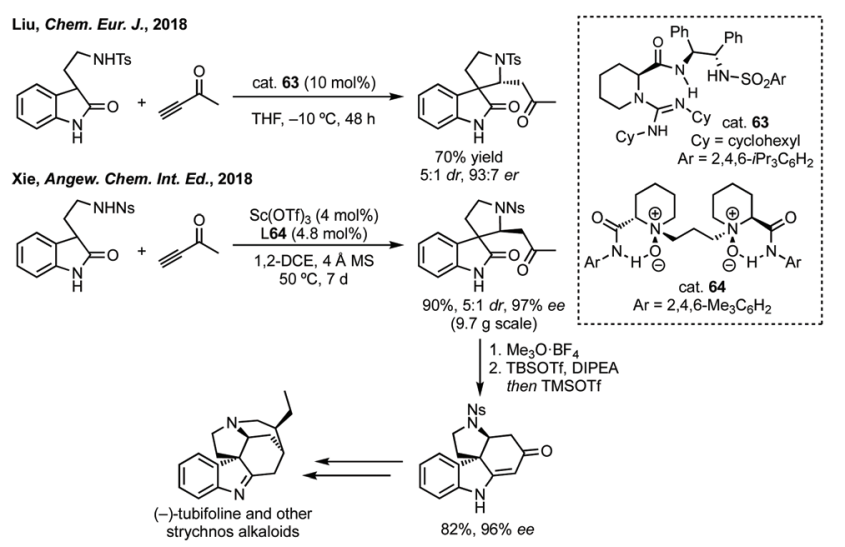

Scheme 48 Selected advances in Michael/Michael additions of alkynones.

Before this, Sasai had developed the same reaction using a chiral phosphine catalyst but with maximum $84 \%$ ee. ${ }^{231}$ More recently, $\mathrm{Wu}$ and Zhang used a chiral bisphosphine catalyst for the same reaction. ${ }^{232}$ A clear demonstration of the utility of these methods was given by Xie who showed the total synthesis of some strychnos alkaloids (Scheme 48). A related reaction has been developed by Miesch involving a copper catalysed hydroamination process. ${ }^{233}$ In a related strategy, Peng and Shao reported an asymmetric propargylation followed by iodocyclisation to construct polycyclic spirooxindoles in onepot or as a discrete asymmetric coupling step followed by cyclisation. $^{234}$

\section{Discrete coupling strategies}

In this section strategies where a discrete coupling followed by cyclisation will be discussed. A common strategy towards spiropyrrolidine oxindoles is an asymmetric Mannich reaction using ketimines followed by cyclisation. In 2012, Lu and then $\mathrm{Li}$ and Wang reported significant advances in enantioselective Michael addition and allylic alkylation of nitroalkanes using cinchona alkaloid derived catalysts. ${ }^{235}$ Reductive cyclisation of the nitro group in the product then afforded spirolactams in high ee. In 2015, Kobayashi developed a calcium/Pybox asymmetric Mannich reaction, which could be cyclised upon deprotection and basic cyclisation (Scheme 49). ${ }^{236,237}$ Using $\mathrm{CaI}_{2}$ with Pybox ligand 65 in $\mathrm{CH}_{2} \mathrm{Cl}_{2}$ at $-78{ }^{\circ} \mathrm{C}$ afforded the

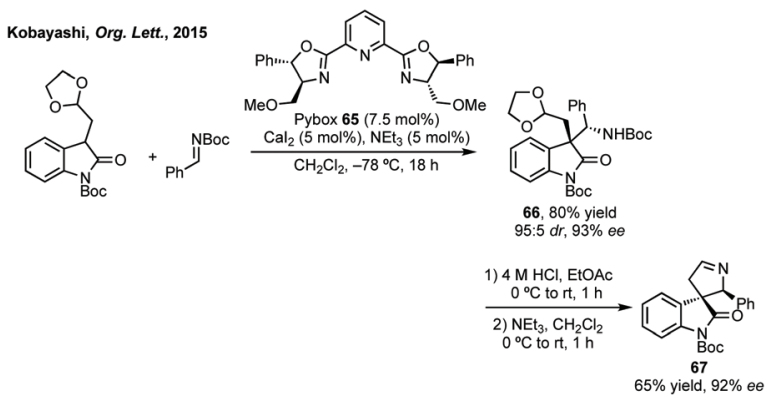

Scheme 49 Enantioselective Mannich reaction followed by deprotection/cyclisation.

Mannich product in high dr (trans product favoured) and excellent enantioselectivity. From acetal product 66, treatment with $\mathrm{HCl}$ followed by $\mathrm{NEt}_{3}$ afforded 3,3'-spiropyrrolinyl oxindole 67 in $65 \%$ yield and $92 \%$ ee.

In 2016, Ooi used triazolium phase transfer catalyst 68 to effect the $\mathrm{C}-\mathrm{H}$ amination of a hydroxylamine derivative in high ee for 5- and 6-membered saturated nitrogen heterocycles (Scheme 50). ${ }^{238}$ More recently, Du and Chen developed an asymmetric allylic alkylation from 3-phenyloxindoles using phase transfer catalyst 69 and $\mathrm{Pd}(\mathrm{OAc})_{2}$ with $\mathrm{Na}_{2} \mathrm{CO}_{3}$ as base (Scheme 50). ${ }^{239}$ This remarkable reaction afforded good yields of the 3,2'-spiropyrrolidine oxindole products in high ee. The products could be readily derivatised to numerous spirocycles including spirocyclohexanes, piperidines and pyrrolidines. Luo and Zhu developed a Heck/carbonylative cyclisation sequence to $3,3^{\prime}$-spiropyrrolidone oxindoles from non-isatin

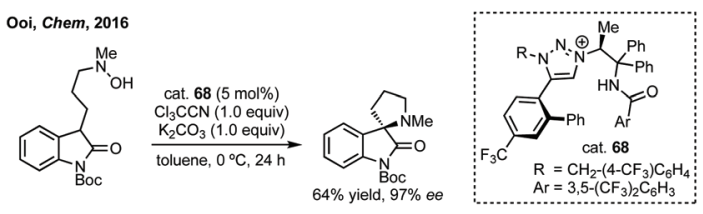

Du and Chen, Angew. Chem. Int. Ed., 2019
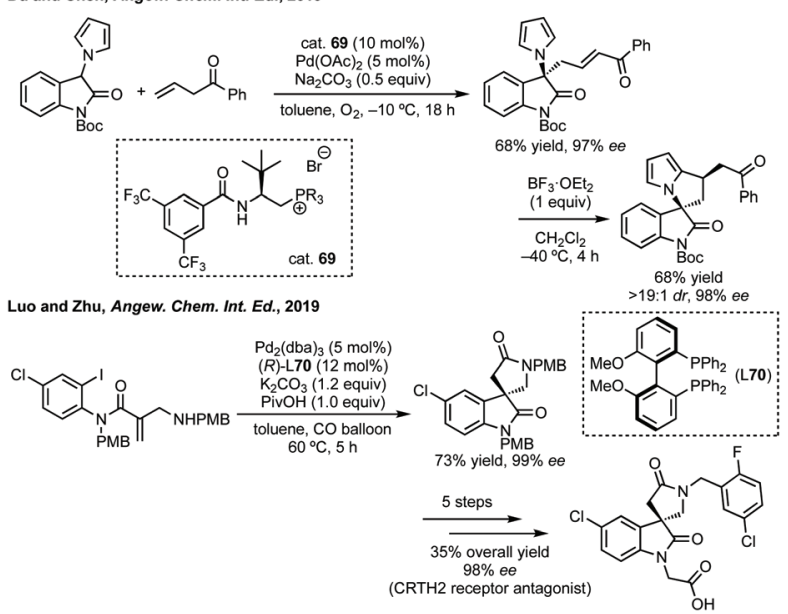

Scheme 50 Selected examples of phase transfer catalysed or metalcatalysed cross-coupling strategies to spiropyrrolidines. $\mathrm{PMB}=$ paramethoxybenzyl. 
derived starting materials (Scheme 50). ${ }^{240}$ They employed chiral bidentate phosphine ligand $\mathrm{L70}$ with $\mathrm{Pd}_{2}(\mathrm{dba})_{3}, \mathrm{~K}_{2} \mathrm{CO}_{3}$ and PivOH in toluene and a $\mathrm{CO}$ atmosphere to affect the Heck/ carbonylation cascade. Notably, the methodology was limited to aryl protected lactams but high yields and enantioselectivities were observed when using the readily removable PMB group. The authors showed the application of this methodology to the synthesis of a CRTH2 receptor antagonist ${ }^{241}$ in 6 steps in 35\% overall yield and 98\% ee (Scheme 50).

In a clearly distinct strategy Zhao and Xia developed a cross-dehydrogenative coupling of pyridines with 3-substituted oxindoles. ${ }^{242}$ The pyridinium salts afforded could be reduced diastereoselectively with $\mathrm{NaBH}_{4}$ in order to access racemic corynoxine in a rapid fashion (Scheme 51). Although the pyridine scope was limited to electron withdrawing groups at C3, the reaction notably worked on unprotected oxindoles.

Addition to isatin derived ketimines is a common route to spiropyrrolidines. Liu reported a one-pot Mannich/hydroamination approach using isatin ketimines. ${ }^{243}$ Zhou used a triple catalysis cascade reaction to generate an isatin derived ketimine in situ which could then undergo Brønsted base catalysed $6 \pi$-electrocyclisation. ${ }^{244}$ Hajra developed an enantioselective tanden aza-Henry reaction-cyclisation of isatinderived ketimines and nitroalkane mesylates to 3,2-spiropyrrolidine oxindoles (Scheme 52). ${ }^{245}$ These conditions were also applicable to piperidine derivatives with a chain extended nitro mesylate substrate. Xu reported a Rh-catalysed arylation of these ketimines, when using $o$-tolylboroxine, treatment of the product with NBS and Boc deprotection allowed cyclisation to product 72 (Scheme 52). More recently, Zhu and Zhang reported an enantioselective para-C-H functionalisation of $N$-monosubstituted anilines with isatin derived ketimines using cat. 73. ${ }^{246}$ The enantioenriched 3 -aminoooxindoles were readily cyclised to spiropyrrolidines in good yield and high ee (Scheme 52).

Other approaches. Van der Eycken has described a post-Ugi reaction Pd-catalysed Buchwald-Hartwig/Michael reaction sequence to very quickly couple four components into $3,2^{\prime}$-spiropyrrolidinyl oxindoles. ${ }^{247}$ Taylor and Unsworth at York used their previously disclosed direct imine acylation methodology $^{248}$ to furnish indoleninyl halide $\mathbf{7 4}$ which upon hydrolysis with aqueous $\mathrm{HCl}$ formed 3,3'-spiropyrrolidone oxindole 75 in high yield and dr (Scheme 53). ${ }^{249}$ Further recent

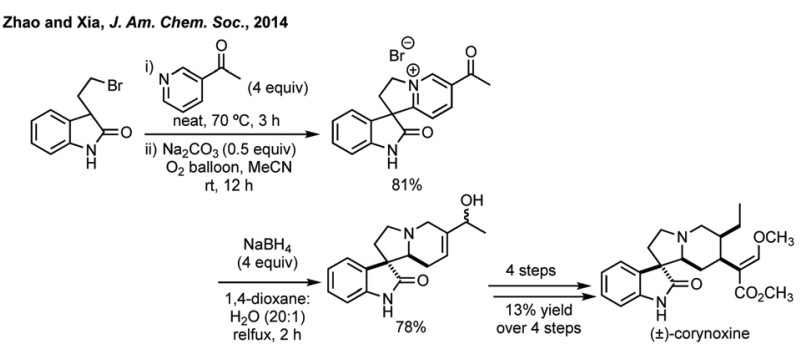

Scheme 51 Synthesis of spiropyrrolidine via pyridinium salts.

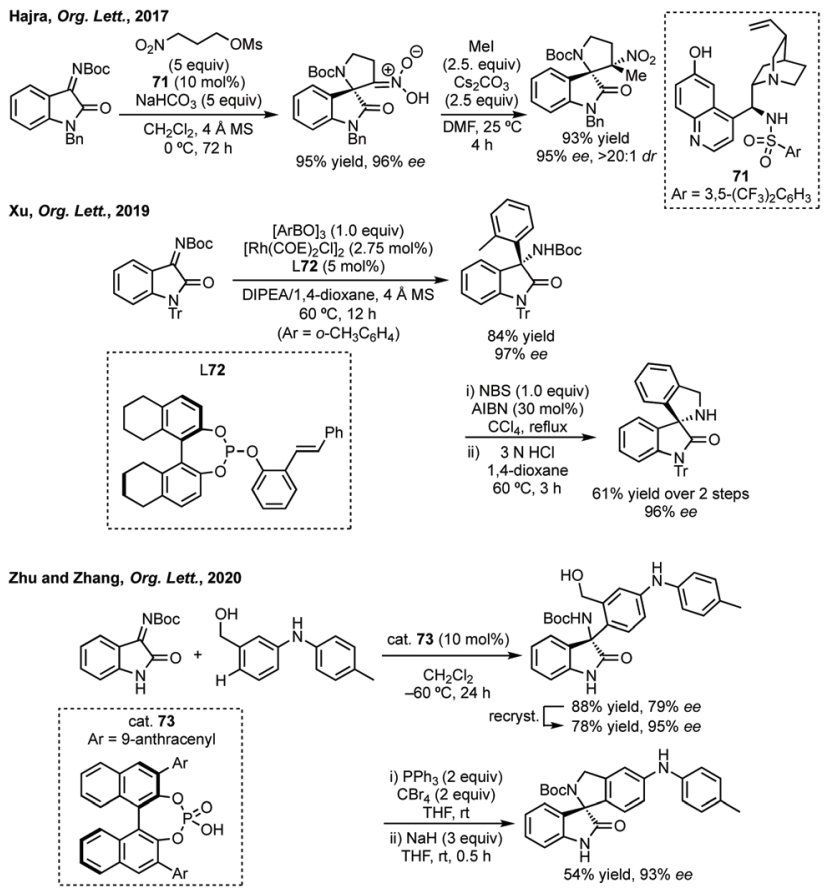

Scheme 52 Synthesis of 3,2'-spiropyrrolidine oxindoles following enantioselective additions to isatin derived ketimines.

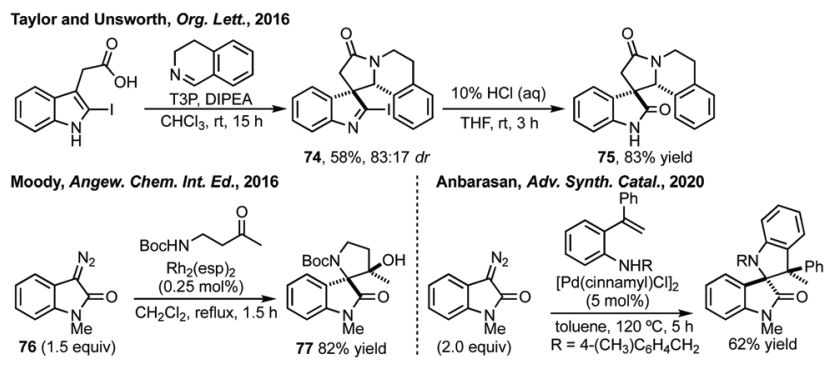

Scheme 53 Selected examples of diastereoselective synthesis of spiropyrrolidines using spirindoleninyl halides and diazooxindoles.

advances towards $3,2^{\prime}$-spiropyrrolidine oxindoles have been made using diazo compounds as starting materials. In 2016, Moody at Nottingham University developed a diastereoselective $\mathrm{NH}$ insertion of diazooxindole 76 with $\beta$-aminoketones to afford spiropyrrolidine 77 (Scheme 53). ${ }^{250}$ Very recently, Anbarasan reported Pd-catalysed amination of 3-diazooxindoles with ortho-vinyl anilines. ${ }^{251}$

Photoredox. Zhao and Jiang have reported a photoredox asymmetric phosphoric acid catalysed combination of $\alpha$-amino radicals and 3 -aryloxindole radicals (Scheme 54). ${ }^{252}$ The excited photoredox catalyst (dicyano-pyrazine (DPZ) derived) affects the decarboxylation of the aryl protected amino acid, generating an $\alpha$-amino radical, which can combine with the 3 -aryloxindole radical generated from 3-chlorooxindole with chirality induced by cat. 78 . The intermediate then spontaneously cyclised in the case of the five-membered ring. 

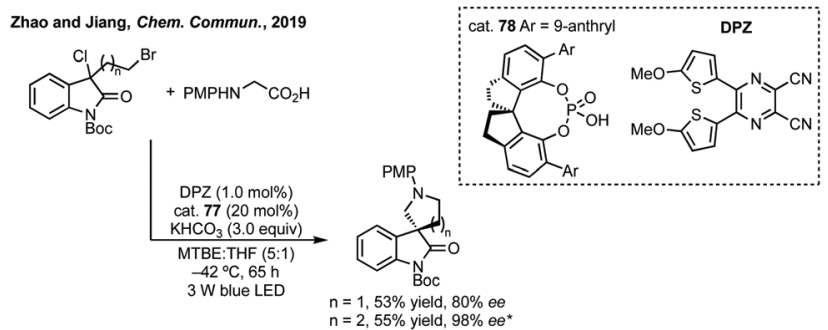

Scheme 54 Photoredox approach to enantioenriched 3,3'-spiropyrrolidinyl oxindoles. * After recrystallisation, initial ee $=87 \%$. PMP $=$ paramethoxyphenyl.

\section{Spirotetrahydrofuranyl oxindoles ${ }^{253}$}

Applications. There are numerous bioactive spiroTHF oxindoles (Fig. 9). Of note is XEN402 (Funapide), developed by xenon and licensed by Teva (TV-45070) for treatment of pain (synthesis discussed below). ${ }^{254}$ Other applications of spiroTHFs include anti-tumour ${ }^{255}$ as well as antibacterial activity. ${ }^{256}$ Spring reported an example in a diversity-oriented synthesis of a library of drug-like macrocycles. ${ }^{257}$

Natural product synthesis. Garg demonstrated the importance of spirotetrahydrofuran oxindoles in the stereocontrolled total synthesis of $N$-methylwelwitindolinone D isonitrile. ${ }^{258}$ Late-stage installation of the key spiroTHF ring proved troublesome and an attempt to cyclise $79(\mathrm{X}=\mathrm{Br})$ under aerobic conditions afforded a spirocyclobutyl oxindole in high yield (Scheme 55). However, Garg and co-workers were able to develop two oxidative functionalisations of the oxindole C3 to afford the spirobutyrolactone $\mathbf{8 0}$ which was 5 steps from the natural product. The total synthesis of $( \pm)$-aspergilline A in 16 steps was developed by Wood and co-workers. ${ }^{259}$ More recently Jia reported a ten-step total synthesis of the related natural product Speradine $\mathrm{C}$ with a key oxidative spirocyclisation to form the spiroTHF ring at a late stage. ${ }^{260}$ Treatment of $\mathbf{8 1}$ with NCS formed a chloronium ion which was spontaneously attacked by the methyl ester to form 82 in 35\% yield, which was one oxidative cyclisation step away from speradine $\mathrm{C}$ (Scheme 55). This use of the nucleophilicity of an indole is reminiscent of the strategy observed extensively for spiropyrrolidine synthesis (Scheme 35), indeed, Scheidt has synthesised (-)-coixspirolactam C (Fig. 9) from indole fused THPs (formed

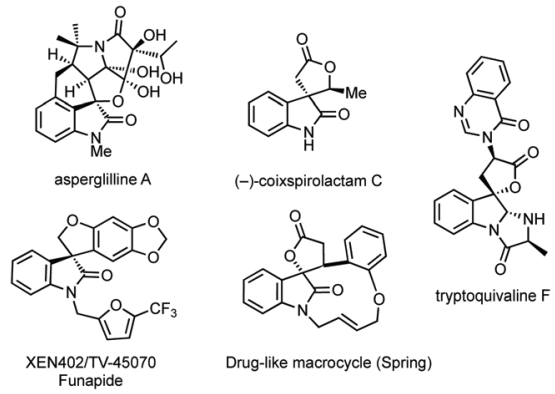

Fig. 9 Selected examples of bioactive spirotetrahydrofuran oxindoles.

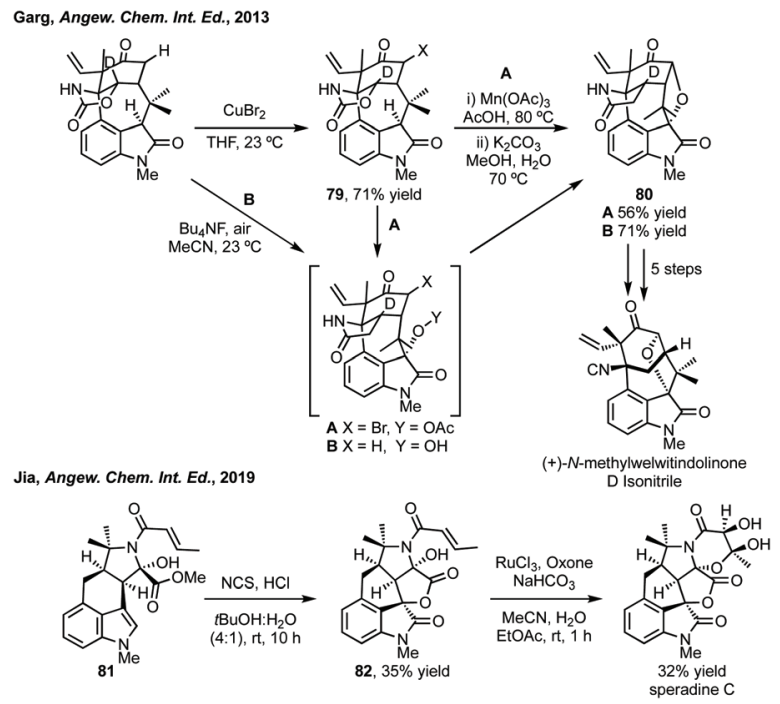

Scheme 55 Selected examples of spiroTHF synthesis in total syntheses.

in an Oxa-Pictet-Spengler) by bromonium ion formation and rearrangement. $^{261}$ Dixon synthesised the spiroTHF oxindole core of the tryptoquivalines using a stereoselective aldol cyclisation/acidic hydrolysis (for the THF ring) and a Cu-catalysed Buchwald type $\mathrm{C}-\mathrm{N}$ bond formation (for the oxindole). ${ }^{262}$

\section{Cycloaddition}

Iminium ion catalysis. In 2012, Melchiorre reported the reaction of 3-hydroxyoxindoles with enals under iminium ion catalysis for the synthesis of chiral butyrolactones and the preparation of maremycin A. ${ }^{263}$ In 2013, Melchiorre was able to further develop this chemistry with dienals to favour 1,6addition in favour of 1,4-addition by using prolinol catalyst 17 with dienal $\mathbf{8 3}$, where the $\beta$-substituent constrains the dienal in the S-cis conformation (Scheme 56). ${ }^{264}$

NHC catalysis. In seminal work, Ma reported an NHC catalysed [3 3 ] annulation of 3-bromoenals and isatins for the synthesis of spirotetrahydrofuranyl oxindoles (Scheme 57). ${ }^{265}$ Using NHC cat. 84 Ma achieved high enantioselectivity of the spirobutenolide oxindole products. This reaction occurred through NHC activation of the aldehyde to form a Breslow intermediate. This intermediate can then react through the carbon alpha to the bromo substituent to afford the oxindole alcohol which undergoes spirocyclisation. At a similar time, Glorius reported a similar annulation between isatins and enals, providing spirocycles with two contiguous quaternary stereocentres, which was highly diastereoselective and enantioselective when cat. 85 was

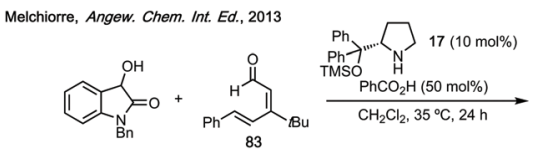

Scheme 56 Melchiorre. 


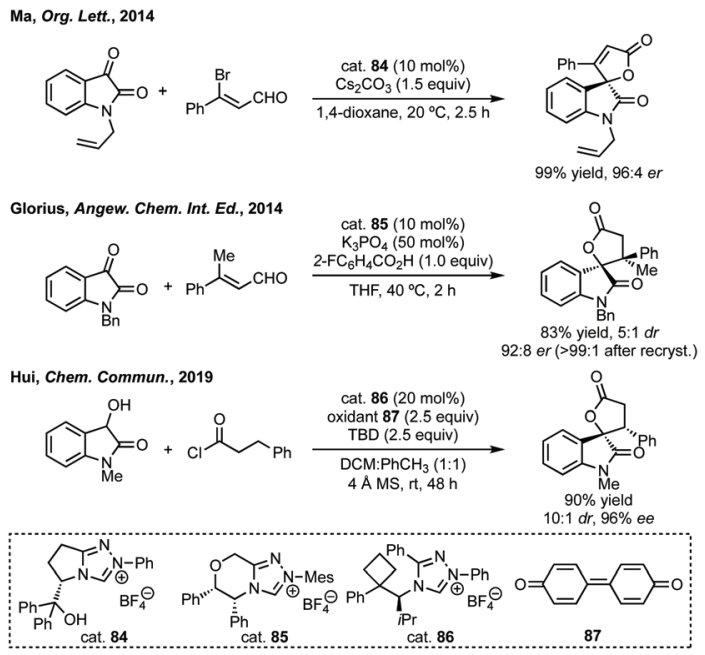

Scheme 57 Selected advances in NHC catalysed [3+2] annulations to spirolactones.

used, importantly in conjunction with ortho-fluorobenzoic acid (Scheme 57). ${ }^{266}$ In 2017, Du reported a diastereoselective [3+2] annulation of oxindole derived aliphatic acids and isatins or $\alpha, \alpha, \alpha$-trifluoroacetophenone with good diastereoselectivity using an NHC catalyst. ${ }^{267}$ Ye then developed a highly diastereoselective and moderately enantioselective $[3+2]$-annulation of 3-hydroxyoxindoles and enals, yielding similar products to the work of Glorius, reportedly by a radical pathway. ${ }^{268}$ Very recently, Hui showed the enantioselective oxidative annulation of acyl chlorides with 3-hydroxyoxindoles (Scheme 57). ${ }^{269}$ There have also been other significant advances in NHC catalysis expanding the starting materials used in conjunction with isatins. ${ }^{270}$

Cascade reactions. As seen for the synthesis of spiropyrrolidines, the use of cascade Michael/cyclisation procedures is also common for spiroTHF oxindoles. ${ }^{271}$ Related to Yuan's use of phosphonates as leaving groups for the Michael addition/ cyclisation (ref. 219), Du used $N$-acylated succinimides as leaving groups. ${ }^{272}$ There are a number of reports of coupling of 3-hydroxyoxindoles and malonitriles, ${ }^{273}$ of note is Pan's highly enantioselective Michael/Pinner cascade reaction using cat. 57 (Scheme 58). ${ }^{274}$ Deng reported an asymmetric Michael/ lactonization procedure between 3-hydroxyoxindoles and 3-methylene oxindoles which resulted in ring opening of the oxindole coupling partner (Scheme 58). ${ }^{275,276}$ Similar to ref. 227 (Scheme 46), Chen and Yang reported a Michael addition/ring opening/ring closing cascade, however, the resultant aniline formed cyclised with the ester of the 3-methylene oxindole in the final step. ${ }^{277}$ In a distinct reaction but using a similar catalyst, Mei and Shi reported an enantioselective $[4+1]$ annulation of 3-chlorooxindoles and ortho-quinone methides (Scheme 58). ${ }^{278}$ Again in a somewhat distinct cascade sequence, Quintavalla has developed an aldol/lactonization/elimination sequence catalysed by cat. 57 (Scheme 58). ${ }^{279}$ Other approaches include the use of quinone

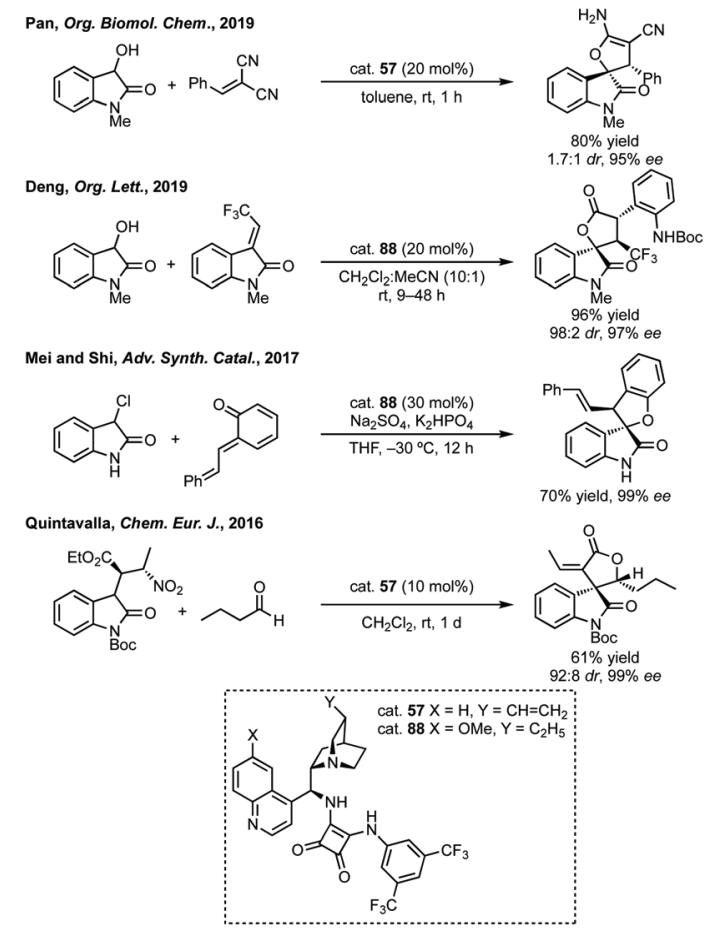

Scheme 58 Selected advances in annulations catalysed by bifunctional hydrogen bonding catalysts.

monoimines and multicomponent reactions of isonitriles, allenes and isatins. ${ }^{280}$

In 2016, Bisai reported an enantioselective aldol reaction of dimeric oxindoles which resulted in ring opening of one of the oxindoles, and in doing so developed a highly enantioselective thiourea catalysed aldol reaction with formaldehyde. ${ }^{281}$ The first process scale synthesis of TV-45070 (Fig. 9) employed a phase-transfer catalysed asymmetric alkylation using a Lygo phase transfer catalyst. ${ }^{282}$ Due to the requirement for multiple protecting groups in the first process scale synthesis of TV-45070, a new route was developed using a thiourea catalysed aldol reaction similar to the one developed by Bisai (Scheme 59). Only moderate enantioselectivity was observed using cat. 89 (up to $73 \%$ ee), but this could be improved by recrystallisation, followed by further two steps to afford the final API.

MBH carbonates. A common precursor to these types of spirocycles is an MBH carbonate. In 2013, Xu and Wang reported a [3+2] annulation of 3-hydroxyoxindoles with $\mathrm{MBH}$ carbonates catalysed by quinidine affording spirolactone oxindoles in high yields and dr and ee (Scheme 60). ${ }^{283}$ In a one-pot reaction Zhou performed a MBH reaction/bromination/[3 + 2]annulation sequence to access bispirooxindoles in exceptional ee. ${ }^{284}$ In 2014, Kesavan reported a one-pot alkylation/cyclisation of 3-OBoc-oxindoles with $\mathrm{MBH}$ carbonates with high enantiocontrol using cat. 27 (Scheme 60). ${ }^{285}$ Related to this, Shi reported an asymmetric phosphine catalysed $[4+1]$ annulation of MBH carbonates (Scheme 60). ${ }^{286,287}$ Chen used EBX reagents to promote an alkynylation of $\mathrm{MBH}$ carbonates which 


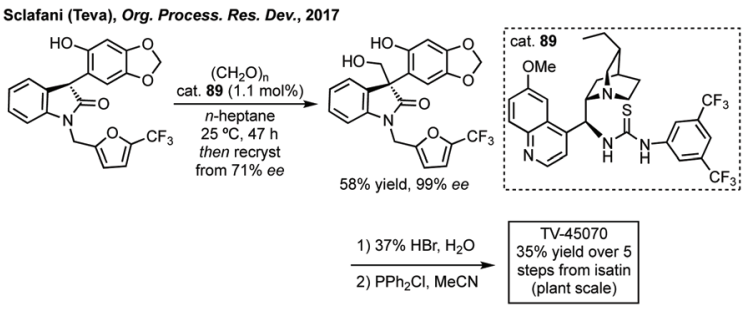

Scheme 59 Plant scale synthesis of TV-45070.

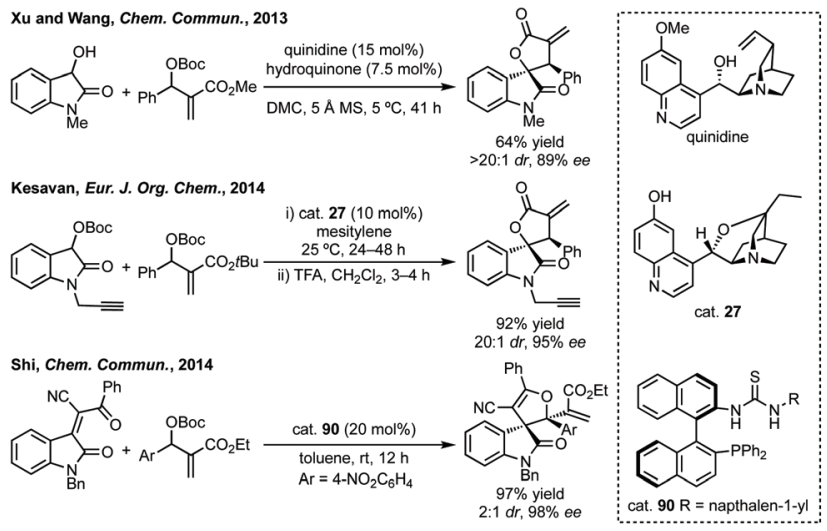

Scheme 60 Selected advances in the use of MBH carbonates to form spirolactone and spiroTHF oxindoles.

could be cyclised to 5- or 6-membered oxygenated spirocycles. ${ }^{288}$

Metal/Lewis acid catalysis. Yoda described an indium catalysed asymmetric allylation which depending on the substrate could spontaneously form spirocycle $\mathbf{9 2}$ or the alcohol product could be treated with acid to afford the cyclised product with retention of ee (Scheme 61). ${ }^{289,290}$ Feng has reported a Ni catalysed addition of vinyl hydrazones to isatins which upon acidic removal of the hydrazone and oxidative cleavage forms the antineoplastic agent 93 in high ee (Scheme 61). ${ }^{291}$ Trost first used Zinc catalysis to synthesise spiroTHF oxindoles in 2012. ${ }^{292}$ In 2019, Chang and Wang used a related Zn based system to promote a Michael/hemiketalisation/Friedel-Crafts cascade reaction to form bispiroTHF oxindoles. ${ }^{293}$ More recently, Hua and Wang reported a related reaction using $\alpha$-hydroxyacetophenone (Scheme 61). ${ }^{294}$

Yin has developed a Pd-catalysed cascade reaction involving dearomatisation of furans to form the THF core of the spirocycle. ${ }^{295}$ Other metal-mediated approaches include the use of $\mathrm{Cu}_{-},{ }^{296} \mathrm{Ti}^{-},{ }^{297} \mathrm{Ru}^{298}$ or Ni-catalysed ${ }^{299}$ spirocyclisations. Trost has also applied his development of Pd-allyl complexes previously discussed in the spiropyrrolidine section to the synthesis of spiroTHFs. ${ }^{300}$ Similar to Moody's use of diazo compounds to synthesise spiropyrrolidines, $\mathrm{OH}$ insertion/cyclisation could be used to synthesise spiroTHFs ${ }^{301}$ and there have been many other approaches using $\mathrm{Rh}$ - or $\mathrm{Cu}$-catalysed decomposition of diazo compounds. ${ }^{302}$

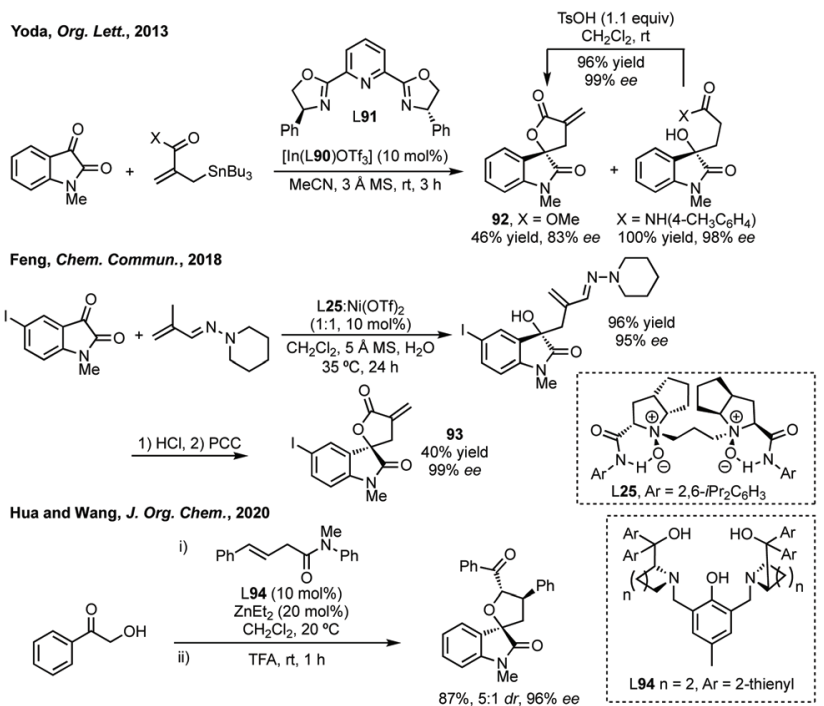

Scheme 61 Recent advances in metal-mediated spirocyclisation methods to spiroTHF oxindoles.

Ring expansion of small-rings. Using the ring strain of cyclopropanes or epoxides for $[3+2]$ cycloadditions is a common strategy for the synthesis of five-membered oxygen heterocycles. In an interesting strategy, Shi and co-workers used vinylcyclopropanes with $\mathrm{Pd}_{2}(\mathrm{dba})_{3}$ to form a Pd-allyl complex which reacted with isatin to form a spiroTHF oxindole with excellent $\mathrm{dr}$ and ee when using ligand 95 (Scheme 62). ${ }^{303} \mathrm{In}$ 2019, Su incorporated the vinyl cyclopropane into the oxindole unit and reacted this with an isatin using $\mathrm{Pd}(\mathrm{OAc})_{2} / \mathrm{XantPhos}$ to afford bispirooxindole THFs diastereoselectively. ${ }^{304}$

Hajra and Kumar have independently developed Lewis acidmediated ring expansion of spiroepoxides with allylsilanes to afford spiroTHF oxindoles with moderate to good $\mathrm{dr}$ (Scheme 63). ${ }^{305}$ In 2016, Hajra had used spiroepoxy oxindoles in a regioselective Friedel-Crafts alkylation, the alcohol product could then undergo an Appel reaction and spontaneous cyclisation through the phenol to afford $2 \mathrm{H}$-spirobenzofuran oxindoles. ${ }^{306}$

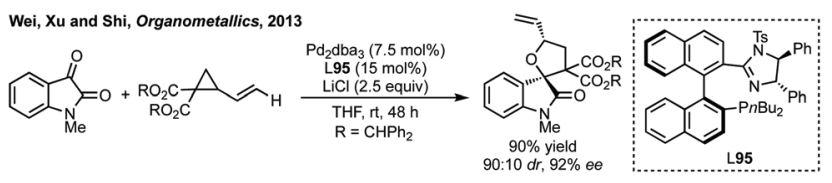

Scheme 62 Use of vinyl cyclopropanes to construct spiroTHFs.

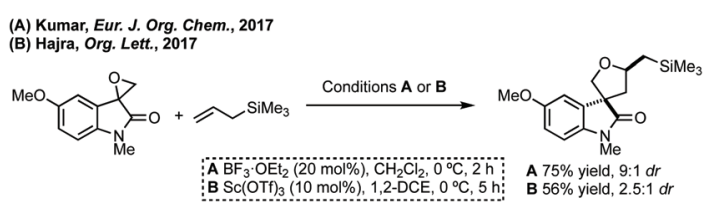

Scheme 63 Use of spiroepoxy oxindoles in a ring opening/closure cascade. 


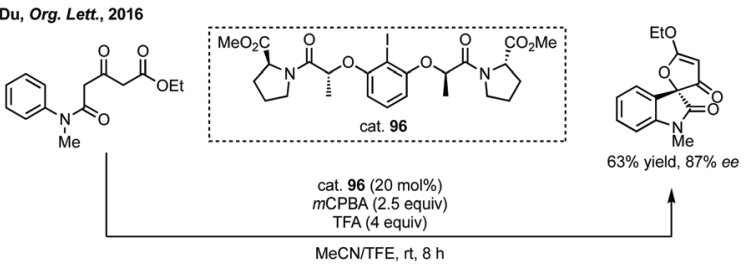

Scheme 64 Chiral hypervalent iodine mediated asymmetric spirocyclisation.

Use of hypervalent iodine reagents. A clearly distinct strategy to access this type of spirocycle is the use of hypervalent iodine reagents. ${ }^{307}$ Building on the work of Gong for the synthesis of bispirooxindoles, ${ }^{308} \mathrm{Du}$ developed an enantioselective spirocyclisation using catalytic chiral hypervalent iodine reagent 96 with $m$ CPBA as oxidant (Scheme 64). ${ }^{309}$

\section{Six-membered rings}

\section{Spirocylohexanyl oxindoles}

Applications. Satavaptan (Fig. 1) is a potent, selective Vasopressin $\mathrm{V}_{2}$ receptor antagonist for treatment of hyponatremia. ${ }^{310}$ Spirocyclohexane oxindoles also feature in a number of patents as anti-cancer, ${ }^{311}$ hepatitis $\mathrm{C}$ inhibitors ${ }^{312}$ and progesterone receptor modulators. $^{313}$

Natural product synthesis. Although not showing any notable bioactivity, gelsemine has proven to be an inspirational target within total synthesis (Fig. 10). ${ }^{314}$ Since 2013, there have been a couple of approaches to gelsemine, including an attempt by Vanderwal from a Zincke aldehyde and a Diels-Alder approach taken by Zhai and Qiu. ${ }^{315}$ Mehta described an approach to spindomycin B (Fig. 10) through a Michael addition $/ \mathrm{S}_{\mathrm{N}}$ Ar sequence. ${ }^{316}$

$[4+2]$-Cycloaddition. By far the most significant route to spirocyclohexane oxindoles is [4+2]-cycloaddition. In 2013, Marinetti reported a $\mathrm{PPh}_{3}$ catalysed diastereoselective $[4+2]$ cycloaddition of 3-methylene oxindoles and allenes. ${ }^{317}$ Chen has developed a similar but enantioselective reaction. ${ }^{318}$ Also in 2013, Ramachary reported the enantioselective [4 2] cycloaddition of alkynones and malonitrile oxindoles using cat. 97 (Scheme 65). ${ }^{319}$ Notably, under these conditions an aminoenyne was formed between the primary amine of the epiquinine derived cat. $\mathbf{9 7}$ due to protonation of the more Lewis basic quinicludine nitrogen. There have been numerous related reports using malonitrile precursors ${ }^{320}$ and these reactions are also used to test new asymmetric ligands. ${ }^{321}$ There
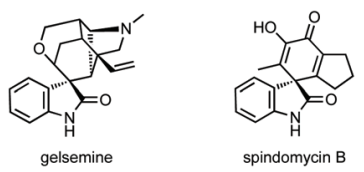

Fig. 10 Selected naturally occurring spirocyclohexane oxindole.

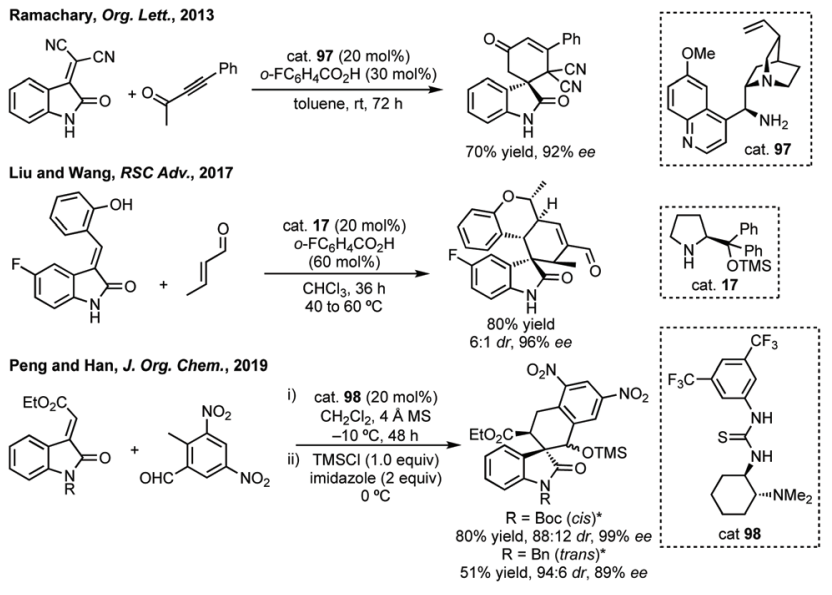

Scheme 65 Selected [4 + 2] annulations. * Indicates stereochemical relationship between OTMS and ester group on cyclohexane ring.

have been a number of reports of combining chromane scaffolds with spirocyclohexane oxindoles. ${ }^{322}$ Of note is Liu and Wang's use of 3-methylene oxindoles with a phenol substituent undergoing an Michael/aldol/oxa-Michael cascade under iminium catalysis (Scheme 65). ${ }^{323}$ There have been many other developments of this type of annulation involving Michael/ aldol $^{324}$ or more elaborate ${ }^{325}$ cascade reactions employing various catalysis modes. An interesting Michael/aldol example was recently reported by Peng and Han with diastereodivergency observed depending on the oxindole $N$-protecting group (Scheme 65). ${ }^{326}$

In 2011, Melchiorre and Barbas III reported asymmetric Diels-Alder reactions between 3-vinyl indoles and electron poor olefins using iminium ion catalysis and hydrogen bonding catalysis. ${ }^{327}$ These works laid the foundations for a body of work which provide tetrahydrocarbazoles fused with spirooxindoles. $^{328}$ Notably, in 2014, Feng reported the asymmetric Diels-Alder reaction between 3-vinyl indoles and 3-methylene oxindoles using Ni catalysis (Scheme 66). ${ }^{329}$ Also, in 2015 Shi developed a similar reaction using 2-vinyl indoles using chiral phosphoric acid catalysis (Scheme 66). ${ }^{330}$ Oxygenated analogues of these tetrahydrocarbazoles, which
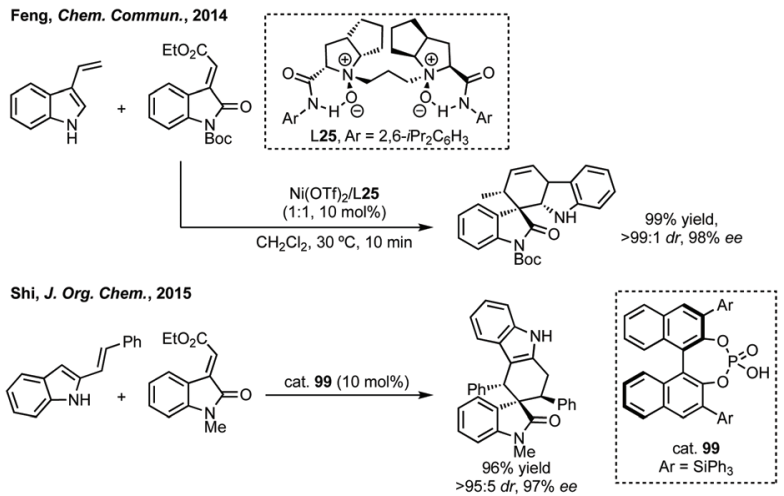

Scheme 66 Selected enantioselective [4 +2] cycloadditions. 

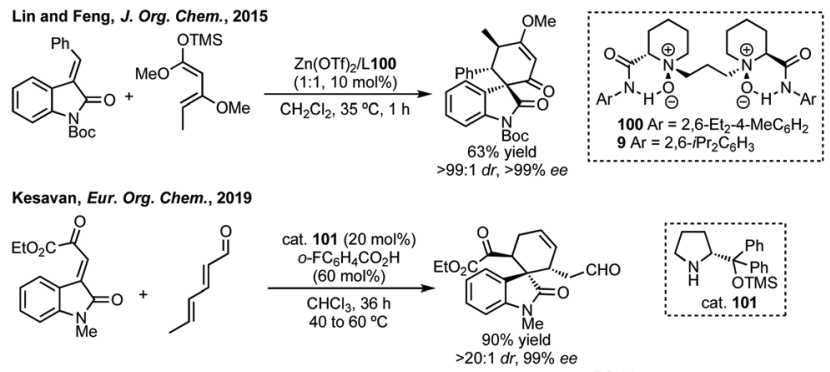

Feng, Angew. Chem. Int. Ed., 2019
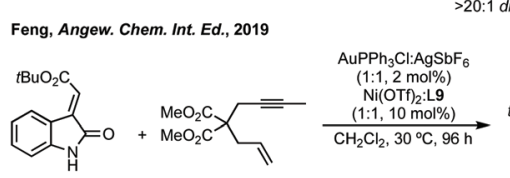

$20: 1 \mathrm{dr}, 99 \%$ e

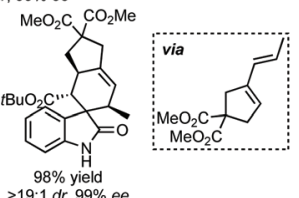

Scheme 67 Selected enantioselective Diels-Alder reactions to make spirooxindoles.

could be produced by an Oxa-Pictet-Spengler reaction can undergo a Claisen rearrangement to spirocyclohexanes (which as we have seen can also form spiroTHF products). ${ }^{331}$

Antilla described the use of chiral Mg-phosphate catalysis for an asymmetric Diels-Alder reaction. ${ }^{332}$ For a related DielsAlder reaction, Lin and Feng used $\mathrm{Zn}(\mathrm{OTf})_{2}$ complexed with L100 in up to 99\% ee (Scheme 67). ${ }^{333,334}$ In 2019, Kesavan described an asymmetric Diels-Alder reaction between 2,4dienals and 3-methylene oxindoles catalysed by prolinol cat. 101 (Scheme 67). ${ }^{335}$ Feng has recently reported Au-catalysed cycloisomerisation followed by Ni-catalysed Diels-Alder cycloaddition to enantioenriched spirocyclohexanes (Scheme 67). ${ }^{336}$ Feng and Dong have also disclosed a Dy(OTf $)_{3}$-mediated ringopening $/[4+2]$-cycloaddition of cyclobutenones and 3-methylene oxindoles. ${ }^{337}$

In terms of other cascade rearrangements, Kim has developed a diastereoselective $6 \pi$-electrocyclisation from $\mathrm{MBH}$ precursors. ${ }^{338}$ Kim further developed this to a one-pot $\mathrm{PPh}_{3}$ mediated coupling of $\mathrm{MBH}$ carbonates and enals where favourable disrotatory ring closure from the $E, Z, E$-isomer proceeds to the major diastereomer (Scheme 68). ${ }^{339}$ In a distinct complexity-generating reaction, Tanaka could form racemic intermediate 102 in a $[4+1]$ annulation of 3-methylene oxindole and di-

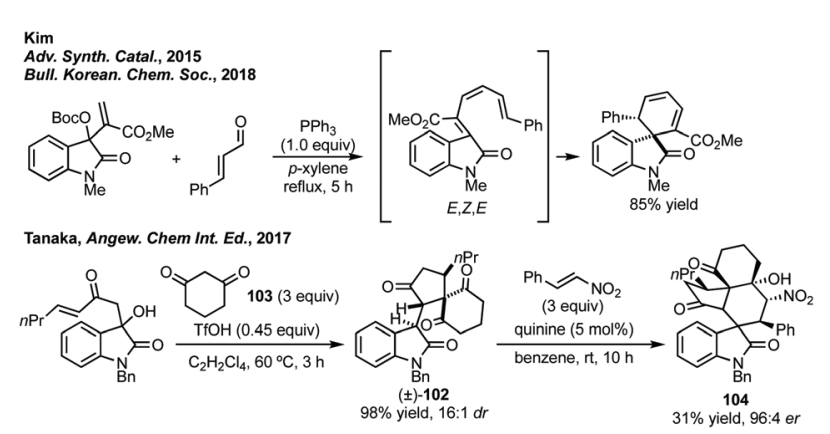

Scheme 68 Selected cycloadditions developed towards spirocyclohexane oxindoles. ketone 103 by treatment with TfOH (Scheme 68). ${ }^{340}$ In a Michael-Henry cascade reaction 102 could react with an electron-poor olefin (such as a nitroalkene) and form polycyclic spirocyclohexane oxindole containing product 104 with excellent enantioselectivity. The yields for these products were low due to only one enantiomer of $\mathbf{1 0 2}$ reacting, therefore, the reaction could also serve to furnish highly enantioenriched 102 in a kinetic resolution.

Metal-mediated $\mathbf{C}-\mathbf{H}$ activation approaches. In 2015, Kim reported a Pd-catalysed Heck/C-H activation approach to spirocyclohexene oxindoles with moderate diastereoselectivity. ${ }^{341}$ More recently Lautens has developed a significant body of work using intercepted Pd-mediated spirocyclisations and in 2016 reported benzyne insertion to an alkylPd ${ }^{\mathrm{II}}$ intermediate formed by $\mathrm{C}-\mathrm{H}$ activation (Scheme 69). ${ }^{342}$ This was followed by insertion of alkynes with high regioselectivity. ${ }^{343}$ These works were followed by Liang and Yang's report on the synthesis of 109 in a triple $\mathrm{C}-\mathrm{H}$ activation approach where the alkylPd ${ }^{\mathrm{II}}$ intermediate is intercepted by 2 further equivalents of aryl iodide (Scheme 69). ${ }^{344}$ Another approach is Pd-catalysed migratory insertion of diazo compounds and Michael addition. $^{345}$

Chiral hypervalent iodine mediated. In the sole example of the application of asymmetric hypervalent iodine mediated dearomative spirocyclisation, Gong synthesised spirooxcyclohexene oxindoles in moderate yields but high enantioselectivity (Scheme 70). ${ }^{346}$ Generally, electron-rich oxindoles were used i.e. phenylfused oxindoles, however, the enantioselectivity was highest for the synthesis of oxindole 110 using cat. 111.

\section{Spiropiperidinyl oxindoles}

Applications. In the last decade spiropiperidinyl oxindoles have been synthesised for medicinal chemistry applications against cancer, ${ }^{347}$ CNS disorders, ${ }^{348}$ renal failure, ${ }^{349}$ treatment of Dengue virus infection ${ }^{350}$ as well as other applications. ${ }^{351}$ Surugatoxin related to neosurugatoxin is also a potent human toxin (Fig. 1). ${ }^{352}$ Most prominently cipargamin (NITD609 or

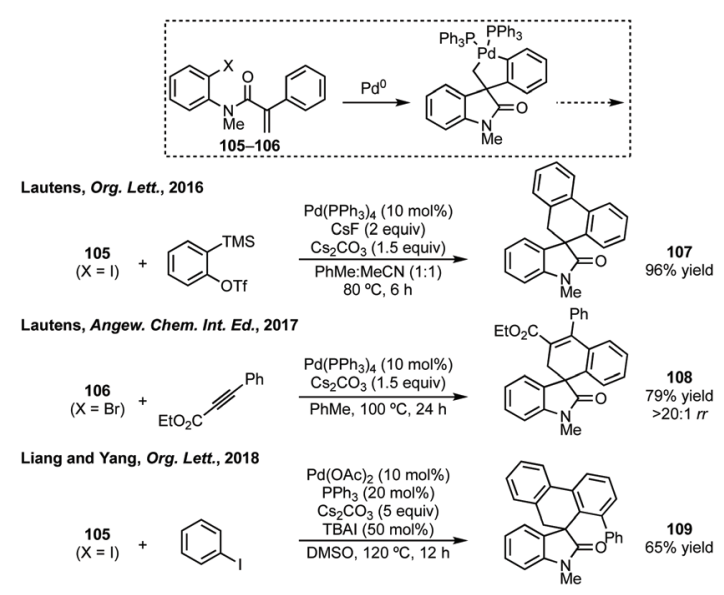

Scheme 69 Selected metal-mediated $\mathrm{C}-\mathrm{H}$ activation approaches via alkyl-Pd" intermediates. 


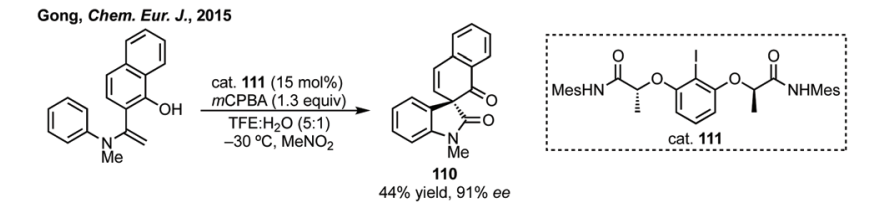

Scheme 70 Chiral iodine mediated spirocyclohexene oxindole formation.

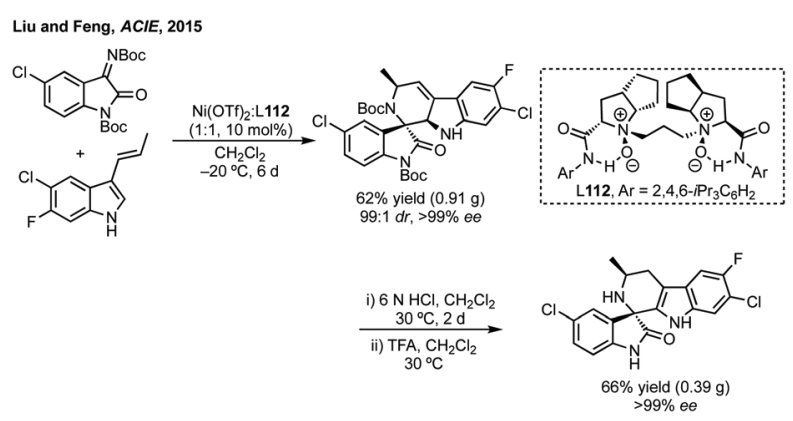

Scheme 71 Concise synthesis of anti-malarial cipargamin.

KAE609) has been developed as an anti-malarial agent. ${ }^{353}$ Shibasaki used a key asymmetric alkynylation of an isatin ketimine to synthesise cipargamin. ${ }^{354}$ Liu and Feng synthesised cipargamin in an aza-Diels-Alder process employing 3-vinyl indoles and Ni catalysis (Scheme 71). ${ }^{355}$

Similar to other ring sizes we have considered, there have been a number of efforts made towards the synthesis of rings with more than one heteroatom, here we only consider the synthesis of piperidines or $\delta$-lactam scaffolds. ${ }^{356}$ Wei and Shi developed a $[4+2]$-cycloaddition of vinyl ketones and $\alpha, \beta$-unsaturated imines derived from isatins catalysed by a bifunctional asymmetric phosphorus-thiourea catalyst (Scheme 72, $\mathrm{R}=$ 2,4,6-triisopropyl phenyl). ${ }^{357}$ In metalmediated approaches, gold catalysed spirocyclisation of in situ generated indoles and isatins was reported by Subba Reddy. ${ }^{358}$ Related to Liu and Feng's reaction (ref. 355), Kumar developed an enantioselective aza-Diels Alder reaction catalysed by Dy $(\mathrm{OTf})_{3}$ and a ligand similar to 112 where $\mathrm{Ar}=2,6-\mathrm{iPr}_{2} \mathrm{C}_{6} \mathrm{H}_{4}{ }^{359}$ Feng, Li and Xiao have independently developed 1,5-hydride transfer reactions to spiropiperidines. ${ }^{360}$ More recently, Shi

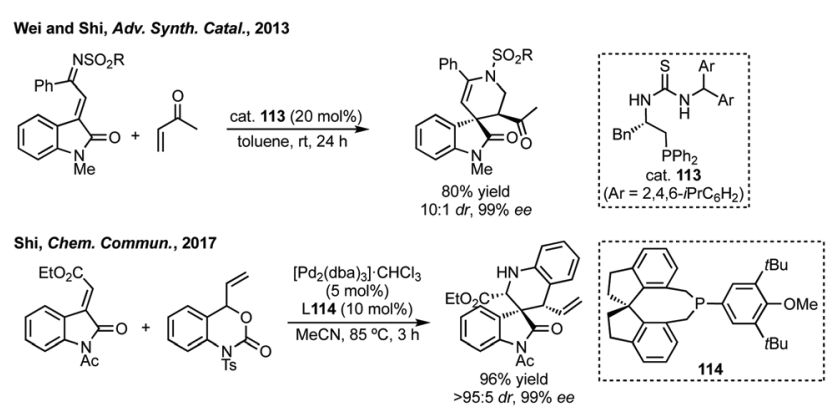

Scheme 72 Selected enantioselective [4 +2]-cycloadditions. developed a Pd-catalysed decarboxylative [4 +2$]$ cycloaddition strategy using vinyl benzoxazinanones and 3-methylene oxindoles (Scheme 72). ${ }^{361}$

NHC catalysis. In 2013, Chi reported the NHC catalysed $[3+3]$ annulation of $\alpha$-aryl esters and isatin derived $\alpha, \beta$-unsaturated ketimines to afford spirocyclic- $\delta$-lactams in moderate diastereoselectivity in up to $62 \%$ ee with an asymmetric NHC. ${ }^{362}$ Yang, Zeng and Zhong used asymmetric cat. 115 to make 3,4'-spiropiperidine oxindoles from isatin derived $\alpha, \beta$-unsaturated aldehydes and imines (Scheme 73). ${ }^{363}$ This reaction proceeds through imine conversion to the corresponding enamine to avoid unwanted $[3+2]$ cycloaddition with the enal. Ye reported a $[4+2]$ cycloaddition of $\alpha, \beta$-unsaturated carboxylic acids (via the dienolate) and isatin ketimines to form 3,2'-spiro- $\delta$-lactam oxindoles using NHC cat. 116 (Scheme 73). ${ }^{364} \mathrm{Xu}$ generated ortho-quinodimethanes to undergo $[4+2]$ annulation with isatin ketimines using cat. 19 producing $\beta$-carboline spirooxindoles (Scheme 73). ${ }^{365}$ More recently, $\mathrm{Xu}$ and Ren reported $\mathrm{a}[4+2]$ annulation of aliphatic aldehydes and oxindole derived $\alpha, \beta$-unsaturated ketimines catalysed by an NHC catalyst. ${ }^{366}$ Enders also recently reported related $[3+3]$ annulations of isatin derived enals and cyclic $N$-sulfonyl ketimines. ${ }^{367}$

Cascade reactions. Shi and Tu reported an enantioselective Povarov reaction using asymmetric phosphoric acid cat. 117 affording 3,2'-spiropiperidine scaffolds in up to $97 \%$ ee. ${ }^{368,369}$ Initial formation of a ketimine between the aniline and isatin is followed by an acid catalysed vinylogous Mannich reaction and Friedel-Crafts alkylation closes the ring (Scheme 74). This report was followed by a related reaction by Zhou and Shi using 3-vinyl indoles in place of the ortho-vinyl phenol. ${ }^{370} \mathrm{Zhu}$ employed ortho-vinyl phenols and 3-methylene oxindoles to react in a Michael addition/Friedel-Crafts cascade catalysed by (DHQD) $)_{2}$ PHAL to form 3,3'-spiropiperidine oxindoles (Scheme 74). ${ }^{371}$ In a related Michael addition/Friedel-Crafts sequence, Yuan utilised electron rich pyrroles to react with an iminium formed from an $\alpha, \beta$-unsaturated aldehyde to form pyrrole-fused 3,2'-spiropiperidine oxindoles. ${ }^{372}$ Related reactions include aza-Michael/Michael addition, Michael/Mannich reaction, Michael addition/Pictet-Spengler, Michael/aldol,

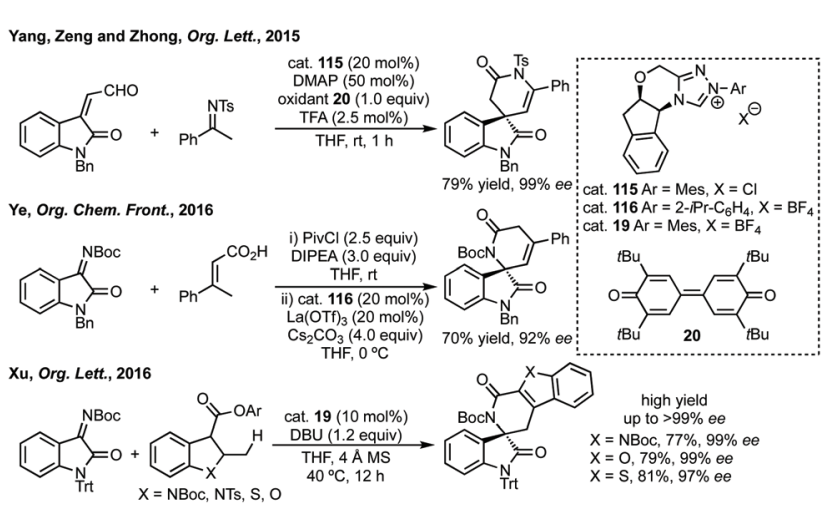

Scheme 73 NHC catalysed cycloadditions to spiro- $\delta$-lactams. 


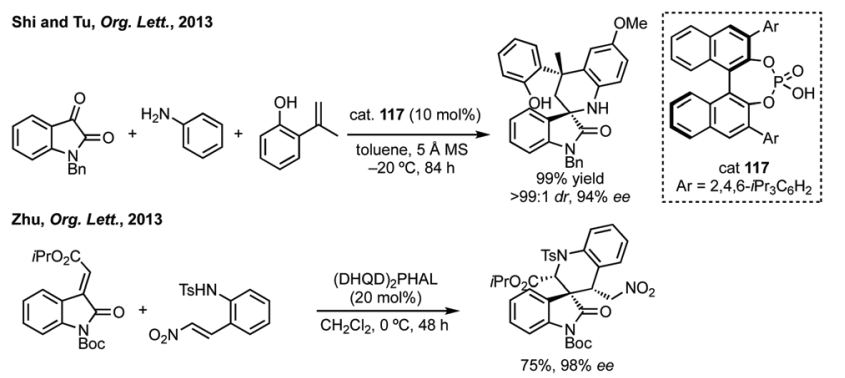

Scheme 74 Selected examples of phosphoric acid catalysed cascade reactions.

Mannich/hemi-aminalisation cascade reactions. ${ }^{373} \mathrm{He}$ and Han developed a $[2+2+2]$ annulation via a Michael/azaHenry cascade reaction and evaluated the products ability to inhibit proliferation of cancer cell lines. ${ }^{374}$ Due to the importance of cipargamin, synthesis of similar $\beta$-carboline spirooxindoles is very popular. ${ }^{375}$ Also, due to the number of bioactive compounds containing the spirodihydropyridine oxindole scaffold, there has been a significant amount of work aimed at racemic synthesis, ${ }^{376}$ of note is Shi's enantioselective $[3+3]$ annulation. ${ }^{377}$ Very recent advances include a copper catalysed aza-Henry reaction by Wang and Zhou ${ }^{378}$ and HFIP mediated $\mathrm{C}\left(\mathrm{sp}^{3}\right)-\mathrm{H}$ functionalisation by hydride transfer. ${ }^{379}$

Stepwise strategies. There are also a number of related works where an asymmetric reaction is followed by consequent deprotection/cyclisation steps. For example, Pedro developed an aza-Henry reaction between isatin ketimines and 4-nitrobutyrate catalysed by a $\mathrm{Cu}(\mathrm{II})$-Box system, which could be deprotected to undergo spontaneous cyclisation to the 3,2'-spiropiperidine oxindole (Scheme 75). ${ }^{380}$ Hajra described an organocatalytic addition of a nitroalkyl goup followed by intramolecular alkylation (Scheme 52). ${ }^{245}$ Meng and Li, and more recently Nakamura, reported enantioselective vinylogous Mannich reactions to generate intermediates which could be

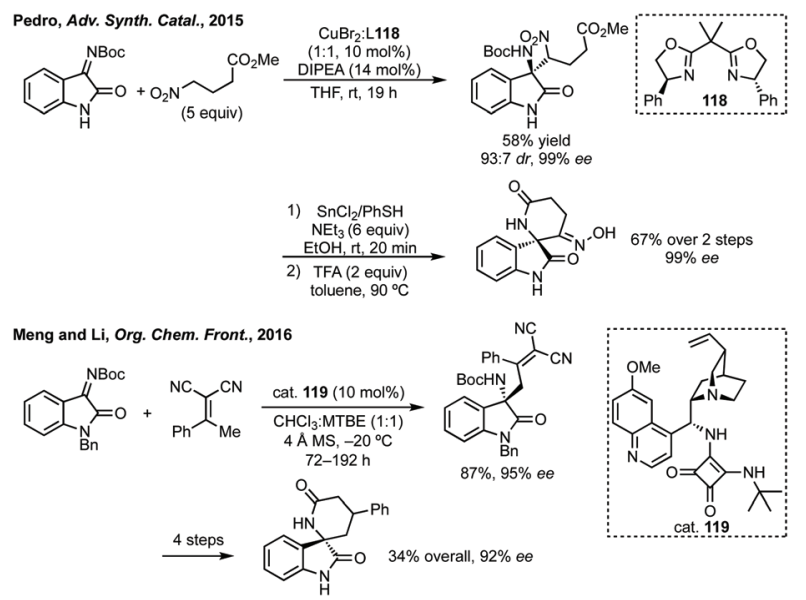

Scheme 75 Selected advances in asymmetric Mannich reactions followed by elaboration to six-membered spirocycles. deprotected and cyclised to spirolactam products (Scheme 75). ${ }^{381}$ Han has also developed an enantioselective Mannich reaction which upon deprotection of the generated Boc-protected amine undergoes lactamisation to the six-membered spirocycle. $^{382}$

\section{Spirotetrahydropyranyl oxindoles}

Applications. SpiroTHP oxindoles have found application in induction of apoptosis, ${ }^{383}$ as anti-malarials, ${ }^{384}$ among others. ${ }^{385}$

Natural product synthesis. Trost cyclised 120 to give cyclolactone $\mathbf{1 2 1}$ in $92 \%$ yield as one diastereomer as an intermediate for the total synthesis of communesin $\mathrm{F}$ and perophoramide (Scheme 76). ${ }^{386}$ Gong reported the first total synthesis of (+)-trigolutes B utilising an enantioselective substitution reaction to form 122 which in 7 steps could be transformed to the natural product (Scheme 76). ${ }^{387,388}$

Cycloaddition/cascade. Liang and Xu employed thiourea cat. 123 in a double Michael addition cascade between $N$-methyl oxindole and 124 (Scheme 77). ${ }^{389}$ Using thiourea cat. 125 Enders developed an oxa-Michael/1,6-addition reaction to form 3,3'-spiroTHP oxindoles in high yield an enantioselectivity (Scheme 77). ${ }^{390}$ Zeng and Zhong reported an enantioselective Michael/aldol/hemiacetalisation process using iminium catalysis. ${ }^{391}$ Han has developed an enantioselective vinylogous aldol/cyclisation/ring-opening cascade of 3-methylene oxindoles and isatins. ${ }^{392} \mathrm{Wu}$ reported an enantioselective Michael/cyclisation reaction between dimedone and isatylidene malonitriles with high yields and enantioselectivities, the trityl protecting group on the isatin was important. $^{393,394}$ More recent examples include a Michael/ aldol/cyclisation cascade to form 5- or 6-membered oxygenated spirocycles by Zhang and a vinylogous aldol reaction/transesterification by Yuan, both using thiourea catalysts (Scheme 77). ${ }^{395}$ Some of these Michael/cyclisation procedures can be deemed formal hetero-Diels-Alder reactions. ${ }^{396}$

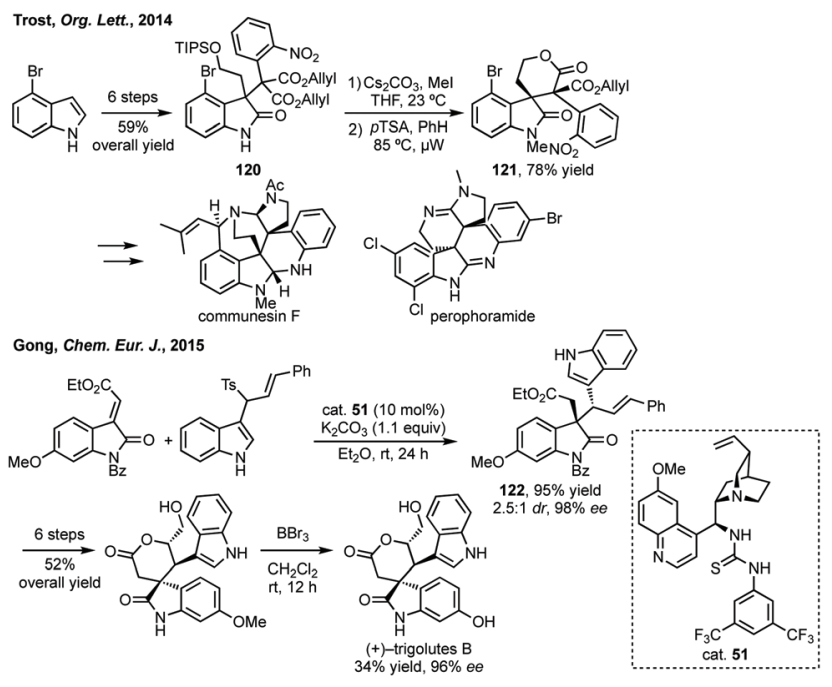

Scheme 76 Selected examples of spiroTHP oxindole synthesis in total synthesis. 


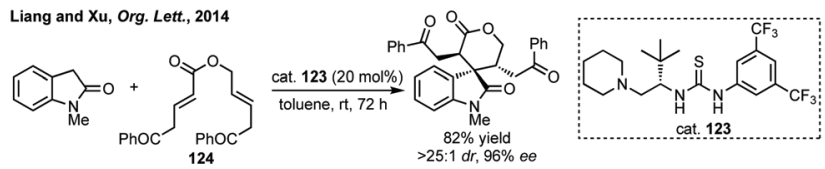

Enders, Angew. Chem. Int. Ed., 2016

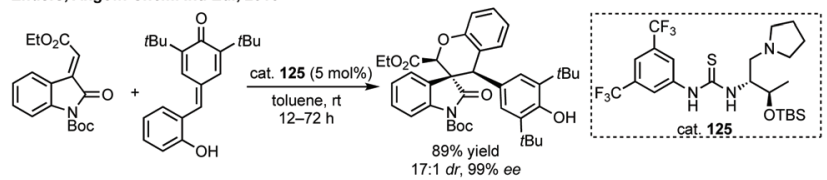

Wang and Yuan, Chem. Commun., 2019
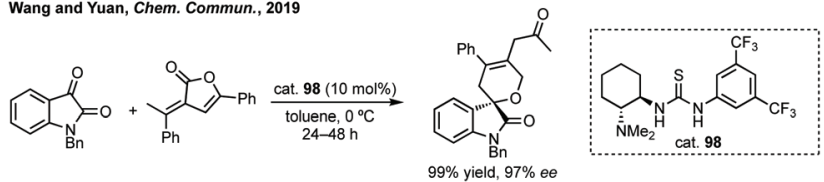

Scheme 77 Selected cascade reactions catalysed by thiourea catalysts.

Recently, Xiao has used ortho-quinone methides derived in situ from oxindole ortho-hydrooxybenzyl alcohols by acid in $[4+2]$ annulations with 2,5-dialkylfurans or 1,3-diketones as dienophiles. $^{397}$ These starting materials can also be used in a biselectrophile coupling in a $[4+2]$ annulation (as well as $[4+1]$ annulation if a pyridinium salt is used instead of a bromide leaving group). ${ }^{398}$ THP fused indoles have been synthesised by enantioselective aldol/chloroetherification/aromatisation, as well as C-O coupling. ${ }^{399} \mathrm{MBH}$ carbonates have also been used for $[4+2]$-annulations. ${ }^{400}$

NHC catalysis. Yao developed the $[4+2]$ annulation of isatins with the HOBt ester of $\alpha, \beta$-unsaturated carboxylic acids, achieving good enantioselectivity with cat. 19 (Scheme 78). ${ }^{401}$ $\mathrm{Lu}$ and $\mathrm{Du}$ reported the NHC catalysed $[3+3]$ annulation of isatin derived $\alpha, \beta$-unsaturated acids and $\alpha$-ketoesters with up to $74 \%$ ee. ${ }^{402}$ In a similar reaction, $\mathrm{Xu}$ reported the annulation of 3-ylidene oxindoles with 1,3-dicarbonyls (Scheme 78). ${ }^{403}$ In an excellent application of dual NHC and Cu-catalysis, Song and Gong used ethylethylene carbonates in a $[3+3]$-annulation of 3-ylidene oxindoles (Scheme 78). ${ }^{404}$

Stepwise approaches. Feng has employed a $\mathrm{Mg} / \mathrm{chiral} N, N^{\prime}-$ dioxide catalyst system for a hetero Diels-Alder reaction. ${ }^{405} \mathrm{Li}$ has recently reported a Bi/chiral phosphoric acid 77 catalysed

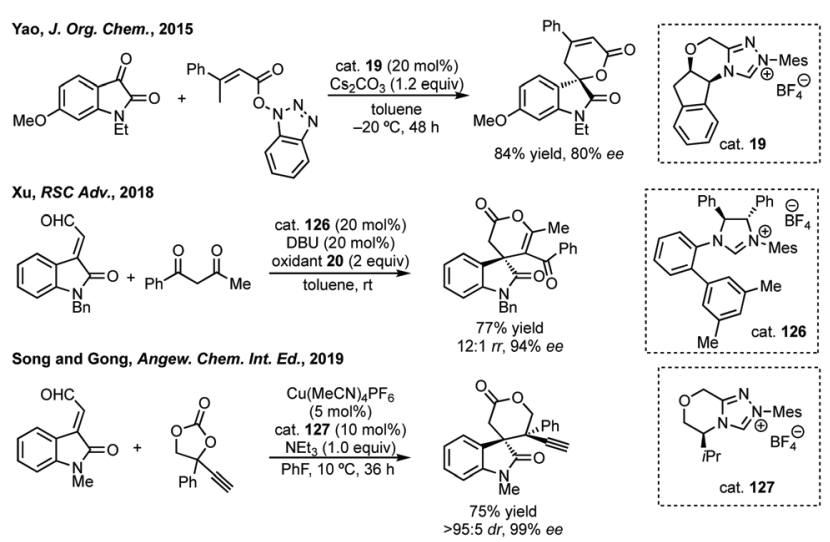

Scheme 78 Selected NHC catalysed cycloadditions.

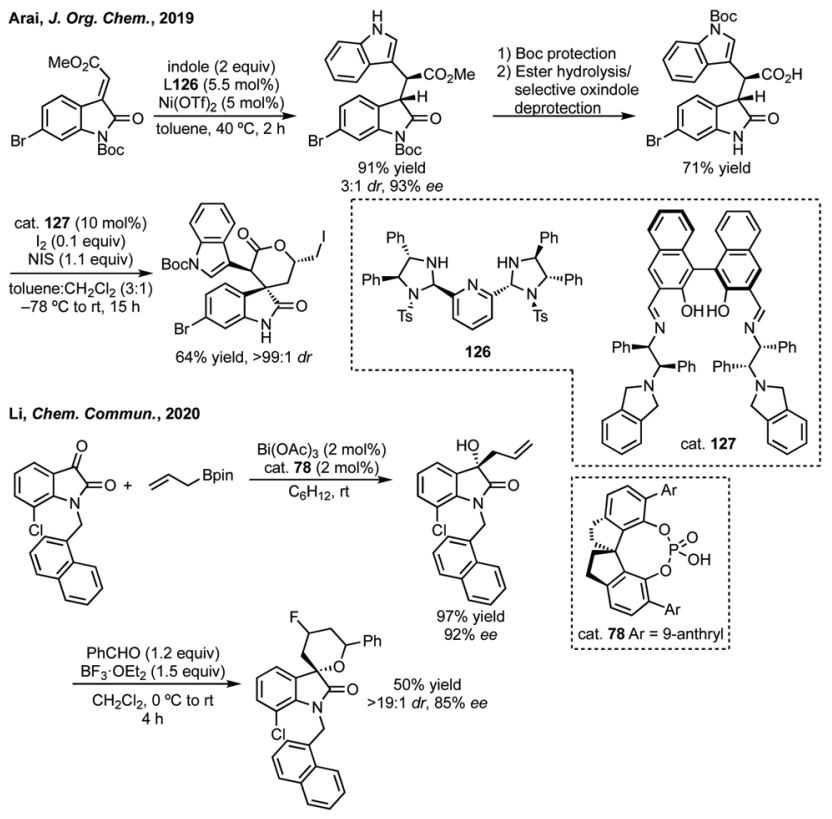

Scheme 79 Selected examples of stepwise synthesis of spiroTHP oxindoles by nucleophilic addition.

allylation of isatins which could be further elaborated to spiroTHP products (Scheme 79). ${ }^{406}$ Arai has employed a TsPyBidine-Ni complex to catalyse the asymmetric addition of indole to 3-ylidene oxindoles and a highly diastereoselective iodocyclisation to 6-membered products was developed using cat. 77 (Scheme 79). ${ }^{407}$

In other approaches, Subba Reddy has developed a $\mathrm{BF}_{3} \cdot \mathrm{OEt}_{2}$ mediated Prins cascade cyclisation between aldehydes and butanamides to furnish spiroTHP oxindoles in high yield and good dr. ${ }^{408} \mathrm{Hu}$ used Rh-carbenes generated from 3-diazooxindoles to undergo $\mathrm{C}-\mathrm{H}$ insertion/aldol condensation to afford spiroTHP oxindoles in high yield and diastereoselectivity. ${ }^{409}$ Another example of $\mathrm{C}-\mathrm{H}$ activation has been shown by Messaoudi with glycosides. ${ }^{410}$ The intramolecular Co-catalysed Pauson-Khand cyclisation of 1,7-enynes generated 3,2'-spiroTHPs with high diastereoselectivity. ${ }^{411}$

\section{Seven-membered rings}

\section{Applications}

Natural products containing seven-membered spirocyclic oxindoles are predominantly bridged carbocyclic examples of gelsemium alkaloids. ${ }^{412}$ There are not many examples of these rings in medicinal chemistry, though nitrogen containing examples do feature in some patents. ${ }^{413}$ A spiroazepane oxindole was synthesised as a cipargamin analogue with antimalarial activity, ${ }^{16}$ and an example with activity against a prostate cancer target (Fig. 1). ${ }^{414}$ While natural products tend to favour bridged carbocyclic seven-membered rings (Fig. 11) and there are some methodologies to synthesise bridged seven-membered rings, this section will focus on non-bridged 


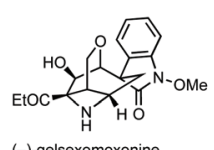

(-)-gelsexomoxonine

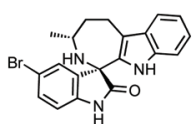

cipagarmin analogue

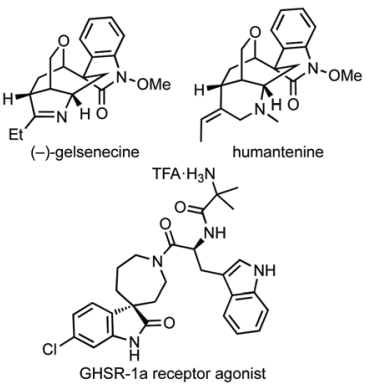

Fig. 11 Selected bioactive seven-membered rings.

examples. ${ }^{415}$ Additionally, we have grouped the methodologies in terms of similarity rather than into $\mathrm{C} / \mathrm{N} / \mathrm{O}$-containing rings due to the small number of publications, the vast majority of which are aimed at spiroazepane synthesis.

\section{Natural product synthesis}

Total synthesis efforts centre around the synthesis of gelsemium alkaloids. Carreira has described elegant approaches to gelsemoxonine (see Fig. 11 for structure). ${ }^{416}$ Ferreira constructed the oxindole of gelsenicine with an oxidative cyclisation of a Weinreb amide with an aromatic ring. ${ }^{417}$ Fukuyama and Ma have independently described divergent syntheses to many gelsedine type alkaloids. ${ }^{418}$ Takayama recently described an asymmetric synthesis of (-)-14-hydroxygelsenicine and six other gelsemium alkaloids. ${ }^{419}$ The spirooxindole was constructed in a diastereoselective Heck cyclisation (Scheme 80).

\section{NHC catalysis}

In 2016, Enders pioneered the use of NHCs for the $[3+4]$ cycloaddition of isatin derived enals with aza-o-quinone methides or azoalkenes to form spiro-benzazepinones or spirodiazepinones (Scheme 81). ${ }^{420}$ Using cat. 128 with $\mathrm{Cs}_{2} \mathrm{CO}_{3}$ to form the aza-o-quinone methide in situ from the $\mathrm{N}$ - $(o$-chloromethyl)aryl amide in EtOAc gave high enantioselectivity and atroposelectivity. Switching starting material in order to make diazepinones was highly stereoselective using cat. 129.

Li developed an NHC catalysed enantioselective synthesis of spirobenzoxepinones in a $[4+3]$ cycloaddition of isatin derived enals and quinone methides (Scheme 82). ${ }^{421}$ High enantioselectivity (up to $>99 \%$ ee and $>20: 1 \mathrm{dr}$ ) was achieved using triazolium cat. 130 in combination with NaOAc in 1,2dichloroethane. Enders published a similar reaction a month after Li's study, which employed cat. 131 to achieve up to 95 : 5

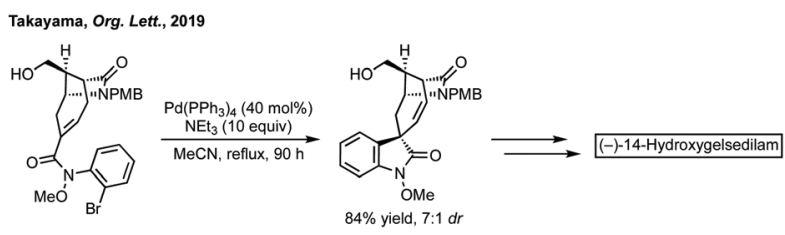

Scheme 80 Pd-Catalysed Heck reaction as key step in the total synthesis of (-)-14-hydroxygelsedilam.

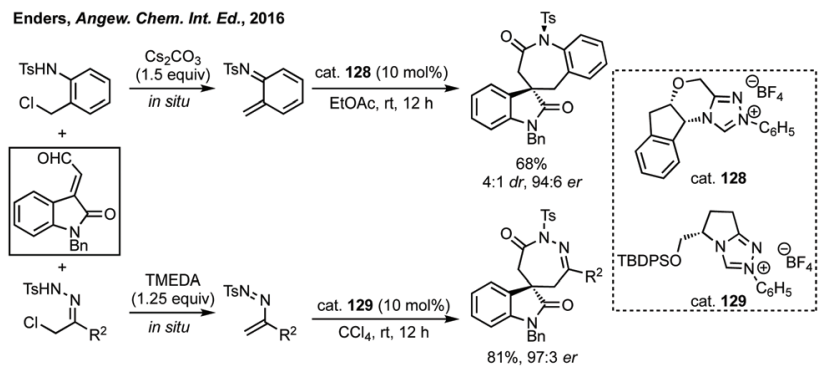

Scheme 81 [4 + 3]-Cycloadditions with 3-ylidene oxindoles for 7-membered ring synthesis.

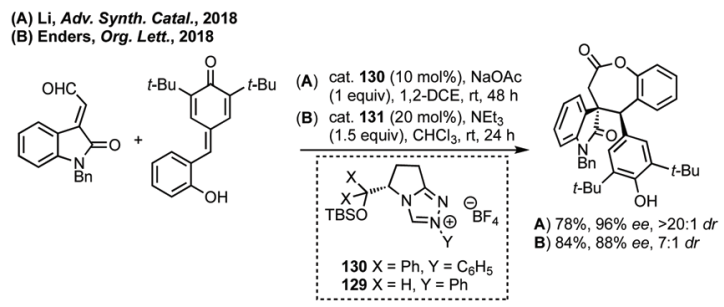

Scheme 82 Isatin-derived enals in [4+3] cycloaddition reactions.

er and good dr. ${ }^{422}$ This was followed by work by Yan Li and Ye on a related $[4+3]$-cycloaddition of isatin derived enals and aurone-derived azadienes. ${ }^{423}$ Using a similar NHC catalyst interesting spiroazepinones were formed with high enantioselectivity and diastereoselectivity. The compounds exhibited moderate cytotoxicity against cancer cell lines.

More recent advances include Fu and Huang's NHC catalysed $[4+3]$-annulation of $\alpha, \beta$-unsaturated aldehydes and amine substituted oxindoles (oxotryptamines, Scheme 83). ${ }^{424}$ Song and Gong's previously discussed excellent $\mathrm{Cu} / \mathrm{NHC}$ dual catalysis could be used with ethynyl benzoxazinanones to construct chiral azepines. ${ }^{404}$

\section{MBH carbonates}

Chen and coworkers reported a $[4+3]$ cycloaddition of a bromo-substituted $\mathrm{MBH}$ derivative and an aza-o-quinone methide precursor (Scheme 84). ${ }^{425}$ Chen used tri-(4-fluoro) phenyl phosphine as a Lewis base to form an allylic ylide from the $\mathrm{MBH}$ precursor and $\mathrm{Cs}_{2} \mathrm{CO}_{3}$ as base to generate the aza-oquinone methide. $\mathrm{Xu}$ published a related reaction at a similar time, ${ }^{426}$ using tributyl phosphine as Lewis base catalysis with a related $\mathrm{MBH}$ precursor and a Boc protected aza-o-quinone

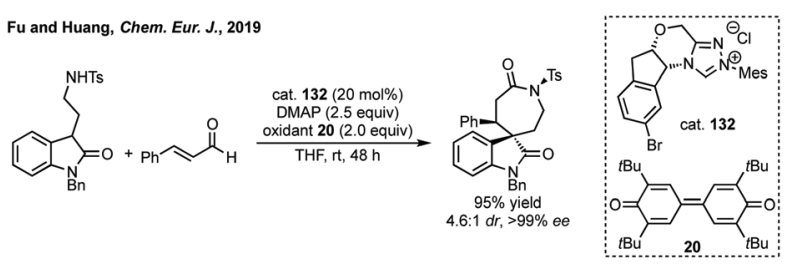

Scheme 83 Selected [4 +3]-annulation reaction of oxotryptamines. 

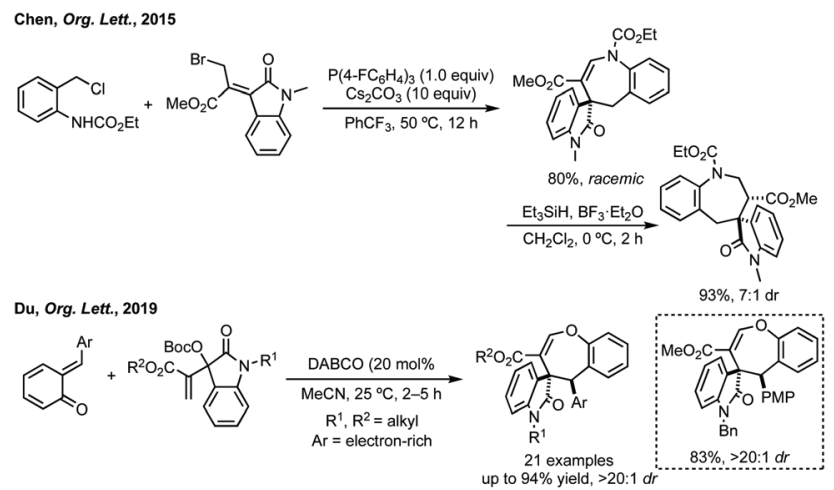

Scheme 84 Selected [4 + 3]-cycloadditions to 7-membered spirocycles using $\mathrm{MBH}$ carbonates or $\mathrm{MBH}$ precursors.

methide precursor to generate seven-membered spirocycles in good yields, including on gram-scale. In a similar fashion, Du recently employed ortho-quinone methides in combination with an isatin derived $\mathrm{MBH}$ precursor to affect a $[4+3]$-cycloaddition. ${ }^{427}$ Using DABCO as Lewis base catalyst in MeCN, high diastereoselectivity with electron-rich ortho-quinone methides was observed (Scheme 84).

$\mathrm{Du}$ and Chen have collaboratively reported an asymmetric Ir catalysed $[4+3]$-cycloaddition between an $\mathrm{MBH}$ carbonate and $\pi$-allyl precursor (Scheme 85). ${ }^{428}$ The $\pi$-allyl precursor includes a vinylogous leaving group i.e. vinyl-OBoc, ethylene oxazinanones or vinyl aziridines (for six-membered rings) which forms an asymmetric Ir-allyl complex to react with the DABCO activated MBH carbonate.

Other approaches to spiroazepanes include a desymmetrising Cu-catalysed $\mathrm{C}-\mathrm{N}$ bond formation in high ee (Scheme 86). ${ }^{429}$ Budynina has used azide anion ring opening of spirocyclopropyl oxindoles (ref. 198) in a Staudinger, domino Michael/aza-Wittig and reduction sequence. ${ }^{430}$ Yang developed a Pd-NHC catalysed allylic alkylation, the products of which could readily elaborated to a spiroazepinone. ${ }^{431}$

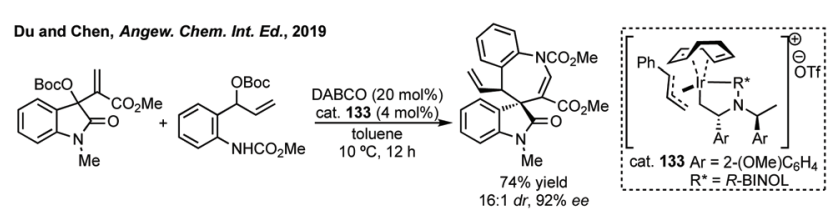

Scheme 85 Reaction of MBH carbonates with $\pi$-allyl precursors.

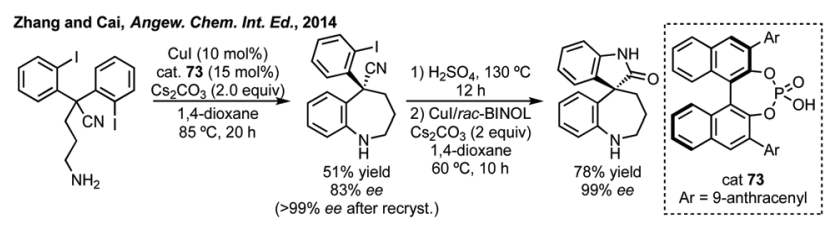

Scheme 86 Cu-Catalysed desymmetrising cross-coupling reaction.

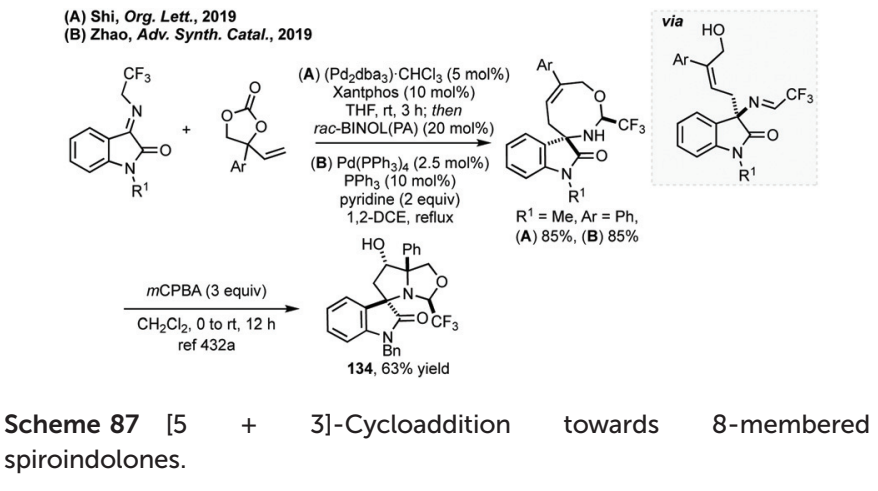

\section{Eight-membered rings}

As with seven-membered spiro-oxindoles there are very few examples of syntheses capable of accessing the eight-membered analogues. Shi and Zhao independently published the Pd-catalysed [5 + 3]-cycloaddition of $\mathrm{N}$-2,2,2-trifluoromethylisatin ketimines and vinylethylene carbonates (Scheme 87). ${ }^{432}$ Shi employed $\left(\mathrm{Pd}_{2} \mathrm{dba}_{3}\right) \cdot \mathrm{CHCl}_{3}$ and Xantphos as a ligand for the decarboxylative allylic substitution and a racemic phosphoric acid catalyst to effect the cyclisation. Meanwhile, Zhao used $\mathrm{Pd}\left(\mathrm{PPh}_{3}\right)_{4}$ in combination with $\mathrm{PPh}_{3}$ as ligand and pyridine as base for the cyclisation. Both procedures afford the antiproduct as the major product in high yields and dr. Shi demonstrated a preliminary result for the enantioselective allylation using $t \mathrm{Bu}-\mathrm{RuPhos}$ as ligand affording the eight-membered spirocycle in $63 \%$ ee. Furthermore, Shi showed that epoxidation of the endogenous double bond with mCPBA would lead to spontaneous epoxide ring opening to form spiropyrrolidine 134 (Scheme 87A).

\section{Summary and conclusions}

We have reviewed the developments in state-of-the-art stereoselective spiroindolone synthesis between 2013 and 2020. The progress of synthetic methodology for each ring size (3- to 8-) has been discussed. The importance of these advances should not be understated, with reference to the significant potential of many of these structures in medicinal chemistry, which we have highlighted with numerous examples. The trends we have observed within this review can be summarised as follows:

1. Spirooxindoles represent a very important class of structures within medicinal chemistry, featuring in approved medicines with a large variety of biological activity, as well as acting as the structural core in a significant number of natural products (eg Fig. 1). Where possible we have highlighted how the synthetic methodologies discussed in this review have influenced the process scale synthesis of these pharmaceuticals, for example in Scheme 59.

2. Spirooxindoles serve as a benchmark in asymmetric synthesis. Many of the methods reviewed here have made substantial advances in asymmetric catalysis. This may be due to the fused backbone of the indolone providing a flat and rigid plat- 
form for construction of 3D spirocycles. These advances are doubly valuable because they fulfill the object of advancing asymmetric methodology while making biologically relevant scaffolds for screening against biologically relevant targets.

3. The advances that have been observed in spirooxindole synthesis generally reflect the advance of organic synthesis since 2013. While there has been a significant rise in the number of publications on this topic, there are a growing number of excellent and innovative reports targeting these scaffolds (Fig. 2). This review has covered advances in stereoselective NHC catalysis, chiral acid catalysis, aminocatalysis, metal catalysis including cross-coupling, hydrogen bonding catalysis and phase transfer catalysis. We have also highlighted total syntheses of natural products containing these core structures.

There will likely be sustained interest in these scaffolds because of the trends observed in recent years coupled with the success of many of the pharmaceutical agents. We envisage that future developments may be targeted to the following objectives:

1. More general methods to access multiple ring sizes. Currently, there are few methodologies that can access multiple ring sizes with simple changes i.e. to starting material structure. For example, ring expansion strategies making use of small rings are useful to access more than one ring size. Ideal methods could also access more than one heteroatom pattern on the spirocyclic ring and be able to control ring substitution.

2. A wider variety of synthetic targets through asymmetric synthesis. Unsubstituted rings can often be synthesised as racemates using traditional methods. Yet, asymmetric synthesis of unsubstituted rings is a challenge and though there are examples within this review there is still a requirement to access the unsubstituted scaffold.

3. Small and larger ring spirocycles. As could be seen from the analysis of the publication numbers (Fig. 2) and reflected in the number of strategies discussed in this review, there is a plethora of methods for 5- and 6-membered rings. Future endeavours in this area should seek to synthesise small or larger rings, eg azetidines and oxetanes are increasingly useful for medicinal chemistry and have not received the same level of attention. Furthermore, 7- and 8-membered rings have not received significant attention due to the difficulty in accessing these structures and we envisage that synthetic advances seen in this review will likely be applied to larger ring synthesis. 8-Membered ring spirocycles, as the first member of the medium rings, may require significant new method development. Higher medium ring homologues were not within the scope of this review, but could pose interesting targets for medicinal chemistry. New syntheses of these smaller and larger ring spirocycles will lead to improved access to this valuable and underexplored chemical space.

We hope that this review will serve as a reference for medicinal and synthetic chemists aiming to synthesise this type of ring structure and inspire future advances in the synthesis of spirooxindoles.

\section{Conflicts of interest}

There are no conflicts to declare.

\section{Acknowledgements}

We gratefully acknowledge The Royal Society for funding [University Research Fellowship, UF140161 (to J. A. B)], and AstraZeneca and EPSRC for iCASE studentship funding.

\section{Notes and references}

1 Y. Zheng, C. M. Tice and S. B. Singh, The use of spirocyclic scaffolds in drug discovery, Bioorg. Med. Chem. Lett., 2014, 24, 3673.

2 Y. J. Zheng and C. M. Tice, The utilization of spirocyclic scaffolds in novel drug discovery, Expert Opin. Drug Discovery, 2016, 11, 831.

3 S. L. Degorce, M. S. Bodnarchuk and J. S. Scott, Lowering Lipophilicity by Adding Carbon: AzaSpiroHeptanes, a logD Lowering Twist, ACS Med. Chem. Lett., 2019, 10, 1198.

4 (a) G. Müller, T. Berkenbosch, J. C. J. Benningshof, D. Stumpfe and J. Bajorath, Charting Biologically Relevant Spirocyclic Compound Space, Chem. - Eur. J., 2017, 23, 703. For benefits of saturated heterocycles vs. aromatic cycles see: (b) T. J. Ritchie and S. J. F. Macdonald, The impact of aromatic ring count on compound developability - are too many aromatic rings a liability in drug design?, Drug Discovery Today, 2009, 14, 1011; (c) T. J. Ritchie, S. J. F. MacDonald, R. J. Young and S. D. Pickett, The impact of aromatic ring count on compound developability: further insights by examining carbo- and hetero-aromatic and -aliphatic ring types, Drug Discovery Today, 2011, 16, 164.

5 E. M. Carreira and T. C. Fessard, Four-Membered RingContaining Spirocycles: Synthetic Strategies and Opportunities, Chem. Rev., 2014, 114, 8257.

6 G. S. Singh and Z. Y. Desta, Isatins As Privileged Molecules in Design and Synthesis of Spiro-Fused Cyclic Frameworks, Chem. Rev., 2012, 112, 6104.

7 T. L. Pavlovska, R. G. Redkin, V. V. Lipson and D. V. Atamanuk, Molecular diversity of spirooxindoles. Synthesis and biological activity, Mol. Diversity, 2016, 20, 299.

8 (a) B. Yu, D. Q. Yu and H. M. Liu, Spirooxindoles: Promising scaffolds for anticancer agents, Eur. J. Med. Chem., 2015, 97, 673; (b) B. Yu, Y.-C. Zheng, X.-J. Shi, P.-P. Qi and H.-M. Liu, Natural Product-Derived Spirooxindole Fragments Serve as Privileged Substructures for Discovery of New Anticancer agents, Anticancer Agents Med. Chem., 2016, 16, 1315.

9 N. Ye, H. Chen, E. A. Wold, P. Y. Shi and J. Zhou, Therapeutic Potential of Spirooxindoles. as Antiviral Agents, ACS Infect. Dis., 2016, 2, 382. 
10 (a) M. M. M. Santos, Recent advances in the synthesis of biologically active spirooxindoles, Tetrahedron, 2014, 70, 9735; (b) E. Sansinenea, E. F. Martínez and A. Ortiz, Organocatalytic Synthesis of Chiral Spirooxindoles with Quaternary Stereogenic Centers, Eur. J. Org. Chem., 2020, 5101.

11 (a) B. M. Trost and M. K. Brennan, Asymmetric Syntheses of. Oxindole and Indole Spirocyclic Alkaloid Natural Products, Synthesis, 2009, 3003; (b) F. Zhou, Y. L. Liu and J. Zhou, Catalytic Asymmetric Synthesis of Oxindoles Bearing a Tetrasubstituted Stereocenter at the C-3 Position, Adv. Synth. Catal., 2010, 352, 1381; (c) L. Hong and R. Wang, Recent Advances in Asymmetric Organocatalytic Construction of 3,3'-Spirocyclic Oxindoles, Adv. Synth. Catal., 2013, 355, 1023; (d) D. Cheng, Y. Ishihara, B. Tan and C. F. Barbas, Organocatalytic Asymmetric Assembly Reactions: Synthesis of Spirooxindoles via Organocascade Strategies, ACS Catal., 2014, 4, 743; (e) R. Narayan, M. Potowski, Z. J. Jia, A. P. Antonchick and H. Waldmann, Catalytic Enantioselective 1,3-Dipolar Cycloadditions of Azomethine Ylides for Biology-Oriented Synthesis, Acc. Chem. Res., 2014, 47, 1296; ( $f$ ) R. Dalpozzo, Recent Catalytic Asymmetric Syntheses of 3,3-Disubstituted Indolin-2-ones and 2,2-Disubstituted Indolin-3-ones, Adv. Synth. Catal., 2017, 359, 1772; (g) G. J. Mei and F. Shi, Catalytic asymmetric synthesis of spirooxindoles: recent developments, Chem. Commun., 2018, 54, 6607.

12 (a) M. Xia and R.-Z. Ma, Recent Progress on Routes to Spirooxindole Systems Derived from Isatin, J. Heterocycl. Chem., 2014, 51, 539; (b) Y. Liu, H. Wang and J. Wan, Recent Advances in Diversity Oriented Synthesis through Isatin-based Multicomponent Reactions, Asian J. Org. Chem., 2013, 2, 374; (c) G. Mohammadi Ziarani, R. Moradi and N. Lashgari, Asymmetric synthesis of chiral oxindoles using isatin as starting material, Tetrahedron, 2018, 74, 1323.

13 (a) S. Peddibhotla, 3-Substituted-3-hydroxy-2-oxindole, an Emerging New Scaffold for Drug Discovery with Potential Anti-Cancer and other Biological Activities, Curr. Bioact. Compd., 2009, 5, 20; (b) J. Kaur, B. P. Kaur and S. S. Chimni, Recent advances in the catalytic synthesis of 3-aminooxindoles: an update, Org. Biomol. Chem., 2020, 18, 4692.

14 (a) A. K. Franz, N. V. Hanhan and N. R. Ball-Jones, Asymmetric Catalysis for the Synthesis of Spirocyclic Compounds, ACS Catal., 2013, 3, 540; (b) A. Ding, M. Meazza, H. Guo, J. W. Yang and R. Rios, New development in the enantioselective synthesis of spiro compounds, Chem. Soc. Rev., 2018, 47, 5946; (c) J. Bariwal, L. G. Voskressensky and E. V. Van Der Eycken, Recent advances in spirocyclization of indole derivatives, Chem. Soc. Rev., 2018, 47, 3831.

15 Analysis carried out on SciFinder on 06/04/2020 and 07/ 04/2020. A general substructure search was carried out with each ring size and heteroatom position iteratively with the following restrictions placed: (1) exclude metalcontaining results; (2) exclude isotope-containing results; (3) only include if hit has references; (4) only include if hit is a single component; (5) limit references to biological or preparative sources.

16 B. K. S. Yeung, B. Zou, M. Rottmann, S. B. Lakshminarayana, S. H. Ang, S. Y. Leong, J. Tan, J. Wong, S. Keller-Maerki, C. Fischli, et al., Spirotetrahydro $\beta$-Carbolines (Spiroindolones): A New Class of Potent and Orally Efficacious Compounds for the Treatment of Malaria, J. Med. Chem., 2010, 53, 5155.

17 A. A. Akaev, M. Y. Melnikov and E. M. Budynina, Chameleon-Like Activating Nature of the Spirooxindole Group in Donor-Acceptor Cyclopropanes, Org. Lett., 2019, 21, 9795.

18 Z. Y. Cao and J. Zhou, Catalytic asymmetric synthesis of polysubstituted spirocyclopropyl oxindoles: organocatalysis versus transition metal catalysis, Org. Chem. Front., 2015, 2, 849.

19 E. P. Bacher and B. L. Ashfeld, Transition metal-free strategies for the stereoselective construction of spirocyclopropyl oxindoles, Tetrahedron, 2020, 76, 130692.

20 B. Sampson, Y. Liu, N. K. Patel, M. Feher, B. Forrest, S.-W. Li, L. Edwards, R. Laufer, Y. Lang, F. Ban, et al., The Discovery of Polo-Like Kinase 4 Inhibitors: Design and Optimization of Spiro[cyclopropane-1,3'[3H]indol]-2' $\left(1^{\prime} \mathrm{H}\right)-$ ones as Orally Bioavailable Antitumor Agents, J. Med. Chem., 2015, 58, 130.

21 S. Chen, H. He, B. Lagu, H. Qin, C. Wu and Y. Xiao, Tricyclic Sulfonamide Derivatives, PCT Int. Appl WO2015102929A1, 2015.

22 D. Brunner, J. Malberg, B. G. Shankar, S. Kolczewski, A. Limberg, E. Prinssen, C. Riemer and T. Stoll, 2-Oxo-2,3dihydro-indoles for the Treatment of CNS Disorders, $P C T$ Int. Appl WO2014040969A1, 2014.

23 (a) T. Jiang, K. L. Kuhen, K. Wolff, H. Yin, K. Bieza, J. Caldwell, B. Bursulaya, T. Y. H. Wu and Y. He, Design, synthesis and biological evaluations of novel oxindoles as HIV-1 non-nucleoside reverse transcriptase inhibitors. Part I, Bioorg. Med. Chem. Lett., 2006, 16, 2105; (b) T. Jiang, K. L. Kuhen, K. Wolff, H. Yin, K. Bieza, J. Caldwell, B. Bursulaya, T. Tuntland, K. Zhang, D. Karanewsky, et al., Design, synthesis and biological evaluations of novel oxindoles as HIV-1 non-nucleoside reverse transcriptase inhibitors. Part 2, Bioorg. Med. Chem. Lett., 2006, 16, 2109; (c) B. Yu, Z. Yu, P. P. Qi, D. Q. Yu and H. M. Liu, Discovery of orally active anticancer candidate CFI-400945 derived from biologically promising spirooxindoles: Success and challenges, Eur. J. Med. Chem., 2015, 95, 35; (d) S. Cockerill, C. Pilkington, J. Lumley, R. Angell and N. Mathews, Pharmaceutical Compounds, PCT Int. Appl WO2013068769A1, 2013.

24 (a) F. C. Stevens, W. E. Bloomquist, A. G. Borel, M. L. Cohen, C. A. Droste, M. L. Heiman, A. Kriauciunas, D. J. Sall, F. C. Tinsley and C. D. Jesudason, Potent oxindole based human $\beta_{3}$ adrenergic receptor agonists, 
Bioorg. Med. Chem. Lett., 2007, 17, 6270; (b) A. Nardi, F. Jakob, I. Konetzki, T. Craan, C. Hesslinger and R. Doodeman, Novel Substituted Pyrimidine Compounds, PCT Int. Appl WO2016008593A1, 2016. Also see ref. 25.

25 D. W. Robertson, J. H. Krushinski, G. D. Pollock, H. Wilson, R. F. Kauffman and J. S. Hayes, Dihydropyridazinone cardiotonics: synthesis and inotropic activity of 5 '-(1,4,5,6-tetrahydro-6-oxo-3-pyridazinyl)spiro[cycloalkane-1,3'-(3H)indol-2'(1')H-ones, J. Med. Chem., 1987, 30, 824.

26 M. Palomba, L. Rossi, L. Sancineto, E. Tramontano, A. Corona, L. Bagnoli, C. Santi, C. Pannecouque, O. Tabarrini and F. Marini, A new vinyl selenone-based domino approach to spirocyclopropyl oxindoles endowed. with anti-HIV RT activity, Org. Biomol. Chem., 2016, 14, 2015.

27 M. Zhou, K. En, Y. Hu, Y. Xu, H. C. Shen and X. Qian, Zinc triflate-mediated cyclopropanation of oxindoles with vinyldiphenyl sulfonium triflate: a mild reaction with broad functional group compatibility, RSC Adv., 2017, 7, 3741.

28 H. Qin, Y. Miao, K. Zhang, J. Xu, H. Sun, W. Liu, F. Feng and W. Qu, A convenient cyclopropanation process of oxindoles via bromoethylsulfonium salt, Tetrahedron, 2018, 74, 6809.

29 S. Hajra, S. Roy and S. A. Saleh, Domino Corey-Chaykovsky Reaction for One-Pot Access to Spirocyclopropyl Oxindoles, Org. Lett., 2018, 20, 4540.

30 (a) S. A. Bonderoff and A. Padwa, Rh(II)-Catalyzed Reactions of Differentially Substituted Bis(diazo) functionalities, Org. Lett., 2013, 15, 4114; (b) S. Muthusamy and R. Ramkumar, Solvent- and transition metal-free synthesis of spiro[cyclopropane-1,3-oxindoles] from cyclic diazoamides, Tetrahedron Lett., 2014, 55, 6389; (c) G. Karthik, T. Rajasekaran, B. Sridhar and B. V. S. Reddy, Catalyst and solvent-free cyclopropanation of electron-deficient olefins with cyclic diazoamides for the synthesis of spiro[cyclopropane-1,3'-indolin]-2'-one derivatives, Tetrahedron Lett., 2014, 55, 7064; (d) S. Muthusamy and R. Ramkumar, Highly Diastereoselective Synthesis of Spirocyclopropaneoxindoles Using $\mathrm{InCl}_{3}$ as a Catalyst in Water, Synlett, 2015, 26, 2156.

31 A. Awata and T. Arai, Catalytic Asymmetric Cyclopropanation with Diazooxindole, Synlett, 2013, 24, 29.

32 Z. Y. Cao, F. Zhou, Y. H. Yu and J. Zhou, A Highly Diastereo- and Enantioselective $\mathrm{Hg}$ (II)-Catalyzed Cyclopropanation of Diazooxindoles and Alkenes, Org. Lett., 2013, 15, 42.

33 Z.-Y. Cao, X. Wang, C. Tan, X.-L. Zhao, J. Zhou and K. Ding, Highly Stereoselective Olefin Cyclopropanation of Diazooxindoles Catalyzed by a $\mathrm{C}_{2}$-Symmetric Spiroketal Bisphosphine/Au(I) Complex, J. Am. Chem. Soc., 2013, 135, 8197.

34 Y. Chi, L. Qiu and X. Xu, Highly enantioselective synthesis of spirocyclopropyloxindoles via a Rh(II)-catalyzed asym- metric cyclopropanation reaction, Org. Biomol. Chem., 2016, 14, 10357.

35 Z. Y. Cao, W. Wang, K. Liao, X. Wang, J. Zhou and J. Ma, Catalytic enantioselective synthesis of cyclopropanes featuring vicinal all-carbon quaternary stereocenters with a $\mathrm{CH}_{2} \mathrm{~F}$ group; study of the influence of C-F $\cdots \mathrm{H}-\mathrm{N}$ interactions on reactivity, Org. Chem. Front., 2018, 5, 2960.

36 M. Tone, Y. Nakagawa, S. Chanthamath, I. Fujisawa, N. Nakayama, H. Goto, K. Shibatomi and S. Iwasa, Highly stereoselective spirocyclopropanation of various diazooxindoles with olefins catalyzed using $\mathrm{Ru}(\mathrm{II})$-complex, $R S C$ Adv. , 2018, 8, 39865.

37 J. L. Meloche and B. L. Ashfeld, A Rhodium(II)-Catalyzed Formal $[4+1]$-Cycloaddition toward Spirooxindole Pyrrolone Construction Employing Vinyl Isocyanates as 1,4-Dipoles, Angew. Chem., Int. Ed., 2017, 56, 6604.

38 T.-R. Li, S.-W. Duan, W. Ding, Y.-Y. Liu, J.-R. Chen, L.-Q. Lu and W.-J. Xiao, Synthesis of $\mathrm{CF}_{3}$-Containing 3,3'Cyclopropyl Spirooxindoles by Sequential $[3+2]$ Cycloaddition/Ring Contraction of Ylideneoxindoles with 2,2,2-Trifluorodiazoethane, J. Org. Chem., 2014, 79, 2296.

39 B. Morandi and E. M. Carreira, Iron-Catalyzed Cyclopropanation with Trifluoroethylamine Hydrochloride and Olefins in Aqueous Media: In Situ Generation of Trifluoromethyl Diazomethane, Angew. Chem., Int. Ed., 2010, 49, 938.

40 G. Ramu, N. Hari Krishna, G. Pawar, K. N. Visweswara Sastry, J. B. Nanubolu and B. Nagendra Babu, SolventControlled, Tunable Domino Reaction of 3-Ylideneoxindoles with in Situ-Generated $\alpha$-Aryldiazomethanes: A Facile Access to 3-Spirocyclopropyl-2-oxindole and Pyrazoloquinazolinone, ACS Omega, 2018, 3, 12349.

41 W. Y. Han, J. Zhao, J. S. Wang, B. D. Cui, N. W. Wan and Y. Z. Chen, Syntheses of $\mathrm{CF}_{2} \mathrm{H}$-containing spirocyclopropyloxindoles from in situ generated $\mathrm{CF}_{2} \mathrm{HCHN}_{2}$ and 3-ylideneoxindoles, Tetrahedron, 2017, 73, 5806.

42 N. Huang, L. Zou and Y. Peng, Enantioselective 1,3Dipolar Cycloaddition of Methyleneindolinones with $\alpha$-Diazomethylphosphonate to Access Chiral Spiro-phosphonylpyrazoline-oxindoles Catalyzed by Tertiary Amine Thiourea and 1,5-Diazabicyclo[4.3.0]non-5-ene, Org. Lett., 2017, 19, 5806.

43 (a) R. Zhou, C. Yang, Y. Liu, R. Li and Z. He, Diastereoselective Synthesis of Functionalized Spirocyclopropyl Oxindoles via $\mathrm{P}\left(\mathrm{NMe}_{2}\right)_{3}$-Mediated Reductive Cyclopropanation, J. Org. Chem., 2014, 79, 10709. For a further study see: (b) E. E. Wilson, K. X. Rodriguez and B. L. Ashfeld, Stereochemical implications in the synthesis of 3,3'-spirocyclopropyl oxindoles from $\beta$-aryl/alkyl-substituted alkylidene oxindoles, Tetrahedron, 2015, 71, 5765.

44 D. Yin, H. Liu, C. D. Lu and Y. J. Xu, Dialkyl PhosphiteInitiated Cyclopropanation of $\alpha, \beta$-Unsaturated Ketones Using $\alpha$-Ketoesters or Isatin Derivatives, J. Org. Chem., 2017, 82, 3252. 
45 L. Zhang, H. Lu, G.-Q. Xu, Z.-Y. Wang and P.-F. Xu, $\mathrm{PPh}_{3}$ Mediated Reductive Annulation Reaction between Isatins and Electron Deficient Dienes to Construct Spirooxindole Compounds, J. Org. Chem., 2017, 82, 5782.

46 (a) J. H. Li, T. F. Feng and D. M. Du, Construction of Spirocyclopropane-Linked Heterocycles Containing Both Pyrazolones and Oxindoles through Michael/Alkylation Cascade Reactions, J. Org. Chem., 2015, 80, 11369; (b) Y. X. Song and D. M. Du, Asymmetric synthesis of spirooxindole-fused spirothiazolones via squaramide-catalysed reaction of 3-chlorooxindoles with 5-alkenyl thiazolones, Org. Biomol. Chem., 2019, 17, 5375; (c) S. Wang, Z. Guo, Y. Wu, W. Liu, X. Liu, S. Zhang and C. Sheng, Organocatalytic asymmetric synthesis of highly functionalized spiro-thiazolone-cyclopropane-oxindoles bearing two vicinal spiro quaternary centers, Org. Chem. Front., 2019, 6, 1442; (d) Y. Zhu, T. Lu, A. Geng, H. Cui and L. Zhang, Ultrafast and Diastereoselective Synthesis of 3-Spirocyclopropyl-2-oxindoles Bearing Three Continuous All-Carbon Quaternary Centers, Heterocycles, 2019, 98, 711; (e) J. B. Wen and D. M. Du, Squaramide-catalysed asymmetric cascade reactions of 2,3-dioxopyrrolidines with 3-chlorooxindoles, Org. Biomol. Chem., 2020, 18, 1647.

47 J. Guo, Y. Liu, X. Li, X. Liu, L. Lin and X. Feng, Nickel(II)catalyzed enantioselective cyclopropanation of 3-alkenyloxindoles with phenyliodonium ylide via free carbene, Chem. Sci., 2016, 7, 2717.

48 (a) L. Wang, W. Cao, H. Mei, L. Hu and X. Feng, Catalytic Asymmetric Synthesis of Chiral Spiro-cyclopropyl Oxindoles from 3-Alkenyl-oxindoles and Sulfoxonium Ylides, Adv. Synth. Catal., 2018, 360, 4089; (b) For a related metal-free diastereoselective transformation (when using a chiral sulfur ylide in combination with an asymmetric hydrogen bonding catalyst achieved a maximum 39\% ee see: J. W. Kang, X. Li, F. Y. Chen, Y. Luo, S. C. Zhang, B. Kang, C. Peng, X. Tian and B. Han, Protecting groupdirected annulations of tetra-substituted oxindole olefins and sulfur ylides: regio- and chemoselective synthesis of cyclopropane- and dihydrofuran-fused spirooxindoles, RSC Adv., 2019, 9, 12255.

49 C. L. Ladd, D. Sustac Roman and A. B. Charette, SilverPromoted, Palladium-Catalyzed Direct Arylation of Cyclopropanes: Facile Access to Spiro 3,3'-Cyclopropyl Oxindoles, Org. Lett., 2013, 15, 1350.

50 H. Li, X. Yan, J. Zhang, W. Guo, J. Jiang and J. Wang, Enantioselective Synthesis of C-N Axially Chiral N-Aryloxindoles by Asymmetric Rhodium-Catalyzed Dual C-H Activation, Angew. Chem., Int. Ed., 2019, 58, 6732.

$51 \mathrm{~J} . \mathrm{Li}, \mathrm{T}$. Du, G. Zhang and Y. Peng, 3-Bromooxindoles as nucleophiles in asymmetric organocatalytic Mannich reactions with N-Ts-imines, Chem. Commun., 2013, 49, 1330.

52 (a) M. A. Loreto, A. Migliorini, P. A. Tardella and A. Gambacorta, Novel Spiroheterocycles by Aziridination of $\alpha$-methylene- $\gamma$ - and - $\delta$-lactams, Eur. J. Org. Chem., 2007, 2365; (b) I. Ammetto, T. Gasperi, M. A. Lorerto,
A. Migliorini, F. Palmarelli and P. A. Tardella, Synthesis of Functionalized Spiroaziridine-oxindoles from 3-Ylideneoxindoles: An Easy Route to 3-(Aminoalkyl)oxindoles, Eur. J. Org. Chem., 2009, 6189; (c) T. Gasperi, M. A. Loreto, A. Migliorini and C. Ventura, Synthesis of Aziridine- and Oxirane-2-phosphonates Spiro-Fused with Oxindoles, Eur. J. Org. Chem., 2011, 385.

53 (a) Q. L. Wang, T. Cai, J. Zhou, F. Tian, X. Y. Xu and L. X. Wang, An unprecedented base-promoted domino reaction of methyleneindolinones and $\mathrm{N}$-tosyloxycarbamates for the construction of bispirooxindoles and spiroaziridine oxindoles, Chem. Commun., 2015, 51, 10726; (b) Y. Y. Liu, S. W. Duan, R. Zhang, Y. H. Liu, J. R. Chen and W. J. Xiao, Base-catalyzed controllable reaction of 3-ylideneoxindoles with O-Boc hydroxycarbamates for the synthesis of amidoacrylates and spiroaziridine oxindoles, Org. Biomol. Chem., 2016, 14, 5224.

54 M. A. Marsini, J. T. Reeves, J. N. Desrosiers, M. A. Herbage, J. Savoie, Z. Li, K. R. Fandrick, C. A. Sader, B. McKibben, D. A. Gao, et al., Diastereoselective Synthesis of $\alpha$-Quaternary Aziridine-2-carboxylates via AzaCorey-Chaykovsky Aziridination of N-tert-Butanesulfinyl Ketimino Esters, Org. Lett., 2015, 17, 5614.

55 (a) S. Hajra, S. M. Aziz, B. Jana, P. Mahish and D. Das, Synthesis of Chiral Spiro-Aziridine Oxindoles via AzaCorey-Chaykovsky reaction of Isatin Derived N-tertButanesulfinyl Ketimines, Org. Lett., 2016, 18, 532; (b) S. Hajra and A. Biswas, Catalyst-Free Stereocontrolled Formal $[3+2]$-Cycloaddition of $\mathrm{CO}_{2}$ for the Synthesis of Enantiopure Spiro[Indoline-3,5'-Oxazolidine]-2,2'-Diones under Aqueous and Ambient Conditions, Org. Lett., 2020, 22, 4990.

56 J. Chen, X. Wen, Y. Wang, F. Du, L. Cai and Y. Peng, Asymmetric Mannich Reaction of Isatin-Based Ketimines with $\alpha$-Diazomethylphosphonates Catalyzed by Chiral Silver Phosphate, Org. Lett., 2016, 18, 4336.

57 J. Q. Zhao, D. F. Yue, X. M. Zhang, X. Y. Xu and W. C. Yuan, The organocatalytic asymmetric Neber reaction for the enantioselective synthesis of spirooxindole 2H-azirines, Org. Biomol. Chem., 2016, 14, 10946.

58 (a) K. Sharma, L. K. Sharma and R. Jain, Facile Synthesis of Spiro[3h-Indole-3,2'oxirane]-3'-(2-Oxo-2-(Thiophene-2Yl- $(2(1 \mathrm{H})$ Ones and their Antibacterial Activity, Heterocycl. Lett., 2015, 5, 383; (b) M. Montana, F. Correard, O. Khoumeri, M. A. Esteve, T. Terme and P. Vanelle, Synthesis of New Quinoxalines Containing an Oxirane Ring by the TDAE Strategy and in Vitro Evaluation in Neuroblastoma Cell Lines, Molecules, 2014, 19, 14987.

59 S. Monticelli, L. Castoldi, S. Touqeer, M. Miele, E. Urban and V. Pace, Recent Advances in the Synthesis and Reactivity of Spiro-Epoxyoxindoles, Chem. Heterocycl. Compd., 2018, 54, 389.

60 M. M. Lou, H. Wang, L. Song, H. Y. Liu, Z. Q. Li, X. S. Guo, F. G. Zhang and B. Wang, The Epoxidation of Carbonyl Compounds with a Benzyne-Triggered Sulfur Ylide, J. Org. Chem., 2016, 81, 5915. 
61 V. Pace, L. Castoldi, A. D. Mamuye, T. Langer and W. Holzer, Chemoselective Addition of Halomethyllithiums to Functionalised Isatins: A Straightforward Access to Spiro-Epoxyoxindoles, Adv. Synth. Catal., 2016, 358, 172.

62 (a) D. Basavaiah, S. S. Badsara and B. C. Sahu, BaylisHillman Bromides as a Source of 1,3-Dipoles: Sterically Directed Synthesis of Oxindole-Fused Spirooxirane and Spirodihydrofuran Frameworks, Chem. - Eur. J., 2013, 19, 2961; (b) Q. Fu and C. G. Yan, Facile synthesis of functionalized spiro[indoline-3,2'-oxiran]-2-ones by Darzens reaction, Beilstein J. Org. Chem., 2013, 9, 918.

63 B. Cheng, B. Zu, Y. Li, C. Tao, C. Zhang, R. Wang, Y. Li and $\mathrm{H}$. Zhai, Synthesis of $\mathrm{CF}_{3}$-containing spiro-epoxyoxindoles via the Corey-Chaykovsky reaction of $\mathrm{N}$-alkyl isatins with $\mathrm{Ph}_{2} \mathrm{~S}^{+} \mathrm{CH}_{2} \mathrm{CF}_{3} \mathrm{OTF}^{-}$, Org. Biomol. Chem., 2018, 16, 3564.

64 K. Luo, X. Yu, P. Chen, K. He, J. Lin and Y. Jin, Visiblelight-induced aerobic epoxidation in cyclic ether: Synthesis of spiroepoxyoxindole derivatives, Tetrahedron Lett., 2020, 61, 151578.

65 S. Crotti, N. Di Iorio, C. Artusi, A. Mazzanti, P. Righi and G. Bencivenni, Direct Access to Alkylideneoxindoles via Axially Enantioselective Knoevenagel Condensation, Org. Lett., 2019, 21, 3013.

66 V. Schulz, M. Davoust, M. Lemarié, J. F. Lohier, J. S. O. De Santos, P. Metzner and J. F. Brière, Straightforward Stereoselective Synthesis of Spiro-epoxyoxindoles, Org. Lett., 2007, 9, 1745.

67 C. Palumbo, G. Mazzeo, A. Mazziotta, A. Gambacorta, M. A. Loreto, A. Migliorini, S. Superchi, D. Tofani and T. Gasperi, Noncovalent Organocatalysis: A Powerful Tool for the Nucleophilic. Epoxidation of $\alpha$-Ylideneoxindoles, Org. Lett., 2011, 13, 6248.

68 M. Miceli, A. Mazziotta, C. Palumbo, E. Roma, E. Tosi, G. Longhi, S. Abbate, P. Lupattelli, G. Mazzeo and T. Gasperi, Asymmetric Synthesis of Spirooxindoles via Nucleophilic Epoxidation Promoted by Bifunctional Organocatalysis, Molecules, 2018, 23, 438.

69 A. Boucherif, Q.-Q. Yang, Q. Wang, J.-R. Chen, L.-Q. Lu and W.-J. Xiao, Enantio- and Diastereoselective Synthesis of Spiro-epoxyoxindoles, J. Org. Chem., 2014, 79, 3924.

70 Y. Kuang, Y. Lu, Y. Tang, X. Liu, L. Lin and X. Feng, Asymmetic Synthesis of Spiro-epoxyoxindoles by the Catalytic Darzens Reaction of Isatins with Phenacyl Bromides, Org. Lett., 2014, 16, 4244.

71 G.-L. Chai, J.-W. Han and H. N. C. Wong, Asymmetric Darzens Reaction of Isatins with Diazoacetamides Catalyzed by Chiral BINOL-Titanium Complex, J. Org. Chem., 2017, 82, 12647.

72 (a) G. Zhu, G. Bao, Y. Li, W. Sun, J. Li, L. Hong and R. Wang, Efficient Catalytic Kinetic Resolution of Spiroepoxyoxindoles with Concomitant Asymmetric FriedelCrafts Alkylation of Indoles, Angew. Chem., Int. Ed., 2017, 56, 5332; (b) G. Zhu, Y. Li, G. Bao, W. Sun, L. Huang, L. Hong and R. Wang, Catalytic Kinetic Resolution of Spiro-Epoxyoxindoles with 1-Napthols: Switchable
Asymmetric Tandem Dearomatization/Oxa-Michael Reaction and Friedel-Crafts Alkylation of 1-Napthols at the C4 Position, ACS Catal., 2018, 8, 1810.

73 R. Zhou, H. Zhang, J. Liu, R. Liu, W. C. Gao, Y. Qiao and R. Li, Chemoselective $\mathrm{P}\left(\mathrm{NMe}_{2}\right)_{3}$-Mediated Reductive Epoxidation between Two Different Carbonyl Electrophiles: Synthesis of Highly Functionalized Unsymmetrical Epoxides, J. Org. Chem., 2018, 83, 8272.

74 M. Yoshikawa, H. Kamisaki, J. Kunitomo, H. Oki, H. Kokubo, A. Suzuki, T. Ikemoto, K. Nakashima, N. Kamiguchi, A. Harada, et al., Design and synthesis of a novel 2-oxindole scaffold as a highly potent and brainpenetrant phosphodiesterase 10A inhibitor, Bioorg. Med. Chem., 2015, 23, 7138.

75 R. K. Ujjinamatada, S. Samajdar, C. Abbineni, S. Mukeherjee, T. Linnanen and G. Wohlfahrt, Spiro[cyclobutane-1,3'-indolin]-2'-one Derivatives as Bromodomain Inhibitors, PCT Int. Appl WO2016203112A1, 2016.

76 A. Fensome, R. Bender, J. Cohen, M. A. Collins, V. A. Mackner, L. L. Miller, J. W. Ullrich, R. Winneker, J. Wrobel, P. Zhang, et al., New progesterone receptor antagonists: 3,3-disubstituted-5-aryloxindoles, Bioorg. Med. Chem. Lett., 2002, 12, 3487.

77 A. Tahri, S. M. H. Vendeville, T. H. M. Jonckers, P. J.-M. B. Raboisson, L. Hu, S. D. Demin and L. P. Cooy-Mans, RSV Antiviral Compounds, PCT Int. Appl WO2014060411A1, 2014.

78 (a) P. S. Baran and J. M. Richter, Enantioselective Total Syntheses of Welwitindolinone A and Fischerindoles I and G, J. Am. Chem. Soc., 2005, 127, 15394; (b) P. S. Baran, T. J. Maimone and J. M. Richter, Total synthesis of marine natural products without using protecting groups, Nature, 2007, 446, 404; (c) J. M. Richter, Y. Ishihara, T. Masuda, B. W. Whitefield, T. Llamas, A. Pohjakallio and P. S. Baran, Enantiospecific Total Synthesis of the Hapalindoles, Fischerindoles, and Welwitindolinones via a Redox Economic Approach, J. Am. Chem. Soc., 2008, 130, 17938.

79 (a) J. M. Ready, S. E. Reisman, M. Hirata, M. M. Weiss, K. Tamaki, T. V. Ovaska and J. L. Wood, A Mild and Efficient Synthesis of Oxindoles: Progress Towards the Synthesis of Welwitindolinone A Isonitrile, Angew. Chem., Int. Ed., 2004, 43, 1270; (b) S. E. Reisman, J. M. Ready, A. Hasuoka, C. J. Smith and J. L. Wood, Total Synthesis of ( \pm -Welwitindolinone A Isonitrile, J. Am. Chem. Soc., 2006, 128, 1448; (c) S. E. Reisman, J. M. Ready, M. M. Weiss, A. Hasuoka, M. Hirata, K. Tamaki, T. V. Ovaska, C. J. Smith and J. L. Wood, Evolution of a Synthetic Strategy: Total Synthesis of $( \pm)$-Welwitindolinone A Isonitrile, J. Am. Chem. Soc., 2008, 130, 2087.

80 L. E. Overman and D. J. Poon, Asymmetric Heck Reactions via Neutral Intermediates: Enhanced Enantioselectivity with Halide Additives Gives Mechanistic Insights, Angew. Chem., Int. Ed. Engl., 1997, 36, 518.

81 D. Katayev, Y. X. Jia, A. K. Sharma, D. Banerjee, C. Besnard, R. B. Sunoj and E. P. Kündig, Synthesis of 3,3- 
Disubstituted Oxindoles by Palladium-Catalyzed Asymmetric Intramolecular $\alpha$-Arylation of Amides: Reaction Development and Mechanistic Studies, Chem. - Eur. J., 2013, 19, 11916.

82 R. Rocaboy, D. Dailler, F. Zellweger, M. Neuburger, C. Salomé, E. Clot and O. Baudoin, Domino $\mathrm{Pd}^{0}$-Catalyzed $\mathrm{C}\left(\mathrm{sp}^{3}\right)-\mathrm{H}$ Arylation/Electrocyclic Reactions via Benzazetidine Intermediates, Angew. Chem., Int. Ed., 2018, 57, 12131.

83 Though non-stereoselective, Zhang and co-workers discovered an unexpected cascade reaction upon treatment of a spirocyclopropyl oxetane with boron trifluoride diethyl etherate to form a spirocyclobutyl oxindole via a carbocationic intermediate: D. D. Wu, C. M. Huang, Y. H. Wu, H. K. Fun, J. H. Xu and Y. Zhang, Acid-mediated transformation of spirocyclopropyl oxetanes: a facile approach to spirocyclopropyl butenolides and $\gamma$-butyrolactones, $R S C$ Adv., 2013, 3, 7529.

84 J. Q. Chen, Y. L. Wei, G. Q. Xu, Y. M. Liang and P. F. Xu, Intramolecular 1,5-H transfer reaction of aryl iodides through visible-light photoredox catalysis: a concise method for the synthesis of natural product scaffolds, Chem. Commun., 2016, 52, 6455.

85 S. M. Hell, C. F. Meyer, G. Laudadio, A. Misale, M. C. Willis, T. Noël, A. A. Trabanco and V. Gouverneur, Silyl Radical-Mediated Activation of Sulfamoyl Chlorides Enables Direct Access to Aliphatic Sulfonamides from Alkenes, J. Am. Chem. Soc., 2020, 142, 720.

86 L. W. Qi, Y. Yang, Y. Y. Gui, Y. Zhang, F. Chen, F. Tian, L. Peng and L. X. Wang, Asymmetric Synthesis of 3,3'Spirooxindoles Fused with Cyclobutanes through Organocatalytic Formal [2 + 2] Cycloadditionns under H-Bond-Directing Dienamine Activation, Org. Lett., 2014, 16, 6436.

87 K. S. Halskov, F. Kniep, V. H. Lauridsen, E. H. Iversen, B. S. Donslund and K. A. Jørgensen, Organocatalytic Enamine-Activation of Cyclopropanes for Highly Stereoselective Formation of Cyclobutanes, J. Am. Chem. Soc., 2015, 137, 1685.

88 (a) Y. H. Jiang, R. Y. Yang, J. Sun and C. G. Yan, Diastereoselective synthesis of dispiro[indoline-3,1'-cyclobutane-2',3"-indolines] via visible light catalyzed cyclodimerization of 3-phenacylideneoxindoles, Heterocycl. Commun., 2016, 22, 151; (b) L. L. Wu, G. H. Yang, Z. Guan and Y. H. He, Metal-free visible-light-promoted intermolecular $[2+2]$-cycloaddition of 3-ylideneoxindoles, Tetrahedron, 2017, 73, 1854.

89 (a) J. W. Skiles and D. McNeil, Spiro indolinone betalactams, inhibitors of poliovirus and rhinovirus 3C-proteinases, Tetrahedron Lett., 1990, 31, 7277; (b) W. Shi, Z. Jiang, H. He, F. Xiao, F. Lin, Y. Sun, L. Hou, L. Shen, L. Han, M. Zeng, et al., Discovery of 3,3'-Spiro[Azetidine]2-oxo-indoline Derivatives as Fusion Inhibitors for Treatment of RSV Infection, ACS Med. Chem. Lett., 2018, 9, 94.

90 G. S. Singh and P. Luntha, Synthesis and antimicrobial activity of new 1-alkyl/cyclohexyl-3,3-diaryl-1'-methylspiro [azetidine-2,3'-indoline]-2',4-diones, Eur. J. Med. Chem., 2009, 44, 2265.
91 R. Kumar, S. Giri and N. Nizamuddin, Synthesis of some $1^{\prime}$-(substituted phenyl)spiro[indole-3,4'-azetidine]-2(3H), $2^{\prime}$ diones as potential fungicides, J. Agric. Food Chem., 1989, 37, 1094.

92 R. Jain, K. Sharma and D. Kumar, Green Synthesis of 1-(1,2,4-Triazol-4-yl)spiro[azetidine-2,3'-(3H)indole]-2'4' $\left(1^{\prime} \mathrm{H}\right)$ diones as Potential Insecticide Agents, J. Heterocycl. Chem., 2013, 50, 315.

93 C. Sun, X. Lin and S. M. Weinreb, Explorations on the Total Synthesis of the Unusual Marine Alkaloid Chartelline A, J. Org. Chem., 2006, 71, 3159.

94 Ref. 92 and (a) H. Deokar, J. Chaskar and A. Chaskar, Synthesis, Screening And Antimicrobial Activity Of Spiro Indolothiazolidinone, Oxazolidinone And Azetidine Derivatives Of Benzenesulfonyl Chloride, Pharm. Chem. J., 2012, 46, 429; (b) B. V. Subba Reddy, G. Karthik, T. Rajasekaran, A. Antony and B. Sridhar, $\mathrm{Rh}_{2}(\mathrm{OAc})_{4}$ atalyzed substrate selective $[4+2] /[2+2]$ cycloaddition of acylketenes: a highly chemo- and regioselective synthesis of spiro(oxindolyl)oxazinones and $\beta$-lactams, Tetrahedron Lett., 2012, 53, 2396.

95 H. M. Zhang, Z. H. Gao and S. Ye, Bifunctional N-Heterocyclic Carbene-Catayzed Highly Enantioselective Synthesis of Spirocyclic Oxindolo- $\beta$-lactams, Org. Lett., 2014, 16, 3079.

96 (a) J. Xu, S. Yuan, J. Peng, M. Miao, Z. Chen and H. Ren, Enantioselective [2 +2$]$ annulation of simple aldehydes with isatin-derived ketimines via oxidative N-heterocyclic carbene catalysis, Chem. Commun., 2017, 53, 3430. For further insights see: (b) X. Li, R. Duan, Y. Wang, L. B. Qu, Z. Li and D. Wei, Insights into N-Heterocyclic CarbeneCatalyzed Oxidative $\alpha-\mathrm{C}\left(\mathrm{sp}^{3}\right)-\mathrm{H}$ Activation of Aliphatic Aldehydes and Cascade $[2+2]$ Cycloaddition with Ketimines, J. Org. Chem., 2019, 84, 6117.

97 J. H. Jin, J. Zhao, W. L. Yang and W. P. Deng, Asymmetric Synthesis of Spirooxindole $\beta$-lactams via Isothiourea-catalyzed Mannich/lactamization Reaction of Aryl Acetic Acids with Isatin-derived Ketimines, Adv. Synth. Catal., 2019, 361, 1592.

98 S. Periyaraja, P. Shanmugam and A. B. Mandal, A CopperCatalyzed One-Pot, Three-Component Diastereoselective Synthesis of 3-Spiroazetidinimine-2-oxindoles and Their Synthetic Transformation into Fluorescent Conjugated Indolones, Eur. J. Org. Chem., 2014, 954.

99 Throughout this review the stereochemical relationship is, where applicable, defined between the aromatic group of the oxindole and the substituent on the ring.

100 S. Guo, P. Dong, Y. Chen, X. Feng and X. Liu, Chiral Guanidine/Copper Catalyzed Asymmetric Azide-Alkyne Cycloaddition/[2 + 2] Cascade Reaction, Angew. Chem., Int. Ed., 2018, 57, 16852.

101 G. Rainoldi, M. Faltracco, L. Lo Presti, A. Silvani and G. Lesma, Highly diastereoselective entry into chiral spirooxindole-based 4-methyleneazetidines via formal $[2+2]$ annulation reaction, Chem. Commun., 2016, 52, 11575. 
102 G. Rainoldi, M. Faltracco, C. Spatti, A. Silvani and G. Lesma, Organocatalytic Access to Enantioenriched Spirooxindole-Based 4-Methyleneazetidines, Molecules, 2017, 22, 2016.

103 (a) L. Su and M. H. Xu, Asymmetric Reformatsky-Type Reaction of Isatin-Derived N-Sulfinyl Ketimines: Efficient and Practical Synthesis of Enantiopure Chiral 2-Oxoindolinyl- $\beta^{3,3}$-Amino Esters, Synthesis, 2016, 48, 2595; (b) In 2017 Hajra synthesised the same intermediates with high dr: S. Hajra, S. S. Bhosale and A. Hazra, An asymmetric acetate-Mannich reaction of chiral isatin derived ketimines and its applications, Org. Biomol. Chem., 2017, 15, 9217.

104 Q. Tan, X. Wang, Y. Xiong, Z. Zhao, L. Li, P. Tang and M. Zhang, Chiral Amino Alcohol Accelerated and Stereocontrolled Allylboration of Iminoisatins: Highly Efficient Construction of Adjacent Quaternary Stereogenic Centers, Angew. Chem., Int. Ed., 2017, 56, 4829.

105 J. S. Yu, H. Noda and M. Shibasaki, Exploiting $\beta$-Amino Acid Enolates in Direct Catalytic Diastereo- and Enantioselective C-C Bond-Forming Reactions, Chem. Eur. J., 2018, 24, 15796.

106 C. Deutsch, D. Kuhn, T. Ross and L. Burgdorf, 8Substituted 2-Amino-[1,2,4] Triazolo [1,5-A] Pyrazines as SYK Tryrosine Kinase Inhibitors and GCN2 Serin Kinase Inhibitors, PCT Int. Appl WO2013124026A1, 2013.

107 D. D. Wu, M. T. He, Q. Di Liu, W. Wang, J. Zhou, L. Wang, H. K. Fun, J. H. Xu and Y. Zhang, Photoinduced reactions of bicycloalkylidenes with isatin and isoquinolinetrione, Org. Biomol. Chem., 2012, 10, 3626.

108 M. Palomba, E. Scarcella, L. Sancineto, L. Bagnoli, C. Santi and F. Marini, Synthesis of Spirooxindole Oxetanes Through a Domino Reaction of 3-Hydroxyoxindoles and Phenyl Vinyl Selenone, Eur. J. Org. Chem., 2019, 5396.

109 P. R. Gentry, T. M. Bridges, A. Lamsal, P. N. Vinson, E. Smith, P. Chase, P. S. Hodder, J. L. Engers, C. M. Niswender, J. Scott Daniels, et al., Discovery of ML326: The first sub-micromolar, selective M5 PAM, Bioorg. Med. Chem. Lett., 2013, 23, 2996.

110 X. Hao, X. Liu, W. Li, F. Tan, Y. Chu, X. Zhao, L. Lin and $\mathrm{X}$. Feng, Chiral Lewis Acid Catalyzed Asymmetric Cycloadditions of Disubstituted Ketenes for the Synthesis of $\beta$-Lactones and $\delta$-Lactones, Org. Lett., 2014, 16, 134.

111 E. Hayashi, M. Isogai, Y. Kagawa, N. Takayanagi and S. Yamada, Neosurugatoxin, a Specific Antagonist of Nicotinic Acetylcholine Receptors, J. Neurochem., 1984, 42, 1491.

112 Z. Bian, C. C. Marvin and S. F. Martin, Enantioselective Total Synthesis of (-)-Citrinadin A and Revision of Its Stereochemical Structure, J. Am. Chem. Soc., 2013, 135, 10886.

113 (a) D. A. Mundal and R. Sarpong, Synthetic Studies toward the Citrinadin A and B Core Architecture, Org. Lett., 2013, 15, 4952; (b) E. V. Mercado-Marin, P. Garcia-Reynaga, S. Romminger, E. F. Pimenta, D. K. Romney,
M. W. Lodewyk, D. E. Williams, R. J. Andersen, S. J. Miller, D. J. Tantillo, et al., Total synthesis and isolation of citrinalin and cylopiamine congeners, Nature, 2014, 509, 318; (c) N. S. Simpkins, I. Pavlakos, M. D. Weller and L. Male, The cascade radical cyclisation approach to prenylated alkaloids: synthesis of stephacidin A and notoamide B, Org. Biomol. Chem., 2013, 11, 4957; (d) B. Zhang, W. Zheng, X. Wang, D. Sun and C. Li, Total Synthesis of Notoamides F, I, and R and Sclerotiamide, Angew. Chem., Int. Ed., 2016, 55, 10435.

114 A. E. Fraley, K. Caddell Haatveit, Y. Ye, S. P. Kelly, S. A. Newmister, F. Yu, R. M. Williams, J. L. Smith, K. N. Houk and D. H. Sherman, Molecular Basis for Spirocycle Formation in the Paraherquamide Biosynthetic Pathway, J. Am. Chem. Soc., 2020, 142, 2244.

115 K. Kong, J. A. Enquist, M. E. McCallum, G. M. Smith, T. Matsumaru, E. Menhaji-Klotz and J. L. Wood, An Enantioselective Total Synthesis and Stereochemical Revision of (+)-Citrinadin B, J. Am. Chem. Soc., 2013, 135, 10890.

116 B. M. Trost, D. A. Bringley, T. Zhang and N. Cramer, Rapid Access to Spirocyclic Oxindole Alkaloids: Application of the Asymmetric Palladium-Catalyzed [3 + 2] Trimethylenemethane Cycloaddition, J. Am. Chem. Soc., 2013, 135, 16720.

117 M. E. Hinze, J. L. Daughtry and C. A. Lewis, Access to the Surugatoxin Alkaloids: Chemo-, Regio-, and Stereoselective Oxindole Annulation, J. Org. Chem., 2015, 80, 11258.

118 L. Shi, L. Li, J. Wang, B. Huang, K. Zeng, H. Jin, Q. Zhang and Y. Jia, Total synthesis of natural spiro-trisindole enantiomers similisines A, B and their stereoisomers, Tetrahedron Lett., 2017, 58, 1934.

119 For a review see: Z. Chen, Z. Chen, W. Du and Y. Chen, Transformations of Modified Morita-Baylis-Hillman Adducts from Isatins Catalyzed by Lewis Bases, Chem. Rec., 2020, 20, 541.

120 For selected significant prior art in this area see: (a) B. M. Trost, N. Cramer and S. M. Silverman, Enantioselective Construction of Spirocyclic Oxindolic Cyclopentanes by Palladium-Catalyzed Trimethylenemethane[3 + 2]-Cycloaddition, J. Am. Chem. Soc., 2007, 129, 12396; (b) J. Peng, X. Huang, L. Jiang, H. L. Cui and Y. C. Chen, Tertiary Amine-Catalyzed Chemoselective and Asymmetric $[3+2]$ Annulation of Morita-Baylis-Hillman Carbonates of Isatins with Propargyl Sulfones, Org. Lett., 2011, 13, 4584; (c) B. Tan, N. R. Candeias and C. F. Barbas, Core-StructureMotivated Design of a Phosphine-Catalyzed $[3+2]$ Cycloaddition Reaction: Enantioselective Syntheses of Spirocyclopenteneoxindoles, J. Am. Chem. Soc., 2011, 133, 4672.

121 Y. Chen, B. D. Cui, Y. Wang, W. Y. Han, N. W. Wan, M. Bai, W. C. Yuan and Y. Z. Chen, Asymmetric $[3+2]$ Cycloaddition Reaction of Isatin-Derived $\mathrm{MBH}$ Carbonates with 3-Methyleneoxindoles: Enantioselective Synthesis of 3,3'-Cyclopentenyldispirooxindoles Incorporating Two 
Adjacent Quaternary Spirostereocenters, J. Org. Chem., 2018, 83, 10465.

122 Y. Chen, B. D. Cui, M. Bai, W. Y. Han, N. W. Wan and Y. Z. Chen, Synthesis of chiral spiro-cyclopentene/cyclopentadiene-oxindoles through an asymmetric $[3+2]$ cycloaddition of isatin-derived $\mathrm{MBH}$ carbonates and $\beta, \gamma$-unsaturated $\alpha$-keto esters, Tetrahedron, 2019, 75, 2971.

123 For related work see: (a) J. Peng, G. Y. Ran, W. Du and Y. C. Chen, Tertiary-Amine-Catalyzed Asymmetric [3 + 2] Annulations. of Morita-Baylis-Hillman Carbonates of Isatins with Nitroolefins to Construct Spirooxindoles, Synthesis, 2015, 47, 2538; (b) G. Y. Ran, P. Wang, W. Du and Y. C. Chen, $\alpha$-Regioselective [3+2] annulations with Morita-Baylis-Hillman carbonates of isatins and 2-nitro1,3-enynes, Org. Chem. Front., 2016, 3, 861; (c) G. Zhan, M.-L. Shi, Q. He, W.-J. Lin, Q. Ouyang, W. Du and Y.-C. Chen, Catalyst-Controlled Switch in Chemo- and Diastereoselectivities: Annulations of Morita-BaylisHillman Carbonates from Isatins, Angew. Chem., Int. Ed., 2016, 55, 2147; (d) Z. H. Wang, C. W. Lei, X. Y. Zhang, Y. You, J. Q. Zhao and W. C. Yuan, Asymmetric domino 1,6-addition/annulation reaction of 3-cyano-4-alkenyl-2Hchromen-2-ones with isatin-derived $\mathrm{MBH}$ cyclopentenylspirooxindoles bearing $2 \mathrm{H}$-chromen-2-ones, Org. Chem. Front., 2019, 6, 3342; (e) J. Q. Zhao, L. Yang, X. J. Zhou, Y. You, Z. H. Wang, M. Q. Zhou, X. M. Zhang, X. Y. Xu and W. C. Yuan, Organocatalyzed Dearomative Cycloaddition of 2-Nitrobenzofurans and Isatin-Derived Morita-BaylisHillman Carbonates: Highly Stereoselective Construction of Cyclopenta[b]benzofuran Scaffolds, Org. Lett., 2019, 21, 660.

124 F. Zhong, X. Han, Y. Wang and Y. Lu, Highly Enantioselective $[3+2]$ Annulation of Morita-BaylisHillman Adducts Mediated by L-Threonine-Derived Phosphines: Synthesis of 3-Spirocyclopentene-2-oxindoles having Two Contiguous Quaternary Centers, Angew. Chem., Int. Ed., 2011, 50, 7837.

125 Work by Miao and co-workers on phosphorus promoted $[3+2]$ cycloaddition of alkynes and 3-methylene oxindoles with moderate enantioselectivity achieved: (a) J. Zhang, C. Cheng, D. Wang and Z. Miao, Regio- and. Diastereoselective Construction of Spirocyclopenteneoxindoles through Phosphine-Catalyzed $[3+2]$ Annulation of Methyleneindolinone with Alkynoate Derivatives, J. Org. Chem., 2017, 82, 10121. For related non-stereoselective activation by phosphorus catalysts see: (b) L. Zhang, H. Lu, G.-Q. Xu, Z.-Y. Wang and P.-F. Xu, $\mathrm{PPh}_{3}$ Mediated Reductive Annulation Reaction between Isatins and Electron Deficient Dienes to Construct Spirooxindole Compounds, J. Org. Chem., 2017, 82, 5782. Also see: (c) D. B. Ramachary, C. Venkaiah and P. M. Krishna, Stereoselective Synthesis of Five-Membered Spirooxindoles through Tomita Zipper Cyclization, Org. Lett., 2013, 15, 4714; (d) C. Gomez, M. Gicquel, J. C. Carry, L. Schio, P. Retailleau, A. Voituriez and
A. Marinetti, Phosphine-Catalyzed Synthesis of 3,3Spirocyclopenteneoxindoles from g-Substituted Allenoates: Systematic Studies and Targeted Applications, J. Org. Chem., 2013, 78, 1488.

126 W. L. Chan, X. Tang, F. Zhang, G. Quek, G. J. Mei and Y. Lu, Phosphine-Catalyzed $(3+2)$ Annulation of Isoindigos with Allenes: Enantioselective Formation of Two Vicinal Quaternary Stereogenic Centers, Angew. Chem., Int. Ed., 2019, 58, 6260.

127 J. Zhang, W.-L. Chan, L. Chen, N. Ullah and Y. Lu, Creation of bispiro[pyrazoline-3,3'-oxindoles] via a phosphine-catalyzed enantioselective $[3+2]$ annulation of the Morita-Baylis-Hillman carbonates with pyrazoloneyldiene, Org. Chem. Front., 2019, 6, 2210.

$128 \mathrm{~S} . \mathrm{Su}, \mathrm{C}$. Li, X. Jia and J. Li, Isocyanide-Based Multicomponent Reactions: Concise Synthesis of Spirocyclic Oxindoles with Molecular Complexity by Using a $[1,5]$-Hydrogen Shift as the Key Step, Chem. - Eur. J., 2014, 20, 5905.

129 B. Tan, N. R. Candeias and C. F. Barbas, Construction of bispirooxindoles containing three quaternary stereocentres in a cascade using a single multifunctional organocatalyst, Nat. Chem., 2011, 3, 473.

130 (a) X. Li, Y. M. Li, F. Z. Peng, S. T. Wu, Z. Q. Li, Z. W. Sun, H. Bin Zhang and Z. H. Shao, Highly Enantioselective One-Pot Synthesis of Spirocyclopentaneoxindoles Containing the Oxime Group by Organocatalyzed Michael Addition/ISOC/Fragmentation Sequence, Org. Lett., 2011, 13, 6160; (b) K. Albertshofer, K. E. Anderson and C. F. Barbas, Assembly of Spirooxindole Derivatives via Organocatalytic Iminium-Enamine Cascade Reactions, Org. Lett., 2012, 14, 5968; (c) W. Sun, G. Zhu, C. Wu, L. Hong and R. Wang, An Organocatalytic Cascade Strategy for the Enantioselective Construction of Spirocyclopentane Bioxindoles Containing Three Contiguous Stereocenters and Two Spiro Quaternary Centers, Chem. - Eur. J., 2012, 18, 6737; (d) W. Sun, G. Zhu, C. Wu, L. Hong and R. Wang, 'Organo-Metal' Synergistic Catalysis: The $1+1>2$ Effect for the Construction of Spirocyclopentane oxindoles, Chem. Eur. J., 2012, 18, 13959; (e) J. Sun, Y. J. Xie and C. G. Yan, Construction of Dispirocyclopentanebisoxindoles via Self-Domino Michael-Aldol Reactions of 3-Phenacylideneoxindoles, J. Org. Chem., 2013, 78, 8354; (f) W. Sun, L. Hong, G. Zhu, Z. Wang, X. Wei, J. Ni and R. Wang, An Organocatalytic Michael-Michael Cascade. for the Enantioselective Construction of Spirocyclopentane Bioxindoles: Control of Four Contiguous Stereocenters, Org. Lett., 2014, 16, 544; (g) L. Z. Ding, T. S. Zhong, H. Wu and Y. M. Wang, Highly Enantioselective Construction of Spirocyclopentaneoxindoles Containing Four Consecutive Stereocenters. through an Organocatalytic IminiumEnamine Cascade Reaction, Eur. J. Org. Chem., 2014, 5139; (h) J. Zhou, Q. L. Wang, L. Peng, F. Tian, X. Y. Xu and L. X. Wang, An organocatalytic domino Michael-alkylation reaction: highly enantioselective construction of spiro- 
cyclopentaneoxindoles and tetronic acid scaffolds, Chem. Commun., 2014, 50, 14601; (i) K. Suman and S. Thennarasu, Base catalysed domino and self-domino Michael-Aldol reactions: one-pot synthesis of dispirocyclopentaneoxindoles containing multiple chiral stereocenters, $R S C$ Adv., 2015, 5, 23291; (j) B. L. Zhao and D. M. Du, Organocatalytic cascade Michael/Michael reaction for the asymmetric synthesis of spirooxindoles containing five contiguous stereocenters, Chem. Commun., 2016, 52, 6162; (k) Y. Du, J. Li, K. Chen, C. Wu, Y. Zhou and H. Liu, Construction of highly enantioenriched spirocyclopetaneoxindoles containing four consecutive stereocenters via thiourea-catalyzed asymmetric Michael-Henry cascade reactions, Beilstein J. Org. Chem., 2017, 13, 1342; (l) R.-Y. Yang, J. Sun, G. Jin and C.-G. Yan, Synthesis of functionalized dispiro[indoline-3,1'-cyclopentane-3',3"-indolines] via cyclodimerization of 3-phenacylideneoxindolines with benzoylhydrazides and arylhydrazines, Mol. Diversity, 2018, 22, 21; (m) B. L. Zhao, Y. Lin and D. M. Du, Enantioselective Construction of Bispirooxindoles via Squaramide-Catalysed Cascade Michael/Cyclization Reaction, Adv. Synth. Catal., 2019, 361, 3387; (n) Y. Lin, B.-L. Zhao and D.-M. Du, Bifunctional Squaramide-Catalyzed Asymmetric $[3+2]$ Cyclization of 2-(1-Methyl-2-oxoindolin-3-yl)malonitriles with Unsaturated Pyrazolones To Construct SpirooxindoleFused Spiropyrazolones, J. Org. Chem., 2019, 84, 10209; (o) S. Xu, X. Liu, X. Zuo, G. Zhou, Y. Gong, X. Liu and Y. Zhou, Oxindole-chromones C3 Synthons Directed Stereocontrolled Construction of Five Contiguous Stereocenters on Spiro[tetrahydrocyclopenta[b]chromanone-oxindole]s, Adv. Synth. Catal., 2019, 361, 5328; ( $p$ ) S. S. Vagh, P. Karanam, C. Liao, T. Lin, Y. Liou, A. Edukondalu, Y. Chen and W. Lin, Enantioselective Construction of Spirooxindole-Fused Cyclopenta[c] chromen-4-ones Bearing Five Contiguous Stereocenters via a Stepwise $(3+2)$ Cycloaddition, Adv. Synth. Catal., 2020, $362,1679$.

131 (a) A. Noole, K. Ilmarinen, I. Järving, M. Lopp and T. Kanger, Asymmetric Synthesis of Congested Spiro-cyclopentaneoxindoles via an Organocatalytic Cascade Reaction, J. Org. Chem., 2013, 78, 8117. Also see for 5- and 6-membered rings: $(b)$ M. Monari, E. Montroni, A. Nitti, M. Lombardo, C. Trombini and A. Quintavalla, Highly Stereoselective $[4+2]$ and $[3+2]$ Spiroannulations of 2- $(2-$ Oxoindolin-3-ylidene)acetic Esters Catalyzed by Bifunctional Thioureas, Chem. - Eur. J., 2015, 21, 11038.

132 L. Deiana, Y. Jiang, C. Palo-Nieto, S. Afewerki, C. A. Incerti-Pradillos, O. Verho, C. W. Tai, E. V. Johnston and A. Cõrdova, Combined Heterogeneous Metal/Chiral Amine: Multiple Relay Catalysis for Versatile Eco-Friendly Synthesis, Angew. Chem., Int. Ed., 2014, 53, 3447.

133 (a) F. Shi, H. H. Zhang, X. X. Sun, J. Liang, T. Fan and S. J. Tu, Organocatalytic Asymmetric Cascade Reactions of 7-Vinylindoles: Diastereo- and Enantioselective Synthesis of C7-Functionalized Indoles, Chem. - Eur. J., 2015, 21, 3465; (b) T. Fan, H. H. Zhang, C. Li, Y. Shen and F. Shi,
The Application of N-Protected 3-Vinylindoles in Chiral Phosphoric Acid-Catalyzed $[3+2]$ Cyclization with 3-Indolylmethanols: Monoactivation of the Catalyst to Vinyliminium, Adv. Synth. Catal., 2016, 358, 2017.

134 J. Q. Zhang, N. K. Li, S. J. Yin, B. B. Sun, W. T. Fan and X. W. Wang, Chiral N-Heterocyclic Carbene-Catalyzed Asymmetric Michael-Intramolecular Aldol-Lactonization Cascade for Enantioselective Construction of $\beta$-Propiolactone-Fused Spiro[cyclopentane-oxindoles], $A d v$. Synth. Catal., 2017, 359, 1541.

135 For earlier work using NHC catalysis see: A. Patra, A. Bhunia, S. R. Yetra, R. G. Gonnade and A. T. Biju, Diastereoselective synthesis of cyclopentanone-fused spirooxindoles by N-heterocyclic carbene-catalyzed homoenolate annulation with isatildenes, Org. Chem. Front., 2015, 2,1584 .

136 L. Wang, S. Li, M. Blümel, R. Puttreddy, A. Peuronen, K. Rissanen and D. Enders, Switchable Access to Different Spirocyclopentane Oxindoles by N-Heterocyclic Carbene Catalyzed Reactions of Isatin-Derived Enals and N-Sulfonyl Ketimines, Angew. Chem., Int. Ed., 2017, 56, 8516.

137 J. Zhang, D. Cao, H. Wang, C. Zheng, G. Zhao and Y. Shang, Enantioselective Construction of Spirocyclic Oxindoles via Tandem Michael/Michael Reactions Catalyzed by Multifunctional Quaternary Phosphonium Salt, J. Org. Chem., 2016, 81, 10558.

138 Q. Jin, C. Zheng, G. Zhao and G. Zou, Bifunctional Quaternary Ammonium Salts Catalyzed Stereoselective Conjugate Addition of Oxindoles to Electron-Deficient $\beta$-Haloalkanes, J. Org. Chem., 2017, 82, 4840.

139 (a) G. M. Dubowchik, C. M. Conway and A. W. Xin, Blocking the CGRP Pathway for Acute and Preventive Treatment of Migraine: The Evolution of Success, J. Med. Chem., 2020, 63, 6600; (b) B. M. Crowley, C. A. Stump, D. N. Nguyen, C. M. Potteiger, M. A. McWherter, D. V. Paone, A. G. Quigley, J. G. Bruno, D. Cui, J. C. Culberson, et al., Novel oxazolidinone calcitonin gene-related (CGRP) receptor antagonists for the acute treatment of migraine, Bioorg. Med. Chem. Lett., 2015, 25, 4777.

140 B. Xiang, K. M. Belyk, R. A. Reamer and N. Yasuda, Discovery and Application of Doubly Quaternized Cinchona-Alkaloid-Based Phase-Transfer Catalysts, Angew. Chem., Int. Ed., 2014, 53, 8375.

141 C. Q. He, A. Simon, Y.-H. Lam, A. P. J. Brunskill, N. Yasuda, J. Tan, A. M. Hyde, E. C. Sherer and K. N. Houk, Model for the Enantioselectivity of Asymmetric Intramolecular Alkylations by BisQuaternized Cinchona Alkaloid-Derived Catalysts, J. Org. Chem., 2017, 82, 8645.

142 J. A. Daponte, Y. Guo, R. T. Ruck and J. E. Hein, Using an Automated Monitoring Platform for Investigations of Biphasic Reactions, ACS Catal., 2019, 9, 11484.

143 X. Zhao, X. Liu, Q. Xiong, H. Mei, B. Ma, L. Lin and $\mathrm{X}$. Feng, The asymmetric synthesis of polycyclic 3-spiroox- 
indole alkaloids via the cascade reaction of 2-isocyanoethylindoles, Chem. Commun., 2015, 51, 16076.

144 A. A. Cobo, B. M. Armstrong, J. C. Fettinger and A. K. Franz, Catalytic Asymmetric Synthesis of Cyclopentene-spirooxindoles Bearing Vinylsilanes Capable of Further Transformations, Org. Lett., 2019, 21, 8196.

145 (a) J. A. Xiao, X. L. Cheng, Y. C. Li, Y. M. He, J. L. Li, Z. P. Liu, P. J. Xia, W. Su and H. Yang, Palladium-catalysed ring-opening $[3+2]$-annulation of spirovinylcyclopropyl oxindole to diastereoselectively access spirooxindoles, Org. Biomol. Chem., 2019, 17, 103. For metal-free approach using cyclopropanes see: (b) D. Pan, C. Mou, N. Zan, Y. Lv, B. A. Song, Y. R. Chi and Z. Jin, NaOH-Promoted Chemoselective Cascade Cyclization of Cyclopropyl Esters with Unsaturated Imines: Access to Bioactive Cyclopenta [c]pyridine derivatives, Org. Lett., 2019, 21, 6624. For Mg catalysed approach: (c) K. Singh, S. Pramanik, T. A. Hamlin, B. Mondal, D. Das and J. Saha, Lewis acid catalyzed annulation of spirocyclic donor-acceptor cyclopropanes with exo-heterocyclic oleifns: access to highly functionalized bis-spirocyclopentane oxindole frameworks, Chem. Commun., 2019, 55, 7069.

146 M. Meazza and R. Rios, Synergistic Catalysis: Enantioselective Ring Expansion of Vinyl Cyclopropanes Combining Four Catalytic Cycles for the Synthesis of Highly Substituted Spirocyclopentanes Bearing up to Four Stereocenters, Chem. - Eur. J., 2016, 22, 9923.

147 For examples see: (a) J. N. Desrosiers, L. Hie, S. Biswas, O. V. Zatolochnaya, S. Rodriguez, H. Lee, N. Grinberg, N. Haddad, N. K. Yee, N. K. Garg, et al., Construction of Quaternary Stereocenters by Nickel-Catalyzed Heck Cyclization Reactions, Angew. Chem., Int. Ed., 2016, 55, 11921; (b) W. Ji, Y. A. Liu and X. Liao, Transition-MetalFree Synthesis of N-Hydroxy Oxindoles by an Aza-NazarovType Reaction Involving Azaoxyallyl Cations, Angew. Chem., Int. Ed., 2016, 55, 13286; (c) W. Kong, Q. Wang and J. Zhu, Water as a Hydride Source in Palladium-Catalyzed Enantioselective Reductive Heck Reactions, Angew. Chem., Int. Ed., 2017, 56, 3987.

148 S. Afewerki, G. Ma, I. Ibrahem, L. Liu, J. Sun and A. Córdova, Highly Enantioselective Control of Dynamic Cascade Transformations by Dual Catalysis: Asymmetric Synthesis of Polysubstituted Spirocyclic Oxindoles, ACS Catal., 2015, 5, 1266.

149 (a) B. M. Trost, D. Zell, C. Hohn, G. Mata and A. Maruniak, Enantio- and Diastereoselective Synthesis of Chiral Allenes by Palladium-Catalyzed Asymmetric [3 + 2] Cycloaddition Reactions, Angew. Chem., Int. Ed., 2018, 57, 12916; (b) B. M. Trost, Y. Wang and C.-I. (Joey) Hung, Use of $\alpha$-trifluoromethyl carbanions for palladium-catalysed asymmetric cycloadditions, Nat. Chem., 2020, 12, 294.

150 P. Drouhin, T. E. Hurst, A. C. Whitwood and R. J. K. Taylor, Copper-Mediated Construction of Spirocyclic Bis-oxindoles via a Double C-H, Ar-H Coupling Process, Org. Lett., 2014, 16, 4900.
151 A. Wetzel, J. Bergman, P. Brandt, M. Larhed and J. Branalt, Regio- and Stereoselective Synthesis of Functionalized Cyclopentene Derivatives via MizorokiHeck Reactions, Org. Lett., 2017, 19, 1602.

152 T. Roy, P. Brandt, A. Wetzel, J. Bergman, J. Brånalt, J. Sävmarker and M. Larhed, Selective Synthesis of Spirooxindoles by an Intramolecular Heck-Mizoroki Reaction, Org. Lett., 2017, 19, 2738.

153 (a) M. Pérez-Gómez, S. Hernández-Ponte, D. Bautista and J. A. García-López, Synthesis of spiro-oxindoles through Pd-catalyzed remote $\mathrm{C}-\mathrm{H}$ alkylation using $\alpha$-diazocarbonyl compounds, Chem. Commun., 2017, 53, 2842. Also see: (b) X. Liu, X. Ma, Y. Huang and Z. Gu, Pd-Catalyzed HeckType Cascade Reactions with N-Tosyl Hydrazones: An Efficient Way to Alkenes via in Situ Generated Alkylpalladium, Org. Lett., 2013, 15, 4814; (c) C. Shao, Z. Wu, X. Ji, B. Zhou and Y. Zhang, An approach to spirooxindoles via palladium-catalyzed remote $\mathrm{C}-\mathrm{H}$ activation and dual alkylation with $\mathrm{CH}_{2} \mathrm{Br}_{2}$, Chem. Commun., 2017, 53, 10429.

154 (a) J. R. Frost, S. M. Huber, S. Breitenlechner, C. Bannwarth and T. Bach, Enantiotopos-Selective C-H Oxygenation Catalyzed by a Supramolecular Ruthenium Complex, Angew. Chem., Int. Ed., 2015, 54, 691; (b) B. Qiu, D. Xu, Q. Sun, J. Lin and W. Sun, Manganese-Catalyzed Asymmetric Oxidation of Methylene $\mathrm{C}-\mathrm{H}$ of Spirocyclic Oxindoles and Dihydroquinolinones with Hydrogen Peroxide, Org. Lett., 2019, 21, 618.

155 (a) M. J. James, P. O'Brien, R. J. K. Taylor and W. P. Unsworth, Selective Synthesis of Six Products from a Single Indolyl $\alpha$-Diazocarbonyl Precursor, Angew. Chem., Int. Ed., 2016, 55, 9671. For a related reaction in total synthesis of spirobacillenes A and B see: $(b)$ H. Yang, J. Feng and Y. Tang, Biomimetic total syntheses of spirobacillenes A and B, Chem. Commun., 2013, 49, 6442.

156 R. Paniagua-Pérez, E. Madrigal-Bujaidar, D. Molina-Jasso, S. Reyes-Cadena, I. Álvarez-González, L. Sánchez-Chapul and J. Pérez-Gallaga, Antigenotoxic, Antioxidant and Lymphocyte Induction Effects Produced by Pteropodine, Basic Clin. Pharmacol. Toxicol., 2009, 104, 222.

157 (a) K. Ding, Y. Lu, Z. Nikolovska-Coleska, S. Qiu, Y. Ding, W. Gao, J. Stuckey, K. Krajewski, P. P. Roller, Y. Tomita, et al., Structure-Based Design of Potent Non-Peptide MDM2 Inhibitors, J. Am. Chem. Soc., 2005, 127, 10130; (b) Y. Zhao, S. Yu, W. Sun, L. Liu, J. Lu, D. McEachern, S. Shargary, D. Bernard, X. Li, T. Zhao, et al., A Potent Small-Molecule Inhibitor of the MDM2-p53 Interaction (MI-888) Achieved Complete and Durable Tumor Regression in Mice, J. Med. Chem., 2013, 56, 5553; (c) Y. Zhao, L. Liu, W. Sun, J. Lu, D. McEachern, X. Li, S. Yu, D. Bernard, P. Ochsenbein, V. Ferey, et al., Diastereomeric Spirooxindoles as Highly Potent and Efficacious MDM2 Inhibitors, J. Am. Chem. Soc., 2013, 135, 7223; (d) A. K. Gupta, M. Bharadwaj, A. Kumar and R. Mehrotra, Spiro-oxindoles as a Promising Class of Small Molecule Inhibitors of p53-MDM2 Interaction 
Useful in Targeted Cancer Therapy, Top. Curr. Chem., 2017, 375, 3.

158 (a) A. Kumar, G. Gupta, A. K. Bishnoi, R. Saxena, K. S. Saini, R. Konwar, S. Kumar and A. Dwivedi, Design and synthesis of new bioisosteres of spirooxindoles (MI-63/219) as anti-breast cancer agents, Bioorg. Med. Chem., 2015, 23, 839; (b) A. Gollner, D. Rudolph, H. Arnhof, M. Bauer, S. M. Blake, G. Boehmelt, X. L. Cockroft, G. Dahmann, P. Ettmayer, T. Gerstberger, et al., Discovery of Novel Spiro[3H-indole-3,2'-pyrrolidin]-2 (1H)-one Compounds as Chemically Stable and Orally Active Inhibitors of the MDM2-p53 Interaction, J. Med. Chem., 2016, 59, 10147; (c) A. Aguilar, J. Lu, L. Liu, D. Du, D. Bernard, D. McEachern, S. Przybranowski, X. Li, R. Luo, B. Wen, et al., Discovery of $4-\left(\left(3^{\prime} \mathrm{R}, 4^{\prime} \mathrm{S}, 5^{\prime} \mathrm{R},\right)-6^{\prime \prime}-\right.$ Chloro-4'-(3-chloro-2-fluorophenyl)-1'ethyl-2"-oxodispiro[cyclohexane-1,2'-pyrrolidine-3',3"-indoline]-5'-carboxamido)bicyclo[2.2.2] octane-1-carboxylic Acid (AA-115/APG-115): A Potent and Orally Active Murine Double Minute 2 (MDM2) Inhibitor in Clinical Development, J. Med. Chem., 2017, 60, 2819; (d) A. Barakat, M. S. Islam, H. M. Ghawas, A. M. Al-Majid, F. F. El-Senduny, F. A. Badria, Y. A. M. M. Elshaier and H. A. Ghabbour, Design and synthesis of new substituted spirooxindoles as potential inhibitors of the MDM2-p53 interaction, Bioorg. Chem., 2019, 86, 598.

159 (a) Y. Li, J. Yang, A. Aguilar, D. McEachern, S. Przybranowski, L. Liu, C. Y. Yang, M. Wang, X. Han and S. Wang, Discovery of MD-224 as a First-in-Class, Highly Potent, and Efficacious Proteolysis Targeting Chimera Murine Double Minute 2 Degrader Capable of Achieving Complete and Durable Tumor Regression, J. Med. Chem., 2019, 62, 448; (b) R. P. Wurz and V. J. Cee, Targeted Degradation of MDM2 as a New Approach to Improve the Efficacy of MDM2-p53 Inhibitors, J. Med. Chem., 2019, 62, 445.

160 J. Yang, Y. Li, A. Aguilar, Z. Liu, C. Y. Yang and S. Wang, Simple Structural Modifications Converting a Bona fide MDM2 PROTAC Degrader into a Molecular Glue Molecule: A Cautionary Tale in the Design of PROTAC Degraders, J. Med. Chem., 2019, 62, 9471.

161 Y. Arun, G. Bhaskar, C. Balachandran, S. Ignacimuthu and P. T. Perumal, Facile one-pot synthesis of novel dispirooxindole-pyrrolidine derivatives and their antimicrobial and anticancer activity against A549 human lung adenocarcinoma cancer cell line, Bioorg. Med. Chem. Lett., 2013, 23, 1839.

162 I. V. Efremov, F. F. Vajdos, K. A. Borzilleri, S. Capetta, H. Chen, P. H. Dorff, J. K. Dutra, S. W. Goldstein, M. Mansour, A. McColl, et al., Discovery and Optimization of a Novel Spiropyrrolidine Inhibitor of $\beta$-Secretase (BACE1) through Fragment-Based Drug Design, J. Med. Chem., 2012, 55, 9069.

163 R. Murugan, S. Anbazhagan and S. Sriman Narayanan, Synthesis and in vivo antidiabetic activity of novel dispiropyrrolidines through $[3+2]$ cycloaddition reactions with thiazolidinedione and rhodanine derivatives, Eur. J. Med. Chem., 2009, 44, 3272.

164 K. Hagiwara, T. Murakami, G. Xue, Y. Shimizu, E. Takeda, Y. Hashimoto, K. Honda, Y. Kondoh, H. Osada, Y. Tsunetsugu-Yokota, et al., Identification of a novel Vprbinding compound that inhibits HIV-1 multiplication in macrophages by chemical array, Biochem. Biophys. Res. Commun., 2010, 403, 40.

165 S. V. Karthikeyan, B. D. Bala, V. P. A. Raja, S. Perumal, P. Yogeeswari and D. Sriram, A highly atom economic, chemo-, regio- and stereoselective synthesis and evaluation of spiro-pyrrolothiazoles as antitubercular agents, Bioorg. Med. Chem. Lett., 2010, 20, 350.

166 (a) C. Marti and E. M. Carreira, Construction of Spiro[pyrrolidine-3,3'-oxindoles] - Recent Applications to the Synthesis of Oxindole Alkaloids, Eur. J. Org. Chem., 2003, 2209; (b) C. V. Galliford and K. A. Scheidt, PyrrolidinylSpirooxindole Natural Products as Inspirations for the Development of Potential Therapeutic Agents, Angew. Chem., Int. Ed., 2007, 46, 8748.

167 (a) T. Mukaiyama, K. Ogata, I. Sato and Y. Hayashi, Asymmetric Organocatalyzed Michael Addition of Nitromethane to a 2-Oxoindoline-3-ylidene Acetaldehyde and the Three One-Pot Sequential Synthesis of (-)-Horsfiline and (-)-Coerulescine, Chem. - Eur. J., 2014, 20, 13583; (b) S. De, M. K. Das, S. Bhunia and A. Bisai, Unified Approach to the Spiro(pyrrolidinyl-oxindole) and Hexahydropyrrolo[2,3-b]indole Alkaloids: Total Syntheses of Pseudophrynamines 270 and 272A, Org. Lett., 2015, 17, 5922.

168 (a) S. G. Wang, Z. L. Xia, R. Q. Xu, X. J. Liu, C. Zheng and S. L. You, Construction of Chiral Tetrahydro- $\beta$-Carbolines: Asymmetric Pictet-Spengler Reaction of Indolyl Dihydropyridines, Angew. Chem., Int. Ed., 2017, 56, 7440; (b) V. Srinivasulu, P. Schilf, S. Ibrahim, M. A. Khanfar, S. M. Sieburth, H. Omar, A. Sebastian, R. A. AlQawasmeh, M. J. O'Connor and T. H. Al-Tel, Multidirectional desymmetrization of pluripotent building block en route to diastereoselective synthesis of complex nature-inspired scaffolds, Nat. Commun., 2018, 9, 4989.

169 (a) G. O. Fonseca, Z. J. Wang, O. A. Namjoshi, J. R. Deschamps and J. M. Cook, First stereospecific total synthesis of (-)-affinisine oxindole as well as facile entry into the $\mathrm{C}(7)$-diastereomeric chitosenine stereochemistry, Tetrahedron Lett., 2015, 56, 3052; (b) M. R. Stephen, M. T. Rahman, V. V. N. P. B. Tiruveedhula, G. O. Fonseca, J. R. Deschamps and J. M. Cook, Concise Total Synthesis of (-)-Affinisine Oxindole, (+)-Isoalstonisine, $(+)$-Alstofoline, (-)-Macrogentine, $(+)-\mathrm{N}_{\mathrm{a}}$-Demethylalstonisine, (-)-Alstonoxine A, and (+)-Alstonisine, Chem. - Eur. J., 2017, 23, 15805.

170 Q. Yu, P. Guo, J. Jian, Y. Chen and J. Xu, Nine-step total synthesis of (-)-strychnofoline, Chem. Commun., 2018, 54, 1125.

171 Y. K. Xi, H. Zhang, R. X. Li, S. Y. Kang, J. Li and Y. Li, Total Synthesis of Spirotryprostatins through 
Organomediated Intramolecular Umpolung Cyclization, Chem. - Eur. J., 2019, 25, 3005.

172 P. Chen, H. Yang, H. Zhang, W. Chen, Z. Zhang, J. Zhang, H. Li, X. Wang, X. Xie and X. She, Total Synthesis of (-)-Gardmultimine A, Org. Lett., 2020, 5, 2022-2025.

173 (a) M. Amat, C. Ramos, M. Pérez, E. Molins, P. Florindo, M. M. M. Santos and J. Bosch, Enantioselective formal synthesis of ent-rhynchophylline and ent-isorhynchophylline, Chem. Commun., 2013, 49, 1954. Also see: (b) M. Pérez, C. Ramos, L. Massi, S. Gazzola, C. Taglienti, N. Yayik, E. Molins, A. Viayna, F. J. Luque, J. Bosch, et al., Enantioselective Synthesis of Spiro[indolizidine-1,3'-oxindoles], Org. Lett., 2017, 19, 4050.

174 (a) X.-H. Chen, Q. Wei, S.-W. Luo, H. Xiao and L.-Z. Gong, Organocatalytic Synthesis of Spiro[pyrrolidin-3,3'-oxindoles] with High Enantiopurity and Structural Diversity, J. Am. Chem. Soc., 2009, 131, 13819. For 3,2'-spiropyrrolidines see: (b) F. Shi, Z. L. Tao, S. W. Luo, S. J. Tu and L. Z. Gong, Scaffold-Inspired Enantioselective Synthesis of Biologically Important Spiro[pyrrolidin-3,2'-oxindoles] with Structural Diversity through Catalytic Isatin-Derived 1,3-Dipolar Cycloadditions, Chem. - Eur. J., 2012, 18, 6885.

175 For a related chiral auxiliary approach see: (a) P. R. Sebahar and R. M. Williams, The Asymmetric Total Synthesis of (+)- and (-)-Spirotryprostatin B, J. Am. Chem. Soc., 2000, 122, 5666; (b) T. Onishi, P. R. Sebahar and R. M. Williams, Concise, Asymmetric Total Synthesis of Spirotryprostatin A, Org. Lett., 2003, 5, 3135.

176 (a) J. Li, J. Wang, Z. Xu and S. Zhu, Combinatorial Synthesis of Functionalized Spirooxindole-Pyrrolidine/ Pyrrolizidine/Pyrrolothiazole Derivatives via ThreeComponent 1,3-Dipolar Cycloaddition Reactions, ACS Comb. Sci., 2014, 16, 506; (b) L. Cui, G. Zhu, S. Liu, X. Bao, $\mathrm{X}$. Zhao, J. Qu and B. Wang, Construction of indoleninesubstituted spiro[pyrrolidine-2,3'-oxindoles] from 2-alkenylindolenines and isatin-derived azomethine ylides, Tetrahedron, 2018, 74, 2369; (c) J. Yue, S. Chen, X. Zuo, X. L. Liu, S. W. Xu and Y. Zhou, Diversity-oriented one-pot multicomponent synthesis of chromanone-based 3,3'-pyrrolidinyl-spirooxindoles via a 1,3-dipolar cycloaddition reaction, Tetrahedron Lett., 2019, 60, 137; (d) M. S. Islam, H. M. Ghawas, F. F. El-Senduny, A. M. Al-Majid, Y. A. M. M. Elshaier, F. A. Badria and A. Barakat, Synthesis of new thiazolo-pyrrolidine-(spirooxindole) tethered to 3-acylindole as anticancer agents, Bioorg. Chem., 2019, 82, 423; (e) L. Wang, X. M. Shi, W. P. Dong, L. P. Zhu and R. Wang, Efficient construction of highly functionalized spiro[ $\gamma$-butyrolactone-pyrrolidin-3,3'-oxindole $]$ tricyclic skeletons via an organocatalytic 1,3-dipolar cycloaddition, Chem. Commun., 2013, 49, 3458; (f) F. Salahi, M. J. Taghizadeh, H. Arvinnezhad, M. Moemeni, K. Jadidi and B. Notash, An efficient, one-pot, three-component procedure for the synthesis of chiral spirooxindolopyrrolizidines via catalytic highly enantioselective 1,3-dipolar cycloaddition, Tetrahedron Lett., 2014, 55, 1515; (g) X. Meng, Y. Du, Q. Zhang, A. Yu, Y. Zhang, J. Jia and X. Liu, Direct Functionalization of Azepane via Azomethine Ylides: A Highly Efficient Synthesis of Spirooxindoles Bearing a 1-Azabicyclo[5.3.0]decane Moiety, Asian J. Org. Chem., 2017, 6, 1719; (h) Y. Du, A. Yu, J. Jia, Y. Zhang and X. Meng, Direct N-H/ $\alpha, \alpha, \beta, \beta-\mathrm{C}\left(\mathrm{sp}^{3}\right)-\mathrm{H}$ functionalization of piperidine via an azomethine ylide route: synthesis of spirooxindoles bearing 3-substituted oxindoles, Chem. Commun., 2017, 53, 1684; (i) X. Zhang, M. Liu, W. Qiu, J. Evans, M. Kaur, J. P. Jasinski and W. Zhang, One-Pot Synthesis of Polycyclic Spirooxindoles via Montmorillonite K10-Catalyzed C-H Functionalization of Cyclic Amines, ACS Sustainable Chem. Eng., 2018, 6, 5574 .

177 (a) Y. Huang, H. L. Fang, Y. X. Huang, J. Sun and C. G. Yan, Synthesis of 7'-Arylidenespiro[indoline-3,1'-pyrrolizines] and 7'-Arylidenespiro[indene-2,1'-pyrrolizines] via $[3+2]$ Cycloaddition and $\beta-\mathrm{C}-\mathrm{H}$ Functionalized Pyrrolidine, J. Org. Chem., 2019, 84, 12437; (b) I. B. Kutyashev, M. V. Ulitko, A. Y. Barkov, N. S. Zimnitskiy, V. Y. Korotaev and V. Y. Sosnovskikh, A regio- and stereocontrolled approach to the synthesis of 4- $\mathrm{CF}_{3}$-substituted spiro[chromeno[3,4-c]pyrrolidine-oxindoles] via reversible $[3+2]$ cycloaddition of azomethine ylides generated from isatins and sarcosine to 3-nitro-2(trifluoromethyl)-2H-chromenes, New J. Chem., 2019, 43, 18495; (c) Z. Zhang, W. Sun, G. Zhu, J. Yang, M. Zhang, L. Hong and R. Wang, Chiral phosphoric acid catalyzed enantioselective 1,3-dipolar cycloaddition reaction of azlactones, Chem. Commun., 2016, 52, 1377; (d) W. Sun, G. Zhu, C. Wu, G. Li, L. Hong and R. Wang, Organocatalytic Diastereo- and Enantioselective 1,3Dipolar Cycloaddition of Azlactones and Methyleneindolinones, Angew. Chem., Int. Ed., 2013, 52, 8633; (e) A. S. Filatov, N. A. Knyazev, A. P. Molchanov, T. L. Panikorovsky, R. R. Kostikov, A. G. Larina, V. M. Boitsov and A. V. Stepakov, Synthesis of Functionalized 3-Spiro[cyclopropa[a]pyrrolizine]- and 3-Spiro[3-azabicyclo[3.1.0]hexane]oxindoles from Cyclopropenes and Azomethine Ylides via $[3+2]-$ Cycloaddition, J. Org. Chem., 2017, 82, 959; (f) X.-C. Yang, J.-Y. Liu, Z. Liu, X.-Q. Hu and P.-F. Xu, Quaternary Carbon Center Forming [3 + 2] Cyclization Reaction by Adjusting the Substituents of Substrates, J. Org. Chem., 2019, 84, 13871.

178 (a) P. Wu, H. Gao, J. Sun and C. G. Yan, Isatin hybrids and their anti-tuberculosis activity, Chin. Chem. Lett., 2017, 28, 329; (b) Y. Huang, Y. X. Huang, J. Sun and C. G. Yan, A $[3+2]$ cycloaddition reaction for the synthesis of spiro [indoline-3,3'-pyrrolidines] and evaluation of cytotoxicity towards cancer cells, New J. Chem., 2019, 43, 8903.

179 C. S. Wang, R. Y. Zhu, J. Zheng, F. Shi and S. J. Tu, Enantioselective Construction of Spiro[indoline-3,2'pyrrole] Framework via Catalytic Asymmetric 1,3-Dipolar Cycloadditions Using Allenes as Equivalents of Alkynes, J. Org. Chem., 2015, 80, 512. 
180 (a) G. Zhu, B. Wang, X. Bao, H. Zhang, Q. Wei and J. Qu, Catalytic asymmetric construction of spiro[pyrrolidine2,3'-oxindole] scaffolds through chiral phosphoric acidcatalyzed 1,3-dipolar cycloaddition involving 3-amino oxindoles, Chem. Commun., 2015, 51, 15510-15513; (b) Q. Wei, G. Zhu, H. Zhang, J. Qu and B. Wang, 1,3Dipolar Cycloaddition of Azomethine Ylides Involving 3-Aminooxindoles: Versatile Construction of Dispiro[pyrrolidine-2,3'-oxindole] Scaffolds, Eur. J. Org. Chem., 2016, 5335; (c) G. Zhu, S. Liu, S. Wu, L. Peng, J. Qu and B. Wang, Assembly of Indolenines, 3-Amino Oxindoles, and Aldehydes into Indolenine-Substituted Spiro[pyrrolidin-2,3'-oxindoles] via 1,3-Dipolar Cycloaddition with Divergent Diastereoselectivities, J. Org. Chem., 2017, 82, 4317; (d) G. Zhu, Q. Wei, H. Chen, Y. Zhang, W. Shen, J. Qu and B. Wang, Asymmetric [3+2] Cycloaddition of 3-Amino Oxindole-Based Azomethine Ylides and $\alpha, \beta$-Enones with Divergent Diastereocontrol on the Spiro [pyrrolidine-oxindoles], Org. Lett., 2017, 19, 1862; (e) G. Zhu, S. Wu, X. Bao, L. Cui, Y. Zhang, J. Qu, H. Chen and B. Wang, Asymmetric [3 3 2] cycloaddition of 3-amino oxindole-based azomethine ylides with $\alpha, \beta$-ynones: a straightforward approach to spirooxindoles incorporating 2,5-dihydropyrroles and pyrroles, Chem. Commun., 2017, 53, 4714; $(f)$ J. He, R.-G. Sun, L. Fan, S.-Y. Tian, T.-P. Huang, Z. Chen and L. Chen, 4-(N,N-Dimethylamino) pyridine (DMAP)-Catalyzed 1,3-Dipolar Cycloaddition of 3-Aminooxindole-Based Azomethine Ylides with $\alpha, \beta$-Unsaturated Acyl Phosphonates for the Construction of Spiropyrrolidinyl-2,3'-oxindoles, Synthesis, 2019, 51, 1353; $(g)$ T. Huang, L. Liu, Q. Wang, M. Wu and D. Kong, 1,3-Dipolar Cycloaddition of 3-Amino Oxindole-Based Azomethine Ylides and O-Vinylphosphonylated Salicylaldehydes for Diastereoselective Synthesis of Oxindole Spiro-P,N-polycyclic Heterocycles, Synthesis, 2020, 52, 1387.

181 (a) J. Sun, G. L. Shen, Y. Huang and C. G. Yan, Formation of diverse polycyclic spirooxindoles via three-component reaction of isoquinolinium salts, isatins and malononitrile, Sci. Rep., 2017, 7, 41024; (b) Y. Huang, W. Min, Q. W. Wu, J. Sun, D. H. Shi and C. G. Yan, Facile one-pot synthesis of spirooxindole-pyrrolidine derivatives and their antimicrobial and acetylcholinesterase inhibitory activities, New J. Chem., 2018, 42, 16211.

182 (a) X. Wang, P. Yang, Y. Zhang, C. Z. Tang, F. Tian, L. Peng and L. X. Wang, Isatin, N,N'-Cyclic Azomethine Imine 1,3-Dipole and Abnormal [3 + 2]-Cycloaddition with Maleimide in the Presence of 1,4-Diazabicyclo[2.2.2] octane, Org. Lett., 2017, 19, 646; (b) X.-J. Song, H.-X. Ren, M. Xiang, C.-Y. Li, F. Tian and L.-X. Wang, Base Catalyzed Abnormal [3 + 2]-Cycloaddition between Isatin N,N'-Cyclic Azomethine Imine 1,3-Dipole and 3-Methyleneoxindole for the One-Step Construction of Tetracyclic Bispirooxindoles, J. Org. Chem., 2020, 85, 3921.

183 J. Day, M. Uroos, R. A. Castledine, W. Lewis, B. McKeeverAbbas and J. Dowden, Alkaloid inspired spirocyclic oxi- ndoles from 1,3-dipolar cycloaddition of pyridinium ylides, Org. Biomol. Chem., 2013, 11, 6502.

184 (a) J. A. Xiao, H. G. Zhang, S. Liang, J. W. Ren, H. Yang and X. Q. Chen, Synthesis of Pyrrolo(spiro-[2.3']-oxindole)-spiro[4.3"]-oxindole via 1,3-Dipolar Cycloaddition of Azomethine Ylides with 3-Acetonylideneoxindole, J. Org. Chem., 2013, 78, 11577; (b) Y. L. Qian, B. Li, P. J. Xia, J. Wang, H. Y. Xiang and $\mathrm{H}$. Yang, Diastereospecific entry to pyrrolidinyldispirooxindole skeletons via three-component 1,3-dipolar cycloadditions, Tetrahedron, 2018, 74, 6821; (c) T. T. Feng, Y. Gong, Q. Di Wei, G. L. Wang, H. H. Liu, M. Y. Tian, X. L. Liu, Z. Y. Chen and Y. Zhou, Diversity-oriented Construction of Chromanone-fused Polycyclic Pyrrolidinyldispirooxindoles, J. Heterocycl. Chem., 2018, 55, 1136; (d) Y. Huang, Y. X. Huang, J. Sun and C. G. Yan, Diastereoselective synthesis of dispirooxindoles via, $[3+2]$ cycloaddition of azomethine ylides to 3-phenacylideneoxindoles and evaluation of their cytotoxicity, RSC Adv., 2018, 8, 23990; (e) J. Guo, Y. Zhao, D. Fang, Q. Wang and Z. Bu, Diastereoselective construction of pyrrolo[2,1-a]isoquinoline-based bispirooxindoles through a three-component [3+ 2] cycloaddition, Org. Biomol. Chem., 2018, 16, 6025; (f) S. Bhandari, S. Sana, B. Sridhar and N. Shankaraiah, Microwave-Assisted One-Pot $[3+2]$ Cycloaddition of Azomethine Ylides and 3-Alkenyl Oxindoles: A Facile Approach to Pyrrolidine-Fused Bis-Spirooxindoles, ChemistrySelect, 2019, 4, 1727; ( $g$ ) W. Dai, X. L. Jiang, Q. Wu, F. Shi and S. J. Tu, Diastereo- and Enantioselective Construction of 3,3'-Pyrrolidinyldispirooxindole Framework via Catalytic Asymmetric 1,3-Dipolar Cycloadditions, J. Org. Chem., 2015, 80, 5737; (h) K. Suman, L. Srinu and S. Thennarasu, Lewis Acid Catalyzed Unprecedented [3 +2$]$ Cycloaddition Yields 3,3'-Pyrrolidinyldispirooxindoles Containing Four Contiguous Chiral Stereocenters with Two Contiguous Quaternary Spirostereocenters, Org. Lett., 2014, 16, 3732; (i) D. Shukla and S. A. Babu, Pd-Catalyzed Diastereoselective Intramolecular Amide $\alpha-\mathrm{C}-\mathrm{H}$ Arylation in Sterically Hindered Monospirooxindole Motifs, Adv. Synth. Catal., 2019, 361, 2075; (j) N. Shahrestani, K. Tovfighmadar, M. Eskandari, K. Jadidi, B. Notash and P. Mirzaei, Synthesis of Highly Enantioenriched Bis-spirooxindole Pyrrolizidine/ Pyrrolidines through Asymmetric [3+2] Cycloaddition Reaction, Asian J. Org. Chem., 2020, 9, 822.

185 (a) T. Arai, H. Ogawa, A. Awata, M. Sato, M. Watabe and M. Yamanaka, PyBidine-Cu(OTf $)_{2}$-Catalyzed Asymmetric $[3+2]$ Cycloaddition with Imino Esters: Harmony of $\mathrm{Cu}-$ Lewis Acid and Imidazolidine-NH Hydrogen Bonding in Concerto Catalysis, Angew. Chem., Int. Ed., 2015, 54, 1595; (b) W. L. Yang, Y. Z. Liu, S. Luo, X. Yu, J. S. Fossey and W. P. Deng, The copper-catalyzed asymmetric construction of a dispiropyrrolidine skeleton via 1,3-dipolar cycloaddition of azomethine ylides to $\alpha$-alkylidene succinimides, Chem. Commun., 2015, 51, 9212.

186 L. Shu, Z. Li, C. Gu and D. Fishlock, Synthesis of a Spiroindolinone Pyrrolidinecarboxamide MDM2 Antagonist, Org. Process Res. Dev., 2013, 17, 247. 
187 J. P. Macdonald, B. H. Shupe, J. D. Schreiber and A. K. Franz, Counterion effects in the catalytic stereoselective synthesis of 2,3'-pyrrolidinyl spirooxindoles, Chem. Commun., 2014, 50, 5242.

188 M. Ma, Y. Zhu, Q. Sun, X. Li, J. Su, L. Zhao, Y. Zhao, S. Qiu, W. Yan, K. Wang, et al., The asymmetric synthesis of $\mathrm{CF}_{3}$-containing spiro[pyrrolidin-3,2'-oxindole] through the organocatalytic 1,3-dipolar cycloaddition reaction, Chem. Commun., 2015, 51, 8789.

189 Q. Sun, X. Li, J. Su, L. Zhao, M. Ma, Y. Zhu, Y. Zhao, R. Zhu, W. Yan, K. Wang, et al., The SquaramideCatalyzed 1,3-Dipolar Cycloaddition of Nitroalkenes with N-2,2,2-Trifluoroethylisatin Ketimines: An Approach for the Synthesis of 5'-Trifluoromethyl-spiro[pyrrolidin-3,2'oxindoles], Adv. Synth. Catal., 2015, 357, 3187.

190 (a) A. Ponce, I. Alonso, J. Adrio and J. C. Carretero, Stereoselective Ag-Catalyzed 1,3-Dipolar Cycloaddition of Activated Trifluoromethyl-Substituted Azomethine Ylides, Chem. - Eur. J., 2016, 22, 4952; (b) H. Z. Gui, Y. N. Gao, Y. Wei and M. Shi, Highly Efficient and Diastereoselective Construction of Trifluoromethyl-Containing Spiro[pyrrolidin-3,2'-oxindole] by a Catalyst-free Mutually Activated [3 + 2] Cycloaddition Reaction, Chem. - Eur. J., 2018, 24, 10038; (c) X. Y. Wu, Y. N. Gao and M. Shi, PhosphineCatalyzed $[3+2]$ Annulation of N-2,2,2Trifluoroethylisatin Ketimines with $\gamma$-Substituted Allenoates: Synthesis of Spiro[indoline-3,2'-pyrrole], Eur. J. Org. Chem., 2019, 1620.

191 (a) Z. H. Wang, Z. J. Wu, D. F. Yue, W. F. Hu, X. M. Zhang, X. Y. Xu and W. C. Yuan, Organocatalytic asymmetric [3+ 2] cycloaddition of N-2,2,2-trifluoroethylisatin ketimines with 3-alkenyl-5-arylfuran-2(3H)-ones, Chem. Commun., 2016, 52, 11708; (b) C. Wang, D. Wen, H. Chen, Y. Deng, X. Liu, X. Liu, L. Wang, F. Gao, Y. Guo, M. Sun, et al., The catalytic asymmetric synthesis of $\mathrm{CF}_{3}$-containing spiro-oxindole-pyrrolidine-pyrazolone compounds through squaramide-catalyzed 1,3-dipolar cycloaddition, Org. Biomol. Chem., 2019, 17, 5514; (c) C. Zou, Y. Han, C. Zeng, T. Y. Zhang, J. Ye and G. Song, Remote regioselective organocatalytic asymmetric $[3+2]$ cycloaddition of N-2,2,2-trifluoroethyl isatin ketimines with cyclic 2,4-dienones, Chin. Chem. Lett., 2020, 31, 377; (d) Y. Yi, Y. Hua, H. Lu, L. Liu and M. Wang, Brønsted Base and Lewis Acid Cooperatively Catalyzed Asymmetric exo'-Selective $[3+2]$ Cycloaddition of Trifluoromethylated Azomethine Ylides and Methyleneindolinones, Org. Lett., 2020, 22, 2527; (e) B. Li, F. Gao, X. Feng, M. Sun, Y. Guo, D. Wen, Y. Deng, J. Huang, K. Wang and W. Yan, Highly efficient enantioselective synthesis of bispiro[benzofuran-oxindole-pyrrolidine]s through organocatalytic cycloaddition, Org. Chem. Front., 2019, 6, 1567; ( $f$ ) X. Liu, D. Lu, J.-H. Wu, J.-P. Tan, C. Jiang, G. Gao and T. Wang, Stereoselective Synthesis of $\mathrm{CF}_{3}$-Containing Spirooxindoles via 1,3-Dipolar Cycloaddition by Dipeptide-Based Phosphonium Salt Catalysis, Adv. Synth. Catal., 2020, 362, 1490; (g) Y. Zhi, K. Zhao, C. Von Essen, K. Rissanen and D. Enders,
Thiourea-Catalyzed Domino Michael-Mannich $[3+2]$ Cycloadditions: A Strategy for the Asymmetric Synthesis of 3,3'-Pyrrolidinyl-dispirooxindoles, Synlett, 2017, 28, 2876; (h) T. L. An and D. M. Du, Chiral Squaramide Catalyzed Asymmetric [3+2] Cycloaddition Reaction for Synthesis of Trifluoromethylated Barbituric Acid Derivatives, ChemistrySelect, 2019, 4, 11302; (i) F.-Y. Chen, L. Xiang, G. Zhan, H. Liu, B. Kang, S.-C. Zhang, C. Peng and B. Han, Highly stereoselective organocatalytic synthesis of pyrrolidinyl spirooxindoles containing halogenated contiguous quaternary carbon stereocenters, Tetrahedron Lett., 2020, 61, 151806.

192 J. X. Zhang, H. Y. Wang, Q. W. Jin, C. W. Zheng, G. Zhao and Y. J. Shang, Thiourea-Quaternary Ammonium Salt Catalyzed Asymmetric 1,3-Dipolar Cycloaddition of Imino Esters To Construct Spiro[pyrrolidin-3,3'-oxindoles], Org. Lett., 2016, 18, 4774.

193 J. H. Siitonen, S. Lira, M. Yousufuddin and L. Kürti, Total synthesis of isatindigotindoline C, Org. Biomol. Chem., 2020, 18, 2051.

194 P. B. Alper, C. Meyers, A. Lerchner, D. R. Siegel and E. M. Carreira, Facile, Novel Methodology for the Synthesis of Spiro[pyrrolidin-3,3'-oxindoles]: Catalyzed Ring Expansion Reactions of Cyclopropanes by Aldimines, Angew. Chem., Int. Ed., 1999, 38, 3186.

195 (a) A. Lerchner and E. M. Carreira, First Total Synthesis of $( \pm)$-Strychnofoline via a Highly Selective Ring-Expansion Reaction, J. Am. Chem. Soc., 2002, 124, 14826; (b) A. Lerchner and E. M. Carreira, Synthesis of ( \pm -Strychnofoline via a Highly Convergent Selective Annulation Reaction, Chem. - Eur. J., 2006, 12, 8208; (c) C. Meyers and E. M. Carreira, Total Synthesis of (-)-Spirotryprostatin B, Angew. Chem., Int. Ed., 2003, 42, 694; (d) C. Marti and E. M. Carreira, Total Synthesis of (-)-Spirotryprostatin B: Synthesis and Related Studies, J. Am. Chem. Soc., 2005, 127, 11505-11515; (e) C. P. Seath, J. W. B. Fyfe, J. J. Molloy and A. J. B. Watson, Synthesis of Oxindoles and Benzofuranones via Oxidation of 2-Heterocyclic BMIDAs, Synthesis, 2017, 49, 891.

196 (a) V. Helan, A. Mills, D. Drewry and D. Grant, A Rapid Three-Component $\mathrm{MgI}_{2}$-Mediated Synthesis of 3,3Pyrollidinyl Spirooxindoles, J. Org. Chem., 2010, 75, 6693; (b) E. M. Buev, V. S. Moshkin and V. Y. Sosnovskikh, Reactivity of spiroanthraceneoxazolidines with cyclopropanes: An approach to the oxindole alkaloid scaffold, Tetrahedron Lett., 2018, 59, 3409.

197 Z. Zhang, W. Zhang, F. Kang, F. C. F. Ip, N. Y. Ip and R. Tong, Asymmetric Total Syntheses of Rhynchophylline and Isorhynchophylline, J. Org. Chem., 2019, 84, 11359.

198 A. A. Akaev, E. V. Villemson, N. S. Vorobyeva, A. G. Majouga, E. M. Budynina and M. Y. Melnikov, 3-(2Azidoethyl)oxindoles: Advanced Building Blocks for OnePot Assembly of Spiro[pyrrolidine-3,3'-oxindoles], J. Org. Chem., 2017, 82, 5689.

199 S. Hajra, S. K. Abu Saleh, A. Hazra and M. S. Singh, Organocatalytic Domino Reaction of Spiroaziridine 
Oxindoles and Malononitrile for the Enantiopure Synthesis of Spiro[dihydropyrrole-3,3'-oxindoles], J. Org. Chem., 2019, 84, 8194.

200 T. R. Li, B. Y. Cheng, S. Q. Fan, Y. N. Wang, L. Q. Lu and W. J. Xiao, Highly Stereoselective [3+2] Cycloadditions of Chiral Palladium-Containing $N^{1}-1,3$-Dipoles: A Divergent Approach to Enantioenriched Spirooxindoles, Chem. Eur. J., 2016, 22, 6243.

201 S. Hajra, S. S. Bhosale, A. Hazra and N. Kanaujia, The one pot asymmetric synthesis of 3,3'-pyrrolidonyl spiroxindoles via a regio- and stereoselective domino reaction, Org. Biomol. Chem., 2019, 17, 8140.

202 A. A. Akaev, S. I. Bezzubov, V. G. Desyatkin, N. S. Vorobyeva, A. G. Majouga, M. Y. Melnikov and E. M. Budynina, Stereocontrolled [3 +2$]$ Cycloaddition of Donor-Acceptor Cyclopropanes to Iminooxindoles: Access to Spiro[oxindole-3,2'-pyrrolidines], J. Org. Chem., 2019, 84, 3340.

203 X. B. Huang, X. J. Li, T. T. Li, B. Chen, W. D. Chu, L. He and Q. Z. Liu, Palladium-Catalyzed Highly Enantioselective Cycloaddition of Vinyl Cyclopropanes with Imines, Org. Lett., 2019, 21, 1713.

204 P. Yuvaraj and B. S. R. Reddy, Synthesis of 3-spiropyrrolidine-3-spirooxindoles from Baylis-Hillman adducts of chromone with azomethine ylides via $[3+2]$ cycloaddition reaction, Tetrahedron Lett., 2013, 54, 821.

205 Q. He, W. Du and Y. C. Chen, Asymmetric $[3+2]$ Annulations to Construct 1,2-Bispirooxindoles Incorporating a Dihydropyrrolidine Motif, Adv. Synth. Catal., 2017, 359, 3782.

206 X. Tang, Y. J. Gao, H. Q. Deng, J. J. Lei, S. W. Liu, L. Zhou, Y. Shi, H. Liang, J. Qiao, L. Guo, et al., Catalyst-free [3 + 2] cyclization of dihydroisoquinoline imines and isatinderived Morita-Baylis-Hillman carbonates via 1,5-electrocyclization: synthesis of tetrahydroisoquinoline-fused spirooxindoles, Org. Biomol. Chem., 2018, 16, 3362.

207 D. Jiang, S. Dong, W. Tang, T. Lu and D. Du, N-Heterocyclic, Carbene-Catalyzed Formal $[3+2]$ Annulation of $\alpha$-Bromoenals with 3-Aminooxindoles: A Stereoselective Synthesis of Spirooxindole $\gamma$-Butyrolactams, J. Org. Chem., 2015, 80, 11593.

208 K.-Q. Chen, Y. Li, C.-L. Zhang, D.-Q. Sun and S. Ye, $\mathrm{N}-$ Heterocyclic, carbene-catalyzed $[3+2]$ annulation of bromoenals with 3-aminooxindoles: highly enantioselective synthesis of spirocyclic oxindolo- $\gamma$-lactams, Org. Biomol. Chem., 2016, 14, 2007.

209 (a) C. Wang, S. Zhu, G. Wang, Z. Li and X. P. Hui, Enantioselective Synthesis of Spiro[indoline-3,2'-pyrroles] through N-Heterocyclic-Carbene-Catalyzed Formal [3 + 2] Annulation, Eur. J. Org. Chem., 2016, 5653. For detailed mechanistic study see: (b) Y. Li, Z. Zhang and C. Liang, Understanding the mechanism and stereoselectivity of NHC-catalyzed [3 +2 ] cycloaddition of 3-bromoenals and isatin N-Boc ketimines, Org. Biomol. Chem., 2018, 16, 9251.

210 X. Y. Chen, J. W. Xiong, Q. Liu, S. Li, H. Sheng, C. von Essen, K. Rissanen and D. Enders, Control of N-Heterocyclic Carbene Catalyzed Reactions of Enals:
Asymmetric Synthesis of Oxindole- $\gamma$-Amino Acid Derivatives, Angew. Chem., Int. Ed., 2018, 57, 300.

211 For a review see: W. Y. Han, J. Q. Zhao, J. Zuo, X. Y. Xu, X. M. Zhang and W. C. Yuan, Recent Advances of $\alpha$-Isothiocyanato Compounds in the Catalytic Asymmetric Reaction, Adv. Synth. Catal., 2015, 357, 3007.

212 Y. M. Cao, F. F. Shen, F. T. Zhang and R. Wang, Catalytic Asymmetric Michael Addition/Cyclization of Isothiocyanato Oxindoles: Highly Efficient and Versatile Approach for the Synthesis of 3,2'-Pyrrolidinyl Mono- and Bi-spirooxindole Frameworks, Chem. - Eur. J., 2013, 19, 1184.

213 (a) Q. Chen, J. Liang, S. Wang, D. Wang and R. Wang, An asymmetric approach toward chiral multicyclic spirooxindoles from isothiocyanato oxindoles and unsaturated pyrazolones by a chiral tertiary amine thiourea catalyst, Chem. Commun., 2013, 49, 1657; (b) In 2014, Yuan showed an example of the same reaction catalysed by quinine: B. D. Cui, S. W. Li, J. Zuo, Z. J. Wu, X. M. Zhang and W. C. Yuan, Quinine-catalyzed asymmetric domino Michael-cyclization reaction for the synthesis of spirocyclic oxindoles bearing two spiro quaternary centers and three consecutive stereocenters, Tetrahedron, 2014, 70, 1895.

214 (a) W. Y. Han, S. W. Li, Z. J. Wu, X. M. Zhang and W. C. Yuan, 3-Isothiocyanato Oxindoles Serving as Powerful and Versatile Precursors to Structurally Diverse Dispirocyclic Thiopyrrolidineoxindoles through a Cascade Michael/Cyclization Process with Amino-Thiocarbamate Catalysts, Chem. - Eur. J., 2013, 19, 5551; (b) X. L. Liu, W. Y. Han, X. M. Zhang and W. C. Yuan, Highly Efficient and Stereocontrolled Construction of 3,3'-Pyrrolidonyl Spirooxindoles via Organocatalytic Domino Michael/ Cyclization Reaction, Org. Lett., 2013, 15, 1246.

215 (a) Z. K. Fu, J. Y. Pan, D. C. Xu and J. W. Xie, Organocatalytic domino Michael/cyclization reaction: efficient synthesis of multi-functionalized tetracyclic spirooxindoles with multiple stereocenters, RSC Adv., 2014, 4, 51548; (b) F. Tan, L. Q. Lu, Q. Q. Yang, W. Guo, Q. Bian, J. R. Chen and W. J. Xiao, Enantioselective Cascade Michael Addition/Cyclization Reactions of 3-Nitro2H-Chromenes with 3-Isothiocyanato Oxindoles: Efficient Synthesis of Functionalized Polycyclic Spirooxindoles, Chem. - Eur. J., 2014, 20, 3415; (c) S. Kayal and S. Mukherjee, Catalytic Asymmetric Michael Addition/ Cyclization Cascade Reaction of 3-Isothiocyanatooxindoles with Nitro Olefins, Eur. J. Org. Chem., 2014, 6696; (d) J. Q. Zhao, M. Q. Zhou, Z. J. Wu, Z. H. Wang, D. F. Yue, X. Y. Xu, X. M. Zhang and W. C. Yuan, Asymmetric Michael/Cyclization Cascade Reaction of 3-Isothiocyanato Oxindoles and 3-Nitroindoles with Amino-Thiocarbamate Catalysts: Enantioselective Synthesis of Polycyclic Spirooxindoles, Org. Lett., 2015, 17, 2238; (e) J. Q. Zhao, Z. J. Wu, M. Q. Zhou, X. Y. Xu, X. M. Zhang and W. C. Yuan, ZnCatalyzed Diastereo- and Enantioselective Cascade 
Reaction of 3-Isothiocyanato Oxindoles and 3-Nitroindoles: Stereocontrolled Syntheses of Polycyclic Spirooxindoles, Org. Lett., 2015, 17, 5020; $(f)$ L. Wang, D. Yang, D. Li, X. Liu, Q. Zhao, R. Zhu, B. Zhang and R. Wang, Catalytic Asymmetric $[3+2]$ Cyclization Reactions of 3-Isothiocyanato Oxindoles and Alkynyl Ketones Via an in Situ Generated Magnesium Catalyst, Org. Lett., 2015, 17, 4260; (g) Y. Lin, L. Liu and D. M. Du, Squaramide-catalyzed asymmetric Michael/cyclization cascade reaction of 3-isothiocyanato oxindoles with chalcones for synthesis of pyrrolidinyl spirooxindoles, Org. Chem. Front., 2017, 4, 1229; (h) J. Q. Zhao, X. J. Zhou, Y. Zhou, X. Y. Xu, X. M. Zhang and W. C. Yuan, Diastereoand Enantioselective Dearomative [3 +2$]$ Cycloaddition Reaction of 2-Nitrobenzofurans with 3-Isothiocyanato Oxindoles, Org. Lett., 2018, 20, 909; (i) L. L. Zhang, B. C. Da, S. H. Xiang, S. Zhu, Z. Y. Yuan, Z. Guo and B. Tan, Organocatalytic double arylation of 3-isothiocyanato oxindoles: Stereocontrolled synthesis of complex spirooxindoles, Tetrahedron, 2019, 75, 1689; $(j)$ H. Gui, X. Wu, Y. Wei and M. Shi, A Formal Condensation and [4 + 1] Annulation Reaction of 3-Isothiocyanato Oxindoles with Aza-o-Quinone Methides, Adv. Synth. Catal., 2019, 361, 5466; (k) M. Bai, Y. Z. Chen, B. D. Cui, X. Y. Xu and W. C. Yuan, Thiourea-catalyzed asymmetric domino Michael-cyclization reaction of 3-isothiocyanato oxindoles with $\beta, \gamma$-unsaturated $\alpha$-keto esters for the synthesis of spirocyclic oxindoles, Tetrahedron, 2019, 75, 2155; (l) L. Liu, B. L. Zhao and D. M. Du, Organocatalytic Asymmetric Michael/Cyclization Cascade Reaction of 3-Isothiocyanato Oxindoles with Maleimides for the Efficient Construction of Pyrrolidonyl Spirooxindoles, Eur. J. Org. Chem., 2016, 4711; $(\mathrm{m})$ R. Chowdhury, M. Kumar and S. K. Ghosh, Organocatalyzed enantioselective Michael addition/cyclization cascade reaction of 3-isothiocyanato oxindoles with arylidene malonates, Org. Biomol. Chem., 2016, 14, 11250; (n) H.-W. Zhao, T. Tian, B. Li, Z. Yang, H.-L. Pang, W. Meng, X.-Q. Song and X.-Q. Chen, Diastereoselective Synthesis of Dispirobarbiturates through $\mathrm{Et}_{3} \mathrm{~N}$-Catalyzed $[3+2]$ Cycloaddition of Barbiturate-Based Olefins with 3-Isothiocyanato Oxindoles, J. Org. Chem., 2015, 80, 10380; (o) S. Chen, G. L. Wang, S. W. Xu, M. Y. Tian, M. Zhang, X. L. Liu and W. C. Yuan, Regio- and stereoselective $[3+2]$ cycloaddition reaction: access to isoxazoledispirobisoxindoles featuring three contiguous stereocenters, Org. Biomol. Chem., 2019, 17, 6551.

216 See ref. 212; (a) H. Wu, L. L. Zhang, Z. Q. Tian, Y. D. Huang and Y. M. Wang, Highly Efficient Enantioselective Construction of Bispirooxindoles Containing Three Stereocenters through an Organocatalytic Cascade Michael-Cyclization Reaction, Chem. - Eur. J., 2013, 19, 1747; (b) F. Tan, H. G. Cheng, B. Feng, Y. Q. Zou, S. W. Duan, J. R. Chen and W. J. Xiao, Highly Enantioselective Organocatalytic Michael Addition/Cyclization Cascade Reaction of Ylideneoxindoles with Isothiocyanato Oxindoles: A
Formal [3 + 2] Cycloaddition Approach to Optically Active Bispirooxindole Derivatives, Eur. J. Org. Chem., 2013, 2071; (c) W. R. Zhu, Q. Chen, N. Lin, K. Bin Chen, Z. W. Zhang, G. Fang, J. Weng and G. Lu, Organocatalytic Michael/cyclization cascade reactions of 3-isothiocyanato oxindoles with 3-trifluoroethylidene oxindoles: an approach for the synthesis of 3 '-trifluoromethyl substituted 3,2'-pyrrolidinyl-bispirooxindoles, Org. Chem. Front., 2018, 5, 1375.

217 M. Monecke and T. Lindel, Tackling the Spiro Tetracyclic Skeleton of Cyanogramide: Incorporation of a Hydantoin Moiety, Org. Lett., 2018, 20, 7969.

218 B. D. Cui, J. Zuo, J. Q. Zhao, M. Q. Zhou, Z. J. Wu, X. M. Zhang and W. C. Yuan, Tandem Michael AdditionRing Transformation Reactions of 3-Hydroxyoxindoles/ 3-Aminooxindoles with Olefinic Azlactones: Direct Access to Structurally Diverse Spirocyclic Oxindoles, J. Org. Chem., 2014, 79, 5305.

219 L. Chen, Z. J. Wu, M. L. Zhang, D. F. Yue, X. M. Zhang, X. Y. Xu and W. C. Yuan, Organocatalytic Asymmetric Michael/Cyclization Cascade Reactions of 3-Hydroxyoxindoles/3-Aminooxindoles with $\alpha, \beta$-Unsaturated Acyl Phosphonates for the Construction of Spirocyclic Oxindole- $\gamma$-lactones/lactams, J. Org. Chem., 2015, 80, 12668.

220 For a related reaction see: B. Cui, Y. Chen, J. Shan, L. Qin, C. Yuan, Y. Wang, W. Han, N. Wan and Y. Chen, An enantioselective synthesis of spiro-oxindole-based 3,4dihydropyrroles via a Michael/cyclization cascade of 3-aminooxindoles with 2-enoylpyridines, Org. Biomol. Chem., 2017, 15, 8518.

221 P. Yang, X. Wang, F. Chen, Z. B. Zhang, C. Chen, L. Peng and L. X. Wang, Organocatalytic Enantioselective Michael/ Cyclization Domino Reaction between 3-Amideoxindoles and $\alpha, \beta$-Unsaturated Aldehydes: One-Pot Preparation of Chiral Spirocyclic Oxindole- $\gamma$-lactams, J. Org. Chem., 2017, 82, 3908.

222 X. C. Yang, M. M. Liu, F. Mathey, H. Yang, Y. Z. Hua and M. C. Wang, Access to Chiral 2,5-Pyrrolidinyl Dispirooxindoles via Dinuclear Zinc-Catalyzed Asymmetric Cascade Reactions, J. Org. Chem., 2019, 84, 7762.

223 P. F. Zheng, Q. Ouyang, S. L. Niu, L. Shuai, Y. Yuan, K. Jiang, T. Y. Liu and Y. C. Chen, Enantioselective $[4+1]$ Annulation Reactions of $\alpha$-Substituted Ammonium Ylides To Construct Spirocyclic Oxindoles, J. Am. Chem. Soc., 2015, 137, 9390.

224 R. Le Goff, M. Sanselme, A. M. Lawson, A. Daïch and S. Comesse, Highly Stereoselective Domino Oxa-Michael/ Aza-Michael/Cyclization: Synthesis of Bicyclic Lactams and Spiroox-indole Skeleton, Eur. J. Org. Chem., 2015, 7244.

225 X. Huang, M. Liu, K. Pham, X. Zhang, W. Bin Yi, J. P. Jasinski and W. Zhang, Organocatalytic One-Pot Asymmetric Synthesis of Thiolated Spiro- $\gamma$-lactam Oxindoles Bearing Three Stereocenters, J. Org. Chem., 2016, 81, 5362. 
226 H. Xu, H. W. Liu, H. S. Lin and G. W. Wang, Solvent-free iodine-promoted synthesis of 3,2'-pyrrolinyl spirooxindoles from alkylidene oxindoles and enamino esters under ball-milling conditions, Chem. Commun., 2017, 53, 12477.

227 J. W. Ren, Q. L. Zhao, J. A. Xiao, P. J. Xia, H. Y. Xiang, X. Q. Chen and H. Yang, A One-Pot Ring-Opening/RingClosure Sequence for the Synthesis of Polycyclic Spirooxindoles, Chem. - Eur. J., 2019, 25, 4673.

228 (a) Y. Lin, B. L. Zhao and D. M. Du, Organocatalytic Asymmetric Synthesis of 3,3'-Pyrrolidinyl-bispirooxindoles via Michael/N-Hemiketalization Cascade Reaction between 3-Aminooxindoles and Isatin-Derived $\beta, \gamma$-Unsaturated $\alpha$-Keto Esters, J. Org. Chem., 2018, 83, 7741; (b) K. Zhao, Y. Zhi, X. Li, R. Puttreddy, K. Rissanen and D. Enders, Asymmetric synthesis of 3,3'-pyrrolidinyl-dispirooxindoles via a one-pot organocatalytic Mannich/deprotection/azaMichael sequence, Chem. Commun., 2016, 52, 2249.

229 B. L. Zhao and D. M. Du, Asymmetric Synthesis of Spirooxindoles with Seven Stereocenters via Organocatalyzed One-pot Three-component Sequential Cascade Reactions, Adv. Synth. Catal., 2019, 361, 3412.

230 (a) T. Kang, P. Zhao, J. Yang, L. Lin, X. Feng and X. Liu, Asymmetric Catalytic Double Michael Additions for the Synthesis of Spirooxindoles, Chem. - Eur. J., 2018, 24, 3703; (b) W. He, J. Hu, P. Wang, L. Chen, K. Ji, S. Yang, Y. Li, Z. Xie and W. Xie, Highly Enantioselective Tandem Michael Addition of Tryptamine-Derived Oxindoles to Alkynones: Concise Synthesis of Strychnos Alkaloids, Angew. Chem., Int. Ed., 2018, 57, 3806.

231 H. Sasai, S. Takizawa, M. Kusaba, K. Kishi, B. Jianfei and T. Suzuki, Facile Synthesis of Spirooxindoles via an Enantioselective Organocatalyzed Sequential Reaction of Oxindoles with Ynone, Heterocycles, 2017, 95, 761.

232 T. Cong, H. Wang, X. Li, H. H. Wu and J. Zhang, Chiral bifunctional bisphosphine enabled enantioselective tandem Michael addition of tryptamine-derived oxindoles to ynones, Chem. Commun., 2019, 55, 9176.

233 F. Beltran, I. Fabre, I. Ciofini and L. Miesch, Direct Spirocyclization from Keto-sulfonamides: An Approach to Azaspiro Compounds, Org. Lett., 2017, 19, 5042.

234 T. Zha, X. Tong, Y. Deng, F. Peng and Z. Shao, Catalytic Asymmetric and Divergent Synthesis of Tricyclic and Tetracyclic Spirooxindoles: Controllable Site-Selective Electrophilic Halocyclization of 1,6-Enynes, Org. Lett., 2019, 21, 6068.

235 (a) G. Y. Chen, F. Zhong and Y. Lu, Asymmetric Allylic Alkylation of Isatin-Derived Morita-Baylis-Hillman Carbonates with Nitroalkanes, Org. Lett., 2012, 14, 3955; (b) L. Liu, D. Wu, S. Zheng, T. Li, X. Li, S. Wang, J. Li, H. Li and W. Wang, Synthesis of Highly Functionalized Chiral 3,3'-Disubstituted Oxindoles via an Organocatalytic Enantioselective Michael Addition of Nitroalkanes to Indolylidenecyanoacetates, Org. Lett., 2012, 14, 134.

236 S. Shimizu, T. Tsubogo, P. Xu and S. Kobayashi, CalciumCatalyzed Asymmetric Synthesis of 3-Tetrasubstituted
Oxindoles: Efficient Construction of Adjacent Quaternary and Tertiary Chiral Centers, Org. Lett., 2015, 17, 2006.

237 For a related reaction of in situ derived imines in a domino aza-Michael/lactamisation including a preliminary asymmetric example see: J. Zhu, S. Fang, S. Jin, R. Ma, T. Lu and D. Du, Application of isatin-derived saturated esters in the synthesis of 3,3'-spirooxindole $\gamma$-butyrolactams, Org. Biomol. Chem., 2019, 17, 8745.

238 K. Ohmatsu, Y. Ando, T. Nakashima and T. Ooi, A Modular Strategy for the Direct Catalytic Asymmetric $\alpha$-Amination of Carbonyl Compounds, Chem, 2016, 1, 802.

239 G.-Y. Ran, X.-X. Yang, J.-F. Yue, W. Du and Y.-C. Chen, Asymmetric Allylic Alkylation with Deconjugated Carbonyl Compounds: Direct Vinylogous Umpolung Strategy, Angew. Chem., Int. Ed., 2019, 58, 9210.

$240 \mathrm{H} . \mathrm{Hu}, \mathrm{F} . \mathrm{Teng}, \mathrm{J}$. Liu, W. Hu, S. Luo and Q. Zhu, Enantioselective Synthesis of 2-Oxindole Spirofused Lactones and Lactams by Heck/Carbonylative Cylization Sequences: Method Development and Applications, Angew. Chem., Int. Ed., 2019, 58, 9225.

241 (a) S. Crosignani, P. Page, M. Missotten, V. Colovray, C. Cleva, J.-F. Arrighi, J. Atherall, J. Macritchie, T. Martin, Y. Humbert, et al., Discovery of a New Class of Potent, Selective, and Orally Bioavailable CRTH2 (DP2) Receptor Antagonists for the Treatment of Allergic Inflammatory Diseases, J. Med. Chem., 2008, 51, 2227; (b) S. Crosignani, C. Jorand-Lebrun, P. Page, G. Campbell, V. Colovray, M. Missotten, Y. Humbert, C. Cleva, J. F. Arrighi, M. Gaudet, et al., Optimization of the Central Core of Indolinone-Acetic Acid-Based CRTH2 (DP2) Receptor Antagonists, ACS Med. Chem. Lett., 2011, 2, 644.

242 J. Xu, L. D. Shao, D. Li, X. Deng, Y. C. Liu, Q. S. Zhao and C. Xia, Construction of Tetracyclic 3-Spirooxindole through Cross-Dehydrogenation of Pyridinium: Applications in Facile Synthesis of $( \pm)$-Corynoxine and (士)-Corynoxine B, J. Am. Chem. Soc., 2014, 136, 17962.

243 X. Chen, H. Chen, X. Ji, H. Jiang, Z. J. Yao and H. Liu, Asymmetric One-Pot Sequential Mannich/Hydroamination Reaction by Organo- and Gold Catalysts: Synthesis of Spiro [pyrrolidin-3,2'-oxindole] Derivatives, Org. Lett., 2013, 15, 1846.

244 X. P. Yin, X. P. Zeng, Y. L. Liu, F. M. Liao, J. S. Yu, F. Zhou and J. Zhou, Asymmetric Triple Relay Catalysis: Enantioselective Synthesis of Spirocyclic Indolines through a One-Pot Process Featuring an Asymmetric $6 \pi$ Electrocyclization, Angew. Chem., Int. Ed., 2014, 53, 13740.

245 S. Hajra and B. Jana, Quinine-Based Trifunctional Organocatalyst for Tandem Aza-Henry ReactionCyclization: Asymmetric Synthesis of SpiroxindolePyrrolidine/Piperidines, Org. Lett., 2017, 19, 4778.

246 C. Liu, F.-X. Tan, J. Zhou, H.-Y. Bai, T.-M. Ding, G.-D. Zhu, S.-Y. Zhang and H. Chemo-, Site-, and Enantioseletive para C-H Aminoalkylation of N-Monosubstituted Aniline Derivatives Affording 3-Amino-2-oxindoles, Org. Lett., 2020, 22, 2173.

247 N. Sharma, Z. Li, U. K. Sharma and E. V. Van Der Eycken, Facile Access to Functionalized Spiro[indoline-3,2'- 
pyrrole]-2,5'-diones via Post-Ugi Domino BuchwaldHartwig/Michael Reaction, Org. Lett., 2014, 16, 3884.

248 S. J. Chambers, G. Coulthard, W. P. Unsworth, P. O'Brien and R. J. K. Taylor, From Heteroaromatic Acids and Imines to Azaspirocycles: Stereoselective Synthesis and 3D Shape Analysis, Chem. - Eur. J., 2016, 22, 6496.

249 (a) J. T. R. Liddon, A. K. Clarke, R. J. K. Taylor and W. P. Unsworth, Preparation and Reactions of Indoleninyl Halides: Scaffolds for the Synthesis of Spirocyclic Indole Derivatives, Org. Lett., 2016, 18, 6328. (Also includes the synthesis of racemic spirocyclopentane oxindoles). For related recent work see: (b) C. Li, L. Xue, J. Zhou, Y. Zhao, G. Han, J. Hou, Y. Song and Y. Liu, Copper-Catalyzed Trifluoromethylation of Ynones Coupled with Dearomatizing Spirocyclization of Indoles: Access to $\mathrm{CF}_{3}{ }^{-}$ Containing Spiro[cyclopentane-1,3'-indole], Org. Lett., 2020, 22, 3291.

250 S. M. Nicolle, W. Lewis, C. J. Hayes and C. J. Moody, Stereoselective Synthesis of Functionalized Pyrrolidines by the Diverted N-H Insertion Reaction of Metallocarbenes with $\beta$-Aminoketone Derivatives, Angew. Chem., Int. Ed., 2016, 55, 3749.

251 A. C. S. Reddy, P. M. Reddy and P. Anbarasan, Diastereoselective Palladium Catalyzed Carbenylative Amination of ortho-Vinylanilines with 3-Diazoindolin-2ones, Adv. Synth. Catal., 2020, 362, 801.

252 G. Zeng, Y. Li, B. Qiao, X. Zhao and Z. Jiang, Photoredox asymmetric catalytic enantioconvergent substitution of 3-chlorooxindoles, Chem. Commun., 2019, 55, 11362.

253 There are a number of works where 5-membered oxygen spirocycles are synthesised as well as nitrogen heterocycles, these will be referenced again in the appropriate section but not further discussed.

254 (a) S. Chowdhury, M. Chafeev, S. Liu, J. Sun, V. Raina, R. Chui, W. Young, R. Kwan, J. Fu and J. A. Cadieux, Discovery of XEN907, a spirooxindole blocker of $\mathrm{Na}_{\mathrm{V}} 1.7$ for the treatment of pain, Bioorg. Med. Chem. Lett., 2011, 21, 3676; (b) Y. P. Goldberg, N. Price, R. Namdari, C. J. Cohen, M. H. Lamers, C. Winters, J. Price, C. E. Young, H. Verschoof, R. Sherrington, et al., Treatment of $\mathrm{Na}_{\mathrm{v}} 1.7$-mediated pain in inherited erythromelalgia using a novel sodium channel blocker, Pain, 2012, 153, 80-85; (c) S. K. Bagal, M. L. Chapman, B. E. Marron, R. Prime, R. I. Storer and N. A. Swain, Recent progress in sodium channel modulators for pain, Bioorg. Med. Chem. Lett., 2014, 24, 3690.

255 (a) A. K. Franz, P. D. Dreyfuss and S. L. Schreiber, Synthesis and Cellular Profiling of Diverse Organosilicon Small Molecules, J. Am. Chem. Soc., 2007, 129, 1020; (b) R. T. Moon, T. L. Biechele, S. Haggarty and D. Fass, Molecular Inhibitors of the WNT/Beta-Catenin Pathway, PCT Int. Appl WO2010075282A1, 2010; (c) S. Rana, E. C. Blowers, C. Tebbe, J. I. Contreras, P. Radhakrishnan, S. Kizhake, T. Zhou, R. N. Rajule, J. L. Arnst, A. R. Munkarah, et al., Isatin Derived Spirocyclic Analogues with $\alpha$-Methylene- $\gamma$-butyrolactone as
Anticancer Agents: A Structure-Activity Relationship Study, J. Med. Chem., 2016, 59, 5121.

256 N. D. Heindel and J. A. Minatelli, Synthesis and Antibacterial and Anticancer Evaluations of $\alpha$-Methylene$\gamma$-butyrolactones, J. Pharm. Sci., 1981, 70, 84.

257 A. Grossmann, S. Bartlett, M. Janecek, J. T. Hodgkinson and D. R. Spring, Diversity-Oriented Synthesis of DrugLike Macrocyclic Scaffolds Using an Orthogonal Organoand Metal Catalysis Strategy, Angew. Chem., Int. Ed., 2014, 53, 13093.

258 E. D. Styduhar, A. D. Huters, N. A. Weires and N. K. Garg, Enantiospecific Total Synthesis of N-Methylwelwitindolinone D Isonitrile, Angew. Chem., Int. Ed., 2013, 52, 12422.

259 (a) M. C. Nakhla and J. L. Wood, Total Synthesis of (士)-Aspergilline A, J. Am. Chem. Soc., 2017, 139, 18504. For an asymmetric synthesis of a related core structure see: (b) L. Caruana, M. Fochi, M. C. Franchini, S. Ranieri, A. Mazzanti and L. Bernardi, Asymmetric synthesis of 3,4annulated indoles through an organocatalytic cascade approach, Chem. Commun., 2014, 50, 445.

260 H. Liu, L. Chen, K. Yuan and Y. Jia, A Ten-Step Total Synthesis of Speradine C, Angew. Chem., Int. Ed., 2019, 58, 6362.

261 M. A. Maskeri, M. J. O’Connor, A. A. Jaworski, A. V. Davies and K. A. Scheidt, A Cooperative Hydrogen Bond DonorBrønsted Acid System for the Enantioselective Synthesis of Tetrahydropyrans, Angew. Chem., Int. Ed., 2018, 57, 17225.

262 T. Wei and D. J. Dixon, Catalytic stereoselective total synthesis of a spiro-oxindole alkaloid and the pentacyclic core of tryptoquivalines, Chem. Commun., 2018, 54, 12860.

263 G. Bergonzini and P. Melchiorre, Dioxindole in Asymmetric Catalytic Synthesis: Routes to Enantioenriched 3-Substituted 3-Hydroxyoxindoles and the Preparation of Maremycin A, Angew. Chem., Int. Ed., 2012, 51, 971.

264 (a) M. Silvi, I. Chatterjee, Y. Liu and P. Melchiorre, Controlling the Molecular Topology of Vinylogous Iminium Ions by Logical Substrate Design: Highly Regioand Stereoselective Aminocatalytic 1,6-Addition to Linear 2,4-Dienals, Angew. Chem., Int. Ed., 2013, 52, 10780. For a related reaction for cyclopentane synthesis see: $(b) \mathrm{X}$. Tian and P. Melchiorre, Control of Remote Stereochemistry in the Synthesis of Spirocyclic Oxindoles: Vinylogous Organocascade Catalysis, Angew. Chem., Int. Ed., 2013, 52, 5360.

265 C. Zheng, W. Yao, Y. Zhang and C. Ma, Chiral Spirooxindole-Butenolide Synthesis through Asymmetric N-Heterocyclic Carbene-Catalyzed Formal $(3+2)$ Annulation of 3-Bromoenals and Isatins, Org. Lett., 2014, 16, 5028.

266 J. L. Li, B. Sahoo, C. G. Daniliuc and F. Glorius, Conjugate Umpolung of $\beta, \beta$-Disubstituted Enals by Dual Catalysis with an N-Heterocyclic Carbene and a Brønsted Acid: Facile Construction of Contiguous Quaternary Stereocenters, Angew. Chem., Int. Ed., 2014, 53, 10515. 
267 J. Cao, S. Dong, D. Jiang, P. Zhu, H. Zhang, R. Li, Z. Li, X. Wang, W. Tang and D. Du, $\beta$-Functionalization of Indolin-2-one-Derived Aliphatic Acids for the Divergent Synthesis of Spirooxindole $\gamma$-Butyrolactones, J. Org. Chem., 2017, 82, 4186.

268 (a) X. Y. Chen, K. Q. Chen, D. Q. Sun and S. Ye, $\mathrm{N}$-Heterocyclic, carbene-catalyzed oxidative [3+2] annulation of dioxindoles and enals: cross coupling of homoenolate and enolate, Chem. Sci., 2017, 8, 1936; (b) Z. Y. Song, K. Q. Chen, X. Y. Chen and S. Ye, Diastereo- and Enantioselective Synthesis of Spirooxindoles with Contiguous Tetrasubstituted Stereocenters via Catalytic Coupling of Two Tertiary Radicals, J. Org. Chem., 2018, 83, 2966; (c) For a related report at a similar time see: S. Mukherjee, S. Joseph, A. Bhunia, R. G. Gonnade, S. R. Yetra and A. T. Biju, Enantioselective synthesis of spiro $\gamma$-butyrolactones by $\mathrm{N}$-heterocyclic carbene (NHC)catalyzed formal $[3+2]$ annulation of enals with 3-hydroxy oxindoles, Org. Biomol. Chem., 2017, 15, 2013.

269 S. Y. Zhu, H. Zhang, Q. W. Ma, D. Liu and X. P. Hui, Oxidative NHC catalysis: direct activation of $\beta \mathrm{sp}^{3}$ carbons of saturated acid chlorides, Chem. Commun., 2019, 55, 298.

270 (a) Z. Jin, S. Chen, Y. Wang, P. Zheng, S. Yang and Y. R. Chi, $\beta$-Functionalization of Carboxylic Anhydrides with $\quad \beta$-Alkyl Substituents through Carbene Organocatalysis, Angew. Chem., Int. Ed., 2014, 53, 13506; (b) J. Xu, S. Yuan, M. Miao and Z. Chen, 1Hydroxybenzotriazole-Assisted, N-Heterocyclic Carbene Catalyzed $\beta$-Functionalization of Saturated Carboxylic Esters: Access to Spirooxindole Lactones, J. Org. Chem., 2016, 81, 11454; (c) Y. Gao, Y. Ma, C. Xu, L. Li, T. Yang, G. Sima, Z. Fu and W. Huang, Potassium 2-oxo-3-enoates as Effective and Versatile Surrogates for $\alpha, \beta$-Unsaturated Aldehydes in NHC-Catalyzed Asymmetric Reactions, Adv. Synth. Catal., 2018, 360, 479; (d) B. Liu, G. Luo, H. Wang, L. Hao, S. Yang, Z. Jin and Y. R. Chi, Carbene-Catalyzed Direct Functionalization of the $\beta$-sp ${ }^{3}$-Carbon Atoms of $\alpha$-Chloroaldehydes, Chem. - Eur. J., 2019, 25, 12719.

271 Indeed for many of the previously discussed papers, where protected 3-aminooxindoles were used, this can be replaced with 3-hydroxyoxindole to produce the analogous oxygenated product. See ref. 218, 219 and 230.

272 S. Ming, B. L. Zhao and D. M. Du, Chiral squaramide-catalysed enantioselective Michael/cyclization cascade reaction of 3-hydroxyoxindoles with $\alpha, \beta$-unsaturated N-acylated succinimides, Org. Biomol. Chem., 2017, 15, 6205.

273 (a) X. Q. Zhu, J. S. Wu and J. W. Xie, Stereoselective construction of Bi-spirooxindole frameworks via a Michael addition/cyclization and an unexpected redox/oxidative coupling/cyclization, Tetrahedron, 2016, 72, 8327; (b) Y. S. Zhu, W. B. Wang, B. B. Yuan, Y. N. Li, Q. L. Wang and Z. W. Bu, A DBU-catalyzed Michael-Pinner-isomerization cascade reaction of 3-hydroxyoxindoles with isatylidene malononitriles: access to highly functionalized bis- pirooxindoles containing a fully substituted dihydrofuran motif, Org. Biomol. Chem., 2017, 15, 984; (c) N. Gupta, G. Bhojani, R. Tak, A. Jakhar, N. ul H. Khan, S. Chatterjee and R. I. Kureshy, Highly Diastereoselective Syntheses of Spiro-Oxindole Dihydrofuran Derivatives in Aqueous Media and Their Antibacterial Activity, ChemistrySelect, 2017, 2, 10902.

274 M. Balha, B. Mondal and S. C. Pan, Organocatalytic asymmetric synthesis of dihydrofuran-spirooxindoles from benzylidene malononitriles and dioxindoles, Org. Biomol. Chem., 2019, 17, 6557.

275 Z. T. Yang, J. Zhao, W. L. Yang and W. P. Deng, Enantioselective Construction of $\mathrm{CF}_{3}$-Containing Spirooxindole $\gamma$-Lactones via Organocatalytic Asymmetric Michael/Lactonization, Org. Lett., 2019, 21, 1015.

276 For an alternative Michael addition/Cyclisation see: C. K. Tang, Z. Y. Zhou, A. B. Xia, L. Bai, J. Liu, D. Q. Xu and Z. Y. Xu, Combining Organocatalysis and Iodine Catalysis: One-Pot Sequential Catalytic Synthesis of Chiral Spirodihydrobenzofuran Pyrazolones and Spirodihydrobenzofuran Oxindoles, Org. Lett., 2018, 20, 5840 .

277 (a) J. W. Ren, L. Zheng, Z. P. Ye, Z. X. Deng, Z. Z. Xie, J. A. Xiao, F. W. Zhu, H. Y. Xiang, X. Q. Chen and H. Yang, Organocatalytic, Enantioselective, Polarity-Matched RingReorganization Domino Sequence Based on the 3-Oxindole Scaffold, Org. Lett., 2019, 21, 2166. For a related cascade reaction. (b) B. L. Zhao and D. M. Du, Squaramide-Catalyzed Enantioselective Cascade Approach to Bispirooxindoles with Multiple Stereocenters, Adv. Synth. Catal., 2016, 358, 3992.

278 X. L. Jiang, S. J. Liu, Y. Q. Gu, G. J. Mei and F. Shi, Catalytic Asymmetric [4+1] Cyclization of ortho-Quinone Methides with 3-Chlorooxindoles, Adv. Synth. Catal., 2017, 359, 3341.

279 (a) L. Cerisoli, M. Lombardo, C. Trombini and A. Quintavalla, The First Enantioselective Organocatalytic Synthesis of 3-Spiro- $\alpha$-Alkylidene- $\gamma$-Butyrolactone Oxindoles, Chem. - Eur. J., 2016, 22, 3865. For another enantioselective aldol/cyclisation see: (b) W. Guo, X. Wang, B. Zhang, S. Shen, X. Zhou, P. Wang, Y. Liu and C. Li, Facile Synthesis of Chiral Spirooxindole-Based Isoelectronic Acids and 5-1H-Pyrrol-2-ones through Cascade Reactions with Bifunctional Organocatalysts, Chem. - Eur. J., 2014, 20, 8545. For aldol/Michael see: (c) D. Trubitsõn, S. Žari, S. Kaabel, M. Kudrjashova, K. Kriis, I. Järving, T. Pehk and T. Kanger, Asymmetric Organocatalytic Cascade Synthesis of Tetrahydro-furanyl Spirooxindoles, Synthesis, 2018, 50, 314.

280 (a) H. Chen, H. Liu, S. H. Zhao, S. B. Cheng, X. Y. Xu, W. C. Yuan and X. M. Zhang, Enantioselective Arylation of 3-Carboxamide Oxindoles with Quinone Monoimines and Synthesis of Chiral Spirooxindole-benzofuranones, Synlett, 2019, 30, 1067; (b) J. Li, Y. Liu, C. Li and X. Jia, Syntheses of Spirocyclic Oxindole-Butenolides by Using Three-Component Cycloadditions of Isocyanides, 
Allenoates, and Isatins, Chem. - Eur. J., 2011, 17, 7409; (c) Z. Tang, Z. Liu, Y. An, R. Jiang, X. Zhang, C. Li, X. Jia and $\mathrm{J}$. Li, Isocyanide-Based Multicomponent Bicyclization with Substituted Allenoate and Isatin: Synthesis of Unusual Spirooxindole Containing [5.5]-Fused Heterocycle, J. Org. Chem., 2016, 81, 9158; (d) K. Zhang, H. Han, L. Wang, Z. Zhang, Q. Wang, W. Zhang and Z. Bu, An unexpected cascade reaction of 3-hydroxyoxindoles with coumarin-3-carboxylates to construct 2,3-dihydrobenzofuran spirooxindoles, Chem. Commun., 2019, 55, 13681; (e) H. Bin Yang, Y. Z. Zhao, R. Sang, Y. Wei and M. Shi, Asymmetric Synthesis of Bioxindole-Substituted Hexahydrofuro[2,3-b]furans via Hydroquinine Anthraquinone-1,4-diyl Diether-Catalyzed Domino Annulation of Acylidenoxindoles/Isatins, Acylidenoxindoles and Allenoates, Adv. Synth. Catal., 2014, 356, 3799.

281 S. De, M. K. Das, A. Roy and A. Bisai, Synthesis of 2-Oxindoles Sharing Vicinal All-Carbon Quaternary Stereocenters via Organocatalytic Aldol Reaction, J. Org. Chem., 2016, 81, 12258.

282 J. A. Sclafani, J. Chen, D. V. Levy, H. Reese, M. Dimitri, P. Mudipalli, M. Christie, C. J. Neville, M. Olsen and R. P. Bakale, The First Asymmetric Pilot-Scale Synthesis of TV-45070, Org. Process Res. Dev., 2017, 21, 1616.

283 Q. L. Wang, L. Peng, F. Y. Wang, M. L. Zhang, L. N. Jia, F. Tian, X. Y. Xu and L. X. Wang, An organocatalytic asymmetric sequential allylic alkylation-cyclization of MoritaBaylis-Hillman carbonates and 3-hydroxyoxindoles, Chem. Commun., 2013, 49, 9422.

284 (a) Y. L. Liu, X. Wang, Y. L. Zhao, F. Zhu, X. P. Zeng, L. Chen, C. H. Wang, X. L. Zhao and J. Zhou, One-Pot Tandem Approach to Spirocyclic Oxindoles Featuring Adjacent Spiro-Stereocenters, Angew. Chem., Int. Ed., 2013, 52, 13735; (b) P. K. Warghude, A. S. Sabale and R. G. Bhat, Access to highly enantioselective and diastereoselective spirooxindole dihydrofuran fused pyrazolones, Org. Biomol. Chem., 2020, 18, 1794.

285 S. Jayakumar, S. Muthusamy, M. Prakash and V. Kesavan, Enantioselective Synthesis of Spirooxindole $\alpha$-exoMethylene- $\gamma$-butyrolactones from 3-OBoc-Oxindoles, Eur. J. Org. Chem., 2014, 1893.

286 (a) F. Le Hu, Y. Wei and M. Shi, Phosphine-catalyzed asymmetric $[4+1]$ annulation of activated $\alpha, \beta$-unsaturated ketones with Morita-Baylis-Hillman carbonates: enantioselective synthesis of spirooxindoles containing two adjacent quaternary stereocenters, Chem. Commun., 2014, 50, 8912. For a related diastereoselective reaction see: (b) R. Zhou, K. Zhang, Y. Chen, Q. Meng, Y. Liu, R. Li and Z. He, $\mathrm{P}\left(\mathrm{NMe}_{2}\right)_{3}$-mediated reductive $[1+4]$ annulation of isatins with enones: a facile synthesis of spirooxindoledihydrofurans, Chem. Commun., 2015, 51, 14663.

287 For a related enantioselective transformation see: (a) N. J. Zhong, F. Wei, Q. Q. Xuan, L. Liu, D. Wang and Y. J. Chen, Highly diastereo- and enantioselective $[3+2]$ annulation of isatin-derived Morita-Baylis-Hillman car- bonates with trifluoropyruvate catalyzed by tertiary amines, Chem. Commun., 2013, 49, 11071.

288 Z. C. Chen, P. Chen, Z. Chen, Q. Ouyang, H. P. Liang, W. Du and Y. C. Chen, Organocatalytic Enantioselective 1,3-Difunctionalizations of Morita-Baylis-Hillman Carbonates, Org. Lett., 2018, 20, 6279.

289 (a) Y. Murata, M. Takahashi, F. Yagishita, M. Sakamoto, T. Sengoku and H. Yoda, Construction of Spiro-Fused 2-Oxindole/ $\alpha$-Methylene- $\gamma$-Butyrolactone Systems with Extremely High Enantioselectivity via Indium-Catalyzed Amide Allylation of N-Methyl Isatin, Org. Lett., 2013, 15, 6182. Also see: (b) M. Takahashi, Y. Murata, F. Yagishita, M. Sakamoto, T. Sengoku and H. Yoda, Catalytic Enantioselective Amide Allylation of Isatins and Its Application in the Synthesis of 2-Oxindole Derivatives Spiro-Fused to the $\alpha$-Methylene- $\gamma$-Butyrolactone Functionality, Chem. - Eur. J., 2014, 20, 11091.

290 For a related Pd-catalysed allylation see: S. Jayakumar, N. Kumarswamyreddy, M. Prakash and V. Kesavan, Palladium Catalyzed Asymmetric Allylation of 3-OBocOxindoles: An Efficient Synthesis of 3-Allyl-3-hydroxyoxindoles, Org. Lett., 2015, 17, 1066.

291 H. Zhang, Q. Yao, W. Cao, S. Ge, J. Xu, X. Liu and X. Feng, Catalytic enantioselective ene-type reactions of vinylogous hydrazone: construction of $\alpha$-methylene- $\gamma$-butyrolactone derivatives, Chem. Commun., 2018, 54, 12511.

292 B. M. Trost and K. Hirano, Dinuclear Zinc Catalyzed Asymmetric Spirannulation Reaction: An Umpolung Strategy for Formation of $\alpha$-Alkylated- $\alpha$-Hydroxyoxindoles, Org. Lett., 2012, 14, 2446.

293 (a) M. M. Liu, X. C. Yang, Y. Z. Hua, J. B. Chang and M. C. Wang, Synthesis of Chiral Bispirotetrahydrofuran Oxindoles by Cooperative Bimetallic-Catalyzed Asymmetric Cascade Reaction, Org. Lett., 2019, 21, 2111. Also see: (b) Y. H. Miao, Y. Z. Hua and M. C. Wang, Dinuclear zinc cooperative catalytic three-component reactions for highly enantioselective synthesis of 3,3'-dihydrofuran spirooxindoles, Org. Biomol. Chem., 2019, 17, 7172.

294 Y.-J. Guo, X. Guo, D.-Z. Kong, H. Lu, L. Liu, Y.-Z. Hua and M.-C. Wang, Catalytic Asymmetric Synthesis of Tetrahydrofuran Spirooxindoles via a Dinuclear Zinc Catalyst, J. Org. Chem., 2020, 85, 4195.

295 (a) J. Liu, X. Xu, J. Li, B. Liu, H. Jiang and B. Yin, Palladium-catalyzed dearomatizing 2,5-alkoxyarylation of furan rings: diastereospecific access to spirooxindoles, Chem. Commun., 2016, 52, 9550; (b) J. Liu, H. Peng, L. Lu, $\mathrm{X}$. $\mathrm{Xu}, \mathrm{H}$. Jiang and B. Yin, Diastereospecific and Enantioselective Access to Dispirooxindoles from Furfurylcyclobutanols by Means of a Pd-Catalyzed Arylative Dearomatization/Ring Expansion Cascade, Org. Lett., 2016, 18, 6440.

296 D. F. Li, Y. Gu, J. R. Zhang, K. Liu and L. M. Zhao, Diastereoselective Construction of Spiro-furo[3,2-c]benzopyranoxindoles through a $\mathrm{Cu}(\mathrm{OTf})_{2} / \mathrm{AcOH}$ Cooperative Promoted Bicyclization Reaction, J. Org. Chem., 2019, 84, 879. 
297 J. L. Nallasivam and T. K. Chakraborty, Titanocene(III)Mediated 5-exo-trig Radical Cyclization: En Route to Spirooxindole-Based Tetrahydrofuran and Bicyclic Lactone, J. Org. Chem., 2019, 84, 16124.

298 (a) E. L. McInturff, J. Mowat, A. R. Waldeck and M. J. Krische, Ruthenium-Catalyzed Hydrohydroxyalkylation of Acrylates with Diols and $\alpha$-Hydroxycarbonyl Compounds To Form Spiro- and $\alpha$-Methylene- $\gamma$-butyrolactones, J. Am. Chem. Soc., 2013, 135, 17230; (b) T. Luong, S. Chen, K. Qu, E. L. McInturff and M. J. Krische, Ruthenium(0)-Catalyzed C-C Coupling of Alkynes and 3-Hydroxy-2-oxindoles: Direct C-H Vinylation of Alcohols, Org. Lett., 2017, 19, 966.

299 C. S. Buxton, D. C. Blakemore and J. F. Bower, Reductive Coupling of Acrylates with Ketones and Ketimines by a Nickel-Catalyzed Transfer-Hydrogenative Strategy, Angew. Chem., Int. Ed., 2017, 56, 13824.

300 B. M. Trost, Z. Jiao and C. I. Hung, Elaborating Complex Heteroaryl-Containing Cycles via Enantioselective Palladium-Catalyzed Cycloadditions, Angew. Chem., Int. Ed., 2019, 58, 15154.

301 S. M. Nicolle, W. Lewis, C. J. Hayes and C. J. Moody, Stereoselective Synthesis of Highly Substituted Tetrahydrofurans through Diverted Carbene O-H Insertion Reaction, Angew. Chem., Int. Ed., 2015, 54, 8485.

302 (a) G. Karthik, T. Rajasekaran, B. Sridhar and B. V. Subba Reddy, Highly regio- and diastereoselective three-component reaction of acyclic/cyclic donor-acceptor carbenoids for the synthesis of angularly fused furocoumarins and spirooxindolylfurocoumarins, Tetrahedron, 2014, 70, 8148; (b) B. V. S. Reddy, G. Karthik, T. Rajasekaran and B. Sridhar, Stereoselective Synthesis of Highly Functionalized Dispirooxindoles through $[3+2]$ Cycloaddition of Carbonyl Ylides with 3-Arylideneoxindoles, Eur. J. Org. Chem., 2015, 2038; (c) B. V. S. Reddy, E. P. Reddy, B. Sridhar and Y. J. Rao, Rhodium-catalyzed cycloaddition of carbonyl ylides for the synthesis of spiro[furo[2,3-a]xanthene-2,3'-indolin]-2'one scaffolds, RSC Adv., 2016, 6, 50497; (d) S. Murarka, C. Golz, C. Strohmann, A. Antonchick and H. Waldmann, Biology-Oriented Synthesis of 3,3-Spiro(2-tetrahydrofuranyl)oxindoles, Synthesis, 2016, 49, 87; (e) A. C. Hunter, S. C. Schlitzer, J. C. Stevens, B. Almutwalli and I. Sharma, A Convergent Approach to Diverse Spiroethers through Stereoselective Trapping of Rhodium Carbenoids with Gold-Activated Alkynols, J. Org. Chem., 2018, 83, 2744; $(f)$ N. P. Massaro, J. C. Stevens, A. Chatterji and I. Sharma, Stereoselective Synthesis of Diverse Lactones through a Cascade Reaction of Rhodium Carbenoids with Ketoacids, Org. Lett., 2018, 20, 7585; ( $g$ ) G. Xu, S. Tang, Y. Shao and J. Sun, $\mathrm{B}\left(\mathrm{C}_{6} \mathrm{~F}_{5}\right)_{3}$-Catalyzed formal $(4+1)$-annulation of ortho-quinone methides with diazoacetates: access to 2,3dihydrobenzofurans, Chem. Commun., 2019, 55, 90969099; (h) S. Muthusamy, A. Prabu and E. Suresh, Coppercatalyzed synthesis of spiro-indolofurobenzopyrans: tandem reactions of diazoamides and O-propargyl salicylaldehydes, Org. Biomol. Chem., 2019, 17, 8088.
303 L. Y. Mei, Y. Wei, Q. Xu and M. Shi, Diastereo- and Enantioselective Construction of Oxindole-Fused Spirotetrahydrofuran Scaffolds through PalladiumCatalyzed Asymmetric [3 +2$]$ Cycloaddition of Vinyl Cyclopropanes and Isatins, Organometallics, 2013, 32, 3544.

304 J. A. Xiao, Y. C. Li, Z. J. Luo, X. L. Cheng, Z. X. Deng, W. Q. Chen, W. Su and H. Yang, Construction of Bispirooxindole Heterocycles via Palladium-Catalyzed Ring-Opening Formal $[3+2]$-Cycloaddition of Spirovinylcyclopropyl Oxindole and 3-Oxindole Derivatives, J. Org. Chem., 2019, 84, 2297.

305 (a) B. M. Sharma, M. Yadav, R. G. Gonnade and P. Kumar, Unified Approach to Fused and Spirocyclic Oxindoles through Lewis-Acid-Promoted Opening of Spiroepoxyoxindoles with Allylsilanes: Application to the Formal Synthesis of ( \pm )-Physovenine, Eur. J. Org. Chem., 2017, 2603; (b) For a related reaction using $\mathrm{Sc}(\mathrm{OTf})_{3}$ as catalyst see: S. Hajra, S. Roy and S. Maity, Reversal of Selectivity in C3-Allylation and Formal $[3+2]$ Cycloaddition of Spiro-epoxyoxindole: Unified Synthesis of Spiro-furanooxindole, $( \pm)$-N-Methylcoerulescine, $( \pm)$-Physovenine, and 3a-Allylhexahydropyrrolo[2,3-b] indole, Org. Lett., 2017, 19, 1998-2001. Also see ref. 63.

306 (a) S. Hajra, S. Maity and S. Roy, Regioselective FriedelCrafts Reaction of Electron-Rich Benzenoid Arenes and Spiroepoxyoxindole at the Spiro-Centre: Efficient Synthesis of Benzofuroindolines and 2H-Spiro[benzofuran]-3,3'-oxindoles, Adv. Synth. Catal., 2016, 358, 2300. For a related report see: (b) S. Hajra, S. Maity, S. Roy, R. Maity and S. Samanta, Brønsted Acid Promoted Regioselective C-3 Arylation and Heteroarylation of Spiroepoxyoxindoles for the Construction of All Carbon Quaternary Centres: A Detailed Study, Eur. J. Org. Chem., 2019, 969.

307 B. A. Laevens, J. Tao and G. K. Murphy, Iodide-Mediated Synthesis of Spirooxindolo Dihydrofurans from Iodonium Ylides and 3-Alkylidene-2-oxindoles, J. Org. Chem., 2017, 82, 11903.

308 H. Wu, Y. P. He, L. Xu, D. Y. Zhang and L. Z. Gong, Asymmetric Organocatalytic Direct $\mathrm{C}\left(\mathrm{sp}^{2}\right)-\mathrm{H} / \mathrm{C}\left(\mathrm{sp}^{3}\right)-\mathrm{H}$ Oxidative Cross-Coupling by Chiral Iodine Reagents, Angew. Chem., Int. Ed., 2014, 53, 3466.

309 (a) Y. Cao, X. Zhang, G. Lin, D. Zhang-Negrerie and Y. Du, Chiral Aryliodine-Mediated Enantioselective Organocatalytic Spirocyclization: Synthesis of Spirofurooxindoles via Cascade Oxidative $\mathrm{C}-\mathrm{O}$ and $\mathrm{C}-\mathrm{C}$ Bond Formation, Org. Lett., 2016, 18, 5580. For related work by Du see: (b) X. Zhen, X. Wan, W. Zhang, Q. Li, D. Zhang-Negrerie and Y. Du, Synthesis of Spirooxindoles from N-Arylamide Derivatives via Oxidative $\mathrm{C}\left(\mathrm{sp}^{2}\right)-\mathrm{C}\left(\mathrm{sp}^{3}\right)$ Bond Formation Mediated by $\mathrm{PhI}(\mathrm{OMe})_{2}$ Generated in Situ, Org. Lett., 2019, 21, 890.

310 (a) C. Serradeil-Le Gal, C. Lacour, G. Valette, G. Garcia, L. Foulon, G. Galindo, L. Bankir, B. Pouzet, G. Guillon, C. Barberis, et al., Characterization of SR 121463A, a 
highly potent and selective, orally active vasopressin V2 receptor antagonist, J. Clin. Invest., 1996, 98, 2729; (b) H. Venkatesan, M. C. Davis, Y. Altas, J. P. Snyder and D. C. Liotta, Total Synthesis of SR 121463 A, a Highly Potent and Selective Vasopressin $\mathrm{V}_{2}$ Receptor Antagonist, J. Org. Chem., 2001, 66, 3653.

311 J.-J. Liu and Z. Zhang, Spiroindolinone Derivatives, PCT Int. Appl WO2008055812A1, 2008.

312 Y. Zhang, J. Zhang, H. Xie, T. Yu, H. Luo, Q. Ren, X. Wu, C. Fu, S. Li, Y. Lei and B. Hu, Preparation of Pyrrolidine Derivatives as Hepatitis C Inhibitors for Treating Hepatitis C Virus Infection, PCT Int. Appl CN103420991, 2013.

313 A. Fensome, W. R. Adams, A. L. Adams, T. J. Berrodin, J. Cohen, C. Huselton, A. Illenberger, J. C. Kern, V. A. Hudak, M. A. Marella, et al., Design, Synthesis, and SAR of New Pyrrole-Oxindole Progesterone Receptor Modulators Leading to 5-(7-Fluoro-3,3-dimethyl-2-oxo-2,3dihydro-1H-indol-5-yl)-1-methyl-1H-pyrrole-2-carbonitrile (WAY-255348), J. Med. Chem., 2008, 51, 1861.

314 (a) H. Lin and S. J. Danishefsky, Gelsemine: A ThoughtProvoking Target for Total Synthesis, Angew. Chem., Int. Ed., 2003, 42, 36; (b) A. Ghosh and R. G. Carter, Recent Syntheses and Strategies toward Polycyclic Gelsemium Alkaloids, Angew. Chem., Int. Ed., 2019, 58, 681.

315 (a) J. K. Lam, S. B. Joseph and C. D. Vanderwal, A Zincke aldehyde approach to gelsemine, Tetrahedron Lett., 2015, 56, 3165; (b) X. Chen, S. Duan, C. Tao, H. Zhai and F. G. Qiu, Total synthesis of (+)-gelsemine via an organocatalytic Diels-Alder approach, Nat. Commun., 2015, 6, 7204.

316 R. Samineni, J. Madapa, S. Pabbaraja and G. Mehta, Stitching Oxindoles and Ynones in a Domino Process: Access to Spirooxindoles and Application to a Short Synthesis of Spindomycin B, Org. Lett., 2017, 19, 6152.

317 M. Gicquel, C. Gomez, P. Retailleau, A. Voituriez and A. Marinetti, Synthesis of 3,3'-Spirocyclic Oxindoles via Phosphine Catalyzed [4 +2] Cyclizations, Org. Lett., 2013, 15, 4002.

318 B. X. Xiao, B. Jiang, X. Song, W. Du and Y. C. Chen, Phosphine-catalysed asymmetric dearomative formal [4+ 2] cycloadditions of 3-benzofuranyl vinyl ketones, Chem. Commun., 2019, 55, 3097.

319 (a) D. B. Ramachary, C. Venkaiah and R. Madhavachary, Asymmetric Synthesis of Druglike Six-Membered Spirooxindoles through an Amino Enyne Catalysis, Org. Lett., 2013, 15, 3042. For a related reaction using 3-methylene oxindoles to react with malonitriles under $\mathrm{Mg}$ catalysis see: $(b)$ H. Mei, L. Lin, B. Shen, X. Liu and X. Feng, Highly enantioselective desymmetrization of prochiral cyclic $\alpha, \alpha$-dicyanoalkenes via the direct vinylogous Michael/cyclization domino reaction, Org. Chem. Front., 2018, 5, 2505. For reaction of related malonitrile oxindoles with allenes: (c) R. Chen, X. Fan, Z. Xu and Z. He, Facile Synthesis of Spirooxindole-Cyclohexenes via PhosphineCatalyzed $[4+2]$ Annulation of $\alpha$-Substituted Allenoates, Chin. J. Chem., 2017, 35, 1469.
320 (a) H. Huang, M. Bihani and J. C. G. Zhao, Stereoselective synthesis of spirooxindole derivatives using an organocatalyzed tandem Michael-Michael reaction, Org. Biomol. Chem., 2016, 14, 1755; (b) Z. Zhou, Q. He, Y. Jiang, Q. Ouyang, W. Du and Y. C. Chen, Double Thiol-Chiral Brønsted Base Catalysis: Asymmetric Cross RauhutCurrier Reaction and Sequential [4 2] Annulation for Assembly of Different Activated Olefins, Org. Lett., 2019, 21, 7184.

321 (a) X. L. He, H. R. Zhao, X. Song, B. Jiang, W. Du and Y. C. Chen, Asymmetric Barton-Zard Reaction To Access 3-Pyrrole-Containing Axially Chiral Skeletons, ACS Catal., 2019, 9, 4374; (b) L. Peng, K. Li, C. Xie, S. Li, D. Xu, W. Qin and H. Yan, Organocatalytic Asymmetric Annulation of ortho-Alkynylanilines: Synthesis of Axially Chiral Naphthyl-C2-indoles, Angew. Chem., Int. Ed., 2019, 58, 17199.

322 (a) X. Zuo, X. L. Liu, J. X. Wang, Y. M. Yao, Y. Y. Zhou, Q. Di Wei, Y. Gong and Y. Zhou, Organocatalytic Reaction of Chromone-Oxindole Synthon: Access to ChromanoneBased Spirocyclohexaneoxindoles with Five Adjacent Stereocenters, J. Org. Chem., 2019, 84, 6679; (b) X. L. Liu, G. Zhou, Y. Gong, Z. Yao, X. Zuo, W. H. Zhang and Y. Zhou, Stereocontrolled Synthesis of BispirooxindoleBased Hexahydroxanthones with Five Contiguous Stereocenters, Org. Lett., 2019, 21, 2528; (c) S. Q. Chang, X. Zou, Y. Gong, X. W. He, X. L. Liu and Y. Zhou, Stereocontrolled construction of six vicinal stereogenic centers on a hexahydroxanthone framework through a formal [2+1+3] annulation, Chem. Commun., 2019, 55, 14003; (d) X. L. Liu, Q. Di Wei, X. Zuo, S. W. Xu, Z. Yao, J. X. Wang and Y. Zhou, Organocatalytic Michael/Michael Cycloaddition Enabled Asymmetric Construction of Hexahydroxanthones with Skeletal Diversity, Adv. Synth. Catal., 2019, 361, 2836; (e) X. L. Liu, Y. Gong, S. Chen, X. Zuo, Z. Yao and Y. Zhou, Bifunctional oxindole-chromone 4C building block directed asymmetric synthesis of bispirocyclic hexahydroxanthones featuring five contiguous stereocenters and two side-by-side oxindoles, Org. Chem. Front., 2019, 6, 1603; $(f)$ M. Zhang, J. X. Wang, S. Q. Chang, X. L. Liu, X. Zuo and Y. Zhou, Highly efficient enantioselective synthesis of bispiro[benzofuranoxindole/benzofuran-chromanone]s through organocatalytic inter-/intramolecular Michael cycloaddition, Chin. Chem. Lett., 2020, 31, 381.

323 W. Ren, X. Y. Wang, J. J. Li, M. Tian, J. Liu, L. Ouyang and J. H. Wang, Efficient construction of biologically important functionalized polycyclic spiro-fused carbocyclicoxindoles via an asymmetric organocatalytic quadruplecascade reaction, $R S C A d v ., 2017,7,1863$.

324 (a) A. K. Ghosh and B. Zhou, Enantioselective synthesis of spiro[cyclohexane-1,3'-indolin]-2'-ones containing multiple stereocenters via organocatalytic Michael/aldol cascade reactions, Tetrahedron Lett., 2013, 54, 2311; (b) S. Roy, M. Amireddy and K. Chen, Organocatalytic formal $[5+1]$ annulation: diastereoselective cascade syn- 
thesis of functionalized six-membered spirocyclic indane1,3-diones/oxindoles via Michael-aldol reaction, Tetrahedron, 2013, 69, 8751; (c) S. Xu, C. Li, X. Jia and J. Li, $\mathrm{AlCl}_{3}$-Promoted Selective Michael Addition with Allenoate and Methyleneindolinone: Synthesis of Spirocyclic Oxindole by Using Allenoate as a Four-Carbon Component Building Block, J. Org. Chem., 2014, 79, 11161; (d) M. Vishwanath, P. Vinayagam, V. P. R. Gajulapalli and V. Kesavan, Asymmetric Organocatalytic Assembly of Oxindoles Fused with Spiro3,4-dihydropyrans with Three Contiguous Stereocenters Consisting of Vicinal Quaternary Centers, Asian J. Org. Chem., 2016, 5, 613. For a desymmetrising aldol reaction see: (e) B. B. Sun, Y. F. Zhang, J. Q. Zhang, S. J. Yin, W. T. Fan, H. Y. Li and X. W. Wang, Cinchona Alkaloid Derived Primary Amine Catalyzed Intramolecular Desymmetrizing Aldolization Reaction of Diacetonyloxindoles, Eur. J. Org. Chem., 2017, 2871.

325 These examples include reactions with more than 2 steps or conjugate additions followed by a different cyclisation mode: (a) B. Zhou, Y. Yang, J. Shi, Z. Luo and Y. Li, Synthesis of Six-Membered Spirocyclic Oxindoles with Five Consecutive Stereocenters in an Asymmetric Organocatalytic One-Pot Michael/Michael/Aldol Addition Sequence, J. Org. Chem., 2013, 78, 2897; (b) Z. Zhou, X. Feng, X. Yin and Y. C. Chen, Direct Remote Asymmetric Bisvinylogous 1,4-Additions of Cyclic 2,5-Dienones to Nitroalkenes, Org. Lett., 2014, 16, 2370; (c) R. Zhou, Q. Wu, M. Guo, W. Huang, X. He, L. Yang, F. Peng, G. He and B. Han, Organocatalytic cascade reaction for the asymmetric synthesis of novel chroman-fused spirooxindoles that potently inhibit cancer cell proliferation, Chem. Commun., 2015, 51, 13113; (d) Q. S. Sun, H. Lin, X. Sun and X. W. Sun, Highly efficient synthesis of enantioenriched fully-substituted spirocyclohexane oxindoles via a Michael-Michael-aldol cascade reaction, Tetrahedron Lett., 2016, 57, 5673. Radical pathway: (e) H. R. Wu, L. Cheng, D. L. Kong, H. Y. Huang, C. L. Gu, L. Liu, D. Wang and C. J. Li, $\mathrm{FeCl}_{3}$-Mediated Radical Tandem Reactions of 3-Benzyl-2-oxindoles with Styrene Derivatives for the Stereoselective Synthesis of Spirocyclohexene Oxindoles, Org. Lett., 2016, 18, 1382.

326 B. Wang, X. H. Wang, W. Huang, J. Zhou, H. P. Zhu, C. Peng and B. Han, Protecting GroupDirected Diastereodivergent Synthesis of Chiral Tetrahydronaphthalene-Fused Spirooxindoles via Bifunctional Tertiary Amine Catalysis, J. Org. Chem., 2019, 84, 10349.

327 (a) Y. Liu, M. Nappi, E. Arceo, S. Vera and P. Melchiorre, Asymmetric Catalysis of Diels-Alder Reactions with in Situ Generated Heterocyclic ortho-Quinodimethanes, J. Am. Chem. Soc., 2011, 133, 15212; (b) B. Tan, G. HernándezTorres and C. F. Barbas, Highly Efficient HydrogenBonding Catalysis of the Diels-Alder Reaction of 3-Vinylindoles and Methyleneindolinones Provides Carbazolespirooxindole Skeletons, J. Am. Chem. Soc., 2011, 133, 12354.
328 Hydrogen bonding catalysis: (a) L. J. Huang, J. Weng, S. Wang and G. Lu, Organocatalytic Diels-Alder Reaction of 2-Vinylindoles with Methyleneindolinones: An Efficient Approach to Functionalized Carbazolespirooxindoles, Adv. Synth. Catal., 2015, 357, 993; (b) J. W. Ren, J. Wang, J. A. Xiao, J. Li, H. Y. Xiang, X. Q. Chen and H. Yang, L-Pyroglutamic, Sulphonamide as Hydrogen-Bonding Organocatalyst: Enantioselective Diels-Alder Cyclization to Construct Carbazolespirooxindoles, J. Org. Chem., 2017, 82, 6441. TfOH catalysed domino reactions: (c) R. Y. Yang, J. Sun, Y. Tao, Q. Sun and C. G. Yan, TfOH-Catalyzed OnePot Domino Reaction for Diastereoselective Synthesis of Polysubstituted Tetrahydrospiro[carbazole-1,3'-indoline]s, J. Org. Chem., 2017, 82, 13277; (d) R. Y. Yang, J. Sun, Q. Sun and C. G. Yan, Selective Synthesis of 3-(9H-Carbazol-2-yl)indolin-2-ones and Spiro[tetrahydrocarbazole-3,3'-oxindoles] via a HOTf Catalyzed ThreeComponent Reaction, J. Org. Chem., 2018, 83, 5909; (e) J. Guo, X. Bai, Q. Wang and Z. Bu, Diastereoselective Construction of Indole-Bridged Chroman Spirooxindoles through a TfOH-Catalyzed Michael Addition-Inspired Cascade Reaction, J. Org. Chem., 2018, 83, 3679. Ag catalysed aminoenyne formation: $(f)$ P. Sharma, N. P. Kumar, N. H. Krishna, D. Prasanna, B. Sridhar and N. Shankaraiah, Silver(I)-catalysed domino alkyne-annulation/Diels-Alder reaction: a mild synthetic approach to tetrahydrospiro[carbazole-4,3'-indoline] scaffolds, Org. Chem. Front., 2016, 3, 1503. Iminium ion catalysis: $(g)$ Z. H. You, Y. H. Chen, Y. Tang and Y. K. Liu, Organocatalytic Asymmetric Synthesis of Spiro-Bridged and Spiro-Fused Heterocyclic Compounds Containing Chromane, Indole, and Oxindole Moieties, Org. Lett., 2018, 20, 6682. Cu mediated 3-component reaction: (h) S.-C. Zhan, J. Sun, R.-Z. Liu and C.-G. Yan, Diastereoselective construction of carbazole-based spirooxindoles via the Levy three-component reaction, Org. Biomol. Chem., 2020, 18, 163.

329 H. Zheng, P. He, Y. Liu, Y. Zhang, X. Liu, L. Lin and $\mathrm{X}$. Feng, Efficient synthesis of carbazolespirooxindole skeletons via asymmetric Diels-Alder reaction of 3-vinylindoles and methyleneindolinones, Chem. Commun., 2014, 50, 8794.

330 Y. Wang, M. S. Tu, L. Yin, M. Sun and F. Shi, Brønsted Acid Catalyzed Asymmetric Diels-Alder Reactions: Stereoselective Construction of Spiro[tetrahydrocarbazole3,3'-oxindole] Framework, J. Org. Chem., 2015, 80, 3223.

331 H. Miyamoto, T. Hirano, Y. Okawa, A. Nakazaki and S. Kobayashi, Stereoselective synthesis of spirocyclic oxindoles based on a one-pot Ullmann coupling/Claisen rearrangement and its application to the synthesis of a hexahydropyrrolo[2,3-b]indole alkaloid, Tetrahedron, 2013, 69, 9481.

332 G. Li, T. Liang, L. Wojtas and J. C. Antilla, An Asymmetric Diels-Alder Reaction Catalyzed by Chiral Phosphate Magnesium Complexes: Highly Enantioselective Synthesis of Chiral Spirooxindoles, Angew. Chem., Int. Ed., 2013, 52, 4628. 
333 (a) J. Zheng, L. Lin, K. Fu, H. Zheng, X. Liu and X. Feng, Synthesis of Optically Pure Spiro[cyclohexane-oxindoline] Derivatives via Catalytic Asymmetric Diels-Alder Reaction of Brassard-Type Diene with Methyleneindolines, J. Org. Chem., 2015, 80, 8836. Also see: (b) Y. F. Zhang, S. J. Yin, M. Zhao, J. Q. Zhang, H. Y. Li and X. W. Wang, Dinuclear zinc-catalyzed desymmetric intramolecular aldolization: an enantioselective construction of spiro[cyclohexanoneoxindole] derivatives, RSC Adv., 2016, 6, 30683.

334 For a related diastereoselective reaction mediated by AcOH see: R. Y. Yang, J. Sun and C. G. Yan, HOAcMediated Domino Diels-Alder Reaction for Synthesis of Spiro[cyclohexane-1,3'-indolines] in Ionic Liquid [Bmim] Br, ACS Omega, 2018, 3, 5406.

335 (a) S. Muthusamy and V. Kesavan, Asymmetric Cycloaddition Reactions of Oxindole $\alpha$-Keto Esters via Cascade Dienamine-Enamine and Trienamine Strategies, Eur. J. Org. Chem., 2019, 4046. For a similar reaction of 2,4-dienals see: (b) A. S. Marques, J. Marrot, I. Chataigner, V. Coeffard, G. Vincent and X. Moreau, In Situ Generation of Cyclopentadienol Intermediates from 2,4-Dienals. Application to the Synthesis of Spirooxindoles via a Domino Polycyclization, Org. Lett., 2018, 20, 792.

336 H. Zheng, Y. Wang, C. Xu, Q. Xiong, L. Lin and X. Feng, Diversified Cycloisomerization/Diels-Alder Reactions of 1,6-Enynes through Bimetallic Relay Asymmetric Catalysis, Angew. Chem., Int. Ed., 2019, 58, 5327.

337 Y. Luo, H. Zhang, S. Wang, Y. Zhou, S. Dong and X. Feng, Asymmetric Catalytic Diverse Ring Opening/ Cycloadditions of Cyclobutenones with (E)Alkenyloxindoles and (E)-Dioxopyrrolidines, Org. Lett., 2020, 22, 2645.

338 L. J. Huang, J. Weng, S. Wang and G. Lu, Organocatalytic Diels-Alder Reaction of 2-Vinylindoles with Methyleneindolinones: An Efficient Approach to Functionalized Carbazolespirooxindoles, Adv. Synth. Catal., 2015, 357, 993.

339 (a) B. K. Min, D. Y. Seo, J. Y. Ryu, J. Lee and J. N. Kim, Synthesis of Spirocyclohexadieneyl-2-Oxindoles by $6 \pi$-Electrocyclization of Trienes Derived from Wittig Reaction of Morita-Baylis-Hillman Carbonates and $\alpha, \beta$-Unsaturated Aldehydes, Bull. Korean Chem. Soc., 2018, 39, 115. For related reaction to bispirooxindoles: (b) B. K. Min, S. Lee, H. J. Roh, J. Y. Ryu, J. Lee and J. N. Kim, Synthesis of dispirocyclohexadiene bisoxindole from Morita-Baylis-Hillman carbonate of isatin, Tetrahedron Lett., 2017, 58, 3251.

340 (a) J. R. Huang, M. Sohail, T. Taniguchi, K. Monde and F. Tanaka, Formal $(4+1)$ Cycloaddition and Enantioselective Michael-Henry Cascade Reactions To Synthesize Spiro[4,5]decanes and Spirooxindole Polycycles, Angew. Chem., Int. Ed., 2017, 56, 5853. For work on related oxygenated heterocycles see: $(b)$ M. Sohail and F. Tanaka, Dynamic stereoselective annulation via aldol-oxa-cyclization cascade reaction to afford spirooxindole pyran polycycles, Commun. Chem., 2019, 2, 73.
341 K. H. Kim, H. R. Moon, J. Lee and J. N. Kim, PalladiumCatalyzed Construction of Spirooxindoles by Arylative Cyclization of 3-( $\gamma, \delta$-Disubstituted)allylidene-2-Oxindoles, Adv. Synth. Catal., 2015, 357, 701. Also see ref. 81.

342 (a) H. Yoon, A. Lossouarn, F. Landau and M. Lautens, PdCatalyzed Spirocyclization via C-H Activation and Benzyne Insertion, Org. Lett., 2016, 18, 6324; (b) M. Pérez-Gómez and J. A. García-López, Trapping $\sigma$-Alkyl-Palladium(II) Intermediates with Arynes Encompassing Intramolecular C-H Activation: Spirobiaryls through Pd-Catalyzed Cascade Reactions, Angew. Chem., Int. Ed., 2016, 55, 14389.

343 (a) H. Yoon, M. Rölz, F. Landau and M. Lautens, Palladium-Catalyzed Spirocyclization through $\mathrm{C}-\mathrm{H}$ Activation and Regioselective Alkyne Insertion, Angew. Chem., Int. Ed., 2017, 56, 10920; (b) I. Franzoni, H. Yoon, J.-A. García-López, A. I. Poblador-Bahamonde and M. Lautens, Exploring the mechanism of the Pd-catalyzed spirocyclization reaction: a combined DFT and experimental study, Chem. Sci., 2018, 9, 1496. For a review see: (c) A. D. Marchese, E. M. Larin, B. Mirabi and M. Lautens, Metal-Catalyzed Approaches toward the Oxindole Core, Acc. Chem. Res., 2020, 53, 1605.

344 X. Luo, Y. Xu, G. Xiao, W. Liu, C. Qian, G. Deng, J. Song, Y. Liang and C. Yang, Palladium-Catalyzed Tandem Reaction of Three Aryl Iodides Involving Triple C-H Activation, Org. Lett., 2018, 20, 2997.

345 D. Arunprasath, B. D. Bala and G. Sekar, Stereoselective Construction of $\alpha$-Tetralone-Fused Spirooxindoles via PdCatalyzed Domino Carbene Migratory Insertion/Conjugate Addition Sequence, Org. Lett., 2017, 19, 5280.

346 D.-Y. Zhang, L. Xu, H. Wu and L.-Z. Gong, Chiral IodineCatalyzed Dearomatizative Spirocyclization for the Enantioselective Construction of an All-Carbon Stereogenic Center, Chem. - Eur. J., 2015, 21, 10314.

347 (a) A. V. Chate, S. P. Kamdi, A. N. Bhagat, C. K. Jadhav, A. Nipte, A. P. Sarkate, S. V. Tiwari and C. H. Gill, Design, Synthesis and SAR Study of Novel Spiro [Pyrimido[5,4-b] Quinoline-10,5'-Pyrrolo[2,3-d]Pyrimidine] Derivatives as Promising Anticancer Agents, J. Heterocycl. Chem., 2018, 55, 2297; (b) J. Li, N. Wu, Y. Tian, J. Zhang and S. Wu, Aminopyridyl/Pyrazinyl Spiro[indoline-3,4'-piperidine]-2ones As Highly Selective and Efficacious c-Met/ALK Inhibitors, ACS Med. Chem. Lett., 2013, 4, 806; (c) F. Shirai, A. Mizutani, Y. Yashiroda, T. Tsumura, Y. Kano, Y. Muramatsu, T. Chikada, H. Yuki, H. Niwa, S. Sato, et al., Design and Discovery of an Orally Efficacious Spiroindolinone-Based Tankyrase Inhibitor for the Treatment of Colon Cancer, J. Med. Chem., 2020, 63, 4183.

348 F. Shirai, T. Tsumura, Y. Yashiroda, H. Yuki, H. Niwa, S. Sato, T. Chikada, Y. Koda, K. Washizuka, N. Yoshimoto, et al., Discovery of Novel Spiroindoline Derivatives as Selective Tankyrase Inhibitors, J. Med. Chem., 2019, 62, 3407.

349 H. Richter, A. L. Satz, M. Bedoucha, B. Buettelmann, A. C. Petersen, A. Harmeier, R. Hermosilla, 
R. Hochstrasser, D. Burger, B. Gsell, et al., DNA-Encoded Library-Derived DDR1 Inhibitor Prevents Fibrosis and Renal Function Loss in a Genetic Mouse Model of Alport Syndrome, ACS Chem. Biol., 2019, 14, 37.

350 J. Xu, X. Xie, N. Ye, J. Zou, H. Chen, M. A. White, P.-Y. Shi and J. Zhou, Design, Synthesis, and Biological Evaluation of Substituted 4,6-Dihydrospiro[[1,2,3]triazolo[4,5-b]pyridine-7,3'-indoline]-2',5(3H)-dione Analogues as Potent NS4B Inhibitors for the Treatment of Dengue Virus Infection, J. Med. Chem., 2019, 62, 7941.

351 (a) G. C. Bignan, K. Battista, P. J. Connolly, M. J. Orsini, J. Liu, S. A. Middleton and A. B. Reitz, Preparation of 3-spirocyclic indolin-2-ones as ligands for the ORL-1 receptor, Bioorg. Med. Chem. Lett., 2005, 15, 5022; (b) S. Ansorge, U. Bank, K. Noordhoff, M. Täger and F. Striggow, Novel Alanyl-Amino Peptidase Inhibitors for Functionally Influencing Different Cells and Treating Immunological, Inflammatory, Neuronal, and Other Diseases, PCT Int. Appl WO2005037257A2, 2005.

352 E. Hayashi and S. Yamada, Pharmacological studies on surugatoxin, the toxic principle from Japanese ivory mollusc (Babylonia japonica), Br. J. Pharmacol., 1975, 53, 207.

353 See ref. 16 and (a) M. Rottmann, C. McNamara, B. K. S. Yeung, M. C. S. Lee, B. Zou, B. Russell, P. Seitz, D. M. Plouffe, N. V. Dharia, J. Tan, et al., Spiroindolones, a Potent Compound Class for the Treatment of Malaria, Science, 2010, 329, 1175; (b) N. J. White, S. Pukrittayakamee, A. P. Phyo, R. Rueangweerayut, F. Nosten, P. Jittamala, A. Jeeyapant, J. P. Jain, G. Lefèvre, R. Li, et al., Spiroindolone KAE609 for Falciparum and Vivax Malaria, N. Engl. J. Med., 2014, 371, 403; (c) H. Turner, Spiroindolone NITD609 is a novel antimalarial drug that targets the P-type ATPase PfATP4, Future Med. Chem., 2016, 8, 227; (d) T. D. Ashton, S. M. Devine, J. J. Möhrle, B. Laleu, J. N. Burrows, S. A. Charman, D. J. Creek and B. E. Sleebs, The Development Process for Discovery and Clinical Advancement of Modern Antimalarials, J. Med. Chem., 2019, 62, 10526.

354 H. Takada, N. Kumagai and M. Shibasaki, Stereoselective Total Synthesis of KAE609 via Direct Catalytic Asymmetric Alkynylation to Ketimine, Org. Lett., 2015, 17, 4762.

355 H. Zheng, X. Liu, C. Xu, Y. Xia, L. Lin and X. Feng, Regioand Enantioselective Aza-Diels-Alder Reactions of 3-Vinylindoles: A Concise Synthesis of the Antimalarial Spiroindolone NITD609, Angew. Chem., Int. Ed., 2015, 54, 10958.

356 For piperazines see: (a) K. Ramakumar, T. Maji, J. J. Partridge and J. A. Tunge, Synthesis of Spirooxindoles via the tert-Amino Effect, Org. Lett., 2017, 19, 4014; (b) L.-L. Wang, T. Jiang, P.-H. Li, R.-J. Sun and Z. Zuo, Asymmetric Syntheses of Spirooxindole-dihydroquinazolinones by Cyclization Reactions between N-substituted Anthranilamides and Isatins, Adv. Synth. Catal., 2018, 360, 4832; (c) R. Ye and C. G. Yan, Construction of Spiro[indoline-3,3'-pyridazines] and Spiro[indene-2,3'-pyridazines] via TEMPO-Mediated Oxidative Aza-Diels-Alder Reactions, Eur. J. Org. Chem., 2019, 5882. For morpholines see: (d) M. Montesinos-Magraner, C. Vila, R. Cantõn, G. Blay, I. Fernández, M. C. Muñoz and J. R. Pedro, Organocatalytic Asymmetric Addition of Naphthols and Electron-Rich Phenols to Isatin-Derived Ketimines: Highly Enantioselective Construction of Tetrasubstituted Stereocenters, Angew. Chem., Int. Ed., 2015, 54, 6320; (e) P. W. Xu, C. Chen, J. K. Liu, Y. T. Song, F. Zhou, J. Yan and J. Zhou, One-Pot Sequential $[3+3]$ Dipolar Cycloaddition of Aldehyde or Ketone and Hydroxylamine with Spirocyclopropyl Oxindole, J. Org. Chem., 2018, 83, 12763; $(f)$ S. Hajra, A. Hazra and S. K. Abu Saleh, One-Pot Synthesis of Enantiopure Spiro[3,4-dihydrobenzo[b,][1,4] oxazine-2,3'-oxindole] via Regio- and Stereoselective Tandem Ring Opening/Cyclization of Spiroaziridine Oxindoles with Bromophenols, J. Org. Chem., 2019, 84, 10412. Urea: $(g)$ M. Stucchi, G. Lesma, F. Meneghetti, G. Rainoldi, A. Sacchetti and A. Silvani, Organocatalytic Asymmetric Biginelli-like Reaction Involving Isatin, J. Org. Chem., 2016, 81, 1877. Carbamate: $(h)$ W. Guo, L. Li, Q. Ding, X. Lin, X. Liu, K. Wang, Y. Liu, H. Fan and C. Li, Synthesis of Chiral Trispirocyclic Oxindoles via OrganicBase/Au(I)-Catalyzed Sequential Reactions, ACS Catal., 2018, 8, 10180. Other: (i) G. Zhu, W. Sun, C. Wu, G. Li, L. Hong and R. Wang, Base-Catalyzed Diastereoselective $[3+3]$ Annulation of 3-Isothiocyanatooxindoles and Azomethine Imines, Org. Lett., 2013, 15, 4988.

357 X. N. Zhang, G. Q. Chen, X. Dong, Y. Wei and M. Shi, Phosphine-Catalyzed Asymmetric $[4+2]$ Annulation of Vinyl Ketones with Oxindole-Derived $\alpha, \beta$-Unsaturated Imines: Enantioselective Syntheses of 2',3'-Dihydro-1'H-spiro[indoline-3,4'-pyridin]-2-ones, Adv. Synth. Catal., 2013, 355, 3351.

358 B. V. S. Reddy, M. Swain, S. M. Reddy, J. S. Yadav and B. Sridhar, Gold-Catalyzed 5-endo-dig Cyclization of 2-[(2Aminophenyl)ethynyl]phenylamine with Ketones for the Synthesis of Spiroindolone and Indolo[3,2-c]quinolone Scaffolds, Eur. J. Org. Chem., 2014, 3313.

359 S. Jayakumar, K. Louven, C. Strohmann and K. Kumar, A Tunable and Enantioselective Hetero-Diels-Alder Reaction Provides Access to Distinct Piperidinoyl Spirooxindoles, Angew. Chem., Int. Ed., 2017, 56, 15945.

360 (a) W. Cao, X. Liu, J. Guo, L. Lin and X. Feng, Asymmetric Tandem 1,5-Hydride Shift/Ring Closure for the Synthesis of Chiral Spirooxindole Tetrahydroquinolines, Chem. Eur. J., 2015, 21, 1632; (b) Z. Mao, F. Mo and X. Lin, Diastereo- and Enantioselective Assembly of Spirooxindole Tetrahydroquinoline Skeletons through Asymmetric Binary Acid Catalyzed Hydride TransferCyclization, Synlett, 2016, 27, 546; (c) S. S. Li, S. Zhu, C. Chen, K. Duan, Q. Liu and J. Xiao, Hydride Transfer Involved Redox-Neutral Cascade Cyclizations for Construction of Spirocyclic Bisoxindoles Featuring a [3,4]Fused Oxindole Moiety, Org. Lett., 2019, 21, 1058.

361 G. J. Mei, D. Li, G. X. Zhou, Q. Shi, Z. Cao and F. Shi, A catalytic asymmetric construction of a tetrahydroquino- 
line-based spirooxindole framework via a diastereo- and enantioselective decarboxylative $[4+2]$ cycloaddition, Chem. Commun., 2017, 53, 10030.

362 L. Hao, C. Chuen, R. Ganguly and Y. Chi, NHC-Catalyzed Ester Activation: Access to Sterically Congested Spirocyclic Oxindoles via Reaction of $\alpha$-Aryl Esters and Unsaturated Imines, Synlett, 2013, 24, 1197.

363 D. Xie, L. Yang, Y. Lin, Z. Zhang, D. Chen, X. Zeng and G. Zhong, Rapid Access to Spirocylic Oxindoles: Application of Asymmetric N-Heterocyclic CarbeneCatalyzed [3 +3$]$ Cycloaddition of Imines to OxindoleDerived Enals, Org. Lett., 2015, 17, 2318.

364 W. Q. Jia, H. M. Zhang, C. L. Zhang, Z. H. Gao and S. Ye, $\mathrm{N}$-Heterocyclic, carbene-catalyzed $[4+2]$ annulation of $\alpha, \beta$-unsaturated carboxylic acids: enantioselective synthesis of dihydropyridinones and spirocyclic oxindolodihydropyridinones, Org. Chem. Front., 2016, 3, 77.

365 J. Xu, S. Yuan and M. Miao, N-Heterocyclic, Carbene Catalyzed $[4+2]$ Annulation Reactions with in Situ Generated Heterocyclic ortho-Quinodimethanes, Org. Lett., 2016, 18, 3822.

366 C. He, Z. Li, J. Xu and H. Ren, Asymmetric Synthesis of Spirocyclic Oxindole $\delta$-Lactams via NHC-Catalyzed Formal $[2+4]$ Annulation of Aliphatic Aldehydes with OxindoleDerived $\alpha, \beta$-Unsaturated Ketimines, J. Org. Chem., 2019, 84, 12177.

367 (a) Q. Liu, X. Y. Chen, S. Li, K. Rissanen and D. Enders, N-Heterocyclic, Carbene Catalyzed Asymmetric Synthesis of Pentacyclic Spirooxindoles via [3+3] Annulations of Isatin-Derived Enals and Cyclic N-Sulfonyl Ketimines, $A d v$. Synth. Catal., 2019, 361, 1991. For a further example see: (b) H. Lu, C. Y. Tan, H. X. Zhang, J. L. Zhang, J. Y. Liu, H. Y. Li and P. F. Xu, Participation of $\beta$-Ketothioamides in $\mathrm{N}-$ Heterocyclic Carbene-Catalyzed [3 +3$]$ Spiroannulation: Asymmetric Synthesis of Functionalized Spiro-piperidinone Derivatives, J. Org. Chem., 2018, 83, 15245.

368 F. Shi, G.-J. Xing, R.-Y. Zhu, W. Tan and S. Tu, A Catalytic Asymmetric Isatin-Involved Povarov Reaction: Diastereoand Enantioselective Construction of Spiro[indolin-3,2'quinoline] Scaffold, Org. Lett., 2013, 15, 128.

369 For other reports of the use of the Povarov reaction to spiropiperidines see: (a) H. Gao, J. Sun and C. G. Yan, Povarov Reaction of $\beta$-Enamino Esters and Isatin-3-imines for Diastereoselective Synthesis of Spiro[indoline-3,2'-quinolines], Synthesis, 2014, 46, 489; (b) G. Bianchini, P. Ribelles, D. Becerra, M. T. Ramos and J. C. Menéndez, Efficient synthesis of 2-acylquinolines based on an aza-vinylogous Povarov reaction, Org. Chem. Front., 2016, 3, 412.

370 (a) H. H. Zhang, X. X. Sun, J. Liang, Y. M. Wang, C. C. Zhao and F. Shi, Catalytic asymmetric Povarov reaction of isatin-derived 2-azadienes with 3-vinylindoles, Org. Biomol. Chem., 2014, 12, 9539. Also see: (b) Z. Mao, F. Mo and X. Lin, Diastereo- and Enantioselective Assembly of Spirooxindole Tetrahydroquinoline Skeletons through Asymmetric Binary Acid Catalyzed Hydride TransferCyclization, Synlett, 2016, 27, 546.
371 H. Mao, A. Lin, Y. Tang, Y. Shi, H. Hu, Y. Cheng and C. Zhu, Organocatalytic oxa/aza-Michael-Michael Cascade Strategy for the Construction of Spiro [Chroman/ Tetrahydroquinoline-3,3'-oxindole] Scaffolds, Org. Lett., 2013, 15, 4062.

372 (a) Y. You, B. D. Cui, M. Q. Zhou, J. Zuo, J. Q. Zhao, X. Y. Xu, X. M. Zhang and W. C. Yuan, Organocatalytic Asymmetric Michael/Friedel-Crafts Cascade Reaction of 3 -Pyrrolyl-oxindoles and $\alpha, \beta$-Unsaturated Aldehydes for the Construction of Chiral Spiro[5,6-dihydropyrido[1,2-a] pyrrole-3,3'-oxindoles], J. Org. Chem., 2015, 80, 5951. Also see: (b) W. T. Fan, N. K. Li, L. Xu, C. Qiao and X. W. Wang, Organo-Catalyzed Asymmetric Michael-HemiketalizationOxa-Pictet-Spengler Cyclization for Bridged and Spiro Heterocyclic Skeletons: Oxocarbenium Ion as a Key Intermediate, Org. Lett., 2017, 19, 6626; (c) Z. Gao, J. Zhang, H. Yang and G. Jiang, Brønsted Acid-Promoted FriedelCrafts Alkylation/Cyclization of (7-Hydroxynaphthalenyl) pyrrole or (2-Hydroxyphenyl)pyrroles with Isatins for the Construction of Pyrrolospirooxindole Derivatives, J. Org. Chem., 2018, 83, 11407; (d) N. K. Li, W. T. Fan, J. Q. Zhang, B. B. Sun, J. B. Chen and X. W. Wang, Diastereodivergent synthesis of bispirooxindoles via asymmetric Friedel-Crafts/ aldol cascade reaction: co-catalyst effects on diastereoselective outcomes, Chem. Commun., 2018, 54, 2260.

373 (a) W. Yang and D.-M. Du, Cinchona-based squaramidecatalysed cascade aza-Michael-Michael addition: enantioselective construction of functionalized spirooxindole tetrahydroquinolines, Chem. Commun., 2013, 49, 8842; (b) Y. M. Huang, C. W. Zheng and G. Zhao, Organocatalyzed aza-Michael-Michael cascade reactions to construct spirooxindole tetrahydroquinolines with allcarbon chiral centers, RSC Adv., 2013, 3, 16999; (c) Y. Tan, E. L. Feng, Q. S. Sun, H. Lin, X. Sun, G. Q. Lin and X. W. Sun, Enantioselective synthesis of spirooxindole benzoquinolizines via organo-catalyzed cascade reactions, Org. Biomol. Chem., 2017, 15, 778; (d) W. Dai, H. Lu, X. Li, F. Shi and S. J. Tu, Diastereo- and Enantioselective Construction of a Bispirooxindole Scaffold Containing a Tetrahydro- $\beta$-carboline Moiety through an Organocatalytic Asymmetric Cascade Reaction, Chem. - Eur. J., 2014, 20, 11382; (e) Y. Liu, J. Xue, Z. Sun, D. Liu, Y. Xing and Y. Li, Substituent-Controlled Selective Synthesis of Spirooxindoles and Oxazolyloxindoles via Two Tandem Reactions, Asian J. Org. Chem., 2016, 5, 43; (f) Q. Zhao, C. Peng, H. Huang, S. J. Liu, Y. J. Zhong, W. Huang, G. He and B. Han, Asymmetric synthesis of tetrahydroisoquinoline-fused spirooxindoles as Ras-GTP inhibitors that inhibit colon adenocarcinoma cell proliferation and invasion, Chem. Commun., 2018, 54, 8359.

374 M. C. Yang, C. Peng, H. Huang, L. Yang, X. H. He, W. Huang, H. L. Cui, G. He and B. Han, Organocatalytic Asymmetric Synthesis of Spiro-oxindole Piperidine Derivatives That Reduce Cancer Cell Proliferation by Inhibiting MDM2-p53 Interaction, Org. Lett., 2017, 19, 6752. 
375 (a) Y. Liao, M. Bai, S. Yu, M. Zhang, F. Hu, X. Xu, W. Yuan and X. Zhang, Construction of Novel Tetrahydro$\beta$-carboline-1-thione Spirooxindoles by Brønsted Acid Mediated Formal [3 + 3] Cyclization of 3-Indolylmethanols with 3-Isothiocyanato Oxindoles, J. Heterocycl. Chem., 2017, 54, 1311; (b) S. Kawamura, K. Dosei, E. Valverde, K. Ushida and M. Sodeoka, N-Heterocycle-Forming, Amino/Carboperfluoroalkylations of Aminoalkenes by Using Perfluoro Acid Anhydrides: Mechanistic Studies and Applications Directed Toward Perfluoroalkylated Compound Libraries, J. Org. Chem., 2017, 82, 12539; (c) L. Qi, H. Hou, F. Ling, L. Fang, W. Luo and W. Zhong, Cinchona Alkaloid Thiourea Catalyzed Asymmetric Synthesis and Anticancer Activity Evaluation of Tetrahydro- $\beta$-spirooxindoles, Heterocycles, 2018, 96, 1119; (d) G. Zhan, M. L. Shi, W. J. Lin, Q. Ouyang, W. Du and Y. C. Chen, Direct Asymmetric Aza-Vinylogous-Type Michael Additions of Nitrones from Isatins to Nitroalkenes, Chem. - Eur. J., 2017, 23, 6286.

376 For examples see: (a) S. J. Kalita, B. Das and D. C. Deka, A Quick, Simple and Clean Synthesis of Spiro(indoline-3,4'pyrazolo[4', 3':5,6]pyrido[2, 3-d]pyrimidines) in Water through a Novel One-Pot Multicomponent Reaction, ChemistrySelect, 2017, 2, 5701; (b) A. Mondal, B. Naskar, S. Goswami, C. Prodhan, K. Chaudhuri and C. Mukhopadhyay, $\mathrm{I}_{2}$ catalyzed access of spiro[indoline3,4'-pyridine] appended amine dyad: new ON-OFF chemosensors for $\mathrm{Cu}^{2+}$ and imaging in living cells, Org. Biomol. Chem., 2018, 16, 302; (c) M. Esmaeilpour, A. R. Sardarian and H. Firouzabadi, Theophylline Supported on Modified Silica-Coated Magnetite Nanoparticles as a Novel, Efficient, Reusable Catalyst in Green One-Pot Synthesis of Spirooxindoles and Phenazines, ChemistrySelect, 2018, 3, 9236; (d) Q. Niu, J. Xi, L. Li, L. Li, C. Pan, M. Lan and L. Rong, Isatins 3-C annulation vs ring-opening: Two different pathways for synthesis of spiro compounds via multicomponent reactions, Tetrahedron Lett., 2019, 60, 151181.

377 (a) Q. N. Zhu, Y. C. Zhang, M. M. Xu, X. X. Sun, X. Yang and F. Shi, Enantioselective Construction of Tetrahydroquinolin-5-one-Based Spirooxindole Scaffold via an Organocatalytic Asymmetric Multicomponent [3+ 3] Cyclization, J. Org. Chem., 2016, 81, 7898; (b) P. Zhou, B. Hu, L. Lu, R. Huang and F. Yu, One-Pot Synthesis of Functionalised 4-Spiro-1,4-Dihydropyridines Via [1+2+1 +2]-Cyclisation, J. Chem. Res., 2017, 41, 513.

378 Y. H. Wang, J. S. Tian, P. W. Tan, Q. Cao, X. X. Zhang, Z. Y. Cao, F. Zhou, X. Wang and J. Zhou, Regiodivergent Intramolecular Nucleophilic Addition of Ketimines for the Diverse Synthesis of Azacycles, Angew. Chem., Int. Ed., 2020, 59, 1634.

379 Y. Bin Shen, L. X. Wang, Y. M. Sun, F. Y. Dong, L. Yu, Q. Liu and J. Xiao, Hexafluoroisopropanol-Mediated Redox-Neutral $\alpha-\mathrm{C}\left(\mathrm{sp}^{3}\right)-\mathrm{H}$ Functionalization of Cyclic Amines via Hydride Transfer, J. Org. Chem., 2020, 85, 1915.
380 M. Holmquist, G. Blay, M. C. Muñoz and J. R. Pedro, AzaHenry Reaction of Isatin Ketimines with Methyl 4-Nitrobutyrate en Route to Spiro[piperidine-3,3'-oxindoles], Adv. Synth. Catal., 2015, 357, 3857.

381 (a) Y. Zhu, Y. Li, Q. Meng and X. Li, An organocatalytic enantioselective vinylogous Mannich reaction of $\alpha, \alpha$-dicyanoolefins with isatin N-Boc ketimines, Org. Chem. Front., 2016, 3, 709; (b) S. Nakamura, K. Matsuzaka, T. Hatanaka and Y. Funahashi, Enantioselective Vinylogous Mannich Reaction of Acyclic Vinylketene Silyl Acetals with Ketimines Using Chiral Bis(imidazoline)-Cu(II) Catalysts, Org. Lett., 2020, 22, 2868. For a phase transfer catalysed version see: (c) C. Cheng, X. Lu, L. Ge, J. Chen, W. Cao, $\mathrm{X}$. $\mathrm{Wu}$ and G. Zhao, Effective asymmetric vinylogous Mannich reaction of isatin imines with $\alpha, \alpha$-dicyanoolefins in the presence of a simple chiral amide phosphonium bifunctional phase transfer catalyst, Org. Chem. Front., 2017, 4, 101.

382 Z. Chang, C. Ye, J. Fu, P. Chigumbu, X. Zeng, Y. Wang, C. Jiang and X. Han, Enantioselective Synthesis of Oxindole-Derived $\alpha$-Aryl- $\beta$-Amino Acid Derivatives and $\delta$-Lactams with Homophthalic Anhydrides, Adv. Synth. Catal., 2019, 361, 5516.

383 K. R. Senwar, P. Sharma, T. S. Reddy, M. K. Jeengar, V. L. Nayak, V. G. M. Naidu, A. Kamal and N. Shankaraiah, Spirooxindole-derived morpholine-fused-1,2,3-triazoles: Design, synthesis, cytotoxicity and apoptosis inducing studies, Eur. J. Med. Chem., 2015, 102, 413.

384 G. Schwertz, M. C. Witschel, M. Rottmann, U. Leartsakulpanich, P. Chitnumsub, A. Jaruwat, W. Amornwatcharapong, W. Ittarat, A. Schäfer, R. A. Aponte, et al., Potent Inhibitors of Plasmodial Serine Hydroxymethyltransferase (SHMT) Featuring a Spirocyclic Scaffold, ChemMedChem, 2018, 13, 931.

385 (a) P. R. Eastwood, J. Gonzalez Rodriguez and V. Giulio Matassa, New Substituted Indolin2-one. Derivatives and Their Use as P39 Mitogen-Activated Kinase-Inhibitors, PCT Int. Appl WO2009132774A1, 2009; (b) P. Eastwood, J. González, E. Gómez, F. Caturla, N. Aguilar, M. Mir, J. Aiguadé, V. Matassa, C. Balagué, A. Orellana, et al., Indolin-2-one p38 $\alpha$ inhibitors III: Bioisosteric amide replacement, Bioorg. Med. Chem. Lett., 2011, 21, 6253.

386 S. J. Han, F. Vogt, S. Krishnan, J. A. May, M. Gatti, S. C. Virgil and B. M. Stoltz, A Diastereodivergent Synthetic Strategy for the Syntheses of Communesin F and Perophoramidine, Org. Lett., 2014, 16, 3316.

387 J. Z. Huang, C. L. Zhang, Y. F. Zhu, L. L. Li, D. F. Chen, Z. Y. Han and L. Z. Gong, Organocatalytic Highly Enantioselective Substitution of 3-(1-Tosylalkyl)indoles with Oxindoles Enables the First Total Synthesis of (+)-Trigolutes B, Chem. - Eur. J., 2015, 21, 8389.

388 For related total synthesis: B. N. Reddy and C. V. Ramana, A concise approach for central core of trigolutes: Total synthesis of trigolute $\mathrm{B}$ and 3-epi-trigolute $\mathrm{B}$ and analogues, Tetrahedron, 2017, 73, 888.

389 S. Zhao, J. B. Lin, Y. Y. Zhao, Y. M. Liang and P. F. Xu, Hydrogen-Bond-Directed Formal $[5+1]$ Annulations of 
Oxindoles with Ester-Linked Bisenones: Facile Access to Chiral Spirooxindole $\delta$-Lactones, Org. Lett., 2014, 16, 1802.

390 (a) K. Zhao, Y. Zhi, T. Shu, A. Valkonen, K. Rissanen and D. Enders, Organocatalytic Domino Oxa-Michael/1,6Addition Reactions: Asymmetric Synthesis of Chromans Bearing Oxindole Scaffolds, Angew. Chem., Int. Ed., 2016, 55, 12104. For a recent diastereoselective oxa-Michael reaction see: (b) M. Pasha, M. Sohail and F. Tanaka, Intramolecular Oxa-Michael Reactions of Aldols Generated from Enones and Isatins to Afford Spirooxindole Tetrahydropyrans, Heterocycles, 2020, 101, 339.

391 (a) L. Zhu, Q. Chen, D. Shen, W. Zhang, C. Shen, X. Zeng and G. Zhong, Enantioselective Construction of Spirocyclic Oxindole Derivatives with Multiple Stereocenters via an Organocatalytic Michael/Aldol/ Hemiacetalization Cascade Reaction, Org. Lett., 2016, 18, 2387. Also see: $(b)$ N. Kumarswamyreddy and V. Kesavan, Enantioselective Synthesis of Dihydrospiro[indoline-3,4'pyrano[2,3-c]pyrazole] Derivatives via Michael/ Hemiketalization Reaction, Org. Lett., 2016, 18, 1354; (c) L. Qiao, Z. W. Duan, X. N. Wu, D. H. Li, Q. Q. Gu and Y. K. Liu, Organocatalytic Diversity-Oriented Asymmetric Synthesis of Structurally and Stereochemically Complex Heterocycles, Org. Lett., 2018, 20, 1630.

392 (a) J.-L. Han and C.-H. Chang, An asymmetric assembly of spirooxindole dihydropyranones through a direct enantioselective organocatalytic vinylogous aldol-cyclization cascade reaction of 3-alkylidene oxindoles with isatins, Chem. Commun., 2016, 52, 2322; (b) J. L. Han, Y. Da Tsai and C. H. Chang, Asymmetric Synthesis of Spirooxindole $\delta$-Lactones with Vicinal Tertiary and Quaternary Stereocenters via Regio-, Diastereo-, and Enantioselective Organocatalytic Vinylogous Aldol-cyclization Cascade Reaction, Adv. Synth. Catal., 2017, 359, 4043.

393 J. L. Hu, F. Sha, Q. Li and X. Y. Wu, Highly enantioselective Michael/cyclization tandem reaction between dimedone and isatylidene malononitriles, Tetrahedron, 2018, 74, 7148.

394 For a further enantioselective example of a related scaffold: (a) S. Konda, S. Jakkampudi, H. D. Arman and J. C. G. Zhao, Enantioselective synthesis of spiro[4 $4 \mathrm{H}^{-}$ pyran-3,3'-oxindole] derivatives catalyzed by cinchona alkaloid thioureas: Significant water effects on the enantioselectivity, Synth. Commun., 2019, 49, 2971. For racemic synthesis of related scaffolds see selected examples: (b) M. Zhang, W. Yang, M. Qian, T. Zhao, L. Yang and C. Zhu, Iodine-promoted three-component reaction for the synthesis of spirooxindoles, Tetrahedron, 2018, 74, 955; (c) A. S. Hussen, A. P. Pandey and A. Sharma, Mechanochemical- (Hand-Grinding-) Assisted Domino Synthesis of Fused Pyran-Spirooxindoles under Solvent- and Catalyst-Free Condition, ChemistrySelect, 2018, 3, 11505; (d) D. Y. Seo, S. Lee, B. K. Min and J. N. Kim, Synthesis of Spirooxindoles Bearing Benzopyrano[2,3-b]indole Moiety by NBS-Mediated
Oxidative Coupling Reaction, Bull. Korean Chem. Soc., 2018, 39, 1011. Also see ref. 371.

395 (a) M. Liu, X. Zhang, X. Huang, G. Dhawan, J. Evans, M. Kaur, J. P. Jasinski and W. Zhang, Recyclable Organocatalyst for One-Pot Asymmetric Synthesis of Dihydrofuranone and Tetrahydropyranone Spirooxindoles, Eur. J. Org. Chem., 2019, 150; (b) Z. H. Wang, X. Y. Zhang, C. W. Lei, J. Q. Zhao, Y. You and W. C. Yuan, Highly enantioselective sequential vinylogous aldol reaction/transesterification of methyl-substituted olefinic butyrolactones with isatins for the construction of chiral spirocyclic oxindole-dihydropyranones, Chem. Commun., 2019, 55, 9327.

396 (a) H. L. Cui and F. Tanaka, Catalytic Enantioselective Formal Hetero-Diels-Alder Reactions of Enones with Isatins to Give Spirooxindole Tetrahydropyranones, Chem. - Eur. J., 2013, 19, 6213; (b) D. B. Ramachary, M. Shiva Prasad, S. Vijaya Laxmi and R. Madhavachary, Asymmetric synthesis of drug-like spiro[chroman-3,3'-indolin]-2'-ones through aminal-catalysis, Org. Biomol. Chem., 2014, 12, 574; (c) M. Chennapuram, I. A. Owolabi, C. Seki, Y. Okuyama, E. Kwon, K. Uwai, M. Tokiwa, M. Takeshita and H. Nakano, New Hybrid-type Squaramide-Fused Amino Alcohol Organocatalyst for Enantioselective Domino Michael Addition/Cyclization Reaction of Oxoindolines with Cyclic 1,3-Diketones, ACS Omega, 2018, 3, 11718.

397 (a) Y. Bin Shen, S. S. Li, X. Liu, L. Yu, Q. Liu and J. Xiao, Dearomative $[4+2]$ Cycloaddition of Oxindole-Embedded ortho-Quinone Methides with 2,5-Dialkylfurans, Adv. Synth. Catal., 2019, 361, 1453; (b) Y. Bin Shen, S. S. Li, X. Liu, L. Yu, Y. M. Sun, Q. Liu and J. Xiao, Formal $[4+2]$ Annulation of Oxindole-Embedded ortho-Quinone Methides with 1,3-Dicarbonyls: Synthesis of Spiro [Chromen-4,3'-Oxindole] Scaffolds, J. Org. Chem., 2019, 84, 3990.

398 H. Shi, L. Wang, S. S. Li, Y. Liu and L. Xu, Divergent syntheses of spirooxindoles from oxindole-embedded fourmembered synthon via cycloaddition reactions, Org. Chem. Front., 2020, 7, 747.

399 (a) Y. Jiang, S. W. Yu, Y. Yang, Y. Le Liu, X. Y. Xu, X. M. Zhang and W. C. Yuan, Synthesis of polycyclic spirooxindoles via an asymmetric catalytic one-pot stepwise Aldol/chloroetherification/aromatization procedure, Org. Biomol. Chem., 2018, 16, 6647; (b) M. Luo, X. Zhu, R. Liu, $\mathrm{S}$. $\mathrm{Yu}$ and $\mathrm{W}$. Wei, $\mathrm{FeCl}_{3}$-Promoted Annulation of 2-Haloindoles: Switchable Synthesis of Spirooxindolechromeno[2,3-b]indoles and Spirooxindole-chromeno[3,2b]indoles, J. Org. Chem., 2020, 85, 3638.

400 (a) J. Peng, G. Y. Ran, W. Du and Y. C. Chen, Divergent Cyclization Reactions of Morita-Baylis-Hillman Carbonates of 2-Cyclohexenone and Isatylidene Malononitriles, Org. Lett., 2015, 17, 4490; (b) A. Yadav, J. Banerjee, S. K. Arupula, S. M. Mobin and S. Samanta, Lewis-Base-Catalyzed Domino Reaction of Morita-BaylisHillman Carbonates of Isatins with Enolizable Cyclic 
Carbonyl Compounds: Stereoselective Access to Spirooxindole-Pyrans, Asian J. Org. Chem., 2018, 7, 1595.

401 (a) Y. Que, T. Li, C. Yu, X. S. Wang and C. Yao, Enantioselective Assembly of Spirocyclic Oxindole-dihydropyranones through NHC-Catalyzed Cascade Reaction of Isatins with $\mathrm{N}$-Hydroxybenzotriazole Esters of $\alpha, \beta$-Unsaturated Carboxylic Acid, J. Org. Chem., 2015, 80, 3289. Also see: (b) J. T. Cheng, X. Y. Chen, Z. H. Gao and S. Ye, N-Heterocyclic Carbene Catalyzed Generation and $[4+2]$ Annulation of Unsubstituted Dienolate Enantioselective Synthesis of Spirocyclic Oxindolodihydropyranones, Eur. J. Org. Chem., 2015, 1047.

402 W. Zhang, J. Xu, J. Cao, C. Fang, J. Zhu, T. Lu and D. Du, $\mathrm{N}$-heterocyclic carbene-mediated formal $[3+3]$ annulation of isatin-derived $\alpha, \beta$-unsaturated acids: Access to functionalized 3,4'-spirooxindole $\delta$-lactones, Tetrahedron, 2017, 73, 3249.

403 J.-B. Lin, X.-N. Cheng, X.-D. Tian, G.-Q. Xu, Y.-C. Luo and P.-F. Xu, A C A $_{1}$-symmetric N-heterocyclic carbene catalysed oxidative spiroannulation of isatin-derived enals: highly enantioselective synthesis of spirooxindole $\delta$-lactones, RSC Adv., 2018, 8, 15444.

404 Z. J. Zhang, L. Zhang, R. L. Geng, J. Song, X. H. Chen and L. Z. Gong, N-Heterocyclic, Carbene/Copper Cooperative Catalysis for the Asymmetric Synthesis of Spirooxindoles, Angew. Chem., Int. Ed., 2019, 58, 12190.

405 J. Zheng, L. Lin, K. Fu, Y. Zhang, X. Liu and X. Feng, Chem. - Eur. J., 2014, 20, 14493-14498.

406 J. Wang, Q. Zhang, Y. Li, X. Liu, X. Li and J.-P. Cheng, $\mathrm{Bi}(\mathrm{OAc})_{3} /$ chiral phosphoric acid catalyzed enantioselective allylation of isatins, Chem. Commun., 2020, 56, 261.

407 R. Sato, T. Tosaka, H. Masu and T. Arai, Catalytic Asymmetric Synthesis of Chiral Bis(indolyl)methanes Using a Ts-PyBidine-Nickel Complex, J. Org. Chem., 2019, 84, 14248.

408 B. V. Subba Reddy, V. Swathi, M. Swain, M. P. Bhadra, B. Sridhar, D. Satyanarayana and B. Jagadeesh, Stereoselective Synthesis of Spiro[tetrahydropyran-3,3'-oxindole] Derivatives Employing Prins Cascade Strategy, Org. Lett., 2014, 16, 6267.

409 S. Jia, Y. Lei, L. Song, A. G. Krishna Reddy, D. Xing and W. Hu, Diastereoselective Intramolecular Aldol-Type Trapping of Zwitterionic Intermediates by Ketones for the Synthesis of Spiro[chroman-4,3'-oxindole] Derivatives, Adv. Synth. Catal., 2017, 359, 58.

410 N. Probst, G. Grelier, N. E. Ghermani, V. Gandon, M. Alami and S. Messaoudi, Intramolecular Pd-Catalyzed Anomeric $\mathrm{C}\left(\mathrm{sp}^{3}\right)-\mathrm{H}$ Activation of Glycosyl Carboxamides, Org. Lett., 2017, 19, 5038.

411 S. R. Kandimalla and G. Sabitha, Diversity-Oriented Synthesis of Oxacyclic Spirooxindole Derivatives through Ring-Closing Enyne Metathesis and Intramolecular Pauson-Khand $(2+2+1)$ Cyclization of Oxindole Enynes, Adv. Synth. Catal., 2017, 359, 3444.

412 See ref. $314 b$ and (a) J. Qu, L. Fang, X. D. Ren, Y. Liu, S. S. Yu, L. Li, X. Q. Bao, D. Zhang, Y. Li and S. G. Ma,
Bisindole Alkaloids with Neural Anti-inflammatory Activity from Gelsemium elegans, J. Nat. Prod., 2013, 76, 2203; (b) W. Zhang, W. Xu, G. Y. Wang, X. Y. Gong, N. P. Li, L. Wang and W. C. Ye, Gelsekoumidines A and B: Two Pairs of Atropisomeric Bisindole Alkaloids from the Roots of Gelsemium elegans, Org. Lett., 2017, 19, 5194; (c) N. P. Li, M. Liu, X. J. Huang, X. Y. Gong, W. Zhang, M. J. Cheng, W. C. Ye, L. Wang and A.-E. Gelsecorydines, Five Gelsedine-Corynanthe-Type Bisindole Alkaloids from the Fruits of Gelsemium elegans, J. Org. Chem., 2018, 83, 5707.

413 (a) O.-G. Berge, A. Claesson and B.-M. Swahn, New Compounds, PCT Int. Appl WO2001005790A1, 2001; (b) J.-J. Liu, J. W. Tilley and Z. Zhang, 3,3-Spiroindolinone Derivatives, PCT Int. Appl WO2008141917A1, 2008.

414 S. Pellegrino, M. Ruscica, P. Magni, G. Vistoli and M. L. Gelmi, Antiproliferative activity on human prostate carcinoma cell lines of new peptidomimetics containing the spiroazepinoindolinone scaffold, Bioorg. Med. Chem., 2013, 21, 5470.

415 (a) Y. Liu, Z. Sun, S. Li, K. Xiang, Y. Zhang and Y. Li, Mg $\left(\mathrm{ClO}_{4}\right)_{2}$-promoted $[4+3]$ cycloaddition of oxindole derivatives with conjugated dienes: concise synthesis of spirocycloheptane oxindole derivatives, $R S C A d v$., 2016, 6, 26954; (b) Z. J. Jia, G. Shan, C. G. Daniliuc, A. P. Antonchick and H. Waldmann, Enantioselective Synthesis of the Spirotropanyl Oxindole Scaffold through Bimetallic Relay Catalysis, Angew. Chem., Int. Ed., 2018, 57, 14493; (c) M. Balha and S. C. Pan, Organocatalytic Asymmetric Synthesis of Bridged Acetals with Spirooxindole Skeleton, J. Org. Chem., 2018, 83, 14703; (d) B. Hu, X. Zhang, Y. Mo, J. Li, L. Lin, X. Liu and X. Feng, Catalytic Asymmetric Tandem Cycloisomerization/[5+2] Cycloaddition Reaction of N-Aryl Nitrone Alkynes with Methyleneindolinones, Org. Lett., 2020, 22, 1034.

416 (a) S. Diethelm and E. M. Carreira, Total Synthesis of (士)-Gelsemoxonine, J. Am. Chem. Soc., 2013, 135, 8500; (b) S. Diethelm and E. M. Carreira, Total Synthesis of Gelsemoxonine through a Spirocyclopropane Isoxazolidine Ring Contraction, J. Am. Chem. Soc., 2015, 137, 6084.

417 E. T. Newcomb, P. C. Knutson, B. A. Pedersen and E. M. Ferreira, Total Synthesis of Gelsenicine via a Catalyzed Cycloisomerization Strategy, J. Am. Chem. Soc., 2016, 138, 108.

418 (a) T. Harada, J. Shimokawa and T. Fukuyama, Unified Total Synthesis of Five Gelsedine-Type Alkaloids: (-)-Gelsenicine, (-)-Gelsedine, (-)-Gelsedilam, (-)-14Hydroxygelsenicine, and (-)-14,15-Dihydroxygelsenicine, Org. Lett., 2016, 18, 4622; (b) P. Wang, Y. Gao and D. Ma, Divergent Entry to Gelsedine-Type Alkaloids: Total Syntheses of (-)-Gelsedilam, (-)-Gelsenicine, (-)-Gelsedine, and (-)-Gelsemoxonine, J. Am. Chem. Soc., 2018, 140, 11608.

419 A. Saito, N. Kogure, M. Kitajima and H. Takayama, Total Synthesis of (-)-14-Hydroxygelsenicine and Six 
Biogenetically Related Gelsemium Alkaloids, Org. Lett., 2019, 21, 7134.

420 (a) L. Wang, S. Li, M. Blümel, A. R. Philipps, A. Wang, R. Puttreddy, K. Rissanen and D. Enders, Asymmetric Synthesis of Spirobenzazepinones with Atroposelectivity and Spiro-1,2-Diazepinones by NHC-Catalyzed $[3+4]$ Annulation Reactions, Angew. Chem., Int. Ed., 2016, 55, 11110. For a mechanistic study see: (b) Y. Li and Z. Zhang, Mechanisms and Stereoselectivities of NHC-Catalyzed $[3+4]$ Cycloaddition Reaction between Isatin-Derived Enal and N-(ortho-Chloromethyl)aryl Amide, Eur. J. Org. Chem., 2019, 2989.

421 W. Li, H. Yuan, Z. Liu, Z. Zhang, Y. Cheng and P. Li, NHC-Catalyzed Enantioselective [4 +3$]$ Cycloaddition of Ortho-Hydroxyphenyl Substituted Para-Quinone Methides with Isatin-Derived Enals, Adv. Synth. Catal., 2018, 360, 2460 .

422 Q. Liu, S. Li, X. Y. Chen, K. Rissanen and D. Enders, Asymmetric Synthesis of Spiro-oxindole- $\varepsilon$-lactones through N-Heterocyclic Carbene Catalysis, Org. Lett., 2018, 20, 3622 .

423 Z.-H. Gao, K.-Q. Chen, Y. Zhang, L.-M. Kong, Y. Li and S. Ye, Enantioselective N-Heterocyclic Carbene-Catalyzed Synthesis of Spirocyclic Oxindole-benzofuroazepinones, J. Org. Chem., 2018, 83, 15225.

424 D. Liu, Z. Hu, Y. Zhang, M. Gong, Z. Fu and W. Huang, Access to Enantioenriched Spiro- $\varepsilon$-Lactam Oxindoles by an N-Heterocyclic Carbene-Catalyzed [4 3] Annulation of Flexible Oxotryptamines with Enals, Chem. - Eur. J., 2019, 25, 11223.

425 G. Zhan, M.-L. Shi, Q. He, W. Du and Y.-C. Chen, $[4+3]$ Cycloadditions with Bromo-Substituted Morita-BaylisHillman Adducts of Isatins and $\mathrm{N}$-(ortho-Chloromethyl) aryl Amides, Org. Lett., 2015, 17, 4750.

426 J. Y. Liu, H. Lu, C. G. Li, Y. M. Liang and P. F. Xu, Lewis Base and Brønsted Base Dual-Catalyzed Formal $[4+3]$ Cyclo-addition Reaction: Synthesis of AzaSpirocycloheptane Oxindole, Synlett, 2016, 27, 1287.
427 J.-Y. Du, Y.-H. Ma, F.-X. Meng, R.-R. Zhang, R.-N. Wang, H.-L. Shi, Q. Wang, Y.-X. Fan, H.-L. Huang, J.-C. Cui, et al., Lewis Base-Catalyzed [4 + 3] Annulation of ortho-Quinone Methides and $\mathrm{MBH}$ Carbonates: Synthesis of Functionalized Benzo[b]oxepines Bearing Oxindole Scaffolds, Org. Lett., 2019, 21, 465.

428 Z. Chen, Z. Chen, Z. Yang, L. Guo, W. Du and Y. Chen, Cooperative Tertiary Amine/Chiral Iridium Complex Catalyzed Asymmetric $[4+3]$ and $[3+3]$ Annulation Reactions, Angew. Chem., Int. Ed., 2019, 58, 15021.

429 F. Zhou, G. J. Cheng, W. Yang, Y. Long, S. Zhang, Y. D. Wu, X. Zhang and Q. Cai, Enantioselective Formation of Cyano-Bearing All-Carbon Quaternary Stereocenters: Desymmetrization by Copper-Catalyzed N-Arylation, Angew. Chem., Int. Ed., 2014, 53, 9555.

430 K. L. Ivanov, A. A. Kravtsova, E. A. Kirillova, M. Y. Melnikov and E. M. Budynina, Domino Michael/azaWittig reaction in the diastereoselective construction of spiro[azepane-4,3'-oxindoles], Tetrahedron Lett., 2019, 60, 1952.

431 W. Ren, Q.-M. Zuo, Y.-N. Niu and S.-D. Yang, PalladiumNHC-Catalyzed Allylic Alkylation of Pronucleophiles with Alkynes, Org. Lett., 2019, 21, 7956.

432 (a) B. Niu, X. Y. Wu, Y. Wei and M. Shi, PalladiumCatalyzed Diastereoselective Formal [5+3] Cycloaddition for the Construction of Spirooxindoles Fused with an Eight-Membered Ring, Org. Lett., 2019, 21, 4859; (b) H. Zhao, L. Wang, J. Guo, W. Ding, X. Song, H. Wu, Z. Tang, X. Fan and X. Bi, Formal [5+3] Cycloaddition of Vinylethylene Carbonates with Isatin-Based $\alpha$-(Trifluoromethyl)imines for Diastereoselective Synthesis of Medium-Heterocycle-Fused Spirooxindoles, Adv. Synth. Catal., 2019, 361, 4761-4771; (c) H. Zhao, L. Wang, J. Guo, W. Ding, J. Du and N. Feng, Eight-membered nitrogenoxygen heterocyclic spiro indolone compound and preparation method thereof, PCT Int. Appl CN108864147A, 2018. 